\title{
A sunny future for photovoltaic systems in the Netherlands? : an analysis of the role of government and users in the diffusion of an emerging technology
}

Citation for published version (APA):

Vasseur, V. (2014). A sunny future for photovoltaic systems in the Netherlands? : an analysis of the role of government and users in the diffusion of an emerging technology. [Doctoral Thesis, Maastricht University]. Datawyse / Universitaire Pers Maastricht. https://doi.org/10.26481/dis.20141002vv

Document status and date:

Published: 01/01/2014

DOI:

10.26481/dis.20141002vv

Document Version:

Publisher's PDF, also known as Version of record

Please check the document version of this publication:

- A submitted manuscript is the version of the article upon submission and before peer-review. There can be important differences between the submitted version and the official published version of record.

People interested in the research are advised to contact the author for the final version of the publication, or visit the DOI to the publisher's website.

- The final author version and the galley proof are versions of the publication after peer review.

- The final published version features the final layout of the paper including the volume, issue and page numbers.

Link to publication

\footnotetext{
General rights rights.

- You may freely distribute the URL identifying the publication in the public portal. please follow below link for the End User Agreement:

www.umlib.nl/taverne-license

Take down policy

If you believe that this document breaches copyright please contact us at:

repository@maastrichtuniversity.nl

providing details and we will investigate your claim.
}

Copyright and moral rights for the publications made accessible in the public portal are retained by the authors and/or other copyright owners and it is a condition of accessing publications that users recognise and abide by the legal requirements associated with these

- Users may download and print one copy of any publication from the public portal for the purpose of private study or research.

- You may not further distribute the material or use it for any profit-making activity or commercial gain

If the publication is distributed under the terms of Article 25fa of the Dutch Copyright Act, indicated by the "Taverne" license above, 
A sunny future for photovoltaic systems in the Netherlands?

Véronique Vasseur 
ISBN 9789461593641

(C) copyright Author Véronique Vasseur, Maastricht 2014

Printing: Datawyse / Universitaire Pers Maastricht 


\title{
A sunny future for photovoltaic systems in the Netherlands?
}

\author{
An analysis of the role of government and users in \\ the diffusion of an emerging technology
}

\section{DISSERTATION}

to obtain the degree of Doctor at Maastricht University, on the authority of the Rector Magnificus Prof. dr. L.L.G. Soete,

in accordance with the decision of the Board of Deans, to be defended in public on Thursday October $2^{\text {nd }} 2014$, at 16:00 hours

by

Véronique Vasseur

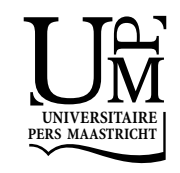




\section{Supervisor}

Prof. dr R.P.M. Kemp

\section{Assessment Committee}

Prof. dr. Pim Martens (chairman)

Dr. Floortje Alkemade

Dr. Jacques Kimman

Prof. dr. ir. Harro van Lente 


\section{Contents}

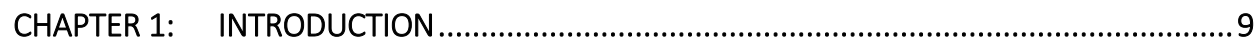

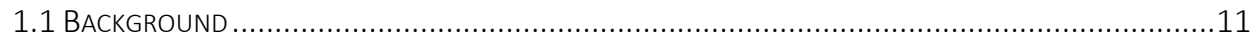

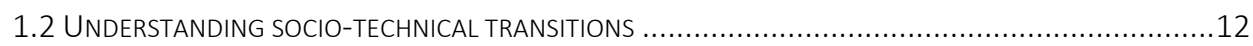

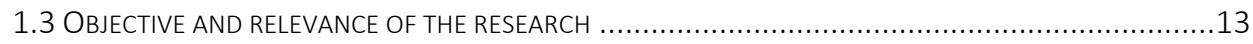

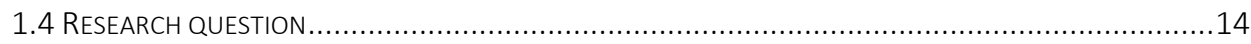

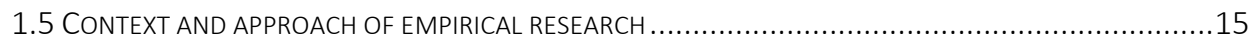

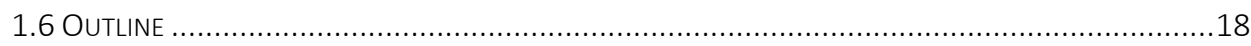

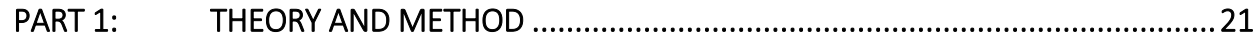

CHAPTER 2: THEORY OF SOCIO-TECHNICAL TRANSITIONS …………………….............23

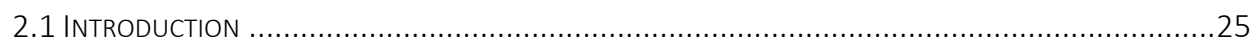

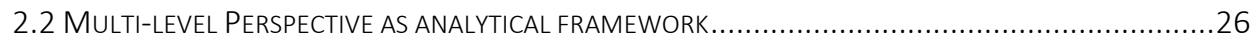

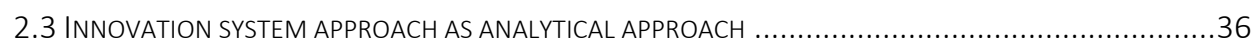

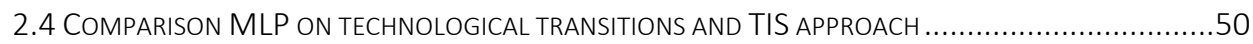

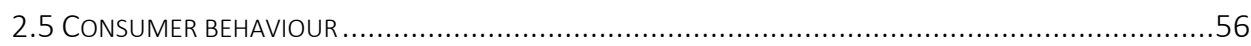

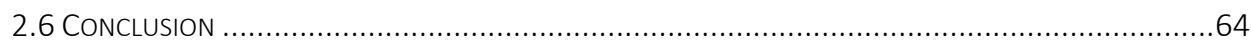

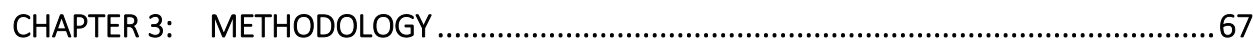

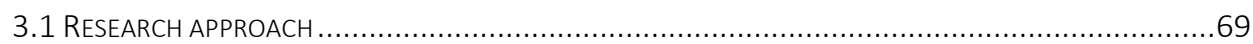

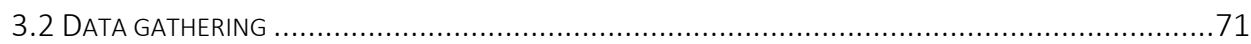

PART 2: $\quad$ TECHNOLOGICAL INNOVATION SYSTEM ……………………………….....77

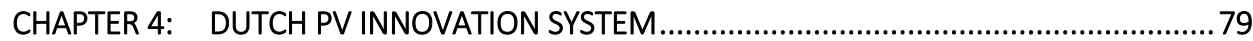

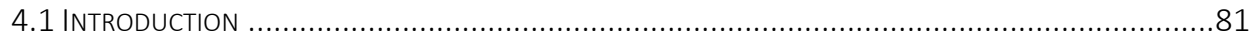

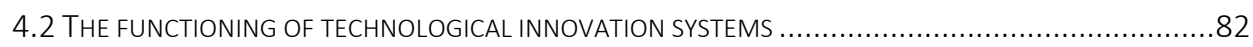

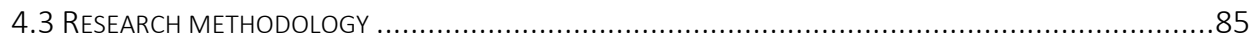

4.4 HISTORICAL OVERVIEW OF PV IN THE NETHERLANDS FROM 1970-2010..................................86

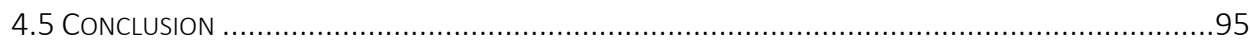

CHAPTER 5: ROLE OF POLICY IN A TECHNOLOGICAL INNOVATION SYSTEM......................97

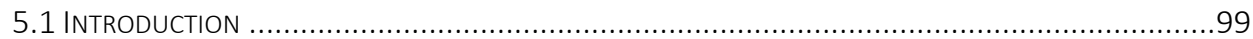

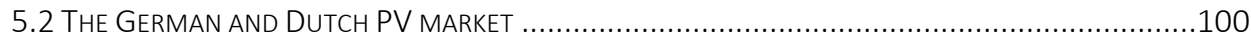

5.3 Policy DEVELopmentS IN GeRMany AND THE NetheRLANDS ..............................................102

5.4 THE TECHNOLOGICAL InNOVATION SYSTEMS FOR PV IN GeRMANY AND THE NETHERLANDS ...........108

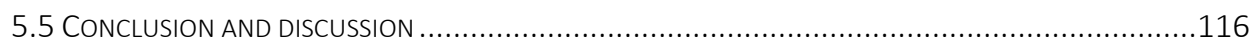


CHAPTER 6: A COMPARATIVE ANALYSIS OF PV INNOVATION SYSTEMS INCLUDING INTERNATIONAL DIMENSIONS - THE CASES OF JAPAN AND THE NETHERLANDS

6.1 INTRODUCTION

6.2 THEORETICAL FRAMEWORK

6.3 Methodology 125

6.4 RESULTS 127

6.5 COMPARISON OF THE JAPANESE AND DUTCH PV INNOVATION SYSTEMS 139

6.6 CONCLUSION AND DISCUSSION 142

INTERMEZZO 1 145

PART 3: $\quad$ CONSUMER BEHAVIOUR 147

CHAPTER 7: A SEGMENTATION ANALYSIS - THE CASE OF PV IN THE NETHERLANDS 149

7.1 INTRODUCTION .151

7.2 THEORETICAL BACKGROUND 152

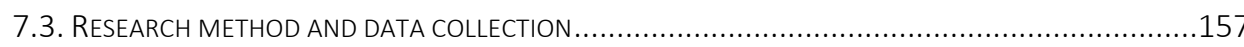

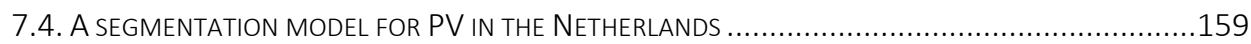

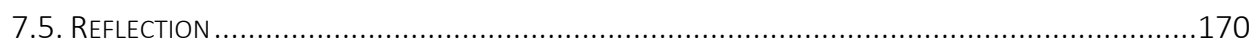

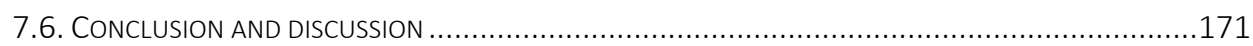

CHAPTER 8: THE ADOPTION OF PV IN THE NETHERLANDS: A STATISTICAL ANALYSIS OF ADOPTIONS FACTORS .................................................................. 175

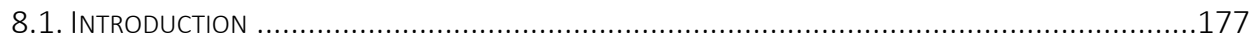

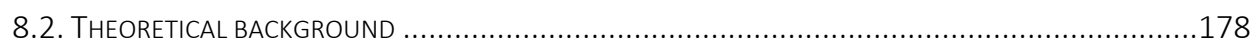

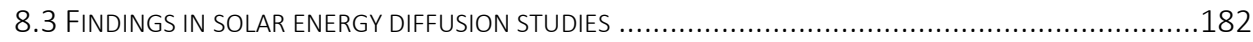

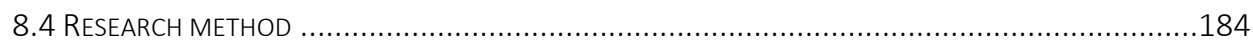

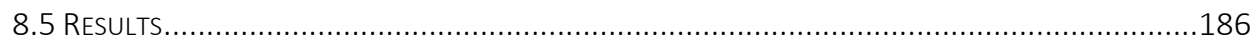

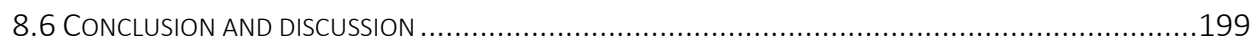

CHAPTER 9: THE ROLE OF USERS IN SOCIO-TECHNICAL TRANSITIONS LOCAL ENERGY INITIATIVE PV ................................................................ 201

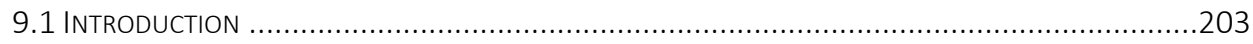

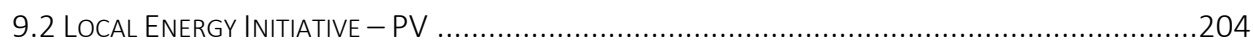

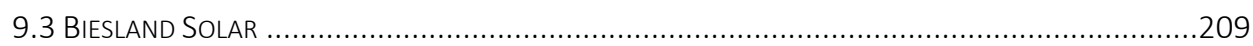

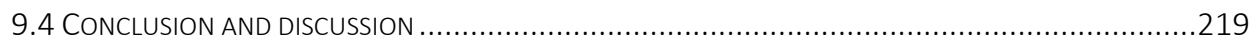




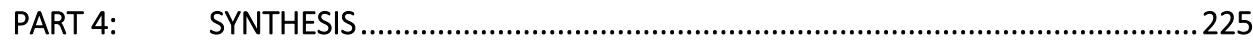

CHAPTER 10: AN INTEGRATED EVALUATION OF THE DIFFUSION OF PV IN THE

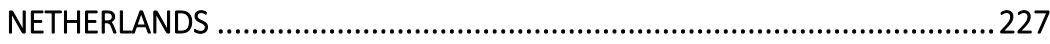

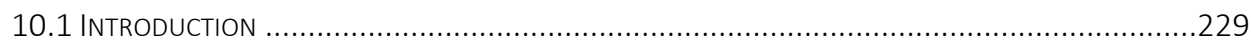

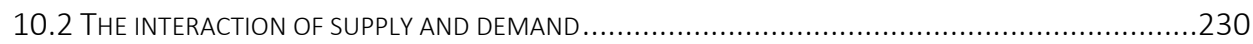

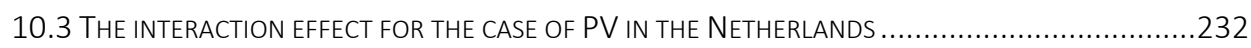

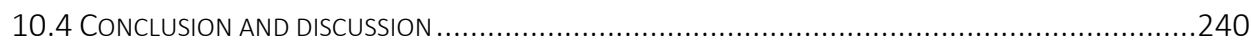

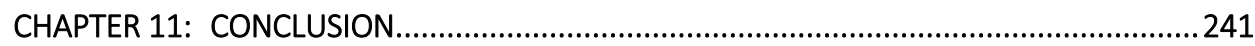

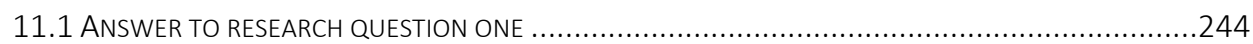

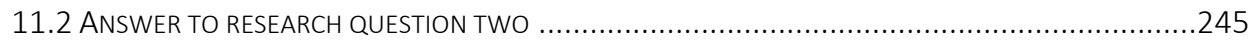

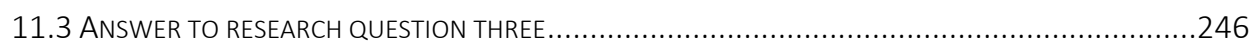

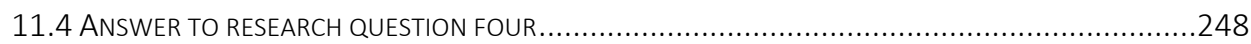

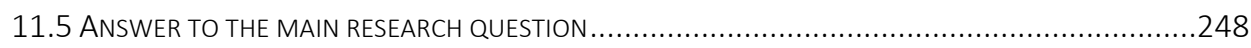

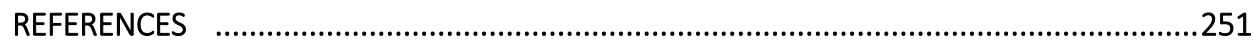

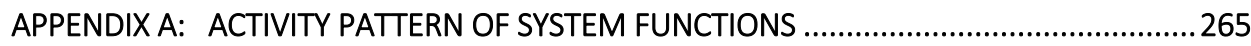

APPENDIX B: OVERVIEW CLASSIFICATION OF DIFFERENT SEGMENTATION MODELS ......269

APPENDIX C: QUESTIONNAIRE AND ANSWER KEY - PV AMONGST DUTCH

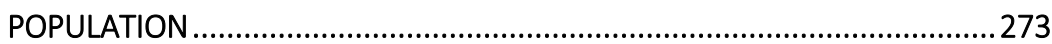

APPENDIX D: QUESTIONNAIRE AND ANSWER KEY - BIESLANDSOLAR ...........................285

SUMMARY

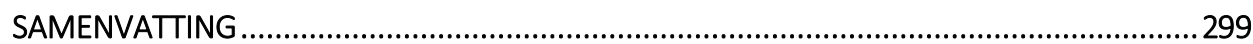

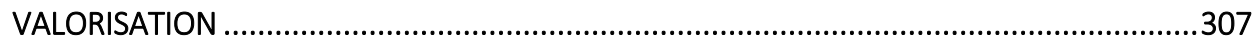

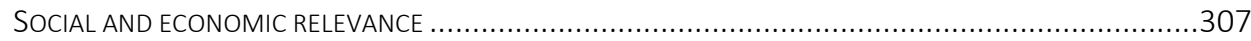

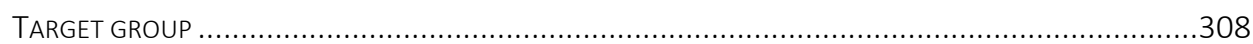

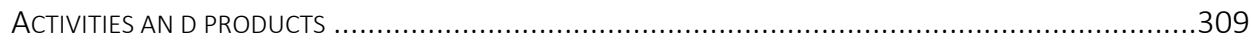

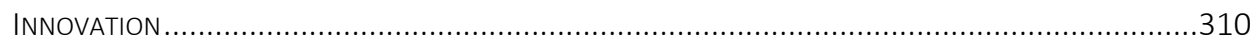

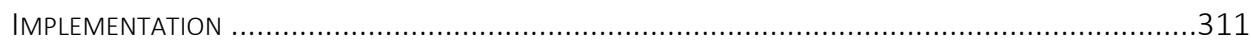

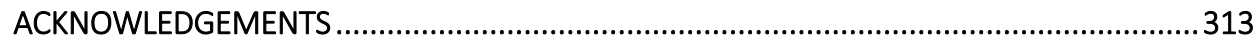

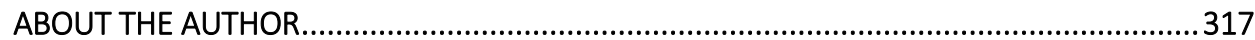



Chapter 1:

Introduction 



\subsection{Background}

It is widely recognized that the dominance of fossil fuel in the world energy system causes severe environmental problems, such as air pollution, acidification and global warming. Moreover, the supply of energy from fossil fuels is limited and it depends for a large part on a small group of politically unstable countries. A possible way to deal with these problems is to develop more sustainable energy technologies, based on renewable energy sources such as wind, biomass, hydropower or solar power. However, these sustainable energy technologies have trouble breaking through since society is locked into the use of fossil fuels (Unruh 2000). Both the supply side and demand side is adapted to the use of fossil fuels in terms of conversion technologies such as power plants and motor cars, knowledge and practices. More sustainable energy technologies -as radical innovations- are available but their diffusion is low since they are in their early phase of development, still inefficient, crude, and badly tuned to the characteristics of the incumbent system. Such a situation is common for radically new technologies (Rosenberg 1976).

A relevant question that arises is: what are the possibilities for moving away from fossil fuels towards renewable energy technologies? To answer this question it is important to understand what factors support and which factors constrain the development, adoption and diffusion of renewable energy technologies. One important constraining factor often mentioned is the more economic use of fossil fuels, given prevailing prices of fossil fuels and low carbon prices (e.g. Unruh 2000).

The success of more sustainable energy technologies is not only determined by technical and economic factors like the price of the technology or technical performance, but also by social factors such as user acceptance and the networks of actors involved.

In innovation studies the role of users, as consumer-citizens who consciously choose for or against a technology, is increasingly accepted, however their role is insufficiently theorized and empirically studied in transition studies. The study of consumer choices is done at a rather general level through the identification of consumer groups. What is missing or lacking is a deeper study of the characteristics of first adopters and rejecters and a segmentation of present rejecters into potential adopters and rejecters. The active role of consumers in transitions processes has been studied by Seyfang and Smith (e.g. Seyfang and Smith 2007) but such studies lack detailed knowledge of the characteristics of the different consumer groups. It is on the element of user acceptance and determinants of adoption that this thesis offers a novel contribution to the literature. 


\subsection{Understanding socio-technical transitions}

Socio-technical transitions are guided processes through which socio-technical systems shift towards a more sustainable direction. Two schools of thought have - largely independent from each other - grappled with the issue of how changes towards sustainability can be brought about and navigated. One body of literature departs from evolutionary economic principles and acknowledges that transitions involve a wide variety of actors as well as technological and institutional changes. The multilevel perspective (MLP) on transitions and the technological innovation systems (TIS) framework, and its related notions on strategic niche management and transitions management, have been applied to the study of transitions and have provided insights for policymakers that seek to manage these processes. The MLP seems appropriate in this thesis, since it describes that transitions and system innovation occur through the interplay between dynamics and multiple levels. In addition, the TIS approach seems also appropriate, since the central idea behind this approach is that determinants of technological change are not only to be found in individual firms or in research institutes, but also in a broader societal structure in which firms and knowledge institutes are embedded (Carlsson and Stankiewicz 1991, Hekkert, Suurs et al. 2007). A well-functioning TIS is a requirement for the technology in question to be developed and widely diffused, but it is difficult to determine whether or not a TIS functions well. For this, the system function approach can be used. The system functions are related to the character of, and the interaction between, the components of an innovation system, i.e. actors, networks, and institutions (Carlsson 1997, Coenen and Diaz Lopez 2010). Both approaches put a lot of emphasis on the role of the user which influences the successful breakthrough of a niche into the regime. However, it is less clear how the users are conceptualised, should be involved in innovation policies and how these users are facilitated to learn. The last aspect especially, is a prerequisite of successful innovation processes which is also pointed out by Lundvall (1992), who states that creating conditions for learning maybe seen as the major function of an innovation system.

Another scholarly group, departing from sociological thinking, focuses on social practices and the question of how they change or remain stable over time. Practice theorists (e.g. Shove and Spaargaren) pay attention to how structure and agency relate and argue that notions of a directed top-down management of transitions are misleading. As an implication, practice theories go beyond individuals and emphasize the fact that human subjectivity is at the heart of processes of structuration, reproduction, and (also environmental) change (Spaargaren and Oosterveer 2010). What is represented in practice theories is a group of individuals as one single actor instead of all the individuals represented as such. To wind up, a problem with socio-technical transitions as it has heretofore developed is its heavy focus on the system level and as a consequence too little attention for the individual actors (the micro level) where the actual learning takes place. One of the consequences of this is the underrepresented role of and attention for users. 


\subsection{Objective and relevance of the research}

This thesis offers an analysis of the technology innovation system for PV in the Netherlands with special attention to the role of users. The thesis consists of six empirical chapters, a theory chapter, a methodology chapter, a synthesis chapter plus the introduction and conclusions chapter.

It is motivated by the observation that little attention in transition and innovation studies is being given to actual adoption decisions by people. The same oddly enough applies to social practice studies, which do not examine the adoption decisions of individual in any detail. In this thesis I study the reasons for adoption and non-adoption of PV technologies in the Netherlands. This is being done through the use of a specially designed questionnaire and through interviews with people involved in a local energy initiative for the adoption of PV in the city of Maastricht in the Netherlands. I also describe and analyse the evolution of the TIS for PV in the Netherlands, where I compare the evolution with that of Japan and Germany. In those chapters, which make up the first empirical part of the thesis, and which were being done in the first period of the PhD, user decisions are not studied. They predate the adoption and non-adoption analysis of which the results are given in Part 3. The purpose of the thesis was not to build a new theory of societal transitions but to study the adoption and non-adoption decisions of people and thereby obtain a deeper understanding of the many concerns and determinants behind adoption and non-adoption of PV systems. In this thesis, users are viewed an important source of information but the thesis does not make an attempt to study the feedback from users that producers obtained over time. This is left for future research. The focus of the study is on the evolution of the TIS for PV in the Netherlands and the heterogeneity of people with regard to their willingness to adopt PV and their heterogeneity with respect to possessing a PV system on their roof (as a consequence of a decision to adopt it or as a consequence of the decision to buy a home with PV panels).

This explorative research into user involvement in the diffusion of more sustainable energy technologies has scientific relevance in studying an understudied topic in the social practice literature and the transition and technological innovation system literature. It has societal relevance in offering information which is relevant for government officials interested in the promotion of PV as a sustainable energy technology, helping them to achieve the $16 \%$ renewable energy goal in 2020 ( a goal from which the Netherlands is more than 10 percentage points away in 2012). Moreover, the energy industry might learn how to react and act on user needs in energy innovation processes. The case of solar energy is relevant given its huge potential worldwide as well as in the Netherlands and the need to reduce greenhouse gas emissions worldwide. 


\subsection{Research question}

The objective and relevance of this PhD research, as defined above, can be further specified in the following main research question:

How does supply interact with demand for the case of PV in the Netherlands and what does this imply for socio-technical transition research?

This central question can be specified in several sub-questions. The first question addresses insights into the possibilities and limitations of various research approaches in transition literature to study the development, adoption and diffusion of emerging more sustainable energy technologies. In this question the state-of-the-art in socio-technical transitions will be studied with special attention to the way in which user behaviour and choices are being conceptualised and studied. Therefore the first sub-question is:

RQ1: How is user behaviour conceptualised in socio-technical transition research? How are user choices studied empirically?

As indicated before, this research consists of two aspects: the technological innovation system approach and the user perspective. The technological innovation system approach is first explored by analysing the mechanisms behind the slow technology diffusion of PV in the Netherlands.

RQ2: Which factors account for the slow diffusion of PV in the Netherlands and what does this imply for policy support and socio-technical management?

The social adoption element is studied by analysing the reasons for adopting or not adopting PV in the Netherlands and assessing the necessary conditions for adopting. The third question considers technology adoption decisions from a user perspective:

RQ3: Which factors account for the adoption and non-adoption of PV in the Netherlands?

In the research framework, it is claimed that the two perspectives interact and mutually influence each other through all kind of learning processes. Therefore, the fourth research question addresses the opportunities and barriers in the transition process of PV in the Netherlands and what can be done to accelerate the development, adoption and diffusion of PV (lessons learned).

$R Q$ 4: What can be learned from combining the user perspective with the technological innovation system approach and the multilevel perspective on socio-technical transitions in terms of possible inducement mechanisms to accelerate the adoption and the diffusion of PV? 
In order to answer these questions, a combination of theoretical and empirical research will be used. The theoretical part of the thesis will describe the potential of niche-based approaches to contribute to wider changes in socio-technical regimes. Social theories that can help to accelerate the transition to a more sustainable energy system are discussed from a systemic and a user perspective. The empirical part of the PhD research comprises a study of the history and dynamics of a more sustainable energy technology, in particular the PV technology. Part of the empirical research is done within the context of a multi-disciplinary project on thin film solar cells, called Organext.

\subsection{Context and approach of empirical research}

The aim of this $\mathrm{PhD}$ research is to create more insight into the role of users, as consumer-citizens, in the development, adoption and diffusion of emerging more sustainable energy technologies. There is still relatively little known about this issue, as the preceding discussion of the research field made clear. For that reason, this research is of an exploratory nature which is not aimed at testing any hypotheses or propositions, but aims to develop new empirical insights. An appropriate research strategy to investigate unexplored research areas is to use case studies (Eisenhardt and Graebner 2007). Yin (2003) defines a case study as "an empirical inquiry that investigates a contemporary phenomenon within its real life context, especially when the boundaries between phenomenon and context are not clearly evident." This PhD research will apply a multiple case design because it is generally considered a more robust design than a single case study.

To answer the research question, the development, adoption and diffusion of PV is used as a case study which results from the gap between the high theoretical expectations to contribute to a sustainable energy supply worldwide, and the actual practice which shows that the sustainable energy technology develops but slowly (KNAW 2007, Van der Hoeven 2009). PV is indeed an emerging more sustainable energy technology by using the abundant power of the sun. This sustainable power source has until recently not been developed as a serious option for energy generation in the Netherlands.

Although the first off-grid solar house was opened in Castricum in 1988 (Lysen 2006), after more than 25 years the use of PV is rather limited. The slow growth and even decline in the Netherlands over the years contrasts sharply with the explosive growth in other European countries, Germany for example, where incentive schemes have stimulated the growth of installed PV capacity such that up to 7 GW per year (IEA-PVPS 2014). The Dutch case clearly shows that a large problem in the formation of a domestic market lies with the inconsistent government market support. As example, the upward trend of installed PV stalled in 2003, the PV market decreased from almost $20 \mathrm{MW}$ per year in 2003 to less than 0.5 MW per year in 2006. The 'gold rush of 2003' has been the result of an announcement of the governments that a subsidy regime would end, no incentive 
came in place till 2008 and the new incentive did not have significant impact on the market. The Dutch policy focused on research and development with the goal of bringing the cost down and raising the efficiency to make solar power more competitive with fossil fuels (Vasseur and Kemp 2011).

Interestingly, since 2011 there is a substantially grown, 195 MW installed PV capacity over 2012. Falling prices and the possibility of net metering make it more interesting for individuals to install panels without a subsidy (IEA-PVPS 2013). A relevant question that arises is whether this will be just a repeat case of the collapsed gold rush towards the installation of PV panels in 2003 or will this herald a sunny future for PV in the Netherlands?

Knowledge development and entrepreneurial activities were not very much affected by the periods of poor market formation. Around 1990 there was a shift in research and development (R\&D) effort in the Netherlands from wind energy to biomass and PV. Especially for PV, this was very remarkable since it was not seen as an attractive option in the previous years for the Netherlands according to policymakers and experts in the field. But by the end of the nineties PV was the most financially stimulated sustainable technology in the Netherlands both in terms of the research as well as its introduction, in spite of the high costs and the relatively small contribution to the energy supply (Verbong et al. 2001). As with any industrial product there is an environmental impact associated with the PV manufacturing process. In 2009, the Los Angeles Times reports that huge amounts of fossil fuels are used in the manufacture of the cells and, just like many other electronics, the waste metals not used in production also present their own disposal problems, mercury and chromium being two of the top problem-makers (Underwood 2009). However, it is important to take these issues in context. All electronic equipment can cause these concerns, and whereas many electrical goods are only designed to last for a couple of years, PV panels are expected to last for at least 30 years. Furthermore, all PV technologies generate far less life-cycle air emissions per GWh than conventional fossil-fuel-based electricity generation technologies and therefore provide PV the benefits of significantly curbing air emissions harmful to human and ecological health (Fthenakis, Kim et al. 2008).

Nevertheless, the PV technology is still in the research and demonstration phase and has had to deal with many ups and downs. There are some promising areas on PV in the Netherlands, for example the City of the Sun Heerhugowaard and Amersfoort, but these projects are relatively small. It is hard to say, but only a few PV districts in 40 years is not really what one might call a success story. Why is this process not scaled and why are there no more successful initiatives launched? Are there problems with the PV industry in the Netherlands and if so, what specifically?

To answer these questions, it is necessary to open the black box and analyse in a detailed manner how the development, adoption and diffusion of PV take place. Such an 
analysis allows me to pinpoint how various factors influence the diffusion process. Insight into the relation of these factors creating a positive inducement mechanism when they support each other is necessary to speed up the diffusion process of an emerging technology.

Hence, it will be interesting to discover the different development paths of the PV source and see what can be learned for other sources. For selecting the case, a theoretical criterion is used to gain insight into different phases of technology development. Four possible phases are identified; pre-development, take-off, acceleration and stabilization (Rotmans, Kemp et al. 2000). This research clustered different PV technologies into three groups based on the similarities of the technologies and evaluated the current phase of development of the technology.

The first group focuses on the first and second generation solar energy. The first generation solar cells refer to the classic $p$-n junction photovoltaic. Typically, this is made from silicon (multi-crystalline and single-crystalline) doped with other elements to make them preferentially positive ( $p$ ) or negative ( $n$ ) with respect to electronic charge carriers. The second generation consists of thin films of photon-absorbers and layered stacks of thin films. They may prove to be much more efficient in solar energy conversion, but they are much more expensive than a simple silicon wafer (first generation).

In the Netherlands, many activities have been taking place with regard to the first and second generation solar energy, but the number of adopters is still very limited. Thus, this kind of solar energy is still at the beginning of the take-off phase.

The second group focuses on the third generation solar energy. The third generation is proposed to be very different from the previous semiconductor devices. It refers to organic solar cells which in general can be divided into two types: dye-sensitized cells and organic cells. Dye-sensitized cells use chemical dyes to capture the light and convert it into electricity. Organic cells use conducting polymer materials to produce electricity. This technology has not yet entered the Dutch market; it is only its early infancy (beginning of pre-development phase). However, it is an interesting case to study since expectations of the technology are high (very low production costs) and already some initiatives are under development in the Netherlands.

The third group focuses on Concentrated Solar Power (CSP). This is a system that uses concentrated solar radiation to convert the energy of the sun into high-temperature heat which can be used to generate electricity in a steam generator. Different technologies have been identified over the last decades for generating electricity, namely dish/engine technology, parabolic trough technology, solar power tower technology and concentrated PV. CSP-investments are growing fast, a lot of CSP plants are under construction and planned. This is an interesting case to study since the generated electricity 
will be transported over long distances in order to provide the Netherlands in such way with electricity. However, both Desertec and the creation of European systems of CSP is very much in the pre-development phase (Desertec.org 2013).

It is also possible to cluster the solar energy technologies into four groups based on the similarities of the technologies; silicon-based technologies, CIS (Copper Indium diSelenide/di-Sulfide) and organic technologies. However, in this research I propose the first classification as I analyse the first and second generation of solar energy. The reason behind this selection is that I will analyse the reasons for adopting or not adopting a PV system in the Netherlands and assessing the necessary conditions for adopting. The second group of PV (third generation solar energy) is mostly used in consumer products and therefore not suitable for this research; however, important events contributing to the build-up of the system, such as a breakthrough in efficiency, have also been included in this thesis.

\subsection{Outline}

Chapter 2 offers a literature review of the socio-technical literature of transitions and technology innovation studies. I describe the potential of niche-based approaches to contribute to wider changes in socio-technical regimes. Social practice theories will be discussed that can help to accelerate the transition to a more sustainable energy system from a systemic and user perspective.

Chapter 3 outlines the research methodologies I apply.

Chapter 4 describes the history of the development of the PV innovation system in terms of seven key processes (system functions) that are essential for the build-up of innovation systems. The data gathering consists of retrieving events from archive data, such as newspapers, magazines and reports, related to PV in the Netherlands during the period 1970-2010 and interviews with experts in the field. The contribution of an event to the fulfilment of a system function may differ considerably from event to event and is indicated in an allocation schem by +1 and -1 . Based on the content of the events and their chronological order, I am able to deduce the effect of one event onto another and the order in which such events occurred. By observing reoccurring sequences of events I am able to identify motors of innovation.

Chapter 5 examines the role of policy in the evolution of technological innovation system and diffusion of solar photovoltaic (PV) panels in Germany and the Netherlands. PV power development and diffusion have been actively supported in both countries; however, Germany has a well-developed technological innovation system and a successful industry, whereas the Netherlands has not. The focus of this study is on the dynamic 
relationship between policy developments and technology innovation systems developments.

Chapter 6 focuses on the development and diffusion of PV in Japan and the Netherlands. Both cases are analysed with the technological innovation systems framework. I included international factors in the framework such as import, export and international knowledge transfer. Based on the differences in cases I can formulate a number of lessons for the Dutch PV TIS

Chapter 7 analyses from a user perspective whether users (consumer-citizens) of PV have similar personal values and (environmental) lifestyles. By taking into account different typologies of lifestyles which are used in the construction market in the Netherlands, I introduced a segmentation model for analysing the diffusion of technological innovations, in particular PV. The empirical analysis, based on a questionnaire completed by 817 Dutch households, resulting in four relatively homogeneous groups of technological users identified based on their adoption or rejection of a specific technological innovation. I took the demographic characteristics, geographical characteristics, physiographical characteristics (cultural beliefs and the importance of the different attributes for PV of the different lifestyles), and behavioural characteristics (motives and barriers to adopt PV) into account.

Chapter 8 studies factors underlying the adoption and non-adoption of PV in the Netherlands. The main purpose of this chapter is to gain insight in and to understand the adoption of PV in the Netherlands from a user perspective. The influence of the following four factors is studied: the perceived relative advantage of the technology, the perceived complexity of the innovation as a negative factor, social influence, and knowledge of grants and costs. For each of the factors, different proxies are used in an attempt to study individual components. In this research, I use descriptive analyses and logistic regression analyses.

Chapter 9 shows how individuals as real people interact with each other about PV, what decisions they reach in terms of adoption and non-adoption for the case of Biesland Solar, a technology specific local initiative. Biesland Solar was initiated by some local citizens and promoted PV via a brochure and organised an information meeting. Empirically this research is based on original data collection through a questionnaire performed direct after the information meeting and on interviews one and a half year later. I structure the results according to three relevant factors influencing the purchasing of PV: (1) provision of information; (2) financial concern; and (3) the personal attitude people have. 
Chapter 10 studies the barriers in the PV transition process in the Netherlands and studies what can be done to accelerate the PV transitions. The research framework of this thesis is further elaborated in this chapter to indicate how various factors influence this process. Instead of the notion of barriers I think in terms of a 'web of constraints' acting as a blocking mechanism. Instead of a single driver I think in terms of multiple drivers creating a positive inducement mechanism when they support each other. Positive stimuli interact with negative ones. Based on the different analyses which are done in this research, I formulated five mechanisms for the case of PV in the Netherlands.

Chapter 11 concludes with answers on the research questions. 
Part 1:

Theory and Method 

Chapter 2:

Theory of socio-technical transitions 



\subsection{Introduction}

There are several definitions on basic concepts such as transitions and system innovations, mentioned in literature, all having the same scope and derived from one of the first definitions. A transition is defined as "transformation processes in which society changes in a fundamental way over one or more generations" (Rotmans, Kemp et al. 2001, p.1) and "in which existing structures are broken down and new ones are established" (Loorbach 2007, p. 17). Geels et al. (2004, p.3) defines a transition as a change "from one socio-technical system to another". Van den Bergh and Kemp (2006, p.1) states that a transition involves "a society-wide change that goes beyond single sectors and involves fundamental and interrelated changes in technology, organization, institutions and culture". A closely related concept for transitions is system innovation, "organization-exceeding, qualitative innovations which are realized by a variety of participants within the system, and which fundamentally change both the structure of the system and the relations between the participants" (Kemp and Loorbach, 2006, p. 107). It is often used as a synonym for transition but according to Rotmans and Kemp (2003, p. 7) transition transcend system innovations, which in turn transcend the level of an individual person, company or organization.

There are at least two different perspectives used in the literature as an analytical framework to describe, understand and analyse the changes associated with transitions and system innovations. The literature on technological transitions distinguishes three different levels from which the development of a technology should be analysed: macrolevel of landscape, meso-level of socio-technical regimes and micro-level of niche. Transitions are driven by the interplay of dynamics arising from each level in this multilevel framework (Geels 2002, Geels 2004). The idea behind the technological innovation system is that technologies develop within the context of a system which consists of actors (e.g. firms and other organizations), institutions, networks, and the interrelations between them (Jacobsson and Johnson 2000, Carlsson, Jacobsson et al. 2002). The approach has developed into a very dynamic approach by not only focusing on the structure of the system (actors, institutions and networks) but also on the key processes that take place within the system and contribute to the build-up of a technological innovation system and thereby to the successful development and diffusion of the emerging technology (Jacobsson and Johnson 2000, Hekkert, Suurs et al. 2007). Both strands of conceptual work are based on common theoretical roots and offer promising complementarities.

Numerous researchers have made empirical studies of technical transitions and technological innovation systems in order to understand their current structure and trace their dynamics related to the development of a specific technology e.g. solar energy and biomass. Due to the different disciplinary background, it is difficult to extract practical guidelines which accelerate the implementation of a specific kind of technology. There- 
fore, this paper seeks to highlight and discuss some aspects of the relationships between the literate of technical transitions and the technological innovation system.

\subsection{Multi-level Perspective as analytical framework}

The multilevel perspective (MLP) is dominant in studies that focus on understanding technological transitions, since it studies the interactions at different levels; macro-level of landscape, meso-level of socio-technical regimes and micro-level of technical niche (Geels 2002, Geels 2004). In the following section, I will reflect the key concepts of this technological transitions literature. Thereafter the interactions between the different levels are described, followed with a discussion.

\section{Socio-technical regime}

The central level of this framework is the meso-level at which the so-called sociotechnical regime is located. The concept of socio-technical regime is an extended version of Nelson and Winter's (1982) technological regime as used in evolutionary economics. Nelson and Winter (1982) referred to shared cognitive routines in an engineering community and explained patterned development along technological trajectories. Rip and Kemp (1998) widened the technological regime concept by defining it with the sociological category of rules: "A technological regime is the rule-set or grammar embedded in a complex of engineering practices, production process technologies, product characteristics, skills and procedures, ways of handling relevant artifacts and persons, ways of defining problems - all of them embedded in institutions and infrastructures" (Rip and Kemp 1998). Engineering beliefs are an element of a regime, together with practices, standards and organizational beliefs and ways of doing things. The concept incorporates ideas from sociology on the relationship between various types of institutions and rules and technology development and use which extend the concept of technological regime, that is the reason why Geels (2002, Geels 2004) proposed to use the term of sociotechnical regime. Holtz et al. (2007) adopt and refine this last view and considered regimes as complex systems related to societal functions. Instead of using technology as an entry point to frame a regime, Holtz et al. (2007) proposed to delineate regimes based on five characteristics i.e. purpose (regimes relate to a societal function); coherence (regime elements are closely interrelated); stability (regimes are dynamically stable); non-guidance (they show emergent behaviour) and autonomy (they are autonomous in the sense that system development is mostly driven by internal processes). The characteristics can be used to define the scale and scope of a transition, to align them with actors involvement and to compare different regimes (Holtz, Brugnach et al. 2007). Markard and Truffer (2008) argue that regimes can be defined from different levels of aggregation and from different perspectives and the choice of a particular level depends to a large extent on the research question. Moreover, defining a regime should be guided by the intention to use its conceptual strengths and key features most effectively. 
These features certainly include the regime structure, the multi-dimensionality of sociotechnical regimes and their influence on innovation processes (Markard and Truffer 2008).

The focus of the mainstream literature is far too often on competition between different regimes while other forms of interactions can occur as well. Therefore Raven and Verbong (2009) introduced a typology to investigate and understand interactions across regimes, based on elaborated case studies describing historical dynamics. They developed four types of interactions, namely competition, symbiosis, integration and spillover. All these types are developed on the systematic level of regimes on the basis of relations between the rules, actors and technologies (Raven and Verbong 2009).

\section{Socio-technical landscape}

The macro-level is formed by the socio-technical landscape, which refers to aspects of the exogenous environment. The metaphor landscape is used because of the literal connotation of relative hardness and to include the material aspect of society (Geels 2002, Geels 2004). This concept is introduced by Rip and Kemp (1998) in a wide-ranging review of theories of technological change. They used the concept for social developments such as globalization, individualization, macroeconomic factors (e.g. economic growth, environmental problems, wars, cultural and normative values) and physical environment/infrastructure such as cities, factories, highways, and electricity infrastructures. The landscape level typically develops autonomously but directly influences the regime level as well as the niches by defining the room and direction for change (Loorbach 2007). According to Geels and Schot (2007), it refers to the technical, physical and material backdrop that sustains society. However, socio-technical landscape in this sense is relatively static. Hence, Geels and Schot (2007) include dynamic aspects of the exogenous environment and elaborates further on the landscape concept. Based on dimensions of external change (frequency, amplitude, speed and scope) they distinguish five types of environmental change including regular change, hyperturbulence, specific shock, disruptive change and avalanche change. At this level, I can also refer to longwave theories that highlight long-term changes in the entire economy. Economic growth and prices seem to follow long-waves of 50-60 year cycles, these cycles are better known as Kondratiev waves (Freeman and Louca 2001).

\section{Technological niches}

Technological niches represent the micro level of the framework. Niches are spaces in which novelties are being developed, produced and used triggered by special resources and circumstances. The circumstances or resources may afford protection against too harsh market selection through subsidies and alignments between various actors (Geels 2002). Hoogma et al. (2005, p.223) defined the concept as "a discrete application domain where actors are prepared to work with specific functionalities, accept teething problems like higher initial costs, and are willing to invest in improvements of new technology and the development of new markets". Technological niches can develop into 
market niches, applications in specific markets in which regular market transactions prevail (Geels 2002). Niches are important for the development of new technologies, because they provide space for key processes such as the articulation and refinements of visions, interactive learning processes, and network formation by which a social constituency can be build-up behind a new technology (Kemp, Schot et al. 1998, Kemp, Rip et al. 2001). Thus the activities in niches are the seeds for change, in other words they are the building blocks where technological transitions started because they are the locations where variety is created. Niches may be actively created by actors through strategic niche management (SNM): "the creation, development and controlled phaseout of protected spaces for the development and use of promising technologies by means of experimentation, with the aim of (1) learning about the desirability of the new technology and (2) enhancing the further development and the rate of application of the new technology" (Kemp, Schot et al. 1998). Three important processes were identified within the framework: voicing and shaping expectations, building of social networks and learning processes. The interplay of these processes is expected to shape the direction and outcome of niche development (Van der Laak, Raven et al. 2007).

\section{Relations and interactions between the different concepts}

The most important insight from the multi-level perspective into technological change is that direction and outcome of technological change are not the result of dynamics at one specific level, but occur as relations between different levels. Geels (2002) described this relationship as a nested hierarchy, where regimes are embedded within landscapes and niches within regimes (see Figure 1).

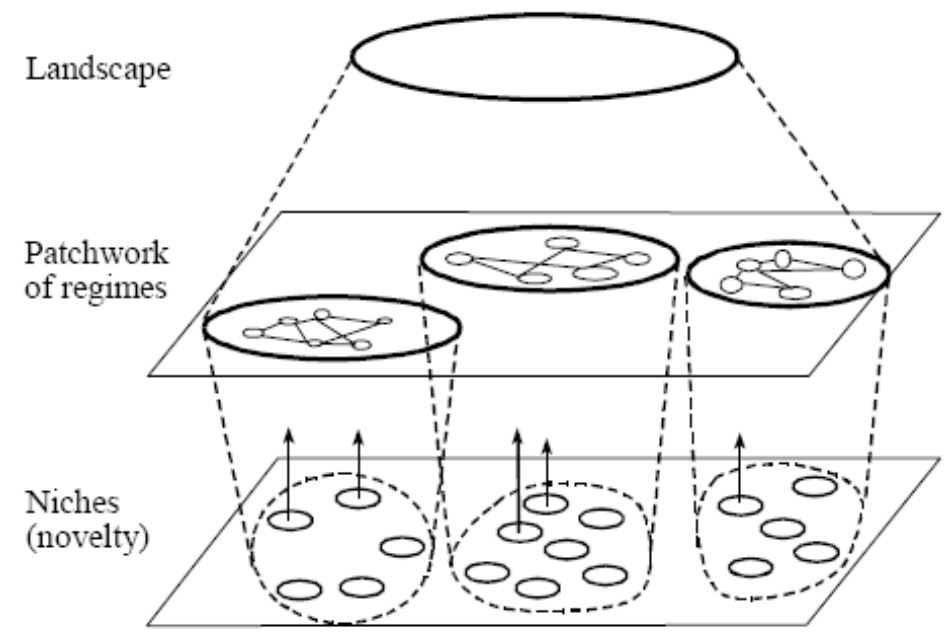

Figure 1. Multiple levels as a nestled hierarchy (Geels 2002, p.1261). 
Technological niches can be identified as important tools for understanding the emergence of a new socio-technical regime. The dotted arrows indicate that the emergence of niches is strongly influenced by the existing regime and landscape (Geels 2002). In technological niches, general rules and visions become more specified and stable as more is learned about the new technology and its use. However, it is usually a hard time to enter established socio-technical regimes, because of misalignments with other elements or because of strategic opposition from firms with vested interests in the old technology. Although, niche-innovations (new technologies) can become regimes, when social networks grow larger and invade mainstream markets.

The implementation of a new technology is also governed by developments at the level of the existing regime and the socio-technical landscape (Kemp, Rip et al. 2001). Dynamics at the landscape level for instance in the form of deep, long-term and aggregated trends (e.g. emerging environmental awareness) can put pressure on regime, which in turn result in changes at the regime level (e.g. the establishment of new policies or the emergence of new user practices). Changing regimes may create opportunities for new technologies (Geels 2002).

Radical new socio-technical systems cannot easily break through due to mismatches with existing regimes and the experience within niches are less clear and more uncertain than in established regimes. A dynamic version of the MLP tries to gain insight into how niches breakthrough the regime and how regimes could change radically, see Figure 2 .

With the multilevel framework and the different phases in mind, I can describe a pattern of transition dynamics. During the predevelopment phase radical innovations emerge, finding applications in niche markets, serving for example the demand for green products. The build-up or bottom-up pressure from niches and the top-down pressure from the macro-level (for example regulations or shifts in demand) can force the regime to change. It is assumed that in the shift from the pre-development to the take-off various niches influence each other and cluster into a larger compatible network, or a nicheregime. During the take-off phase the niche-regime expands rapidly because the system has chosen new directions. The incumbent regime will destabilize during the acceleration phase. Large amounts of capital will be re-allocated and invested in a new economic infrastructure and institutional structure. During the stabilization phase, the large scale transformation slows down and incremental change takes over as the new regime is built up. 
Increasing structuration

of activities in local practices

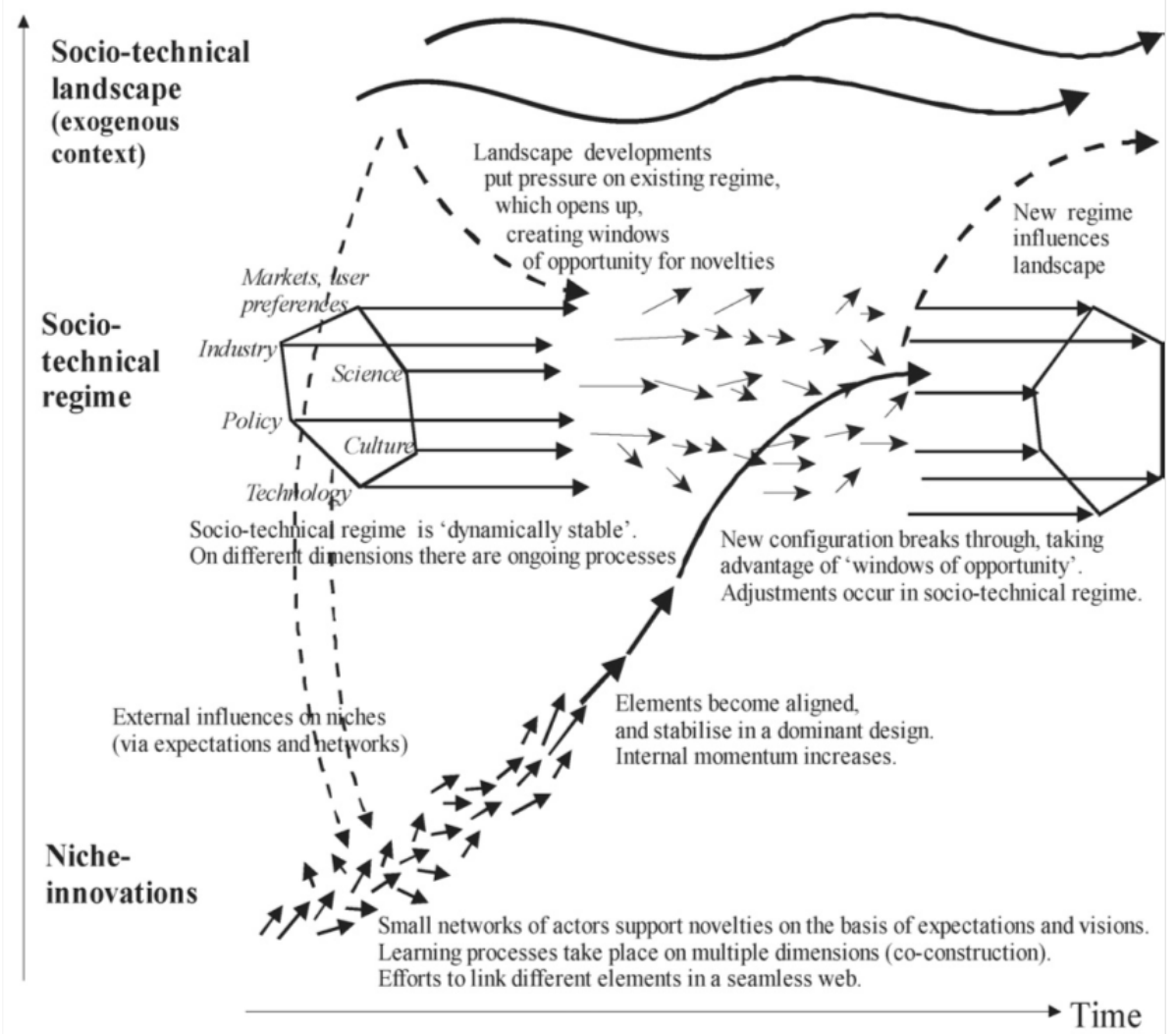

Figure 2. A dynamic multilevel perspective (Geels and Schot 2007, p. 401) ${ }^{1}$.

It is clear that this transition is only one of many possible trajectories a system can go through. For example, if landscape pressure occurs at a time when niche-innovations are not yet fully developed, the transition path will be different than when they are fully developed. Different researchers have made a characterization of the transition processes.

Kemp and Rotmans (2004) distinguish two types of transitions: evolutionary transitions and goal-oriented transitions. Evolutionary transitions evolve in a non-planned manner while by goal-oriented transitions the goal or vision of the end state is guiding decisionmakers, orienting strategic decision of private decision-makers. Berkhout, Smith and Stirling state that the MLP stress too much emphasis on the niche level as the main point of regime changes, while there are more contexts in which regime change can occur.

\footnotetext{
${ }^{1}$ We used the latest version of the multilevel perspective because the downward arrows towards the niche levels and the $y$-axis are added.
} 
They understand regime change to be a function of two processes: the articulation of pressures, and the degree to which responses are coordinated and based on resources available within the regime. They combine the two adaptation dimensions to construct a typology of four transitions. Endogenous renewal is a transition context in which the pressure to change the regime is clearly articulated and there is a high coordination of response based on resources originating within the incumbent regime. Reorientation of trajectories is a transition context in which adaptation is internal to the incumbent regime in which pressures are poorly articulated and responses uncoordinated. Emergent transformation arises from uncoordinated pressures for change and responses are based on resources and capabilities lying outside the incumbent regime. Purposive transitions are intended and coordinated change processes that emerge from outside the existing regime (Berkhout, Smith et al. 2004, Smith, Stirling et al. 2005).

Geels and Schot (2007) based their typology of transition on elaborated case studies describing historical transitions. They use the nature and timing of interactions between the levels. The timing of the interaction refers to whether the niches have matured enough to replace the regime when the macro developments occur. With nature of the interaction they mean that niches and the macro developments can disrupt the incumbent regime. Geels and Schot (2007) identified four different transitions paths plus a path which does not represent a truly radical transition, but addresses a possible sequence of transition paths external landscape pressure (regular change), called the reproduction process. The first path is the transformation path, which occurs when there is moderate landscape pressure (disruptive change) at a moment when nicheinnovations have not yet been sufficiently developed, regime actors will respond by modifying the direction of development paths and innovation activities. The dealignment and re-alignment path occurs when there is a large and sudden landscape change (avalanche change) the increasing regime problems may cause regime actors to lose faith. The technological substitution occurs when there is much landscape pressure (specific shock, avalanche change, disruptive change) at a moment when niche innovations have developed sufficiently, niches will break through and overtake the business of regime actors. The last path they distinguish is the reconfiguration pathway, where niches are initially adopted in the regime to solve local problems.

Finally, De Haan (2007) argues that there are three innovation patterns that are associated with three distinct transition paths. The first path is the re-constellation, which describe how large scale alternatives are forced upon the regime. The adaptation path described how the incumbent regime responds to niches which may happen in two ways. The incumbent regime adopts the innovative ideas or products, which in turn leads to a change of the practices. A third path they have identified is the empowerment path, which describes how small scale niches grows and eventually replaces the incumbent regime. 
In recent years, the MLP has been applied to various historical cases relating to energy (Verbong and Geels 2007), transport (Schot, Mom et al. 2002), aviation (Geels 2006), waste management (Parto, Loorbach et al. 2007), and water management (Van der Brugge 2009). The results of these studies gain insights in how transition from an old system to a new system is going, why pressure on the regime occurs, what the influence of landscape factors are, what the role of niches is, the role that policy played, and so on. It provides a nuanced picture of transitions, which makes it clear that the outcome is not established in advance and that the interaction between the different levels play an important role. Several of these cases show that the importance of niches should be nuanced. This is performed in various studies which the MLP use from a niche perspective. This studies emphasis on how niches differs from the regime, how niches were developed, how to strengthen relations in order to influence the regime, and so on. Most of this research is situated within the SNM approach, which in detail studied what kind of processes in niches occur. Case studies analysing the possibilities of SNM are related to the electricity sector (Raven 2005), eco-housing and organic food in UK (Smith 2007), sustainable mobility in Sweden and the UK (Nykvist and Whitmarsh 2008). Also from these studies are lessons learned for further refinement of the understanding of transitions in general, and the ability of the MLP in particular. Smith (2007), for example, refines the MLP further by highlighting the power relation between niche and regime which influence how socio-technical practices that work in the context of the niche are subsequently interpreted, adapted and accommodated within the incumbent regime.

To wind up, the MLP is sociologically oriented and specifically designed to explain the spread of novelty and dynamics of regime transformation. It implies that some general patterns can be distinguished. The MLP is a useful analytical tool to unravel the multitude of developments that play out at different scales. The framework is often used in a retrospective way to explain how transformation occurred and to assess which phase a transition is in.

\section{Discussion}

With this elaborated literature review of the MLP in mind it is intended to subject the MLP to a critique, which will shed light on the applicability of the approach to analyse technological transitions.

The key point of the multilevel perspective is that transitions and system innovations occur through the interplay between dynamics at multiple levels. The approach is very suitable for finding outside factors which could hinder or promote the development of an innovation. However, the framework does not focus on factors dealing directly with the technology itself such as research and development activities.

The framework can look back on several years of theoretical development and a large number of empirical case studies, in which it has been tested and refined. The interpretation of the performed case studies informs the transition paths that have been sug- 
gested and ultimately provide the empirical underpinning for the claims of the MLP. However, the interpretation is made by the researchers itself while a number of aspects of the research process rely on this interpretation. In addition, it is important to keep in mind that it is possible that the case studies are constructed poorly or related sources used uncritically, the strength of the MLP as a whole is undermined (Genus and Coles 2008). Reviewing the research it would appear that the characteristics of transitions differ from case study to case study. There are also differences in the focus of transition research, i.e., the core research question. Within transition research, there are questions of how changes at the level of technology systems occur, while other studies are directed at radical technical innovations. Thus, the performed case studies have not been conducted on systematic manner, which makes it unclear whether the MLP has been fully or clearly applied. To make the framework more explicit a structured method may be necessary. In the following, I will highlight some limitations of the different levels.

\section{Socio-technical regime}

In analyses of transitions, regimes are in the main focus and transitions are viewed as fundamental change in regimes, influenced by higher and lower levels. The use of the regime concept in empirical studies would be very helpful in discovering promoting and limiting factors outside of the development of the technology itself. However, the concept of socio-technical is not applied coherently in the technological transitions literature, and the regime concept is weakly operationalized as it is used in an impressionistic way. While there is a shared understanding in terms of regime characteristics the interpretation of regime as a rule set and regime as a system is quite diverse. What is seen as the regime depends to a large extent on the research question and the other way around it has a strong influence on framing the research question. In order to make the notion of regime tangible, the concept should be justified and made as clear and explicit as possible in order to fully unfold the analytical power of the concept and to allow for a cross comparison of case studies.

\section{Socio-technical landscape}

It is interesting to explore the macro level from a theoretical viewpoint. It is important to find out which factors at this level have influenced the promotion of niche technologies in society, because such factors are not systematically studied. However, it could not lead to any practical recommendations because those factors are not under control of any person.

\section{Technological niches}

Successful niche development requires the development of complementary technologies, more robust expectations and a broad, highly aligned network. The breakthrough of a new technology is expected to come from an accumulation of niches discussed in the SNM approach, which focuses heavily on the creation of a protected market space 
for experimentation purposes and to promote future market diffusion. This approach does not look at entire countries, but Geels and Raven (2006) made a distinction between local and global elements in the development of new trajectories ${ }^{2}$. However, socio-technical circumstances that influence the successful breakthrough of a niche into the regime are absent from the basic theory, and it has also neglected the situation of unstable regimes.

The concepts and tools to investigate innovation dynamics at the niche level can be more elaborated. Research focused on the role of various niche-internal processes, it highlights interactions between learning processes, network building and expectations (Geels and Raven 2006). Empirical findings showed that the analysis of these nicheinternal dimensions needed to be complemented with attention to niche-external processes.

Also actors and strategy making have received little attention in the conceptualisation of niches. Are niches actively created by actors or do they emerge in an unplanned way? Do niche actors form alliances with particular regime actors? It would be interesting to map out niches in terms of the relevant actor groups, including users. Finally, little explanation is paid for dynamics beyond the niche level such as complementary effects of developments in different niches or the emergence of niche transcending institutions. A first proposition to anticipate this is done by Geels and Schot (2007) through the concept of niche-accumulation.

From these descriptions, I can conclude that the MLP approach has a broad scope in that niches, regimes but also landscapes are taken under consideration. As a result, this approach may lack insights concerning the mechanisms within the different levels. It is particularly difficult to describe precisely the internal evolution of a system.

\section{Relations and interactions between the different concepts}

The MLP can be used to describe how new technologies emerge within more of less protected niches, and how they become working from configurations that shape and reshape regimes. From this I can conclude that the interactions between niche and regime are important. However, the insight into the key processes that influence the successful breakthrough of a niche into the regime is lacking at the moment. Thus the MLP needs to be completed with a theory on the successful growth of a niche for it to become part of the regime. Or in a broader view, a theory which includes the interaction process between an innovation and the surrounding networks and institutions since the landscape influences both niches and regimes.

\footnotetext{
${ }^{2}$ The local network consists of actors who work on the project, and develop and align heterogeneous bits and pieces on location. The global network consists of actors who have some distance to the project, but are related through providing resources, such as finance, political support, technical specifications, that generate a space in which local actors can work (Geels and Raven 2006).
} 
A regular misconception it that the three levels are absolute, rather than that they depend on the system. A distinct consequence of this is that there is no rule as to which kind of entity should be located on which level, but rather it depends on the choice of the system of interest (Smith 2007). However, the lack of functional distinctions between the levels makes it difficult to use the framework with a currently unfolding case unless prior assumptions are made initially about the nature of the processes involved. An interesting question which follows from this is how to apply the different conceptual levels empirically.

Steering of transitions is difficult if not impossible, as they involve complex interactions between the dynamics within and outside a social-technological system. Even when a government commits itself to a certain transition, it cannot control the transition in a top-down manner, if only because it is a central part of the change. Historically, the government can be characterized as following part rather than as guiding part of a transition. However, they can play a bigger role if the relationships with producers, users, scientists, socio-cultural groups, designers become more essential (Paredis 2009). Designers, users and others have their own ideas about the benefits and functionality of new technologies, and what the market wants - views which may concur with those of regime actors. Policy can stimulate bottom-up lessons but this may not be enough. Topdown should not come in the place of bottom-up processes but build on these and guide these. Only a combination of bottom-up (developed in small market niches) and topdown (organized in demonstration projects) will work (Loorbach 2007).

The different phases of the transition are not to forecast the course of the transition through time, but to help us to recognize where a specific technology are in the process. However, in its current form it is still rather generic and lacks detail. So the main challenge lies in refining the phases, for example through further dividing them into different sub-phases. Through combining the different phases with the multi-level concept, some generic patterns of transition dynamics were identified. These help us to understand how the regime is transforming (regime-preserving or regime-altering), but they do not provide us with information on what is changing in the regime. During a transition, different kinds of regime structures (cultural, institutional, infrastructural) need to change, but it is not clear if each of these structures should change, when they should change, or how they are related to other pattern of change. Furthermore, Genus and Coles (2008, p.5) argues that "there is a question mark over the definition, conceptualization and verification of transition paths within transition research. It is unclear whether a new, unique transition path can or should be identified for each new case study". Of course, there is a need to empirically ground them.

The discussion about system innovation and transitions has so far been conducted from the same perspective: to describe, map and analyse the entire long term process of 
technological change. The MLP is a structural process approach, which provides an overall framework to analyse transitions with the idea that explanations of system innovations have to be sought in a very broad way. However, there is too much emphasis stressed on structures, technologies and the supply side of the economy, while there is paid too little attention to the demand side and the role of consumers. Thus the MLP needs to be further developed as an actor-oriented approach which looks at how actors exercise influence and try to steer transitions, develop visions and adapt them through searching and learning processes. Geels (2004, p.43), however, has also pointed this out when he argues that the MLP "needs to be complemented with an actor-oriented approach working from the inside out".

Although substantial insights have been gained, the MLP approach is still an unfinished research program. The comments highlight the need for greater clarity and robustness in the use of multi-level models of technological transition. More empirical evidence is needed for validation and it is valuable to experiment with transition management in other countries, also outside Europe.

\subsection{Innovation system approach as analytical approach}

Another strand of research on transition and system innovations rooted in evolutionary economics is the innovation system literature. In the last twenty years, a large number of approaches have emerged. A survey of the literature on IS reveals that all authors use a different definition of an innovation system. Because it is such a broad concept, authors can define it differently and stress the element(s) they consider the most important. The last years, more attention is paid whether and how the insights of the innovation system literature can be combined with the insights of transition and system innovations. There are some weaknesses and strengths of the two approaches and there is still research going on to conceptualise them. In the next section, the need to apply an innovation system perspective is explained followed by the sets of functions which have been emerged in the literature.

\section{Innovation process}

According to the Oslo Manual (OECD 2005), innovation is the implementation of a new or significantly improved product (good or service), or process, a new marketing method, or a new organizational method in business practice. The innovation that is being developed or adopted may be new to the world or new to the company. The adoption of a new process or business practice developed elsewhere counts as innovation.

The innovation system starts from the idea that innovations are often developed within systems formed by actors and organizations. Companies, governments, universities, consumers, and other organizations all contribute in a different and interactive way to innovations. These actors and organizations, the relationships between them and the 
institutions influencing them, together form the innovation system (Carlsson et al., 2002).

Before the innovation system will be further explained, it is important to keep in mind that the view of innovation process as an autonomous development has changed over the years. The predominating paradigm until the middle of the 1990's was the closed innovation system, which is described as a stage gate process which could be managed inside a large venture (Coopers 1993, Wheelwright and Clark 1993). The closed stage gate process assumes that research results, development output and economic results remain under the control of the organization as much as possible. However, it is difficult to protect knowledge and technology even under a regime of intellectual property rights. Instead of setting up a defensive security system, companies may share the knowledge with others, to benefit from knowledge from others and from a 'first mover advantage' in the market. Chesbrough (2003) launched the term open innovation system in his book the new Imperative for Creating and Profiting from Technology. The difference between a closed innovation paradigm and an open innovation paradigm is visualized in Figure 3.

Chesbrough (2003) defines an open innovation as "a paradigm that assumes that firms can and should use external ideas as well as internal ideas, and internal and external paths to market, as the firms look to advance their technology". The central idea behind open innovation is that knowledge is not anymore proprietary to the organization, detecting recent technological developments and latent markets is just as important as conducting research yourself. An open innovation system assumes that as much external ideas as possible are used to generate innovations (Von Hippel 2001, Linder, Jarvanpaa et al. 2003).

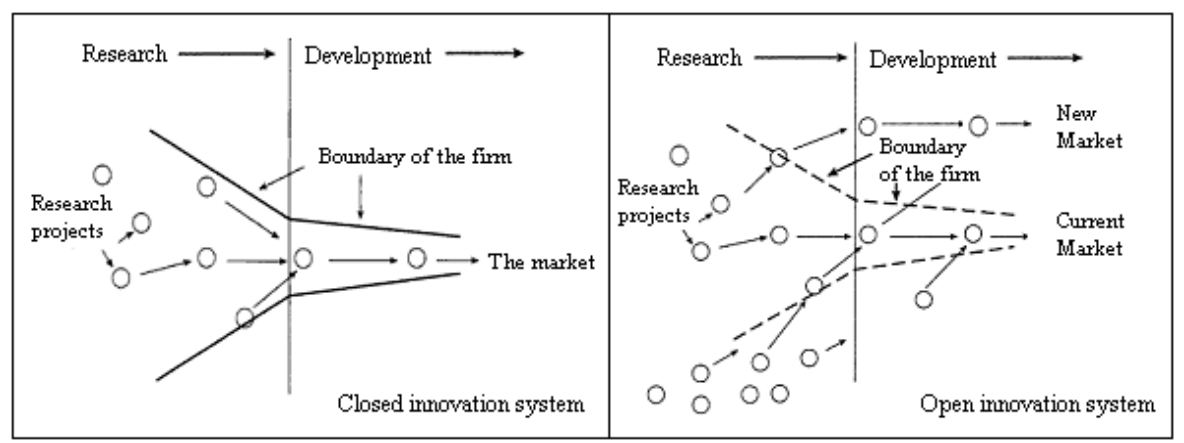

Figure 3. Closed versus open innovation system (Chesbrough 2003).

Definitions of the innovation system

Freeman introduced the concept of innovation system as in 1987. He stressed the importance of institutions and defined the innovation system as "the network of institutions in the public and private sectors whose activities and interactions initiate, import, modify, and diffuse new technologies" (Freeman 1987, P.1). This concept is further developed by Lundvall and Nelson into national innovation system (NIS). Lundvall (1992, 
p.2) defined it as "the elements and relationships which interact in the production, diffusion and use of new, and economically useful, knowledge ... and are either located within or rooted inside the borders of a nation state", while Nelson (1993) defined it as "a set of institutions whose interactions determine the innovative performance ... of national firms. They emphasize the importance of institutions and learning processes. Lundvall (1992, p.12) writes that an innovation system comprises "all parts and aspects of the economic structure and the institutional set-up affecting learning as well as searching and exploring - the production system, the marketing system and the system of finance present themselves as subsystems in which learning takes place". Metcalfe (1995, p.38) added the importance of governments and policies to this definition, and defined it as "that set of distinct institutions which jointly and individually contributes to the development and diffusion of new technologies and which provides the framework within which governments form and implement policies to influence the innovation process". As such "it is a system of interconnected institutions to create, store and transfer the knowledge, skills and artifacts which define new technologies". The notion of NIS places a major emphasis on the role of nation states, where the geographical boundaries of the innovation system as are fixed. Within the boundaries, country specific factors influencing the innovative capabilities of national firms are studied (Edquist 1997) Such a conception is highly relevant to understand macro-economical differences between states. Researchers initially focused on the national level. However, for most researchers the national level added an unnecessary amount of complexity due to the vast amount of actors, institutions and relations involved. This has led to the creation of regional innovation systems (RIS) and sectoral innovation systems (SIS), which as the names suggest focus on a region or a sector, respectively. The regional innovation system is located within a country approach where cultural variables are important in order to reinforce regional innovative capability and competitiveness (Doloreux and Parto 2004). The basic idea is similar to that of the NIS approach, but here the innovative performance of a region is used as the unit of analysis. Both approaches, NIS and RIS, typically do not take into account a detailed analysis of technological innovation processes. The sectoral innovation system breaks with the geographical orientation and focuses on the level of the industrial sector (Edquist 2001). Breschi and Malerba (1997, p. 131) defined the SIS as "...the system (group) of firms developing and making a sector's products and generating and utilizing a sector's technologies...".

However, as Carlsson and Stankiewicz (1991) argue, the geographical orientation of the innovation systems approach fails to address the problem of how specific technological innovations are more or less successful. In this case the detailed characteristics of structures that constitute a technological field are more important determinants. Carlsson and Stankiewicz (1991, p. 94) define a technological innovation system as "a technological system may be described as a network of agents interacting in the economic/industrial area under a particular institutional infrastructure and involved in the generation, diffusion, and utilization of technology". 
The innovation system as concept has become very popular among academics and policymakers due to its heuristic power. There is variety and ambiguity in the definitions used, but nevertheless innovation system as studies share a common ground upon which all researchers agree. The approach places innovation and learning processes at the centre of focus; adopts a holistic and interdisciplinary perspective; employs historical and evolutionary perspectives; emphasizes interdependence and nonlinearity; encompass both product and process innovations; emphasizes the role of institutions. Central to this approach is the idea that organizations are not innovating in isolation but in the context of a system (Freeman and Lundvall 1988, Lundvall 1992, Nelson 1993, Smits and Kuhlmann 2004).

Technological innovation system approach as analytical framework

Due to the interest in technological transition processes, the appropriate innovation system in this case is the technological innovation system (TIS), i.e. socio-technical systems focused on the developments, diffusion and use of a particular technology. This implies that there is a technological system for each technology and that each system is unique in its ability to develop and diffuse a new technology (Jacobsson and Johnson 2000). The concept of technology refers to "material and immaterial objects that can be used to solve real-world technical problems as well as to the technical knowledge" (Bergek, Jacobsson et al. 2008, p.408). Not only components exclusively dedicated to the technology in focus are included, but all components that influence the innovation process for that technology (Bergek, Jacobsson et al. 2008, p.409).

In addition to the authors that explicitly speak of technological innovation systems there are others using very similar concepts. A closely related concept is that of competence blocs developed by Eliasson and Eliasson (1997, p.14). Competence blocs are defined primarily from the demand (product or market) side as the total infrastructure needed to create, select, recognize, diffuse, and exploit new ideas in clusters of firms. The main differences between this concept and that of Carlsson and Stankiewicz (1991) are that the competence bloc is not input determined but defined in terms of its end results and that it is concerned with the selection of successful innovations. However, these differences are not easily noticed in the work of both authors. Another related concept is used by Bijker $(1987,1995)$ which stresses the need to view every artifact as a sociotechnical ensemble, since it is impossible to separate the technical from the social, economical or political. The resulting notion of a socio-technical system, consisting of different artifacts and actors, strongly resembles the technological system concepts described by Carlsson and Stankiewicz (1991).

The TIS approach can be used to at least three levels of analysis: to a technology in the sense of a knowledge field, to a product or an artifact, and finally to a set of related products and artifacts aimed at satisfying a particular function (Carlsson, Jacobsson et al. 2002). Eliasson and Eliasson (1997) have labeled this latter level of analysis as a competence bloc. TIS has proven itself capable of explaining why and how sustainable energy technologies have developed and diffused into a society, or have failed to do so (Negro 
2007). In applying the TIS approach, Carlsson et al. (2002) has emphasized four basic assumption. First, the primary unit of analysis is the system as a whole rather than its individual components (actors, organizations, institutions). ${ }^{3}$ Second, the system is dynamic, i.e. I need to take feedback explicitly into account. Third, the contribution of the system to global knowledge is quite modest, it may be more important to raise absorptive capacity than to create new technology. Fourth, each component in the system operates with bounded rationality.

An important difference between the TIS and the other concepts lies in its spatial aspect. While national, regional and sectoral innovation systems maintain strict geographical boundary, a TIS transcends these boundaries as the technology is used in several sectors, and multiple countries are involved in the research and diffusion of the technology (see Figure 4). However, though the technology (or the knowledge it embodies) is international in nature when researching them, TIS is virtually always restricted to national boundaries since it is affected by the national institutional framework (Hekkert, Suurs et al. 2007).

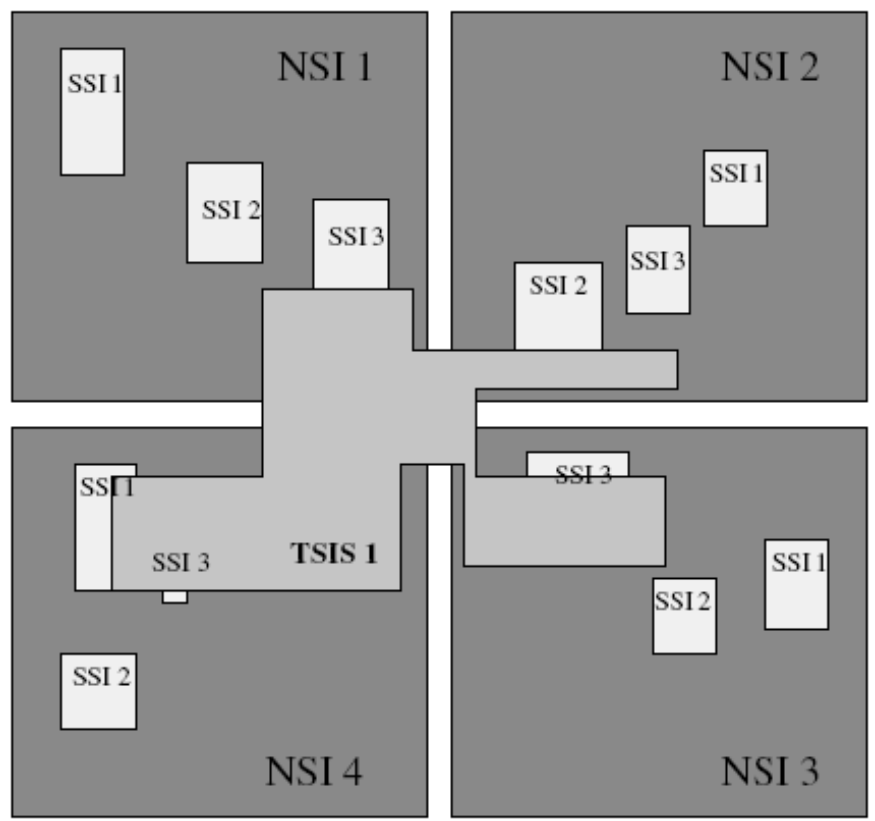

Figure 4. Boundary relations between national, sectoral and technology specific innovation system (Hekkert, Suurs et al. 2007).

\footnotetext{
${ }^{3}$ The first assumption is similar to several of the other innovation system approaches.
} 
Another significant feature that differentiates this approach from other approaches is that it often analysed an emerging system rather than a mature system (Carlsson 1997). Carlsson (1997, p.4) reported "a newly emerging system has characteristics of from those of mature systems, and the configuration of actors and institutions change over time within each system. This was already put forward by Carlsson and Stankiewicz (1991, p.111): "Technological innovation systems are defined in terms of knowledge/competence flows rather than flows of ordinary goods and services. They consist of dynamic knowledge and competence networks. In the presence of an entrepreneur and sufficient critical mass, such networks can be transformed into development blocks, i.e. synergistic clusters of firms and technologies within an industry or a group of industries."

Since the TIS is a theoretical construct applied to and defined in a specific research context, the delineation of system is essential. It is challenging because there is no right or wrong way to draw system boundaries. Edquist (2004) defined the boundaries on the basis of the activities that are conceptualised as the key determinants of the innovation process. He suggests that TIS consist of anything relevant for the development, diffusion and use of a particular technology, but this delineation is rather impractical. A more practical approach to delineate the system is to shape the TIS concept to the specific purpose of an analysis. When understanding of the system increases during the research, it is possible to broaden the system boundaries by incorporating indirect structures that seem to be important. Bergek et al. (2008) outline three types of choices that researchers need to consider; the choice between knowledge field and product, the choice between width and depth, and the choice of spatial domain. I would like to make one small addition in the form of the choice of time period. Depending on the choices made, different sets of actors, institutions and networks will be incorporated (Bergek, Jacobsson et al. 2008, Markard and Truffer 2008).

The TIS approach can be analysed in terms of its structural composition and in terms of its dynamics. Both perspectives will be explained below.

\section{Structural composition of technological innovation system ${ }^{4}$}

The idea behind the innovation is that technologies develop within the context of a system which consists of actors (e.g. firms and other organizations), institutions, networks, and the interrelations between them (Jacobsson and Johnson 2000, Carlsson, Jacobsson et al. 2002). Since a system seems to be comprehensive, some insight in the structure of the innovation system seems to be appropriated. By doing this, the innovation system can be described by distinguishing subsystems, or system components, and mutual rela-

\footnotetext{
${ }^{4}$ Within each innovation system approach the system differs in terms of concepts used and the actors identifies, but the structure of it is the same.
} 
tions (see Figure 5) (Van Lente, Hekkert et al. 2003, Smits and Kuhlmann 2004, Alkemade, Kleinschmidt et al. 2007).

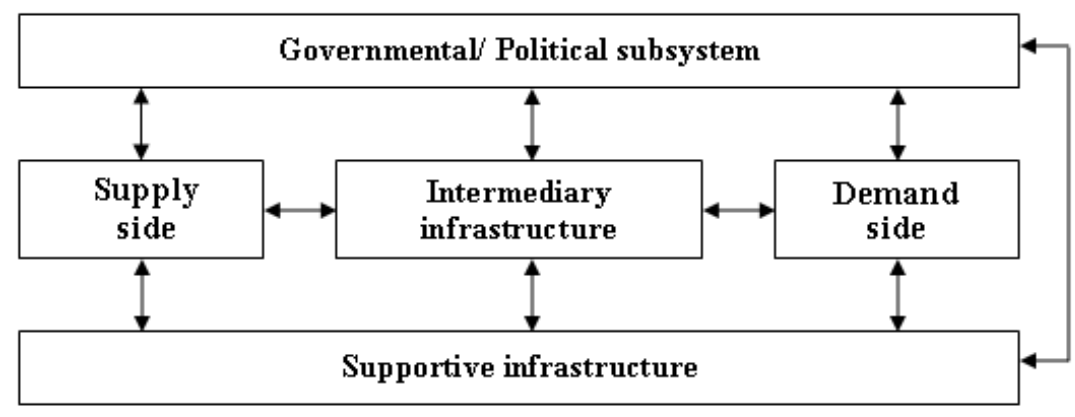

Figure 5. The innovation system ${ }^{5}$.

The supply and the demand side contain the actors that supply or demand the innovation. The supply side provides the knowledge and the development of new technologies on a commercial level. Developers (universities, public research organizations and industrial laboratories), managers, marketers and entrepreneurs are part of this subsystem, which provide communication with each other as well with other components of the innovation system that can articulate or influence the demand. The new technology and knowledge need to be adapted by users, consumer's as well large industrial users (e.g. firms and governments). The demand side is able to provide demand articulation to other components of the innovation system, which is an important force to guiding and shaping future innovations. This subsystem consists of potential users (consumers, firms, governmental departments), with their preferences, habits and willingness to pay.

The intermediary infrastructure includes organizations, institutions and instruments who are aiming to improve the interface and exchange of knowledge between the other components of the innovation system. To stimulate the implementation and diffusion of new technologies, intermediaries attempt to support the relation and interactions between all the other actors. The motivation to either help or hinder the implementation and diffusion depends upon the goals of the intermediary.

Since the diffusion of new technologies strongly depends on government policies the governmental/political subsystem is of importance. Policy makers play a role in providing and guarding the infrastructure and institutional settings in which the innovation system resides. This subsystem consists of actors that aim to influence the innovation system by using policy measure and instruments. This system provides the institutional context

\footnotetext{
${ }^{5}$ The framework of the innovation system is originated from Alkemade et al. (2007), the interaction between the subsystems are adopted from the innovation system presented by Smits and Kuhlmann (2004).
} 
that provides incentives, legislation, norms and standards for other components of the innovation system to create and diffuse the technology. The main actor is the national government because this level of policy maker has the highest influence in terms of national policy making and national resource allocation (Dolata 2008). When other levels of policy makers (regional government; European level government) should be involved then this will be explicitly mentioned. Furthermore the governmental subsystem consists of different ministries and other governmental organizations, but also provinces and municipalities.

The supportive infrastructure comprises material and immaterial infrastructure which support and facilitate the other subsystems in the innovation system by generating, assessing, and transferring knowledge. Scientific and applied research institutions (universities; public research organizations) play an import role since they perform research to further enhance new technological characteristics. This kind of research is not intended to commercializing the technology, it does not need to collect revenues from their findings by selling products to customers. This forms an important difference with the actors from the supply side which consists of market related actors. The supportive infrastructure consists of actors that produce the input materials that the new technology requires, financial resources can come from banks or investors while feedstock resource come from farmers (Van Lente, Hekkert et al. 2003, Smits and Kuhlmann 2004, Alkemade, Kleinschmidt et al. 2007).

Based on the above, the innovation system is an interactive process in which different types of interconnected actors and institutions engage in the production, diffusion and use of new technologies. Important to note is that the actors and institutions can play several roles and thus occupy multiple positions in the innovation system. It is expected that they contain networks which are even more likely stretched across different subsystems.

The performance of the structural composition of the innovation system is determined by how well developed each of the subsystems is and by the relations that exist between subsystems. A subsystem is well developed when it contains a diversity of actors, which are actively contributing to the diffusion and use of the emerging technology in focus (Alkemade, Kleinschmidt et al. 2007). The system approach is well suited to help policymakers deal with dynamic complex processes as innovation, by focusing on the relationships between actors and on the knowledge flows in the system (Larosse 2004).

\section{Dynamics of technological innovation system}

The structural analysis of the TIS is seen as a quite static approach, it involves elements that are relatively stable over time. Mapping the contours of innovation systems and analysing the interaction or the lack of interaction between components (subsystems) does not explain how the system came into being. In order to achieve the desired change in a system, a dynamic framework is required which focuses on system functions. 
The idea behind the so-called functions of innovation systems approach is to consider the TIS as being a system with a purpose which is to be served through the fulfillment of a set of functions (Hekkert, Suurs et al. 2007). Similar to the notion of functions, other authors have proposed to analyse innovation systems in terms of activities, e.g. (Liu and White 2001). Activities are conceptualised as "the factors that influence the development, diffusion, and use of innovations" (Edquist 2004, p. 487).

\section{Functions of innovation system}

For a TIS to function correctly it is generally assumed it needs to fulfill a specific set of functions, or activities, where each function relates to such a specific process or activity that takes place within the system. As far as I know, several of such sets have been proposed: Edquist and Johnson (1997), McKelvey (1997), Galli and Teubal (1997), Johnson 6 (2001), Rickne (2000), Liu and White (2001), Edquist (2004), Jacobsson et al. (2004), Carlsson et al. (2005), Bergek et al. (2005) Hekkert et al. (2007). The lists show much overlap and differences reside mostly in the particular way of clustering activities. There is currently no agreement on the preferred set of functions. As stated by Hekkert and Negro (2008), "...another group of researchers with different backgrounds might highlight different processes and come up with a different categorization of events and thereby to a different set of functions" (Hekkert and Negro 2008). However there are two sets which are most prominent in the recent literature. Both the research group of Hekkert (2007) and the research group of Bergek and Jacobsson (2005) have introduced a fairly similar set of seven functions. Both are based on the newest insights and have been used in several case studies. As the seven functions of Hekkert et al. (2007) are currently used to examine the Dutch transition paths, this will facilitate translation. The framework has been used in several case studies in the Netherlands and abroad, including comparative studies. For these reasons I explain the Hekkert et al.'s (2007) functions of innovation framework in more detail to determine the strength of the innovation systems and points of improvement. The framework consists of seven functions which all relates to activities that take place in a TIS which are highly important for it performing well.

\section{Function 1: Entrepreneurial activities}

The existence of entrepreneurs is essential for a well functioning innovation system. The role of the entrepreneur is to turn the potential of new knowledge, networks, and markets into concrete actions in order to generate and take advantage of new business opportunities (Hekkert, Suurs et al. 2007) and overcome uncertainties associated with emerging technologies (Carlsson and Stankiewicz 1991). The importance of entrepreneurial activities was already discussed by Carlsson and Stankiewicz (1991) who stressed economic competences as a crucial factor in the development of an emerging technolo-

\footnotetext{
${ }^{6}$ Johnson was Bergek's maiden name.
} 
gy. This also relates to Schumpeter's idea of the entrepreneur as the source of innovation and the driver of creative destruction (Van de Van, Polley et al. 1999).

Entrepreneurs can be new entrants who recognize such opportunities in new markets or incumbent company that diversify their business strategy to take new advantage of new developments (Hekkert, Suurs et al. 2007).

\section{Function 2: Knowledge development}

The knowledge development or mechanism of learning is at the heart of any innovation process. Lundvall (1992) formulates this as follow: "The most fundamental resource in the modern economy is knowledge and, accordingly, the most important process is learning". Four types of learning processes were distinguished by Kamp (2002); learning by searching, learning by doing, learning by using and learning by interacting. Of these the first three fall under the category of knowledge development while learning by searching entails the creation of new knowledge. The combination of old and new knowledge in innovative ways and the reuse of old knowledge by imitation are included. Another distinguishing of learning processes is made by Boon (2008); first-order learning (the development of demands, following a cycle of agenda-setting - demand synthesis expression - evaluation) and second-order learning (developing underlying assumptions, objectives, self-positioning in relation with the other-positioning).

\section{Function 3: Knowledge diffusion through networks}

The network can be considered as an intermediate form of organization between hierarchy and markets in an Innovation System. According to Carlsson and Stankiewicz (1991) the essential function of networks is the exchange of information. This is important in a strict R\&D as well as in a heterogeneous context where R\&D meets government, competitors and market. These networks allow policy decisions to be based on the latest technological insight.

\section{Function 4: Guidance of the search}

Resources are almost always limited in nature. Therefore it is important which technology is chosen for further investments when various technological options exist. Without this selection there will be insufficient resources left for the individual options. This function refers to those activities within the innovation system that can positively affect the visibility and clarity of specific wants among technology users. These activities can be carried out by a variety of system components such as industry, government and/or market (Hekkert, Suurs et al. 2007).

\section{Function 5: Market formation}

New technologies often encounter difficulties to compete with embedded technologies. Rosenberg (1976, p. 195) argues that "most inventions are relatively crude and inefficient at the date when they are first recognized as constituting a new innovation. They 
are, of necessity, badly adapted to many of the ultimate uses to which they will eventually be put; therefore, they may offer only very small advantages, or perhaps none at all, over previously existing techniques. Diffusion under these circumstances will necessarily be slow...". Users experience helps companies to improve their products and to customise them. User feedback is an important source of information according to von Hippel (1988). Companies may decide to introduce products into the market even when it is not yet profitable, to benefit from user feedback and to establish a strong position in the market.

\section{Function 6: Resources mobilization}

Resources are necessary as a basic input to all of the activities in the innovation system. Resources can be financial or human capital (Hekkert, Suurs et al. 2007). This function is difficult to analyse by specific indicators, because the actors in the field are likely to give different answers to the question of whether resources are sufficiently available. The actors of an emerging system will always say that insufficient resources are available, while the actors of an incumbent system will insist that sufficient resources are provided (Negro 2007).

\section{Function 7: Creation of legitimacy}

When a new technology may does not fit an incumbent regime, parties with vested interests will oppose it (Hekkert, Suurs et al. 2007). Newcomers have to organize themselves to marshal support, by creation an advocacy coalition. Advocacy coalitions put a new technology on the agenda, lobbying for resources and favorable tax regimes. This leads to a creation of legitimacy for a new technological trajectory (Negro 2007).

The functions approach is useful for making policy, especially regarding new sustainable technologies (Hekkert, Suurs et al. 2007). In order to stimulate such a technology, insight in the functioning of the TIS may help determine the optimal policy strategy. Also, if it turns out the innovation system is not functioning correct, it can be improved by stimulating weak functions or by removing blocking mechanisms. When more functions are fulfilled the expectation is that there will be a better performance of the TIS which results in higher chances for successful development and diffusion and implementation of new technologies. The different functions can influence each other which resulted in different patterns. The research group of Hekkert has labeled the process as "motors of change" while the group of Jacobsson speak of a process of cumulative causation. A virtuous cycle exists when the functions strengthen each other in a positive feedback loop, negative feedback loops are known as vicious cycles (Jacobsson and Bergek 2004, Hekkert, Suurs et al. 2007). It should be noted that a vicious cycle can be overcome and it is not uncommon for virtuous and vicious cycles to alternate over time within a single innovation system. 
Co-evolution and competition between different technological innovation systems Blocking and inducement mechanisms are highly important during the early development of a TIS since the components are still less developed and external forces mainly driving the system. Blocking mechanisms could come from other TIS competing in the same market and political arena. In particular, incumbent firms may try to hinder the evolution of new technologies (niches) competing with themselves. Especially, in the energy field powerful coalitions are built up and dependence on established suppliers is generated, therefore so called lock-in mechanisms have to be overcome (Unruh 2000). Thus, there is competition between different TIS but co-evolution is possible as well (e.g. knowledge to produce silicon was developed in order to produce semiconductors but is beneficial to manufacture solar cells as well). Other possible interactions between different TIS are spillovers. For instance a coalition between advocates for solar cells and wind power is very likely to have shared interest such as favorable institutions or legitimation of renewable power. Since emerging TIS most likely share structural elements, one TIS may be influenced by functions of another. Hence, boosting the function of one system could generate positive externalities that foster the building of the structural components of the other systems. Similarly, negative effects can be transferred as well.

\section{Discussion}

\section{Innovation system}

Innovation systems are described as networks of actors and institutions that develop, diffuse and use innovations. However, there are no straightforward rules on how to define the boundaries of an innovation system, or how to define what belongs to the system and what does not. Depending on the case studied, the boundaries can be defined by technological, sectoral or by geographical factors. If the boundaries are defined by geographical factors, they can be national, regional or local. Lundvall (1992) argues that it might be impossible to identify the boundaries in detail. Therefore, as Edquist (2001) argues, it might be better to try to identify the core elements in innovation systems, and focus on the relations between these. Thus, the researcher himself needs to define the boundaries of the system he/she is studying. Markard and Truffer (2008) argues that defining the boundaries depends for a large extent on the research question and the purpose of analysis (descriptive delineation) but it is also possible to delineate the system on an empirical basis where the interactions among components within the system are stronger than the interactions between the system and its environment, for example with using a patent analysis (conceptual delineation). In order to make the boundaries of an innovation system tangible, a further refinement to the delineation (descriptive, conceptual or both) of the innovation system is needed (Markard and Truffer 2008). 


\section{Technological innovation system (general, structure and dynamics)}

So far innovation system analyses take technological features into account only as far as knowledge flows and economic factors are concerned. The exclusive focus on knowledge flows is a feature inherited from the NIS approach that may suit the analysis of a whole nation. However, this conception is not appropriate for studying emerging TIS since the material features of technology are neglected. By taking into account the material dimension of technology it is possible to identify important potential drivers and barriers that could not have been identified otherwise. This issue brings the TIS approach closer to the literature on SNM.

The TIS approach has developed into a very dynamic approach by not only focusing on the structure of the system (actors, institutions and networks) but also on the key processes that take place within the system and contribute to the build-up of a TIS and thereby to the successful development and diffusion of the emerging technology (Jacobsson and Johnson 2000, Hekkert, Suurs et al. 2007). This functional perspective on innovation systems emphasizes the importance of what the system does or how it works in comparison to how it is composed or structured (Bergek, Jacobsson et al. 2005). The structure and function are two intertwined sides of the same innovation system since the structure influences its function and the other way around. It is possible that a structurally different TIS is similar in terms of functions and vice versa. From this I can conclude that there is not an optimal structure to guarantee a well performing system, but the performance of one system can be better or worse than another one. An interesting question which follows from this is how to assess the overall system performance. It should be noted that the development and the diffusion of the innovative technology (or product) is usually used as indicator for the performance of TIS. However it looks like more interesting to divide the TIS into two parts, the development and the diffusion of the technology, and identify separate cycles in each part. Such a split of the TIS into two parts has not explicitly been done before.

An increasing number of researchers have started focusing on TIS dynamics, e.g. Bergek, Carlsson, Edquist, Hekkert, Jacobsson, Negro, Rickne, Suurs, after Carlsson and Stankiewicz introduced the concept of TIS. Notions such as momentum and motors of change play an important role in these studies. The concept is used until now successfully in different cases; biomass \& bio fuels, hydrogen, wind, solar, natural gas, carbon capture and storage. It becomes clear that using the TIS approach makes it able to study the characteristics of the system associated with an emerging technology, it analyses the strengths and weaknesses as well as the dynamics, which can be compared to those of another emerging TIS. However, it lacks the description of the transition from one system to another. The TIS theory focuses on the growth of the system itself and the importance of substituting other systems is not highlighted. Moreover, what is missing at the moment is a comparison of the specific emerging technology with the system of an incumbent technology system, e.g. electricity generation based on fossil fuels. On the 
basis of such a system comparisons researchers are able to give policy recommendations with the goal to improve system performance or to eliminate structures that block functions. In the literature, the concept is only used to support innovation and competitiveness that pursues economic growth, another social purpose is not given priority.

\section{Functions of an innovation system}

In recent years, the identification and assessment of functions of innovation systems has received a lot of attention. There are several lists of functions in the literature suggested. Although, there has been no consensus or empirical proof up till now to which set of functions performs best in describing the dynamics of a TIS. In order to make the results of different innovation case studies comparable, it remains an important issue for conceptual improvement to use a set of functions, the relationship between the functions and the function of the system as a whole that is commonly defined and understood.

In recent years special attention has been given to success or failure of policy transfer as policy transfer from one country to another has increased (Stone 2001). One major shortcoming with policy transfer was that it failed to look at the institutional embeddedness of policies or problems that they were targeting. Thus the institutional background should not be forgotten when trying to learn from lessons from other countries. The functions approach does try and take this into consideration as it looks specifically at the development patterns of different functions in different countries and specific actor interactions. However, the thresholds for the functions are still ambiguous: these might differ significantly in different countries, causing the transposing of lessons to be difficult. Furthermore, in different countries, the functions may play a different role. This could result in different interactions between the functions, causing different virtuous and vicious cycles. Therefore, it is important to research the geographical limitations of the functions approach. One cannot simply take the success from one area to another and use the policy implications of the functions approach as a 'recipe' as that could lead to a 'recipe of disaster'. Thus, it is useful to take into account the geographical boundaries of the TIS.

Since the functions of the work of Hekkert are explained in more detail, I will also discuss this set of functions. An important point relates to the relative importance of the seven functions. Though all seven functions are important for the functioning of the TIS, recent research indicates that not every function is equally important. Research performed by Hekkert and Negro (2008) emphasizes the importance of three functions in establishing virtuous cycles; entrepreneurial activities, guidance of the search and market formation. However the analysis is only based on four case studies, two in Germany and two in the Netherlands. Bergek et al. (2008) are the only other authors which have discussed this issue. A great deal is still unknown about the relation between the importance of functions and the phase of development of the technology under scrutiny, an issue which 
Jacobsson and Bergek (2004) greatly emphasize. Bergek et al. (2008) state that the importance of each function is expected to vary in time depending on whether the technology is in the formative phase ${ }^{7}$ (Bergek, Jacobsson et al. 2008). However their analysis is tentative and does not provide any practical guidelines.

In addition to the different function of an innovation system, some external aspects to the TIS are important in the functioning of the system. The analysis only looks at the immediate causes of manufacturing companies within the TIS, it withholds the issue if the companies receive sufficient supply, and simplifies all causes that lie outside of the influence sphere of the actors (e.g. worldwide supply of silicon). Another important external aspect for its functioning is institutional change. In the Netherlands, for example, the liberalization of the energy market has had a profound impact on the willingness of actors, in particular power companies, to work with and support renewable technologies. However, despite their influence, institutional changes are difficult to place in the functions analysis framework as it exists now.

The difference between the goal of the TIS and the goal of actors within the TIS has an impact on the evaluation of the functioning of the TIS. It should be noted that whether a TIS functions well the technology is being developed and diffused. However this is not always the aim of the actors within the innovation system ${ }^{8}$. It is important to note that actors can play several roles and thus occupy multiple positions in the innovation system, either in different phases of a technological transition or simultaneously. The demand side of the innovation system including the consumers of the technology are mentioned in the theory, but scant attention is paid to this when analysing whether a system is functioning well. In addition, even though there are similarities between the different innovation system approaches, they emphasize different aspect of innovation systems. Within each approach the system models differ in term of concepts used and the actors identified and emphasized.

\subsection{Comparison MLP on technological transitions and TIS approach}

The literature on the MLP on technological transitions and the TIS offers the potential to provide a better understanding of technological change. Both strands of conceptual work are based on common theoretical roots and offer promising complementarities. Both perspectives are rooted in evolutionary economic theorizing, they highlight the importance of networking, institutions and learning processes, and both consider phe-

\footnotetext{
${ }^{7}$ The formative phase is equally to the predevelopment phase and the take-off phase as described by Rotmans et al (2001).

${ }^{8}$ For instance, the government might be quite happy with only developing a technology and exporting technology or products abroad, and not have a (large) domestic market. Or it might be content to simply import the products and not be burdened with high R\&D costs, which for new innovations are at least partly government funded.
} 
nomena such as path dependence, lock-in, interdependence, non-linearity and coevolution. Both frameworks are the result of several years of theoretical development and have been applied in a large number of empirical case studies. The combination of the MLP on technological transition and the TIS is useful to explain the interdependence of the emerging TIS with other niches and regimes and to improve the understanding of the different phases of an emerging technology.

Some similarities can be identified and therefore a parallel can be drawn between MLP on technological transitions and the TIS approach. In the following the similarities will be described in terms of stability, uncertainty and the role of consumers. Thereafter some differences between the two theories will be underlined in terms of the intertwined character of both perspectives, the role of innovations and the innovation dynamics. Later on, both frameworks will be compared and a first conceptualisation between the perspectives will be given and reviewed.

Similarities between the MLP and TIS

\section{Stability}

The evolution of a system may be described by a change in its degree of stability. A regime is described as a stable system whereas a niche is relatively unstable, which can be compared to a stable stabilization phase and an unstable predevelopment phase of a TIS, relatively. Stability and instability of systems are the origin of technological transition (Geels 2004). The stability of a system can be explained by using the concepts of path dependence and lock-in, where path dependence could be described as a succession of inescapable events that lead to lock-in where timing, strategy and historic circumstances determine the winner (Unruh 2000). An example is carbon lock-in in the energy sector which generates high barriers, difficult to overcome by new entrants. According to Geels (2004) there are three ways of creating stability. First, rules and regimes lead to routines which orient perceptions and actions. Different types of rules creating stability can be distinguished: cognitive rules, normative rules, regulative rules and the alignment between these rules ${ }^{9}$. This is clearly linked to institutions and their alignment in the TIS approach. Second, actors and organizations are involved in interdependent networks resistant to change because of organizational deep structures and strong vested interests. In particular, legitimacy for a new technology is difficult to gain when these networks contain strong lobbying groups and political forces. Third, socio-technical systems, in particular the artefacts and material networks, might have a certain hardness due to inertia of systems. This leads to a resistance to change (Geels 2004). Stability is also reinforced by network externalities: the more a technology is used, the larger the range of products and artefacts associated with this technology and the harder the emergence of a competing technology. In particular, stability is reinforced by the reduction of uncer-

\footnotetext{
${ }^{9}$ See Geels (2004) for further explanation about these four types of rules.
} 
tainty and the strengthening of legitimation due to the benefits from positive externalities.

\section{Uncertainty}

An important characteristic of innovation decisions is that they inherently involve many uncertainties, e.g. technological uncertainty, resource uncertainty, competitive uncertainty, supplier uncertainty, consumer uncertainty and political uncertainty (Meijer 2008). As a result niches are particularly important since they provide a space where learning processes can be developed and uncertainty decreased (Kemp, Schot et al. 1998). Comparatively, the significance of creating protected space is underlined by the function analyses (the function related to the market formation) in the predevelopment phase of a TIS. Although they are protected spaces, niches are not totally independent from regimes rules (Geels 2004). Hence, a key challenge for entrepreneurs exploiting a new niche is not to get stuck to these rules and manage to adapt them to their specific applications, this challenge refers to institutional alignment (Jacobsson and Bergek 2004) described in the TIS theory.

\section{Role of consumers}

Both perspectives have a strong focus on technology as central point in a technological transition, to the extent that cultural and social aspects are ignored. Also the influence of life styles and the role of end-users in a technological transition usually get little attention. The technological focus reinforces the tendency to start thinking in a linear way in function of the winning transition path. The focus on co-evolution of technology and society described in both perspectives is likely to disappear under the influence of case studies. Current empirical work is focused on the diffusion, development and utilization of innovative technologies or products, explicitly on interactions between researchers and entrepreneurs.

\section{Differences between the MLP and TIS}

\section{Two intertwined theories}

The TIS approach helps us to explain the development, diffusion and utilization of new technologies. The analysis of a TIS can be divided in two parts: a structural part and a functional part. The structural composition, which identifies the actors, institutions and networks, is a prerequisite to understand the dynamics since the current picture of the system can be defined. The functional part incorporates the key processes more directly related to developing, diffusing and utilizing the technology and can therefore describe the systems performance and what creates dynamics. The TIS approach focuses on the growth of the system itself and the importance of other systems is not highlighted. Although external forces are mentioned in the TIS approach, this theory does not direct attention on these forces' origin. It is particularly difficult to locate the TIS within a broader environment. Thus, the TIS framework aims at explaining dynamics within the 
system and does not centre on its surroundings. On the other hand, the MLP on technological transition allows us to understand the shift from one system to another. It describes why and how a transition from one system to another could happen ${ }^{10}$. Why a transition from one system to another happens is explained by Geels (2004). He argues that a transition is explained by instability of a system, which may be caused by changes on the landscape level (such as climate change), technical problems or problems of capacity, negative externalities and effects on other systems (e.g. environmental impacts, health risks and concerns about safety), changing user preferences and strategic and competitive games between firms. Geels (2002) explains in another publication how transitions take place from one system to another by using three mechanisms in technological transition: niche-cumulation ${ }^{11}$, technological add-on and hybridization, riding along with market growth. Thus, the MLP theory enables us to highlight the interdependencies of the system with different regimes or niches, and therefore the origin of inducing and blocking mechanisms outside the system. However, since this approach has a broad scope where niches, regimes and landscapes are taken under consideration, it lacks insights concerning the mechanisms within the different levels. It is thus difficult to describe precisely the internal evolution of a system. Furthermore, this approach may have a weakness when it comes to systems performance assessment. Indeed, some systems characteristics such as social aspects may be difficult to identify. In the TIS theory, these aspects that are still difficult to analyse are more stressed which makes it easier to put into practice.

The functions of innovation system approach is a useful addition to the MLP and SNM to determine internal evolution of a system, because it gives insight into the key processes that allow growth of a niche. The approach goes one step further by mapping the dynamic processes around a technology. The technology can be used in several niches, but TIS is also related to multiple regimes. Regimes may represent barriers, but they can also provide opportunities in which the various landscape factors may play a role. There is competition and co-evolution possible between different TIS, but the TIS remains blind to the broader context of transitions (landscape and regime change). Both regime and landscape are contexts for interactions of actors, but in a different way. The function of the concept socio-technical landscape is that it accounts for technology-exogenous factors that influences development, while regimes refer to social structures and rules that enable and constrain activities within communities of practice (Geels 2002).

\footnotetext{
${ }^{10}$ The TIS approach refers also to this by the shift from a predevelopment phase to an acceleration phase which may lead to a mass market, but it lacks of deep information regarding the process of transition from one system to another.

${ }^{11}$ One example of niche-cumulation is the use of solar cells at first in satellites, later in calculators and then for isolated emergency phones on highways.
} 
From this elaborated explanation I can conclude that the MLP on technological transitions and the TIS approach are two intertwined theories which can be used for the same innovative technology or product. It becomes clear that the TIS are introduced to overcome weaknesses of the MLP on technological transitions while the shortcomings of the TIS approach can in turn be overcome through taken into account the MLP.

\section{Role of innovations}

The role for innovations in terms of incremental and radical innovation processes differs between both theories. The MLP approach makes a difference between radical and incremental innovations. Niches create and protect radical innovations while regimes generate incremental innovations that strengthen the regime. The TIS approach does not make a difference between radical and incremental innovations and therefore can be applied to regime- or niche-like empirical situations (Markard and Truffer 2008).

\section{Innovation dynamics}

Another difference between both perspectives is the concepts and tools to investigate innovation dynamics. At the niche level the dynamics are less elaborated than those developed in the TIS approach. In order to cope with this, Geels suggested to make a clear distinction of learning, network creation and formation of expectations as three key processes for the analysis of niche level dynamics (Geels and Raven 2006). However little has been said why these particular processes should receive particular attention.

\section{Combination of the MLP and TIS}

Since the study is based on two established theories, a strong integrated framework is desired. Common known weaknesses of the MLP on technological transition and the TIS approach can be overcome when they are combined instead of using them exclusively. A synthesis outlines the strength of adding elements from the MLP on technological transition to the TIS approach.

First, the notion of transition from one system to another is strengthened in the TIS approach by the MLP. Second, the TIS approach may not be precise regarding the origin of external forces. On the contrary, the MLP is very good for finding outside factors and investigating them more thoroughly by incorporating the landscape and potentially several regimes in the analysis, which may influence the evolution of a new niche by inducing and blocking mechanisms. Third, the TIS approach gives a clear concept how to analyse and to explain the dynamics within a system, whereas the MLP is harder to apply to practical studies because of its broadness. Therefore, the TIS approach is more appropriate when it comes to the identification of policy challenges or priorities within a particular industry. However, the MLP assists to explain the TIS place within a broad environment. 


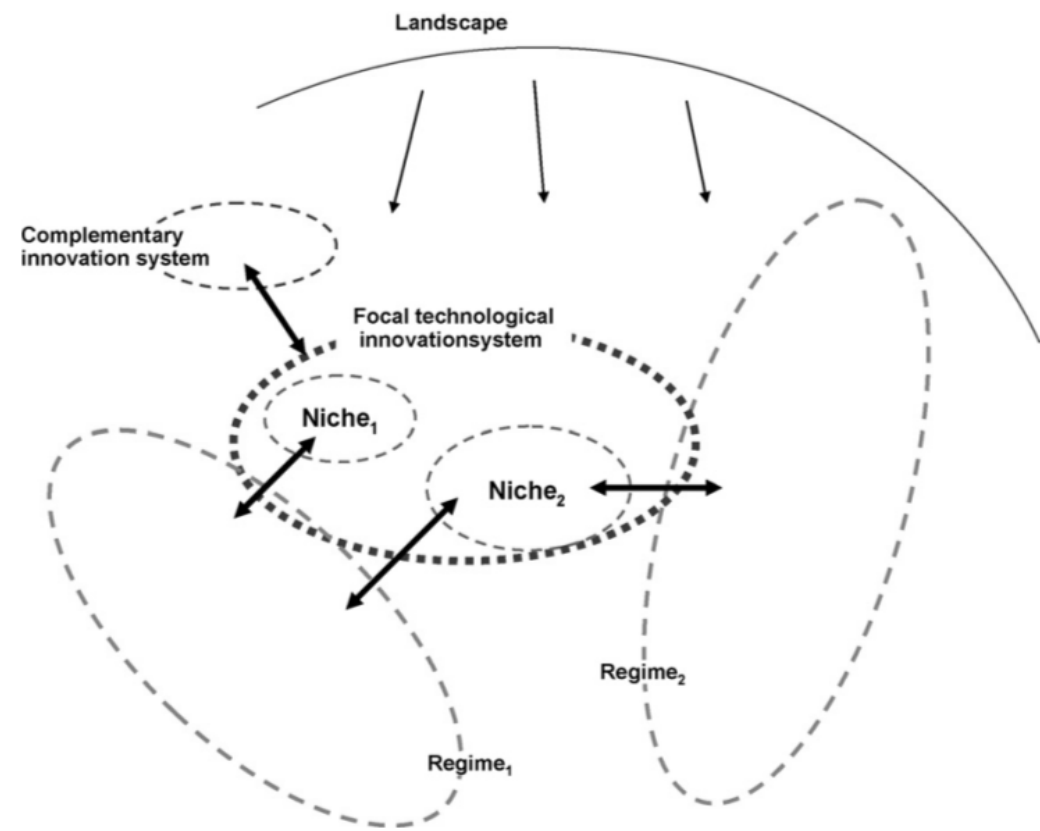

Figure 6. TIS and interactions with the conceptual elements of the MLP (Markard and Truffer 2008).

Markard and Truffer (2008) have made a first conceptualisation of both perspectives. The combined framework is visualized in Figure 6. The TIS is the set of actors, institutions and networks that support a particular innovation process, centered on a particular technology or product, and focuses on the fulfillment of the functions of the innovation system. The technology is used in several niches belonging to a TIS in a world of existing regimes. As described above, regimes may hinder the development of a TIS, but they can also provide opportunities in which the various landscape factors may play a role. Moreover, a focal TIS can interact with another TIS which can have a competitive or complementary relationship. Markard and the Truffer note that this is only a first conceptualisation which has to be refined further and applied to an increasing set of empirical cases.

The combined framework offers the possibility to account for emergent effects in innovation processes that occur beyond individual niches. It also offers a basis for an actororiented analysis of innovation processes, which explicitly considers different actor strategies, resource endowments and agency. Furthermore, the framework facilitates performance analyses on the basis of functions as it makes a clear analytical distinction of system structures and functions (Markard and Truffer 2008). However, since the demand side, in particular the consumers and the focus exclusively on the technology is lacking in MLP on technological transitions as well as in TIS approach, this is also lacking in the integrated framework. 
Thus, the discussion about system innovation and technological transitions has so far been conducted from the same perspective: major systems to perform certain social functions, groups of actors who put systems to work, guided by a system of rules and institutions. It is a method of analysis that uses structures, institutions and large processes. The discourse have always stressed that statements have to be sought of a very broad field, but in fact research is an overexposure of structures, technologies, the supply side of the economy, and an underexposure of the demand side and the role of consumers in transitions. Geels $(2004$, p.43) already mentioned this, when he argues that the MLP "needs to be complemented with an actor-oriented approach working 'from the inside out'". Despite the recognition of this point, transition studies (also studies performed by Geels) use a similar reasoning to frame the research, all concentrated on the technology itself as starting point of the analysis. However, technological changes are also always and simultaneously cultural changes and changes in everyday behaviour routines of people, households, consumers and citizens. Here the work of consumption and environmental sociologists, especially that of Elisabeth Shove (Lancaster University) and the group around the Gert Spaargaren (University Wageningen) on change processes is of particular relevance. For them practices are the unit of analysis and not technologies. In the following section, the theories of both researchers will be elaborate further.

\subsection{Consumer behaviour}

Consumer behaviour is a very broad research field with its roots in economy and social psychology, however, this theoretical chapter will emanate from the theoretical approaches from Shove and Spaargaren. Both researchers have studied the specific conditions for consumption in socio-technical systems like energy, water and waste systems, and formed a theoretic basis of the relations between providers and consumers. Although Shove and Spaargaren offer similar criticisms ${ }^{12}$ of transition theory, their approaches are not equal. Shove stresses the importance on how social practice ${ }^{13}$ have changed over time, how it becomes normal and what the consequences on sustainability are, by using the concepts of cleanliness, comfort and convenience. Spaargaren uses this theoretical approach by Shove and put the social practices into a conceptual model, which has a strong emphasis on sustainability of existing lifestyles and on the ecological modernization of the society.

\footnotetext{
${ }^{12}$ Both authors argue that the social practices are discussed in socio-technical analysis, but that 'socio' in practice is interpreted very narrowly. The emphasis is on systems, markets, institutions, infrastructure, and there is little room for how people really behave, what their lifestyle are in terms of food, move or live, how and why they make choices.

${ }^{13}$ The concept of social practice refers to "a routinized type of behaviour which consists of several elements interconnected to one other: forms of bodily activities, forms of mental activities, 'things' and their use, a background knowledge in the form of understanding, know-how, states of emotion and motivational knowledge" (Reckwitz, 2002, p. 249).
} 
Comfort, Cleanliness and Convenience - Shove

Shove brings together the sociology of consumption and technology to investigate the evolution of these changes, as well the social meaning of the practices themselves (Shove 2003b). Shove introduces three domains of everyday life, those of comfort, cleanliness, and convenience (CCC). By using these concepts, Shove explores in her research the questions of how new conventions become normal, and what the consequences are for sustainability (Shove 2003a).

The CCC is a set of "cross cutting terms which encompass a variety of inter-linked conventions and habits and as such offer a vocabulary with which to explore and follow the evolution of routine, and with which to show how new arrangements become normal" (Shove, 2003b, p.3). The areas of CCC are important since they all require a lot of resources such as energy and water, and because all three aspects have been subject to recent and radical change. Shove works on the supposition that domestic consumption practices are not just a combination of objects and systems of provision, but also intimately linked in reproducing what people are referring to as normal or, for them, ordinary ways of life (Shove 2003a).

The environmental challenge is to understand how meanings and practices of CCC (or comparable services like the provision of a "normal" diet or "normal" forms of mobility fall into the realm of the taken for granted, and how they change (Shove, 2003a, p. 396). Shove considers two aspects of change, one relating to escalation (are conventions of comfort, cleanliness, and convenience changing in ways that are increasingly resourceintensive?), the other concerning the direction of development - are expectations and practices standardizing and converging around the world, and if so, with what environmental consequence? (Shove 2003a).

\section{Comfort}

Comfort can be interpreted as a state of mind related to self-conscious satisfaction and the body's relationship with the immediate physical environment. The concept has been bound to objects that may enhance this state of mind, e.g. comfortable clothes or comfortable furniture. This has in turn resulted in standardized and restricted definitions of normality. The label of comfort now describes an attribute of the object in question while people have made themselves comfortable in all sorts of different ways and meanings of what this involves have varied historically and culturally. So, comfort is not only an attribute, but also an achievement. By viewing comfort as an achievement, conventions surrounding the arrangements come in focus rather than the physical human body (Shove 2003a, Shove 2003b, Shove 2003c).

\section{Cleanliness}

Cleanliness touches upon the moral and symbolic significance of practice. It is important in making social distinctions and reproducing order (Shove, 2003c). Cleanliness has been modified which in turn has shaped the business of cleaning as well as the ideas of what 
cleanliness is. It also generally involves the use and synchronization of a variety of sociotechnical systems (Shove, 2003a). Technical objects have made us reassess the meaning of cleaning, since they contain definitions of dirt, disorder and appropriateness in the way they are constructed. Shove (2003b, p.160) argues that "...changing concepts of cleanliness reflect changes in actions, tools and techniques developed when people do what they think of as cleaning". Thus in order to understand changing practice, cleanliness should be regarded as a complex service which can be shaped and given meaning by the activities carried out to achieve it.

\section{Convenience}

Convenience is associated with the ability to shift and reorder activities and events. Warde, Shove, and Southerton (1998 in Shove, 2003a) distinguish between modern and hypermodern forms of convenience, where modern convenience refers to the reduction of time taken to achieve a goal, whereas hypermodern convenience is about storing or shifting time, thereby providing people with greater flexibility or control over their own schedule. So convenience helps people shift and manipulate schedules and, at the same time, bind them into sets of social and economic relations that have the unintended consequence of further fragmenting the temporal order of society (Shove, 2003c).

Convenience is more about being able to do something at short notice than about saving time, thus a convenient technical arrangement should facilitate sudden changes and reordering of activities in everyday life. However, each convenient technical arrangement relates to an everyday life split into smaller and smaller activity pieces, and to a reliance of individual modes of coordination (Shove, 2003b).

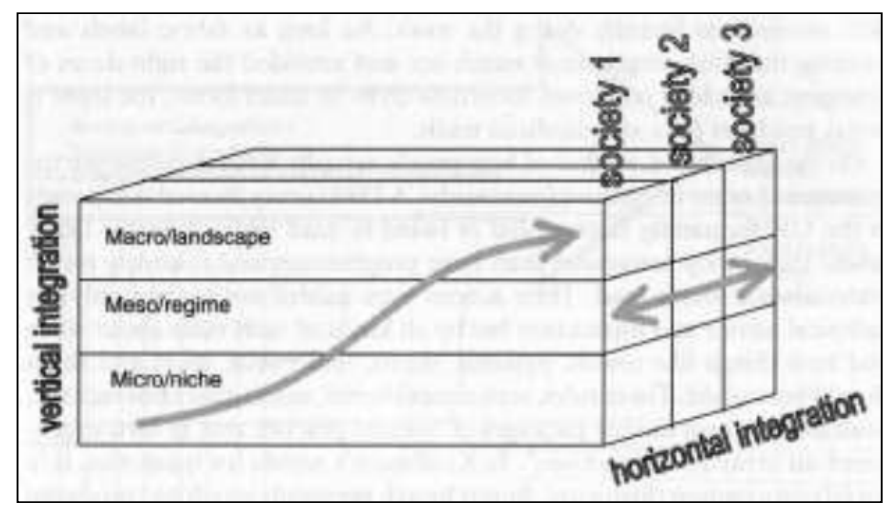

Figure 7. Horizontal and vertical dimensions of socio-technical change (Shove, 2004, p. 85).

In line by using the concept of the MLP on technological transitions but criticising the understanding that novelties always develop in niches and spread from there, Shove (2003b) has studied how practice of CCC has co-developed with all three levels of technologies. She has shown that the dynamics of technological change at the level of everyday practices are not understood adequately when working only in the vertical dimen- 
sion and in particular only bottom-up (niche-regime-landscape) as suggested in some versions of transition theory. The bottom-up view of technological innovation is dismissed. From her rich empirical studies on social practices, she in the end concludes that there is more to technological change than just the vertical integration of practices. Therefore Shove (2004) introduced the notion of horizontal coordination or integration between social practices as a second way of investigating the dynamics of technology related changes, whereby the notion of 'system of systems' is used to refer to clustered social practices at one level of analyses (Shove, 2003b; Shove, 2004). As Figure 7 suggest, technological systems carry concepts, classifications, scripts and framing or problems between socio-technical regimes and landscapes. So the cultural and environmental consequences of horizontal trends are inherently unpredictable given the local context of appropriation are of defining importance (Shove 2004).

There is more that could be said about the relationship between the horizontal and vertical dimensions of system innovations, but in this context it is used to make clear that the transition towards sustainability depends partly in system innovations but also on system integration (Shove, 2004).

So when a new product arrives in a social practice, it is important to analyse not just how the object fits in into the existing configuration of objects and their technical infrastructures. It is also important to analyse how these objects become incorporated into the CCC concepts governing the practices and how these CCC-levels are affected by the normalization and incorporation of new things.

\section{Discussion}

In looking at how norms and standards in social practices are set and have changed over time, Shove has given a valuable contribution to the theoretic development within resource use by putting this use in a socio-cultural perspective where social norms and technical standards influence what is done, how it is done and with what devices. So, the core set of concerns are obviously the interdependencies between (everyday consumption) practices, (socio-technological) devices and (socio-technical) systems. Important is how they fit or not fit together and what their relative weight is when it comes to explaining social change in everyday life.

The approach is thoroughly historic, but in an exciting contemporary way. However, the challenge is to change the perspective to look also forward in order to anticipate the evolution of normality and their implications for the acceptance and diffusion of particular innovations. The evolution is normality is not a purely social process but occurs in tandem with product offerings and changes in the material context. To us Shove's dismissal of the perspectives of sustainable consumption seems somewhat too harsh, because consumers through the political process and feedback to producers can participate in influencing future norms and standards in society through making demands on products, and services and on the systems underpinning the social practices. 
The social practices model - Spaargaren

The social practice model (SPM), developed by Spaargaren, offers an integrative model to analyse and understand transitions towards sustainable consumption at the level of everyday life. The SPM has its roots in Giddens theory of structuration (Spaargaren 2003). This theory does not focus on the individual actor or societal totality but on "social practices ordered across space and time" (Giddens, 1984, p.2). Giddens suggests in his theory that human agency and social structure are in a relationship with each other, and it is the repetition of the acts of individual agents which reproduces the structure. This means that there is a social structure (traditions, institutions, moral codes, and established ways of doing things) which can change when people start to ignore them, replace them, or reproduce them differently (Giddens 1984). In line with Giddens's structuration theory, Spaargaren argues that in order to study consumer behaviour, the social practices in which actors are involved when pursuing their daily routines should be the start of analysis (Spaargaren, Mommaas et al. 2007).

\section{Actor Social practices Structure}

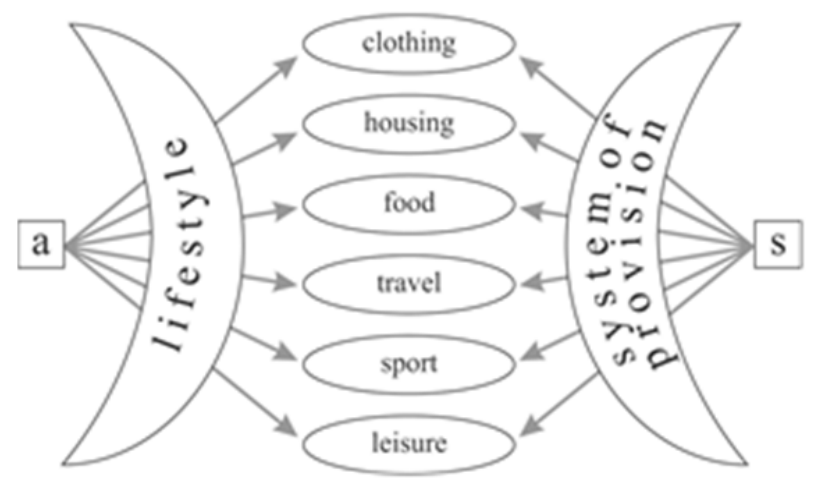

Figure 8. The social practice model (Spaargaren, 2003).

The SPM is a contextual model of consumption that combines an actor-oriented approach with a system of provision perspective on consumer behaviour (see Figure 8). The SPM combines the notion of human agents as knowledgeable and capable actors in sustainable transitions, with an equal emphasis on the influence of the social and technological context on human behaviour. The focus is on the social practice itself in which actors with their lifestyles and routines on the one hand, and structure of rules and resources, norms and values, provisioners and infrastructure on the other hand are analysed in interaction (Spaargaren and van Vliet 2000, Spaargaren 2003, Spaargaren 2006, Spaargaren, Martens et al. 2006, Spaargaren, Mommaas et al. 2007, Verbeek and Mommaas 2008). This model actually builds on to the concepts of comfort, cleanliness and convenience explained in the theoretical approach of Shove. 
At the centre of the model one finds the actual behavioural practices (social practices), situated in time and space, which an individual shares with other human agents (shared routines) (Spaargaren and van Vliet, 2000). The actor side of the model refers among other things to the lifestyles of consumers. Giddens (1991, p.81) defines lifestyle as "a more or less integrated set of practices which an individual embraces, not only because such practices fulfil utilitarian needs, but because they give material form to a particular narrative of self-identity". The reason why the concept of lifestyle is important is that consumers might realize environmental improvement by changing their behaviour in accordance with specific lifestyle characteristics. Thus, the actor side of the model is referred to as the modes of access because it incorporates the multiple modes in which consumers have access to supply (Spaargaren and van Vliet, 2000; Verbeek and Mommaas, 2008). The structure side of the model can be described as the system of provision dimension of consumer behaviour, which comprised of rules, resources, shared norm and values. It refers to the mode in which product are provided to consumers (Verbeek and Mommaas, 2008). Thus the way in which sustainable socio-technical innovations are being presented (modes of provision), can have an important influence on the use of these socio-technical innovations (modes of access).

The model looks into the possibilities for designated groups of actors to reduce the overall environmental impacts of their normal daily routines involving clothing, housing, food, travel, sport, and leisure. The model analyses the process of reducing the environmental impacts of consumption in distinct domains of social life in terms of the deliberate achievements of knowledgeable and capable agents who make use of the possibilities offered to them in the context of specific systems of provision (Spaargaren, 2003). The SPM is however not a model that predicts the direction of changes, nor is it a model that assumes a transition to sustainable development. On this way, social structures are no longer treated as external variables but are brought into the centre of the analysis.

\section{Consumption junction}

Between design and use there are several steps. A new product or service has to go through a production-consumption chain of intermediate links and networks, which can be specified in terms of the modes of design, production, provisioning, access, use, and disposal that prevail in the selected social practices or consumption domains. The sociotechnical innovations within production-consumption chains and networks are visualized in Figure 9. How the innovation process occurs depends on how the innovation is approached.

The literature on technological transitions and system innovations is mainly concentrated on the technical side of socio-technical innovations, which is more reasoned from the right to left side of the model. An innovation is placed in the market by providers and the supply side is most decisive for the product and its dissemination and use. The literature 
on consumption sociology ensures that the demand side is more central. In other words reasoning from left to right, where the interaction (or lack thereof) between demand side and dynamics is of importance (Spaargaren, et al., 2007). To emphasize the importance of studying this interaction, Cowan (1987) has introduced the concept consumption junction. He defined it as "the place and the time at which the consumer makes choices between competing technologies, and tries to ascertain how the network may have looked when viewed from the inside out, which elements stood out as being more important, more determinative of choices, than the others, and which path seemed wise to pursue and which too dangerous to contemplate" (Cowan, 1987, p.263). Thus the consumption junction is a more specific place and time at which consumers and providers meet (access and provisioning). Moreover, at consumption junctions, different principles that guide reasoning in a situation (logics) prevail. Technology and market oriented producer logics meet the everyday life logics of end users of products and services (Spaargaren, 2006).

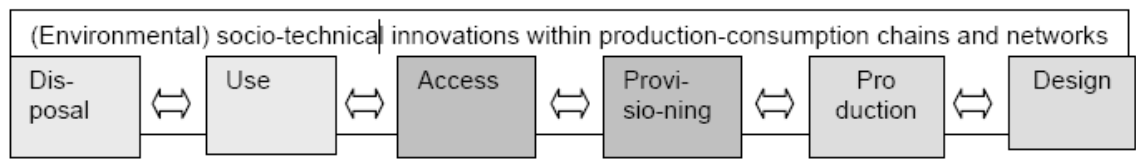

\section{Consumption junction}

Figure 9. The consumption junction (Spaargaren, et al., 2007).

To understand why some innovations are being picked up by specific groups of consumers and others not, lock-in factors or slots have to be identified and analysed, as they can occur at all the relevant sections of the production-consumption chains (Spaargaren, 2003).

Consumers do not easily undergo a transition to sustainable products. Since the mideighties there are definitely innovations on the market that consumption can make more sustainable. However, those innovations move very limited to the consumers. The reason for this can be partly assigned to the notion that people in general act in a habitudinal way. They do not make a consciousness decision about what to do and do not reflect on the reasons for the routine. A transition can only take place if consumers for some reason are forced to reflect on their behaviour and the need for change (Spaargaren, et al., 2002; Spaargaren, et al., 2007).

The process of de-routinization and re-routinization is conceptualised as a stage process. In general, a transition starts with more emphasis on the formulation of the problem and solution direction, the environmental heuristic, and in the later stages there is more attention to analysis of innovation processes with the associated characteristic slots (Spaargaren, Beckers et al. 2002). Figure 10 shows how such a transition at the level of everyday life practice behaviour looks like. 


\section{Discussion}

The SPM seems appropriate in this research since the main premise of this approach is that environmentally relevant behaviour does not stand on its own but is part of daily routines which an individual follows. The extent to which environmental concerns are taken on board while following these routines is influenced by lifestyle 'choices' of individuals and by the possibilities offered to consumers in the context of different systems of provision (Spaargaren 2003).

The SPM focuses attention on the role of consumers at the consumption junction in shaping consumption behaviour. The challenge is to analyse concrete productionconsumption slots in the consumption junction, in order to find clues for possible actor or demand based transitions towards more sustainable technologies or products. However, it does not become clear how routines have been constructed as the result of mutual influence between changing systems of provision and changes in people's everyday life. From this point of view it will be valuable to incorporate an everyday life perspective to include some degree of interpretative flexibility with regard to technological innovations.

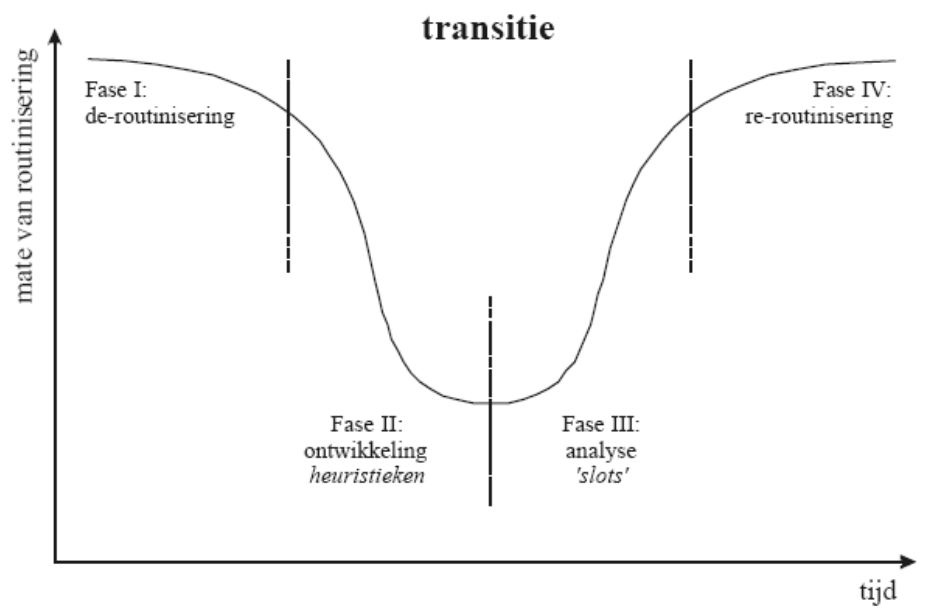

Figure 10. Phases is a transition process (Spaargaren, et al., 2002). ${ }^{14}$

Relation of the both approaches

Shove and Spaargaren have studied the specific conditions for consumption in sociotechnical systems like energy, water and waste systems, and formed a theoretical basis of the relations between providers and consumers. The approach of Shove examines how a new practice becomes normal and what the consequences on sustainability are while the model of Spaargaren has a strong emphasis on sustainable lifestyles and on the ecological modernization of the society.

\footnotetext{
${ }^{14}$ The figure is only available in Dutch.
} 
Both approaches are based upon each other. Shove (2003a, p. 396) refers to the theory of Spaargaren when she suggest that "instead of seeking more environmentally friendly ways of meeting given levels of service and of ecological modernizing society (Spaargaren, 1997), longer-term, more penetrating questions have to do with the specification of service itself". She suggests that the cultural aspects of domestic consumption should be emphasized and explored. By using the concepts of CCC, Shove paints a picture of how social practices have changed over time, influenced by the increased access to energy supply. She explores the questions of how new conventions become normal and what the consequences are for sustainability. Spaargaren uses this theoretic approach by Shove and put the social practices into a conceptual model for studying consumption practices. More in detail, he studied individual behaviour and its underlying reasons, interests and motives in the context of social practices situated in time and space and shared with others. Beliefs, norms and values can be analysed as the rules which belong to a specific social practice. Rules and resources together constitute the structures that are involved in the reproduction of social practices. Subsequently, Shove further elaborates on the notion of slots as they can be identified both at the modes of provisioning as well as at the modes of access and consumption in production-consumption chains.

The social practices are thus linked to the lifestyle preferences of consumers and to the systems of provision. These systems of provision can be seen as a network of social actors, e.g. utilities, planners, and technicians, that constitute the technological systems that consumers are part of. Looking at the consumption side, it should be analysed, whether networks of provision are capable of providing new technologies or products that fit the needs of consumers who seek to decrease the environmental pressure of their lifestyles. And the other way around, whether new technologies fit with the lifestyle of consumers and the norms regarding CCC they have with regard to TIS.

\subsection{Conclusion}

The literature on the MLP on technological transitions and the TIS offers the potential to provide a better understanding of technological change. The literature is concerned with fundamental changes in functional systems of provision and consumption, the sustainable consumption theory. It involves contributions from innovation researchers, historians of technology, political scientists and systems analysts. It is not rooted in one discipline and people tend to be multidisciplinary.

Before the relation between the different approaches will be given, a short overview of the different literature strands is given. MLP on technological transitions describe how new technologies emerge within more of less protected niches, and how they become working from configurations that shape and reshape regimes (e.g. Geels, Kemp, Rotmans). Technological innovation systems focus on the structure of the system (actors, 
institutions and networks) and on the key processes that take place within a system and contribute to the build-up of a technological innovation system and thereby to the successful development, diffusion and utilization of the emerging technology (e.g. Hekkert, Negro, Bergek). Sustainable behaviour studies the specific conditions for consumption in socio-technical systems and formed a theoretic basis of the relations between providers and consumers (e.g. Shove and Spaargaren).

While the definition of a transition ${ }^{15}$ may refer to any societal change, most authors in the transition literature limit themselves to technological changes. To study technological innovation, authors use a socio-technical systems perspective. Scholars recognize the relative neglect of cultural and social aspects in their theories (e.g. Geels 2005, Genus and Coles 2008), while changes in technological systems also imply changes in routines for the actors involved. Aspects that used to be taken for granted require conscious awareness and responsibilities which have to be redefined and roles for provider as well as consumer actors changed. Therefore the literature on MLP on technological transitions and TIS, which largely focus on systems and structures, need to be complemented with more social theories to conceptualise the behaviour of consumers. To this end I have introduced the sustainable consumption theory which is based on the work of Shove and Spaargaren. With this proposed combination in mind, some questions arise, such as to what extent technologies and lifestyles of consumers fit together?

Both Spaargaren (2003) and Shove and Walker (2007) criticize the literature on transitions for not taking into account the actual situation in which the consumers of the new technologies find themselves. Shove and Walker (2007, p. 768) state that "transition managers rarely attend to the dynamics or to the distinctive periodicities and mechanisms of change associated with them. Nor do they have the conceptual resources with which to enter these ordinary arenas of everyday life". However, their criticism is oriented towards the negligence of the role of the citizen as consumer, but the citizen as an active actor in transition processes is also neglected.

Spaargaren has started the discussion on how to integrate theories of transition of technology and theories of practice. Spaargaren (2006, p. 17) asks if I can see socio-technical landscapes as webs of practices, regime level as clustered practices or integrated practices, and niche as social practices. As described above, also Shove combines practice theory and ideas from transition theory. Shove shows that transition have to be understood from niche to landscape (bottom-up) and from landscape to niche (top-down)

\footnotetext{
${ }^{15}$ A transition is earlier defined as "transformation processes in which society changes in a fundamental way over one or more generations" (Rotmans, Kemp et al. 2001, p.1) and "in which existing structures are broken down and new ones are established" (Loorbach 2007, p. 17).
} 
processes, as well as on a level where systems of system develop as well as systems of new fabrics.

The frameworks are the result of several years of theoretical development and have been applied in a large number of empirical case studies. However, some shortcoming of the framework can be determined.

(1) Insight into the key processes that influence the successful breakthrough of a niche into the regime is lacking in the MLP at the moment. Thus it needs to be completed with a theory on the successful growth of a niche for it to become part of the regime. Or in a broader view, a theory which includes the interaction process between an innovation and the surrounding networks and institutions since the landscape influences both niches and regimes.

(2) The MLP stressed too much emphasis on structures, technologies and the supply side of the economy, while there is paid too little attention to the demand side and the role of consumers. Thus the MLP needs to be further developed as an actor-oriented approach which looks at how actors exercise influence and try to steer transitions, develop visions and adapt them through searching and learning processes.

(3) The development and the diffusion of the innovative technology (or product) is usually used as indicator for the performance of TIS. However it looks like more interesting to divide the TIS into two parts, the development and the diffusion of the technology. Such a split of the TIS into two parts has not explicitly been done before.

(4) The TIS approach makes it able to study the characteristics of the system associated with an emerging technology, it analyses the strengths and weaknesses as well as the dynamics, which can be compared to those of another emerging TIS. However, it lacks the description of the transition from one system to another. The TIS theory focuses on the growth of the system itself and the importance of substituting other systems is not highlighted. Moreover, what is missing at the moment is a comparison of the specific emerging technology with the system of an incumbent technology system, e.g. electricity generation based on fossil fuels.

(5) In addition to the different function of an innovation system, some external aspects to the TIS are important in the functioning of the system. The analysis only looks at the immediate causes of manufacturing companies within the TIS, it withholds the issue if the companies receive sufficient supply, and simplifies all causes that lie outside of the influence sphere of the actors (e.g. worldwide supply of silicon). Another important external aspect for its functioning is institutional change.

(6) The demand side of the innovation system including the consumers of the technology is mentioned in the theory, but scant attention is paid to this when analysing whether a system is functioning well.

As the focus on consumers is lacking in MLP on technological transitions as well as in TIS approach, this is also lacking in the integrated framework. 
Chapter 3:

Methodology 



\subsection{Research approach}

In the previous chapter (Chapter 2), a literature review is performed which looks for perspectives that define the nature of transitions, identify the relevant aspects of transitions, and offer a basis to describe and explain transitions respecting the dual nature of systems in transitions: being both technological and social. In more detail, from a systemic perspective, there can be looked at the main paradigms, modes of governance and debates concerning technological innovations. From an everyday-life perspective, it is possible to analyse how practices came about and what the mechanisms are through which these practices have changed. The chapter was concluded by discussing some shortcomings in transition literature. While the transition literature have provided significant contributions to the understanding of technological innovation processes including the emphasis on the role of user, as a consumer-citizen, which influences the successful breakthrough of a niche into the regime, it is less clear how these users are conceptualised, should be involved in innovation policies and how these users are facilitated to learn. Especially this last aspect is a prerequisites of successful innovation processes which is also pointed out by Lundvall (1992) who states that creating conditions for learning maybe seen as the major function of an innovation system. To address this knowledge gap, I present a three step approach in which technology and society coconstruct each other. I propose that both, technology and society, can contribute to an overarching explanation of transition in socio-technical systems so that the multiple disciplinary nature of transitions can be addresses.

Demand for innovation interacts and co-evolves with supply. Demand is created gradually as an innovation diffuses and as various forms of learning take place, both on the consumer and of the producer side (Saviotti 2005). Escpecially in the early phase of development a market for the new technology has to be created and the user demands are not clearly articulated. Actions of users influence whether or not new technologies are successfully developed and implemented, these action in turn help to fit the technological properties of the technology with the determinants of choice of users. Note user requirements will differ among users in ways that unknown to the provider of the innovation. To clarify this point, I consider the adoption of an electric toothbrush and leave aside the complete transition context. The very first rechargeable electric toothbrush sold in the United States was introduced in 1961 by General Electric. In the beginning, through e.g. advertisement initial perceptions were created by potential users of the electric toothbrush. These potential users were the users of the traditional toothbrush (dominant regime). The early adopters of the electric toothbrush learned about the pros and cons and spread their perception and attitude. Based on the experience gathered through these early adopters, some technical properties could be developed which made the electrical toothbrush more attractive (what are the wants, needs and beliefs of the adopters). When a model was released that did not have an electrical cord plugged into an outlet near running water, sales of the electric toothbrush began to increase 
dramatically. If such developments outrun the learning processes that spread the needs about the early deficiences of the toothbrush, it may develop into an attractive one competitive enough to overthrow the tranditional dominant one. However, it is also possible that there are not enough experiences or critical mass of users to trigger any significant development. Depending on the strength of the learning at both sides (demand and supply), it is possible to observe dynamics that lie somewhere in between these two extreme ones. Though, it should be kept in mind that this is a simplified example to demonstrate how learning processes can be interrelated and how they can combine and form non-linear feedback in the system.

Coming back to the three-step approach, the approach is build upon the idea that technological innovations can be studied as a system in which different phases are differentiated that shape new technologies and technological landscapes. A system in which suppliers, users (consumer-citizens), inventors on the one hand, content, facts and meanings on the other hand, but also social, legal and ethical problems emerge as the result of what is called technological innovation. In this approach, I distinguish three steps: (1) development and diffusion of innovative technologies; (2) adoption of innovative technologies; (3) learning processes. Each of these steps addresses a different aspect of the dynamics of technological innovations. By following a technological innovation over time, the different aspects will be more or less salient.

The three-step approach begins with explanations behind the slow development and diffusion of innovative technologies using the framework of technological innovation system. The strength of the framework is that it takes a system perspective to explain how different structural components of the innovation system (technology, actors, networks and institutions) influence the development and diffusion of a specific technology. There is a strong focus on technology as central point in a socio-technical transition, to the extent that cultural and social aspects are more or less ignored. This system also embedd governmental aspects (regulation and steering) as one could argue that they are an integral part of technological development by now. Step 2 elaborates on the adoption of innovative technologies from a user perspective. The adoption is driven by consumer demand (society) and is characterized by the number of individuals or households that decide to adopt or reject a technology or product. Technology development is shaped by the use and users of new technologies. One cannot expect that an innovative technology will be adopted and used by users the way that the producers/designers originally intended. They also actively participate in the provision of definitions and meaning of a technology. The history of the bike is a good example of this process ${ }^{16}$ (Bijker, Hughes et al. 1987). Step 3 focuses on learning processes. Instead of being sepa-

\footnotetext{
${ }^{16}$ Bijker explores e.a. the role of changing gender relationship in shaping a technology. Young men and women for example competed to define to what problem the bike would be a solution and how it was used.
} 
rate processes, technology innovation system (step 1) and the perspective of users (step 2) interact and mutually influence each other through all kind of learning processes. Improving those learning processes will stimulate technological change and social change. Depending on the strength of the learning at both sides, it is possible to observe dynamics that lie somewhere in between these two extreme ones.

To wind up, the focus of the research approach is on social-technical transitions in which technology (technological innovation) on the one hand, and society (users with their lifestyles and habits) on the other hand are analysed in interaction. It offers insight in the production-consumption chain where producers and consumers interact and mutually influence each other (consumption junction). The research appraoch is however not a tool that predicts the direction of change, nor it is a tool that assumes a transition to a more sustainable energy system. It is a tool that can be used to get insight in aspects that are relevant in a transition towards a more sustainable energy system.

\subsection{Data gathering}

For the analyses, different types of data are gathered from different sources (Yin 2003 p.86): scientific articles, grey literature, websites, patents and interviews. Below I concisely describe which method I used and how I applied it.

\section{Literature review}

The first step in this research (RQ1) is a literature review in order to define more clearly what is to be examined, with the intention of having a sufficient outline for determining what data to collect and how to analyse the data (Yin 2003). I look for perspectives that define the nature of transitions, identify the relevant aspects of transitions, and offer a framework to describe and explain transitions respecting the dual nature of systems in transitions: being both technological and social. The literature review included a broad range of scientific literature. Socio-technological transitions (e.g. Rotmans, Kemp et al. 2001, Geels, Elzen et al. 2004, Kemp and Loorbach 2006, Van den Bergh and Kemp 2006, Loorbach 2007), phases of technology development (e.g. Rotmans, Kemp et al. 2001, Van Lente, Hekkert et al. 2003, Olsson, Folke et al. 2004, Geels 2005, Olsson, Gunderson et al. 2006), multilevel perspective (e.g. Geels 2002, Geels 2004), strategic niche management (e.g. Kemp, Schot et al. 1998, Kemp, Rip et al. 2001), innovation system approach (e.g. Carlsson and Stankiewicz 1991, Lundvall 1992, Edquist 1997, Hekkert, Suurs et al. 2007, Bergek, Hekkert et al. 2008), functions of the innovation system (e.g. Edquist and Johnson 1997, Galli and Teubal 1997, Johnson 2001, Liu and White 2001, Rickne 2001, Jacobsson and Bergek 2004, Bergek, Jacobsson et al. 2005, Carlsson, Jacobsson et al. 2005, Hekkert, Suurs et al. 2007), social practices approach (e.g. Spaargaren and van Vliet 2000, Spaargaren 2003, Spaargaren, Martens et al. 2006, Spaargaren, Mommaas et 
al. 2007, Verbeek and Mommaas 2008), comfort, cleanliness, and convenience-Shove (e.g. Shove 2003a, Shove 2003b, Shove 2003c).

\section{Event analysis}

The method used to map interaction patterns between system functions is inspired by the process method used by Van de Ven and colleagues (Van de Ven, Polley et al. 1999, Poole, Van de Ven et al. 2000). Stemming from organisational theory, the usual focus is on innovation projects in firms and firm networks; in our case, the analysis is applied to a TIS level (for a more extensive description of the methodology I refer to (Negro 2007, Negro, Hekkert et al. 2007, Negro and Hekkert 2008, Suurs and Hekkert 2009b)).

Basically, the approach consists of retrieving as many events as possible that have taken place in the innovation system using archive data, such as newspapers, magazines, reports and interviews with experts of the field. The events are stored in a database and classified into event categories. Each event category is allocated to one system function using a classification scheme (see Table 1). These events can then be plotted in graphs per year and per System Function.

Table 1. Overview of classification scheme.

\begin{tabular}{|c|c|c|}
\hline Function & Indicator & Sign \\
\hline \multirow{4}{*}{$\begin{array}{l}\text { Function 1: } \\
\text { Entrepreneurial activities }\end{array}$} & Project started & +1 \\
\hline & Project stopped & -1 \\
\hline & Organisations entering the market & +1 \\
\hline & Organisations leaving the market & -1 \\
\hline \multirow{4}{*}{$\begin{array}{l}\text { Function 2: } \\
\text { Knowledge exchange }\end{array}$} & Research projects & +1 \\
\hline & Technological projects & +1 \\
\hline & Development projects (demonstration + pilot plant) & +1 \\
\hline & $\begin{array}{l}\text { Desktop studies on the technology (future of PV + } \\
\text { performance of PV-systems) }\end{array}$ & +1 \\
\hline \multirow{5}{*}{$\begin{array}{l}\text { Function 3: } \\
\text { Knowledge diffusion through } \\
\text { networks }\end{array}$} & Workshops & +1 \\
\hline & Conferences & +1 \\
\hline & Reports & +1 \\
\hline & Platform & +1 \\
\hline & Roadmap & +1 \\
\hline \multirow[t]{4}{*}{$\begin{array}{l}\text { Function 4: } \\
\text { Guidance of the search }\end{array}$} & $\begin{array}{l}\text { Regulations by the government (positive expectation on } \\
\text { PV-technology) }\end{array}$ & +1 \\
\hline & $\begin{array}{l}\text { Deficit of government regulations (negative expectation } \\
\text { on PV-technology) }\end{array}$ & -1 \\
\hline & $\begin{array}{l}\text { Specific tax regimes (positive expectation on PV- } \\
\text { technology) }\end{array}$ & +1 \\
\hline & $\begin{array}{l}\text { Deficit of tax regimes (negative expectation on PV- } \\
\text { technology) }\end{array}$ & -1 \\
\hline
\end{tabular}




\begin{tabular}{|c|c|c|}
\hline Function & Indicator & Sign \\
\hline \multirow{12}{*}{$\begin{array}{l}\text { Function 5: } \\
\text { Market formation }\end{array}$} & Positive opinions of experts & +1 \\
\hline & Negative opinions of experts & -1 \\
\hline & Positive expectations of experts & +1 \\
\hline & Negative expectations of experts & -1 \\
\hline & Regulation programmes & +1 \\
\hline & Lack of regulation programmes & -1 \\
\hline & Stimulation programmes & +1 \\
\hline & Lack of stimulation programmes & -1 \\
\hline & Environmental standards & +1 \\
\hline & Lack of environmental standards & -1 \\
\hline & Specific favourable tax regimes & +1 \\
\hline & Lack of favourable tax regimes & -1 \\
\hline \multirow{4}{*}{$\begin{array}{l}\text { Function 6: } \\
\text { Resources mobilization }\end{array}$} & Subsidies for and investments in the technology & +1 \\
\hline & Lack of subsidies and investments & -1 \\
\hline & R\&D subsidy programmes & +1 \\
\hline & Lack of R\&D subsidy programmes & -1 \\
\hline \multirow[t]{6}{*}{$\begin{array}{l}\text { Function 7: } \\
\text { Creation of legitimacy }\end{array}$} & $\begin{array}{l}\text { The technology is promoted by organisations, government } \\
\text { (awards, brochures, competitions) }\end{array}$ & +1 \\
\hline & $\begin{array}{l}\text { Lack of promotion by organisations, government (awards, } \\
\text { brochures, competitions) }\end{array}$ & -1 \\
\hline & Lobby activities for the technology & +1 \\
\hline & Lobby activities against the technology & -1 \\
\hline & Positive opinions of experts branch organisations & +1 \\
\hline & Negative opinions of experts branch organisations & -1 \\
\hline Context & $\begin{array}{l}\text { General events about renewable energy, technology } \\
\text { description, exogenous activities to TIS }\end{array}$ & $\begin{array}{l}\text { No sign }(0), \text { no } \\
\text { allocation }\end{array}$ \\
\hline
\end{tabular}

The contribution of an event to the fulfilment of a system function may differ considerably from event to event. Some events have a positive contribution, such as the opening of a large-scale building integrated PV project, while others contribute negatively, as for instance an expression of disappointment, or the opposition of an important political group. This is indicated in the allocation scheme by +1 and -1 . The final outcome of the process analysis is a narrative (storyline) of how the development of the TIS has changed over time and the role of the different system functions within this development. In the narrative the focus is on extracting motors of innovation. Based on the content of the events and their chronological order, I am able to deduce the effect of one event onto another and the order in which such events occurred. By observing reoccurring sequences of events we are able to identify motors of innovation. 


\section{Questionnaire}

The empirical analysis of the user perspective is conducted via two questionnaires. The first questionnaire is an internet questionnaire regarding the Dutch citizens. The majority of the questions were multiple choice questions with a few open questions. The data gathering took place in September 2011. 817 people out of 1371 have responded to the questionnaire, which is a response rate of $60 \%$. This is a representative sample over the Dutch population (21-65 year) regarding gender, age distribution, level of education and spatial distribution in the Netherlands Table 2.

Table 2. Representative sample of the Dutch population.

\begin{tabular}{|c|c|c|}
\hline Gender & Response & CBS \\
\hline$\overline{M e n}$ & $53 \%$ & $50 \%$ \\
\hline Women & $47 \%$ & $50 \%$ \\
\hline Age distribution & Response & CBS \\
\hline $21-24$ & $4 \%$ & $8 \%$ \\
\hline $25-29$ & $9 \%$ & $10 \%$ \\
\hline $30-34$ & $9 \%$ & $10 \%$ \\
\hline $35-39$ & $9 \%$ & $12 \%$ \\
\hline $40-44$ & $13 \%$ & $13 \%$ \\
\hline $45-49$ & $14 \%$ & $13 \%$ \\
\hline $50-54$ & $14 \%$ & $12 \%$ \\
\hline $55-59$ & $15 \%$ & $11 \%$ \\
\hline $60-65$ & $13 \%$ & $12 \%$ \\
\hline Level of education & Response & CBS \\
\hline Low (primary, vmbo, Ibo) & $28 \%$ & $29 \%$ \\
\hline Middle (havo, vwo, mbo) & $41 \%$ & $42 \%$ \\
\hline High (hbo, university) & $32 \%$ & $29 \%$ \\
\hline Spatial distribution in the Netherlands & Response & CBS \\
\hline Drenthe & $3 \%$ & $3 \%$ \\
\hline Flevoland & $3 \%$ & $2 \%$ \\
\hline Friesland & $5 \%$ & $4 \%$ \\
\hline Gelderland & $9 \%$ & 125 \\
\hline Groningen & $4 \%$ & $4 \%$ \\
\hline Limburg & $10 \%$ & $7 \%$ \\
\hline Noord-Brabant & $14 \%$ & $15 \%$ \\
\hline Noord-Holland & $16 \%$ & $16 \%$ \\
\hline Overijssel & $6 \%$ & $7 \%$ \\
\hline Utrecht & $7 \%$ & $7 \%$ \\
\hline Zeeland & $3 \%$ & $2 \%$ \\
\hline Zuid-Holland & $20 \%$ & $21 \%$ \\
\hline
\end{tabular}


The questionnaire consists of a variety of questions. For example, I asked their impression on their own lifestyle in the view of sustainability. A description of sustainable development was given to all respondents through an information button to ensure everybody had the same information. I also asked the respondents whether they think that the implementation of PV should be stimulated, for example by providing subsidies, maximum three answers were possible and how they think that actors in the field should take the lead in general, not per leader. Furthermore, I asked to rank the importance of different characteristics of a PV system in deciding to adopt PV by importance. But there is also a section which aimed to find out which aspects non-adopters of PV find important in order to observe the barriers for and during adopting a PV system. I asked the respondents who not have a PV system themselves to indicate their agreement of different questions based on possible motives for purchasing a PV system. On the other hand I also investigate the different motives adopter of PV had for purchasing a PV system.

The second questionnaire is conducted after an information meeting in the neighbourhood Biesland in the city of Maastricht. This questionnaire consists of multiple choice questions and open questions. The questionnaire first addressed a number of general solar energy questions to test differences in tacit knowledge and preferences. Subsequently the questionnaire continued with questions specifically aiming at investigating the usefulness of the meeting. The final part of the questionnaire consisted of general demographic questions. The information meeting, thus also the questionnaire took place in June 2012. 18 people responded to the questionnaire.

\section{Interviews}

Open-semi structured interviews were conducted to reflect upon developments and personal experience during the transition of PV in the Netherland. To verify the results of the technology perspective and the completeness of this research, experts in the field are asked to give their opinion, this is done through interviews. From the data of the event analysis seven key actors are selected. These key actors are experts in the field of $\mathrm{PV}$, situated across the different subsystems in the Innovation Systems. In this way prejudiced data is out of the question. In Table 3 a list of the experts is given which were interviewed during this research. The interview is split up into four parts. The first part of the interview contains questions about the function of the expert and the organizations. The second part contains questions about the storyline. A preliminary short storyline is constructed over the previous 5 years, this is given beforehand to the experts. In this way the events which were found in the different sources are filled up and checked on the validity and completeness. The third part tried to figure out to what extent the respondent is satisfied concerning the fulfilment of the different Systems Functions. The fourth part contains some questions concerning the Netherlands in comparison with other countries and how they think about the future of PV in the Netherlands. 
Table 3. List of interviewed people.

\begin{tabular}{lll}
\hline Contact person & Organisation & Place in innovation system \\
\hline Marcel Bartels & FOM & supportive infrastructure \\
Wim Sinke & ECN/UU & supportive infrastructure \\
Jadranka Cace & Rencom & supply side \\
ODE & intermediary infrastructure \\
Dennis Gieselaar & Oskomera & supply side \\
Bert Janson & Holland Solar & intermediary infrastructure \\
Roland van Zolingen & SenterNovem & intermediary infrastructure \\
Martin Fleuster & TUE & supportive infrastructure
\end{tabular}

Finally, some follow-up interviews with people (adopters and non-adopters of PV) of the neighbourhood Bieland were conducted. These interviews took place one and a half years after the information meeting. The interviews were semi-structured and in the form of a discussion that occurs just like a general dialogue. As I do not get all interviewee's permission, conversations were not recorded for later reviewing and direct quoting. Instead, notes were taken during each interview. The goal of the interviews was to corroborate and provide depth to the questionnaire results, and to assess the attitude and behaviour of the households. Thus these informal interviews were used to clarify and refine issues as they emerged. 
Part 2:

Technological Innovation System 



\section{Chapter 4: \\ Dutch PV innovation system}

This chapter is based on Negro, S.O., Vasseur, V., Van Sark, W.G.J.H.M., Hekkert, M.P. (2012). "Solar eclipse: The rise and 'dusk' of the Dutch PV innovation system." Int. J. Technology, Policy and Management Science 12, 135-157. 



\subsection{Introduction $^{17}$}

It is widely recognised that the dominance of fossil fuels in the world energy system causes severe environmental problems, such as climate change. However, the diffusion and implementation of alternative technologies, such as renewable energy technologies that would at least partly solve this problem, proceeds slowly. New technologies have to compete with an incumbent technological system that is locked-in the use of fossil fuel (carbon lock-in) and that benefits from long periods of experience, leading to high efficiency, low costs, optimal institutional arrangements, and many vested interests (Unruh 2000). These renewable energy technologies on the other hand are in their early phases of development and therefore still inefficient and badly adapted to the function they need to fulfil in society. This makes rapid diffusion a very difficult process (Rosenberg 1976).

A relevant question, therefore, is how to break through the lock-in situation, and create a situation where renewable energy is widely used in society? To answer this question, it is necessary to open the black box of carbon lock-in, and to analyse in a detailed manner how the development and diffusion of renewable energy sources takes place. Such an analysis should also allow us to pinpoint key mechanisms that block or induce this development process. Insight into these mechanisms is necessary to design policy arrangements that can efficiently deal with these blocking and inducement mechanisms, in order to speed up the diffusion process of renewable energy technologies.

For opening the black box and analysing the development and diffusion process of renewable energy technologies, many different perspectives can be used. In this paper we use the framework of Technological Innovation System (TIS). In the last years this framework has been developed and nowadays it is often applied to analyse technological transformation processes (Hekkert, Suurs et al. 2007, Negro, Hekkert et al. 2007, Bergek, Hekkert et al. 2008). The strength of the framework is that it takes a system perspective to explain how different structural components of the innovation system (technology, actors, networks and institutions) influence the development and diffusion of a specific technology.

\footnotetext{
${ }^{17}$ The analysis in this chapter covers the period from 1970 until 2010. More recent developments, such as the substantial growth of the solar PV market since 2011 and changes in institutional conditions have not been included in this research. Since 2010, regional and local initiatives have stimulated the market for PV systems in the Netherlands by providing economic incentives and creating more attention to, and awareness of the application of PV systems (entrepreneurial activities). Since many of the positive developments during those years have been arisen in the meantime, the outcomes and approach of this chapter are very valuable and insightful with respect to (possible) future developments.
} 
In this paper the specific technology that will be analysed is photovoltaic solar energy technology (PV) in the Netherlands. The reason for this is that there is a long history of policy efforts in the Netherlands to stimulate PV but results in terms of diffusion of PV panels in the Netherlands is disappointingly low, which clearly constitutes a case of slow diffusion. Nonetheless, new silicon production plants or module assembly plants are being constructed. This could be due to the rapid growth of the global market and that of neighbouring countries such as Germany, which is home to the largest PV market. The growth in the European market has been principally driven by the dynamism of the German market (Vasseur and Kemp 2011). In this case study we will pay particular attention to the influence of neighbouring markets and assess how it influences the diffusion and policy process in the Netherlands. Therefore, the research question that will be answered in this paper is:

What are the barriers that hamper the build-up of the Dutch PV innovation system and what are the implications for policy?

In the next section the theoretical framework will be described in more detail. Section 3 provides insights in the methodology used in order to identify the barriers for the development of PV. In section 4 the development, diffusion and decline of PV technology in the Netherlands will be elaborated and analysed. Section 5 will conclude this paper by answering the above mentioned research questions and discuss the policy implications.

\subsection{The functioning of technological innovation systems ${ }^{18}$}

The theoretical framework used to analyse the evolution of PV in the Netherlands is that of an emerging technological innovation system (TIS). A TIS is defined to comprise a set of actors and institutions whose actions and interactions contribute to the development and diffusion of a new technology. Institutions are in this case the rules of the game and consist of formal institutions (e.g. regulations) and informal institutions (e.g. values, expectations). When a TIS starts to emerge very few actors are involved who put efforts in developing the technology in question. When time goes by and success occurs the TIS is likely to grow in number of actors, strength of networks and in terms of institutions aligned in order to support the new technology (Hekkert, Suurs et al. 2007, Van Sark, Brandsen et al. 2007, Hekkert and Negro 2008). This is called the formative phase of a TIS (Jacobsson 2008).

Recent studies have shown great progress in understanding this formative phase of a TIS (Hekkert, Suurs et al. 2007, Jacobsson 2008, Hekkert and Negro 2009). The basic conclu-

\footnotetext{
${ }^{18}$ Since the chapter was originally written in article-format, this theoretical section largely overlaps with Chapter 2 .
} 
sion that follows from these studies is that a number of key processes need to take place in a TIS in order for the system to grow in terms of structural elements (Edquist and Johnson 1997, Galli and Teubal 1997, Johnson 1998, Jacobsson and Johnson 2000, Liu and White 2001, Rickne 2001, Bergek 2002, Jacobsson and Bergek 2004, Carlsson, Jacobsson et al. 2005, Hekkert, Suurs et al. 2007, Negro, Hekkert et al. 2007). These processes are often labelled as functions of innovation system (or system functions). Based on Hekkert et al (2007) we discern the following system functions (see Table 4).

Table 4. System functions of technological innovation system.

\begin{tabular}{ll}
\hline Function & Description \\
\hline Function 1: & The existence of entrepreneurs in innovation systems is of prime importance. \\
Entrepreneurial activities & The role of the entrepreneur is to turn the potential of new knowledge \\
& development, networks and markets into concrete action to generate and take \\
& advantage of business opportunities.
\end{tabular}

Function 2:

Knowledge exchange

Function 3:

Knowledge diffusion through networks

Function 4:

Guidance of the search

Function 5:

Market formation

Function 6:

Resources mobilisation

Function 7:

Creation of legitimacy
Mechanisms of learning are at the heart of any innovation process. Therefore, $R \& D$ and knowledge development are prerequisites within the innovation system. This function encompasses 'learning by searching' and 'learning by doing'.

The essential function of networks is the exchange of information. This is important in a strict R\&D setting, but especially in a heterogeneous context where R\&D meets government, competitors and market. Network activity can be regarded as a precondition to 'learning by interacting'. When user producer networks are concerned, it can also be regarded as 'learning by using'.

The activities within the innovation system that can positively affect the visibility and clarity of specific wants among technology users fall under this system function. Expectations are also included, as occasionally expectations can converge on a specific topic and generate a momentum for change in a specific direction.

A new technology often has difficulties to compete with incumbent technologies, as is often the case for sustainable technologies. Therefore it is important to create protected spaces for new technologies. One possibility is the formation of temporary niche markets for specific applications of the technology. This can be done by governments but also by other agents in the innovation system.

Resources, both financial and human, are necessary as a basic input to all the activities within the innovation system.

In order to develop well, a new technology has to become part of an incumbent regime, or has to even overthrow it. Parties with vested interests will often oppose this force of 'creative destruction'. In that case, advocacy coalitions can function as a catalyst to create legitimacy for the new technology and to counteract resistance to change. 
Both the individual fulfilment of each system function and the interaction dynamics between them are of importance. When more functions are fulfilled the expectation is that there will be a better performance of the TIS which results in higher chances for successful development, diffusion and implementation of new technologies. The different system functions can influence and reinforce each other which result in different functional patterns. In his PhD thesis Suurs (2009) has labelled this process as 'motors of innovation'. These motors of innovation help to explain TIS build-up around sustainable energy technologies. Suurs (2009) identified five motors, where each is characterised in terms of dominant functions and interactions between these functions, see Table 5)

Table 5. Motors of innovation (based on Suurs 2009).

\begin{tabular}{ll}
\hline Motor & Description \\
\hline Motor 1: & The first and least developed motor is dominated by the functions knowledge \\
Science and technology push & exchange $(+\mathrm{F} 2)$ and -diffusion $(+\mathrm{F} 3)$, guidance of the search $(+\mathrm{F} 4)$ and \\
motor & resources mobilisation $(+\mathrm{F} 6)$. The role of entrepreneurial activities $(+\mathrm{F} 1)$ and \\
& the creation of legitimacy $(+\mathrm{F} 7)$ played also a role but it is typically weak or \\
& even absent. \\
& This motor is expected to precede the initiation of a project, because it is \\
& plausible that a certain knowledge base and expectations are required before a \\
& complex project is initiated; the Science and Technology Push motor can \\
& provide this.
\end{tabular}

Motor 2:

Entrepreneurial motor

Motor 3:

System building motor

Motor 4:

Market motor

Motor 5:

Motor of decline
The more elaborate entrepreneurial motor is stressed to replace the science and technology push motor, maintaining its virtuous cycle and adding to it the functions creation of legitimacy $(+\mathrm{F} 7)$ and entrepreneurial activities $(+\mathrm{F} 1)$. The cumulative causation is created by new entrants or diversifying incumbent actors that start experimenting (+F1), positive expectations (+F4) in turn leads to lobby activities for support ( $+F 7$ ) from other actors (e.g. government) to mobilise resources $(+F 6)$, which in turn leads to more entrepreneurial activities (+F1).

This motor resembles the entrepreneurial motor with some changes; it includes a more important role of market formation (+F5). The main difference lies in the connection between creation of legitimacy $(+F 7)$, on the one hand, and market formation (+F5) and guidance of the search (+F4) on the other. Outsiders are increasingly involved in networks by enacting new entrants, governments, intermediaries and stakeholders in their system. From this network, outsiders attempt to develop the innovation system by enhancing the motors virtuous cycles.

The market motor is characterised by a strong fulfilment of all functions, except the creation of legitimacy $(+F 7)$ is not strongly fulfilled. This function is not as important for this motor because market formation (+F5) is no longer a political issue. The market environment has been created as the result of formal regulations. Market formation (+F5) is taken up as part of regular business activities (i.e. marketing activities and promoting strategies) that are directly connected to entrepreneurial activities (+F1).

This motor does not explain structural barriers that block motors of innovation; it shows event sequences that constitute an accelerated breakdown of TIS structures. 
Motors of innovation cannot be regarded as independent of the structures of a TIS. On the contrary, motors of innovation emerge from a configuration of structural factors and in turn rearrange that configuration. There exists a mutual relation between the structural configuration of a TIS and the system functions which are fulfilled in it. For the purpose of this paper, the focus will be on the dynamic aspect, i.e. the system functions. Some motors of innovation and their connection to factors internal to a TIS will be identified. However, external factors, such as for example the development of foreign PV markets, are important as well. They will be considered as a part of the analysis wherever they affect the dynamics of the TIS (Suurs and Hekkert 2009b).

The aim of the paper is to identify motors of innovation of the PV TIS and provide handholds for policy making to accelerate the diffusion and implementation of PV technology in the Netherlands.

\subsection{Research methodology}

The method used to map interaction patterns between system functions is inspired by the process method used by Van de Ven and colleagues (Van de Ven, Polley et al. 1999, Poole, Van de Ven et al. 2000). Stemming from organisational theory, the usual focus is on innovation projects in firms and firm networks; in our case, the analysis is applied to a TIS level (for a more extensive description of the methodology we refer to (Negro 2007, Negro, Hekkert et al. 2007, Negro and Hekkert 2008, Suurs and Hekkert 2009b)).

Basically, the approach consists of retrieving as many events as possible that have taken place in the innovation system using archive data, such as newspapers, magazines, reports and interviews with experts of the field. The events are stored in a database and classified into event categories. Each event category is allocated to one system function using a classification scheme (see Table 1). These events can then be plotted in graphs per year and per System Function. Here only the occurrence (+ or -) of the event rather than the content are represented (see Appendix A:

Activity pattern of System Functions for an overview of all System Functions of the Dutch PV TIS).

The contribution of an event to the fulfilment of a system function may differ considerably from event to event. Some events have a positive contribution, such as the opening of a large-scale building integrated PV project, while others contribute negatively, as for instance an expression of disappointment, or the opposition of an important political group. This is indicated in the allocation scheme by +1 and -1 . The final outcome of the process analysis is a narrative (storyline) of how the development of the TIS has changed over time and the role of the different system functions within this development. In the narrative the focus is on extracting motors of innovation. Based on the content of the 
events and their chronological order, we are able to deduce the effect of one event onto another and the order in which such events occurred. By observing reoccurring sequences of events we are able to identify motors of innovation.

\subsection{Historical overview of PV in the Netherlands from 1970-2010}

In this section a chronological description of the events that took place in the PV trajectory is presented. The description will be subdivided into different year periods. The end of each period is chosen on the basis of change in activities or key events, therefore not all periods are of equal length. The symbols F1-F7 refer to the seven System Functions as described in section 2. In Appendix A:

Activity pattern of System Functions, an overview of all events plotted per function per year can be found. By comparing the shape of the lines of each System Function with the storyline, patterns and cycles can be identified. The content and, thereby, the relative impact of the event on the System Function fulfilment, is subsequently elaborated in the narrative.

The dawn of PV in the Netherlands (1970-1994)

The interest in PV as an alternative energy source started in the Netherlands in the seventies due to the oil crises. Dutch policy makers became aware that the Dutch economy is too dependent on fossil fuels and that a diversification strategy is necessary. The Dutch government publishes two 'Energy White Papers' in 1974 and in 1979 that clearly state the need for alternative energy sources (+F4). In the energy research community these signals are picked up and research projects start to explore PV technology. The research leads to positive outcomes (+F2) which influence the scientists to lobby for the expansion of fundamental research on PV and its acceptance as a renewable energy source (+F7). Within this lobby, the Dutch Solar Trade Association 'Holland Solar' is founded in 1983, which will become a main sparring partner for the Ministry of Economic Affairs. The members of the association are companies or organisations active in the field of solar thermal energy and/or photovoltaic solar energy for small- and large-scale applications and lobby strongly to the government (Reinshagen 1984, Bokhoven 1987, Verbong, van Selm et al. 2001, HollandSolar 2007). The Dutch government is susceptible to this lobby and by the end of 1984 a coordinated programme starts for fundamental PV research at three Dutch universities together with Dutch members of the 'International Solar Energy Society' (ISES) ${ }^{19}$, the so-called ISES-programme, (+F4) (Duurzame Energie 1987, Verbong, van Selm et al. 2001). Over the years the popularity of PV within the government continues to grow and in their budgets the Ministry of Economic Affairs

\footnotetext{
${ }^{19}$ The ISES-programme has two research themes concerning PV, one on crystalline gallium arsenide (GaAs) cells that have the potential of high efficiency (35-40\%) and the other on amorphous silicon (a-Si) with low production costs and an efficiency of potentially $15-20 \%$.
} 
pays more attention to research on PV conversion (Blok 1985). In 1986 the National Research Programme on $\mathrm{PV}^{20}$ (with a budget of 2.7 million Euros) is started (+F2), aiming to follow international activities concerning PV by building up and maintaining expertise on several specific areas that are already present in the Netherlands. Another goal is also to promote the development of PV conversion concerning the future energy provision in the Netherlands (Duurzame Energie 1987, Verbong, van Selm et al. 2001).

Towards the end of the eighties there is a temporary reservation of the national government towards PV as it doubted whether PV is a suitable renewable energy technology for the Netherlands (-F4). The doubts are related to the fact whether the Netherlands are sunny enough for PV to generate substantial amounts of power and to the question on how to fit PV into a strongly centralised energy system. Ultimately, PV gets the benefit of the government's doubts and the Dutch government starts to develop instruments to create a market for PV. They implement the 'Support Regulation Energy Savings and Flow Energy' (SES) ${ }^{21}$ in 1988 and will renew it in 1991. This regulation states that $40 \%$ of the purchase costs of a PV system are compensated (Natuur \& Milieu 1990, Duurzame Energie 1991) (+F5). Further support for PV is provided in the 'White Paper on Energy Savings ${ }^{22}$ published in 1990. The goal is that in 2010 PV has to replace 2 PJ of fossil fuels, which is equal to $240 \mathrm{MWp}$ of PV modules (+F4). This is the first time that a specific aim is formulated for PV. This is a clear response to the high oil prices (Andriessen 1993, EnergieNed 2000, Verbong, van Selm et al. 2001). Additional policy documents by the government and the statements of the distribution companies to further support PV are published in the coming years (+F4), which are a strong indication for the insiders that they are on the right track. This triggers their expectations and they start to carry out more research (+F2) in order to contribute to a well working PV technology. The 'Energy research Centre of the Netherlands' (ECN) starts to cooperate with a large number of Dutch as well as foreign parties, originating from both the research world and the industrial sector. These research groups have an important role during this phase of the PV innovation system. In 1994, ECN and the company R\&S ${ }^{23}$ produce an industrial PV module with an efficiency of $16 \%(+F 2)$, and R\&S starts a pilot production line for multicrystalline silicon PV (+F1). The Netherlands acquire an important position in the global PV research world with these technological improvements (Duurzame Energie 1994, Energie \& Milieu 1994). This leads to such pilot projects set up by several Dutch Universities (+F2), where PV is placed on house roofs (e.g. Castricum, Amersfoort-Nieuwland, Heerhugowaard-City of the Sun, Barendrecht) (+F1) (Schoen 2001, Verbong, van Selm et

\footnotetext{
20 In Dutch: NOZ-PV, Nationaal OnderZoeksprogramma PV.

${ }^{21}$ In Dutch: Steunregeling voor Energiebesparing en Stromingsenergie.

22 In Dutch: Nota Energiebesparing.

${ }^{23}$ R\&S = Renewable Energy Systems, a subsidiary company of Shell, who took over the employees of Holec Energy Systems B.V. in 1984. In 1981 Holec Energy Systems BV was founded and produced semi-crystalline silicon panels (Verbong, van Selm et al. 2001)
} 
al. 2001). These projects not only lead to knowledge development on PV system performance $(+F 2)$, but also guide the search by highlighting the importance of this technology $(+\mathrm{F} 4)$.

The dynamics characterising this first period involve positive expectations (+F4) leading to the setting up of several R\&D programmes, and directly linked to it, the allocation of financial resources (+F6) to PV. More specific budgets and support and legitimacy from industrial parties (e.g. R\&S) result in a boost of activities in the form of feasibility studies by several Dutch Universities (+F2), the first entrepreneurial experiments (+F1) and also cooperation between research institutes and industrial parties (+F3). Thus, here we observe a first motor of innovation, labelled as Science and Technology Push (STP) Motor, given the dominance of scientists and technology developers in developing PV.

The sunny side of the PV innovation system (1994-2000)

This period is marked by the introduction of the 'Third Energy White Paper' ${ }^{24}$ in 1995 $(+F 4)$, where the aim is to achieve a $10 \%$ share of renewable energies in 2020 . PV comes on the third place as important renewable energy technology, but its actual impact will be for the long-term (Min EZ 1995). In order to achieve the goals of market formation and energy saving, several generic programmes and policies for renewable energies are set up (+F5, +F6) (see Table 6 for an overview for the programmes and policies).

Table 6. Overview of programmes and policies.

\begin{tabular}{|c|c|c|}
\hline Period & $\begin{array}{l}\text { Financial } \\
\text { stimulation }\end{array}$ & Aim \\
\hline $1996-2003$ & REB & $\begin{array}{l}\text { To reduce the energy use of companies and households. It } \\
\text { comprised a tax on the use of energy }\end{array}$ \\
\hline $1996-2003$ & VAMIL & $\begin{array}{l}\text { To accelerate depreciation of investment which were } \\
\text { included on the energy list }\end{array}$ \\
\hline 1996 - still running & EIA & $\begin{array}{l}\text { To offset investments in technologies against taxable profit } \\
\text { which were included on the energy list }\end{array}$ \\
\hline $1996-2004$ & BSE & $\begin{array}{l}\text { To stimulate the use of sustainable energy and environmental } \\
\text { energy technologies by providing subsidy for research and } \\
\text { development projects in the field of renewable energy }\end{array}$ \\
\hline 1996 - still running & Green Funds & $\begin{array}{l}\text { To stimulate private investments in environmentally friendly } \\
\text { projects like PV by means of a tax exemption of this interest }\end{array}$ \\
\hline $1997-2000$ & EBF & $\begin{array}{l}\text { To give the possibility to lean money for investments in } \\
\text { energy saving technologies against a lower interest (3\%) }\end{array}$ \\
\hline $1997-2004$ & EET & $\begin{array}{l}\text { To come to a solution of the } \mathrm{CO}_{2} \text {-problem by development } \\
\text { and application of new and innovative technologies }\end{array}$ \\
\hline
\end{tabular}

\footnotetext{
${ }^{24}$ The aim is to achieve a $10 \%$ share of renewable energies in 2020 . PV comes on the third place as important renewable energy technology, but its actual impact will be for the long-term (EZ 1995)
} 
However these programmes and measures are not specific for PV. Therefore SenterNovem on behalf of the Ministry of Economic Affairs starts to prepare the follow-up for a third national research programme on PV (NOZ-PV 96-00), which will run until the year $2000(+F 6)$. This research programme is more market oriented than the previous two programmes. The main aim of the programme is the realisation of conditions and the removal of the bottlenecks for the large-scale implementation of PV panels in the Dutch energy system in the twenty first century (Duurzame Energie 1995a, Roos and Blom 2001). Further targets for market development are set in 1997 when the 'PV Covenant' is voluntarily signed by several players in the PV field, e.g. SenterNovem, the Ministry of Economic Affairs, a number of utilities and property developers, building material manufacturers, PV industry, research institutes, consultants and others (+F4) (Schoen 2001). It functioned as a good platform to transfer knowledge, because of the diverse parties involved trying to influence national policy (+F3) (Duurzame Energie 1997).

The programme and the covenant trigger entrepreneurs to become more active $(+\mathrm{F} 1)$ and starting the development of a Dutch PV market (+F5). R\&S, becoming Shell Solar Energy BV, opens a new production line for multi-crystalline silicon PV panels with a capacity of $2.5 \mathrm{MWp}$ per year with the intention of expanding within a period of five years to approximately 20 MWp per year (+F1) (TW 1997, TW 1997a, Duurzame Energie 1997b). In the same year, the 'City of the Sun' on the Vinex-location between Heerhugowaard, Alkmaar and Langedijk (HAL-location) started thinking about the construction of an emission free city including up to 5 MW PV (+F1) (EnergieVerslag 1997). The costs are 30 billion euros (60 billion guilders) being the largest PV project in the world (Duurzame Energie 1997c). In this project the local government is the main initiator, while that role in other projects (e.g. Nieuw Sloten and Nieuwland in Amersfoort) is mainly played by energy distribution companies (Duurzame Energie 2000). Also NGO's start to become active and behave like real entrepreneurs: Greenpeace starts the 'Solaris' project (1998) which offers customers a complete PV module for 500 Euros (+F1). Together with another programme 'PV GO!' ${ }^{25}$ they install PV modules on more than 3000 houses (see Figure 1 for an increase in installed capacity) (Duurzame Energie 2000a, Schoen 2001). The realisation of these projects together can be seen as an attempt to create a mass market for PV in the Netherlands by lowering prices due to benefits of scale and learning experiences. At the same time the research in the Netherlands focuses on several items which are closely linked, namely cost reductions, performance improvements and integration into buildings.

The event sequence of this period is characterised by an initial impulse of multiple system functions simultaneously, where entrepreneurial activities (+F1) serve as a pivot in

\footnotetext{
${ }^{25}$ In 2000 NOVEM launched the PV-GO! rebate programme for small systems as well as PV on large buildings. PV-GO! contributes up to $25 \%$ of the system costs.
} 
the unfolding of more positive dynamics. The PV covenant and several research and market formation programmes trigger entrepreneurs to set up pilot projects on house roofs and for R\&S to expand their production line. As the entrepreneurial activities have a pivotal position we observe an Entrepreneurial Motor. It differs from the STP motor where the entrepreneurial activities are an important outcome but not so much an essential driver of further developments. The Entrepreneurial Motor builds for a large part upon the technological and institutional progress established by the STP motor.

The 'dusk' of the PV innovation system (2001-2003)

This period is marked by a large political shift as national government changed its policy concerning renewable energies (PV-Nieuwsbrieven 2002/2003). Since the main contribution to the $10 \%$ target is expected to come from wind energy and biomass, it is decided that all dedicated (R\&D, demonstration and market development) programmes for other renewables, such as thermal solar energy and PV, will be ended (-F5, -F6) (Sinke 2002). In addition, on the first of July 2001, the energy market is liberalised (Duurzame Energie 2001a). From this moment on PV has to compete on a free market with cheap fossil fuels and other renewable energy options. It is feared that the diffusion of PV could be endangered, but contrarily to other renewable energy technologies (such as biomass digestion or gasification that collapsed after the liberalisation (Negro, Hekkert et al. 2007, Negro, Suurs et al. 2008)) the installed capacity of PV continues to grow (see Figure 11). This can be explained by the 'Energy Contribution Regulation' (EPR) ${ }^{26}$ that stimulates people to buy energy efficient equipment and to produce green energy by giving subsidy (+F5) (Duurzame Energie 2002a, Duurzame Energie 2003). Additionally, the support from environmental organisations (Greenpeace, WWF) and energy distribution companies (Nuon and Eneco Energy) contribute to the diffusion of PV in the Netherlands. Also, the market for small-scale PV systems is boosted by dedicated campaigns of municipalities, some of them offering extra subsidies. For example the programme 'ZonZeker' by the Province of Groningen together with Essent stimulated consumers to buy PV modules and boilers (+F5) (Duurzame Energie 2001c), and the programme 'More roofs under the sun' (Novem) stimulated house building agencies to include PV in their constructions (+F5) (Duurzame Energie 2004b). Together these activities reinforce and legitimise the use and diffusion of solar energy in the liberalised energy market (Negro, Sinke et al. 2008).

\footnotetext{
${ }^{26}$ In Dutch: Energie Premie Regeling
} 


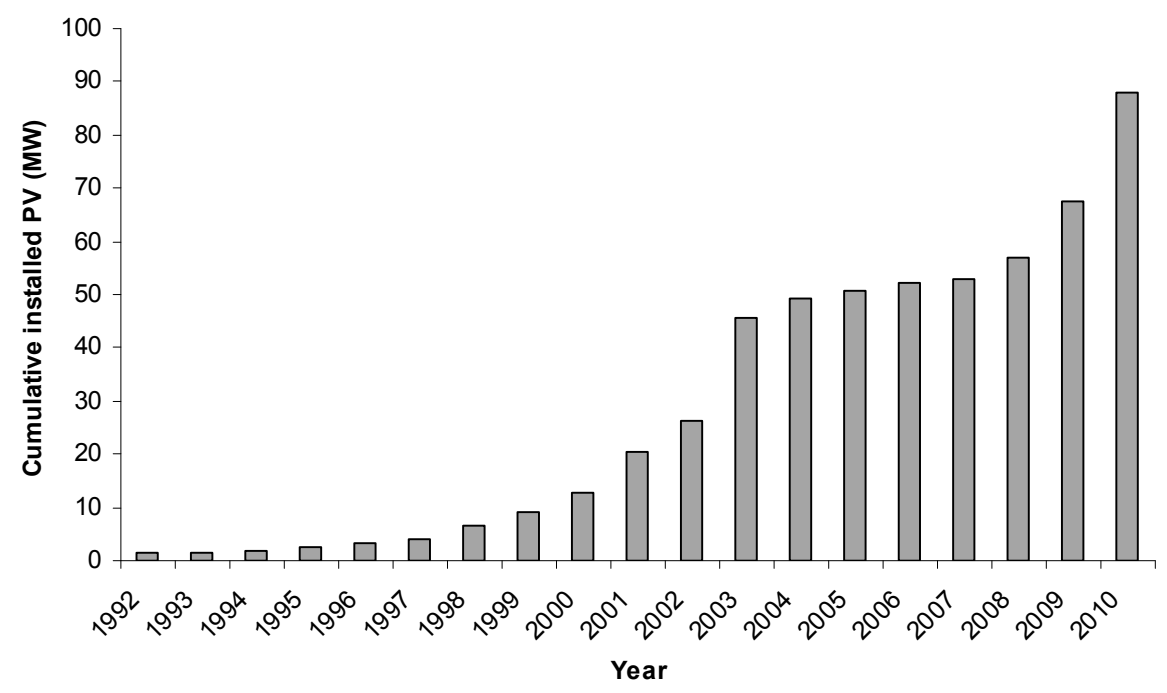

Figure 11. Cumulative installed PV in the Netherlands per year.

So far so good, it seems that the previously build-up Entrepreneurial Market is strong enough to withstand changes within the institutional setting and that enough support and momentum is present in order to move from an Entrepreneurial Market to a System Building Market. However, several crucial events happen in the next two years and provide a serious blow to the PV TIS, however not without the PV sector 'fighting back' until the bitter end.

First, in December 2002 Shell Solar announces the closing of the PV plant in Helmond (F1); one reason being that they want to concentrate their activities in North-America, Germany and Portugal due to attractive regulations and high demand in these countries. A second reason is to streamline the production after starting a joint venture between Shell Solar Energy and Siemens (Duurzame Energie 2002c, Duurzame Energie 2004). With the closure of the plant in Helmond the production of solar panels decreases to practically zero in the Netherlands and all knowledge, expertise and skills are leaving the Netherlands. A new plant is being built in Germany using all knowledge generated in the Netherlands (TW 1997, TW 1997a, Duurzame Energie 1997b). The interest in other countries can be explained by the growth of the worldwide PV market.

Secondly, despite the success of EPR programme which led to an increase of the total installed capacity of PV in the Netherlands, the programme is ended due to several reasons: i) the budgets of the EPR were insufficient; ii) inflated subsidies ${ }^{27}$ and free-riding

\footnotetext{
${ }^{27}$ At the beginning of the century 6 programmes were active: 'Energy Contribution Regulation' (EPR), 'Energy Performance Advice' (EPA), 'Energy Investment Non Profit sector' (EINP) 'New Energy Research' (NEO), 'Sus-
} 
behaviour $^{28}$, iii) bad monitoring by the government in the years 2001-2002 with as consequence that far more subsidies were granted than the available budget could provide. Adding up all these reasons led the government to announce the discontinuation of the EPR within a month (-F4, -F5), due to its large success. This announcement results in a 'gold rush' by actors in the PV sector in order to exploit this subsidy as long as it lasts; in that last month about 90,000 PV panels are sold to households (about 8 million kWh per year, corresponding to a consumption of 2.500 households), for a value of 100 million Euros (YourEnergy.net, PV-Nieuwsbrieven 2002/2003, Duurzame Energie 2003, SenterNovem n.d./2010). This huge run is responsible for the peak installation of PV in the Netherlands in 2003 (see Figure 11), before its collapse.

After this rush the expectations are very low as thousands of jobs (installers and consultants), the knowledge about the technology and the installation will be lost (Volkskrant 2003). This will also lead to reluctance of the business sector to make investments in solar energy (-F6), and a drop in the net sales (HollandSolar 2007). The PV Covenant is also not extended because of the too high demands for financial support of the industry $(-\mathrm{F} 3)$.

Summarising, this period is dominated by the unpredictability of the government, explicitly removing all support for PV and the liberalisation of the energy market combined with a simultaneous rapid growth of the global PV market. This results in decreasing investments in the Dutch PV sector, and a shift by investors, manufacturers and entrepreneurs towards the worldwide PV market, looking for support and collaboration on European level, or financial support by neighbouring countries (for example municipalities in Germany). This shift also leads to a great loss of employment and knowledge, skills and expertise in the sector. With the final removal of the subsidies the gold rush towards the installation of PV panels collapses. This results in a collapse of the Dutch PV innovation system, as the previous positive motors of innovation transform into a motor of decline. The impact of a motor of decline on TIS structures is clearly the deterioration of the TIS, especially the involvement of insiders but also of technologies, infrastructure and important institutions. After all, as technological promises are broken, the set of cognitive rules is bound to change which is not something that can be changed easily as it is based on trust (Suurs 2009).

tainable Energy in the Netherlands' (DEN), and 'Environmental Quality of the Electricity Production' (MEP). Most programmes were of short duration and ended also in this period due to the coalition agreement. (SenterNovem; DE 2003a; Sinke, Swens et al. 2008).

${ }^{28}$ In some regions, where the utility Eneco had taken over the utility REMU, the addition of subsidies lead to the absurd situation that PV systems could be purchased for about 0.01 Euro/Wp. Due to these exaggerated subsidies and free-riding behaviour the government decided to reduce the expenditure on PV (PVNieuwsbrieven 2002/2003). 
Recovery of PV in the Netherlands (2003-2010)

Nonetheless the previous blow, advocates and insiders of the technology reorganise themselves to launch new lobby activities and experiments in order to show that PV is still an option. Dutch entrepreneurs notice the upcoming foreign market and try to remain in the race as leading country in terms of knowledge and technology production. This leads to a boost of activities by Dutch entrepreneurs concentrating on the export market such as Germany and Spain, as those latter countries enjoy favourable financial stimuli (such as high feed-in tariffs for PV) (HollandSolar 2007). Solland Solar for example, is located in Heerlen/Aachen (the so-called Avantis Park) on the border between the Netherlands and Germany and obtaining subsidy from two countries (Stromen 2004a, Stromen 2004b).

The faith of entrepreneurs and industry in a sunny future for PV panels continues when a 'Roadmap Solar Energy' is developed in 2005 by Holland Solar (Dutch PV association) in collaboration with the Dutch PV sector. The roadmap puts forward a vision for the future of PV and the steps for further market development $(+F 3,+F 4)$ (Bode 2005, HollandSolar 2007). It is also one of the documents used as basis for PV transition path (Negro, Sinke et al. 2008). This roadmap is offered to the government as input in order to formulate a common vision (Negro, Sinke et al. 2008). However, with the fall of the government in 2006 the vision is not included in its future agenda and on top of that the temporary Minister of Economic Affairs ends the 'Environmental Quality of the Electricity Production' (MEP) ${ }^{29}$ in August 2006 without warning. The official reason being that the goal of $10 \%$ renewable energy in 2010 will be achieved easily without subsidies, whereas the actual reason is supposed to be (again) the expiration of the governmental budget (-F5) (Energie+ 2006). Nonetheless, Holland Solar continues the lobby activities and believes that solar energy could still contribute to the renewable energy supply of the Netherlands. However, the lobby power of the insiders and outsiders in favour of PV is limited, previous documents and agreements are ignored by the government and their wishes and ideas regarding market strategy are not taken into consideration. The government mainly sees a role for PV in the far future, i.e. after 2020, as the expectations are that PV will reach consumer price levels only over ten years of time (Montfoort and Ros 2008). Therefore mainly R\&D activities $(+F 2,+F 3)$ are supported and financed by the government (EOS programme $\left.{ }^{30}\right)(+F 6)$.

\footnotetext{
${ }^{29}$ In Dutch: 'Milieukwaliteit Elektriciteitsproductie' (MEP). The MEP, introduced in 2003, is a kWh subsidy paid to domestic producers of electricity from renewable sources and CHP who feed-in to the national grid. The State guarantees the subsidy for a maximum of ten years, though not for CHP. However, the tariff for PV was limited, lower than under the EPR which means that it is very unlikely that this regulation will increase the investments in PV and entrepreneurial activities, as the costs for PV modules will remain very high.

${ }^{30}$ A set of energy research and technology development programmes: The New Energy Research (NEO), Innovation Subsidy Collaboration Projects (IS), Energy Research Subsidy - Demonstration (EOS DEMO), Energy Research Subsidy - Long Term (EOS LT), Transition - Unique Opportunities Scheme (Transition UKR) (SenterNo-
} 
After the gold rush researchers go back to the drawing table to do further research in order to reduce the costs and be less dependent on the high subsidies. In the meantime the production activities in the Netherlands (i.e. Solland Solar) continue due to export. Due to the strong presence of support from advocacy coalitions by Holland Solar (+F7) and especially entrepreneurial activities (+F1), some outsiders (e.g. Derbisolar, Triodos, Henderson global investors) are incorporated into the PV TIS. This in turn affects the build-up of a broad base of insiders, including local governments, supply-side and demand-side firms.

In 2007 a new government is installed which announces an ambitious sustainability plan aiming at an annual energy consumption reduction of $2 \%$, a $\mathrm{CO}_{2}$ emission reduction of $30 \%$ by 2002 compared to 1990 and a contribution of $20 \%$ of renewable energy production in 2020 (Coalitieakkoord 2007, Bundy 2008, Negro, Sinke et al. 2008). Following these ambitions the government sets up of a new market implementation programme, called 'stimulation of renewable energy production' (SDE) ${ }^{31}(+\mathrm{F} 5)$. One month after the implementation of this programme, more applications are submitted than money available (17.8 MW in stead of $10 \mathrm{MW}$ ) (NWEA 2008, ODE 2009). Due to this overwhelming public interest, an additional budget is allocated in 2009 to allow another $11.8 \mathrm{MW}$ to be installed over the coming years. The adjusted SDE are available for small-scale as well as for larger scale PV installations (15 kWp - $100 \mathrm{kWp)} \mathrm{(Senternovem} \mathrm{2010).} \mathrm{However,} \mathrm{the}$ actual realisation of the previously applied projects is lower than expected ${ }^{32}$ (see Figure 11 where no substantial increase of installed capacity occurs between 2007 and 2008).

Besides the SDE regulation, the government also pays extra attention to the 'Energy Transition plan'. Within this programme, the Dutch government collaborates directly with market players through a number of Energy Transition Platforms, which advise the government on desired and required legislation and support schemes to realise the above mentioned targets (IEA-PVPS 2008). As part of this, a transition platform for renewable electricity supply (TP-DEV) is established including PV technology, in order to enable the transition towards a sustainable electricity supply (Energie+ 2007, Sinke 2007). This initiative of the government seems to provide some intention of commitment to seriously realise the implementation of renewable energy technologies, and triggers several activities within the Dutch PV sector, for example several solar companies are set up in the Netherlands around 2007: Scheuten Solar, FESTpv and Advanced Photovoltaic Applications BV (APA). These activities from the government and from the

\footnotetext{
vem; Sinke, Swens et al. 2008). These programmes cover a full range of renewable energy technologies where $\mathrm{PV}$ is one of the priority areas.

${ }^{31}$ In Dutch: 'Steunregeling Duurzame Energie'

32 This results from the complex administration procedures that are required when adopting PV panels and the lack of capable installers who can realise the complex installation procedures (ODE 2009).
} 
PV sector could form the beginning of the so-long awaited large-scale implementation of $P V$ in the Netherlands.

This final period is dominated mainly by research and lobby activities. The government mainly supports R\&D activities and the SDE regulation that is supposed to trigger the installation of PV panels remains too marginal with respect to its budget and too bureaucratic to really provide a boost of market formation. However, due to the growth of the global PV market and the attractive financial instruments in Germany, entrepreneurial activities continue in the Netherlands and several solar companies are set up. In this period we observe an Entrepreneurial Motor that evolved around lobby and entrepreneurial activities.

\subsection{Conclusion}

After 30 years of policy efforts, PV technology has not been implemented on large scale. Throughout the years the many activities carried out by entrepreneurs, researchers and investors however, they do not seem to have major impact nor to lead to a momentum in order to move from the Entrepreneurial Motor to a System Building Motor. The main barriers are inconsistent regulations, unpredictable behaviour of the government and the lack of a clear vision for PV. After the government removed the EPR subsidy in 2003 and simultaneously the global PV market was growing the Netherlands did not pursue consistent efforts to promote deployment. Shell Solar, and with it the human capital, moved to Germany to profit from the favourable, stable and long-term institutional conditions implemented there. The government made no effort to keep the industry in the Netherlands. The German market was a good enough substitute for the home market to keep the sector going also in times when Dutch policy was not in favour of creating a market for solar energy. Therefore, the policy implication might be that a government may decide not to strengthen some parts of the innovation system when neighbouring countries fulfil these functions sufficiently.

However, this creates two types of risks. First, this strategy might lead to the build-up of a PV sector, but certainly not in reaching national sustainable energy goals as no capacity is installed in the country itself. Second, only knowledge development and entrepreneurial activities related to engineering and building PV cells are kept alive. Other complementary knowledge and entrepreneurial activities are not supported, such as integration of $\mathrm{PV}$ in design of houses, knowledge about installation, easy net metering, services related to feedback of solar energy in the grid and so on. In short, an important part of the innovation system that is necessary to make PV an integral part of the energy system is not build-up. These risks are a plea for creating a home market as an integral part of the innovation system build-up. Especially because the observed consistency of stimulating $R \& D$, but much less the rest of the innovation system, is still very much in line with 
the 'linear model'. From this it becomes clear that consistency in policy is not seen as a necessity for successful technology development and diffusion. However, when an innovation system perspective is the basis of policy making then the opposite reasoning is expected. This lack of systems thinking is a major problem when we take the transition towards a sustainable energy system serious. It takes a long time to get the innovation system build-up process going again after periods of decline. In addition, transition is only possible with high degrees of consistency regarding the creation of the right boundary conditions in which the technology in question can flourish. Policy strategies should therefore target the fulfilment of all system functions in a continuous and longterm way in order for motors of innovation to occur that contribute to the build-up of the innovation system and the implementation of the technology in question. Specifically, system functions such as guidance of the search and market formation need to be targeted by continuous and long-term efforts to gain social involvement and confidence by many insiders and outsiders. 


\section{Chapter 5: \\ Role of policy in a technological innovation system}

This chapter is based on Vasseur, V. and Kemp, R. (2011). "The role of policy in the evolution of technological innovation system for photovoltaic power in Germany and the Netherlands." International Journal of Technology, Policy and Management (IJTPM) 11, 



\subsection{Introduction ${ }^{33}$}

There is a long literature on how regulation affects innovation, whether it acts as a barrier or stimulus. Community Innovation Survey data has been used to study the influence of regulation on innovation (Schwann 2005) finding that it plays both roles. In the field of environmental economics, the influence of environmental policy instruments on innovation have been studied in theoretical models and econometric regressions, often with the aim of determining what instrument provides the greatest stimulus on innovation. There is a growing consensus that policy instruments cannot be ranked based on their stimulus for innovation (high, low) but that impacts of policy instruments depend on how the instrument is formulated and used, as well as on the situational context. As Mickwitz et al (2008) write "generalisations of the role of policy instruments innovation and diffusion in environmentally friendlier technologies, without considering the specific characteristics of the situation, are dangerous" (Mickwitz, Hyvättinen et al. 2008, p. 27). Relevant aspects of policy instrument design are: stringency; predictability; differentiation with regard to industrial sector, plant, new investment; timing; the time path of the standards and the credibility of policy commitments to future standards; enforcement (inspection and penalties for non-compliance) and combination with other instruments of policy (Kemp and Pontoglio 2008).

In this paper we study the influence of policy on the evolution of the technological innovation system ${ }^{34}$ for solar photovoltaic power ${ }^{35}$ (PV) in two countries (Germany and the Netherlands). The focus is on the dynamic relationship between regulatory policies and research policies and technology development and diffusion. The comparison between policy developments and technological innovation system developments in two countries allows us to draw conclusions on the role of policy.

\footnotetext{
${ }^{33}$ The analysis in this chapter covers the period from 1970 until 2009. More recent developments, such as the substantial growth of the solar PV market since 2011 and changes in institutional conditions have not been included in this research. Since many of the positive developments during those years have been arisen in the meantime, the outcomes of this chapter are very valuable and insightful with respect to (possible) future developments.

${ }^{34}$ A technological innovation system is defined by Carlsson and Stankiewicz $(1991$, p. 94) as "a network of agents interacting in the economic/industrial area under a particular institutional infrastructure and involved in the generation, diffusion, and utilization of technology". This implies that there is a technological system for each technology and that each system is unique in its ability to develop and diffuse a new technology.

${ }^{35}$ There are three generations solar cells discerned in the literature. The first generation solar cells are based on crystalline silicon, currently most applied in the market. The second generation solar cells are based on thinfilm technologies still using the scarce silicon but less than the first generation. Because both technologies are dependent on silicon, the third generation organic solar cells (dye-based cells, molecules or polymers) are introduced. This generation solar cells are developed only at laboratory scale by research centres and universities.
} 
The analysis is conducted via literature research (professional journals, newspapers, reports, and websites) and interviews with companies and experts in the field. To minimise personal bias, the reconstruction of the events and overall narrative is checked by experts. Quantitative information from desk research is combined with qualitative insights about the historic context and the opinions of field experts. The causal relationship between different policies and innovation diffusion is also studied statistically through correlation and linear regression analysis.

The structure of the paper is as follows. Section 2 offers a description of the development of the PV market in Germany and the Netherlands. Section 3 describes the policies to support PV in Germany and the Netherlands. Section 4 gives an overview of the technological innovation system for PV in the two countries and provides explanations for the observed differences. Section 5 states the conclusions and policy lessons.

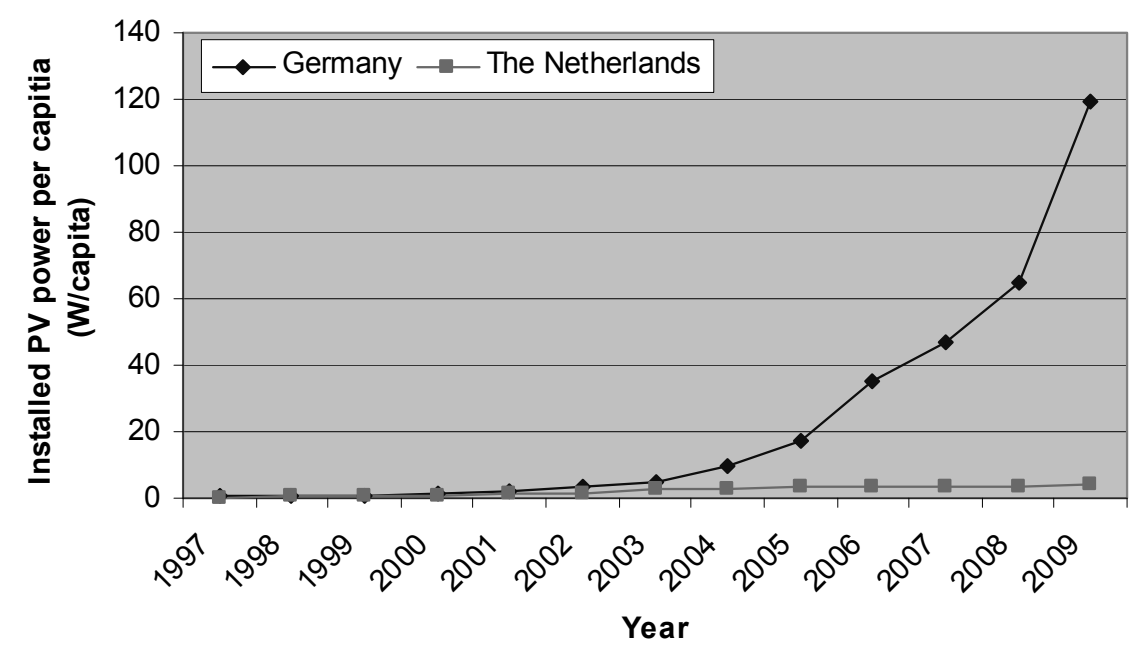

Figure 12. Development of the installed PV power per capita in Germany and the Netherlands.

\subsection{The German and Dutch PV market}

The European PV market is consistently growing, outpacing other regions worldwide. Within Europe, the most important market is the German market. The growth in the European market has been principally driven by the dynamism of the German market. The cumulative installed PV power in Germany has increased from $186 \mathrm{MW}$ in 2001 to 9845 MW in 2009 (IEA-PVPS 2010a), making Germany the largest market for PV installations worldwide with a global market share of 35\% in the year 2008 (John 2009). This in contrast to the Netherlands, where only 10.7 MW of PV were installed in 2009 which brings the cumulative installed PV power to 67.5 MW (IEA-PVPS 2010a). The develop- 
ment of the installed PV power per capita in Germany and the Netherlands is given in Figure 12.

Before comparing the German and Dutch PV innovation systems, let us compare some quantitative indicators for both countries (see Table 7). Insights in the differences of installed power or public budgets might also provide clues for how to accelerate the diffusion of PV technology.

Large differences are clearly visible, for instance, the total amount of installed power per capita (4.1 Watt and 199.6 Watt respectively) and the costs for market stimulation (54 MEUR and 3.2 BnEUR respectively) in 2009. There are also large differences in the PV industry visible, if we compare Germany with the Netherlands we see that the number of active companies is higher in Germany ( $\approx 70$ compared to $\approx 7$ ), the total production volume $(6,516 \mathrm{MW}$ compared to $170 \mathrm{MW})$ and the number of jobs in $2009(64,600 \mathrm{FTE}$ compare to 566 FTE).

Table 7. Comparison between Germany and the Netherlands (2009). Source: IEA-PVPS 2010a; IEA-PVPS $2010 \mathrm{~b}$.

\begin{tabular}{|c|c|c|c|}
\hline Category & Factor & Germany & The Netherlands \\
\hline \multirow{3}{*}{$\begin{array}{l}\text { Installed } \\
\text { power }\end{array}$} & Total installed PV power end 2009 & $9845 \mathrm{MW}$ & $67.5 \mathrm{MW}$ \\
\hline & Cumulative installed PV power per capita end 2009 & 119.6 W/capita & $4.1 \mathrm{~W} /$ capita \\
\hline & PV power installed during 2009 & $3845 \mathrm{MW}$ & $10.669 \mathrm{MW}$ \\
\hline \multicolumn{2}{|c|}{ Public budg-Public budgets for PV R\&D in 2009} & 52.9 MEUR & 12.0 MEUR \\
\hline \multirow[t]{4}{*}{ ets } & Public budgets for PV R\&D per capita in 2009 & 0.65 MEUR/capita & 0.73 MEUR/capita \\
\hline & Public budgets for industrial R\&D in 2009 & 190 MEUR & - \\
\hline & Costs for market stimulation for PV in 2009 & 3.2 BnEUR & 54 MEUR \\
\hline & & 39 EUR/capita & 3.27 EUR/capita \\
\hline \multirow[t]{4}{*}{ Industry } & Total cell and module production in 2009 & 6,516.2 MW/year & $170 \mathrm{MW} / \mathrm{year}$ \\
\hline & Turnover in 2009 & 8.6 BnEUR & 413 MEUR \\
\hline & Number of active companies in 2009 & $\approx 7$ & $\approx 70$ \\
\hline & Estimated PV jobs in 2009 (FTE's) & 64,600 & 566 \\
\hline \multirow[t]{2}{*}{ Pricing } & $\begin{array}{l}\text { System prices in } 2009 \\
\text { (grid-connected < 10kW; > } 10 \mathrm{~kW} \text { ) }\end{array}$ & $\begin{array}{l}\text { 3.0-4.3 EUR/W; } \\
\text { 2.8-3.8 EUR/W }\end{array}$ & 4.8-5.5 EUR/W* \\
\hline & Module prices in 2009 & 1.5-2.5 EUR/W & 3.3-4.5 EUR/W* \\
\hline
\end{tabular}

These numbers show that Germany has a fledging PV market and the Netherlands does not. To find an explanation for this, a comparison regarding the policy developments that took place in the PV trajectory and the RTD and industry developments must be made. 


\subsection{Policy developments in Germany and the Netherlands}

\section{PV Policy overview Germany}

\section{Stromeinspeisungsgesetz}

The first feed-in law in Germany was the 'Stromeinspeisungsgesetz' introduced in 1990. This took the form of a simple one-page bill for assisting producers of electricity from small hydro stations and wind energy installations (BMU 2000, Berchem 2006). The feed-in law puts a legal obligation on utilities and energy companies to purchase electricity from renewable energy producers at a favourable price per unit, and this price is usually guaranteed over a certain period (usually 20 years). Tariff rates are usually differentiated for each renewable technology in order to take account for different generation costs. The extra cost of the favourable tariff rate is usually passed on from suppliers to consumers and shared among all energy consumers by way of a premium in the per enduser kWh prices. By spreading the cost between all end-users the increase in prices per household is very small. However, the compensation rates have not been sufficient to stimulate a large-scale market introduction of electricity generated from other sources, especially PV and biomass (Bubenzer and Luther 2003, Mendonca 2007).

\section{0,000 roofs solar power programme (HTRP)}

In 1999, the government started its market launch policy for PV with the ' 100,000 roofs solar power programme' for PV (HTRP). It is a low-interest loan programme where investors can receive a nearly zero-interest loan for 10 years from the governmental bank KfW for the installation of PV (Bubenzer and Luther 2003, IEA-PVPS 2004). The market launch policy stimulated the demand for PV systems, thereby creating new jobs and increasing the competitiveness of the German companies on the world market and attaining a high level of technological know how (Stryi-Hipp 2004a). The goal of the programme was very high compared to the market dimension of about $10 \mathrm{MWp}$ in 1998 and gave the market and the industry a long-term perspective over 6 years ((Stryi-Hipp 2004b).

Due to the very fast increase in the number of applications, it was decided to stop the 100,000 roofs solar power programme one and a half years earlier than planned (end of June 2003) since it had fulfilled its aim of installing 100,000 new appliances (IEA-PVPS 2004). In total, the programme provided loans for approximately 65,700 grid connected PV systems with a capacity of 345.5 MW in total (IEA-PVPS 2004, IEA-PVPS 2005, Mints 2007).

\section{EEG 2000}

In 2000, the stromeinspeisungsgesetz was implemented under the new name 'Erneuerbare Energien Gesetz' (EEG) (Renewable Energy Law). The EEG introduced a number of changes including a differentiation in tariff rates depending in the renewable energy type, size and site. The EEG extended the range of technologies to be covered, and re- 
placed the Stromeinspeisungsgesetz rates per kWh with fixed rates over a fixed period (BMU 2000, Mendonca 2007). The EEG guaranteed a feed-in tariff of at least 50.62 cent per kWh for PV system (Bolinger and Wiser 2002). To promote efficiency improvements and prevent windfall profits, the feed-in tariffs for new systems are lower than those for systems in the previous year. As of 1 January 2002, the minimum compensation paid shall be reduced by $5 \%$ annually for new systems commissioned as of this date (BMU 2000). A PV system installed in 2002 receives $50.62-5 \%(2002)=48.1$ cents; and in $200348.1-5 \%(2003)=45.7$ cent for every kWh for 20 years (see Table 8 ).

Table 8. Development of the basic PV feed-in tariff of the EEG for new systems (up to $30 \mathrm{~kW}$ ), the rates are guaranteed for an operations period of 20 years.

\begin{tabular}{|c|c|c|c|c|c|c|c|c|c|c|}
\hline & 2001 & 2002 & 2003 & 2004 & 2005 & 2006 & 2007 & 2008 & 2009 & 2010 \\
\hline Tariff (€/kWh) & 0.51 & 0.48 & 0.46 & 0.574 & 0.545 & 0.518 & 0.492 & 0.468 & 0.43 & 0.39 \\
\hline
\end{tabular}

EEG 2004

In 2004, parliament adopted an amendment to the EEG committed Germany to increase the share of renewable energy in the country's total electricity supply to $12.5 \%$ by 2010 , and to at least by $20 \%$ by 2020 . The feed-in rate was increased to compensate for the elimination of the 100,000 roofs programme.(BMU 2004, Stryi-Hipp 2004a)

\section{EEG 2008}

In 2008, another amendment of EEG was introduced in the form of a stronger price reduction. According to the new law, the tariff will decrease between 8 and $10 \%$ in 2010 and then 9\% annually after 2011 (BMU 2008). PV systems received a feed-in tariff of 0.33-0.43 EUR/KWh, depending on the amount of electricity sold to the public grid ${ }^{36}$.

\section{PV Policy overview the Netherlands}

\section{REB}

In 1996, the 'Regulating Energy Taxes' (REB) was implemented to reduce the energy use of companies and households; it comprised a tax on the use of energy. Since PV was more expensive than for example wind and biomass, the REB hardly stimulated investments in PV (Energie \& Milieu 1994).

\section{EPR}

In 2001, PV was included in the 'Energy Contribution Regulation' (EPR). The EPR is a subsidy scheme, in which individual system owners have to apply for subsidies through

\footnotetext{
${ }^{36} 43.01$ cents per kilowatt-hour for the first 30 kilowatts of output, 40.91 cents per kilowatt-hour for output between 30 and 100 kilowatts, 39.58 cents per kilowatt- hour for output between 100 kilowatts and 1 megawatt, and 33.0 cents per kilowatt-hour for output over 1 megawatt (BMU 2008).
} 
their utilities. Funds for the subsidy programme come from the energy tax (Haas 2002). After installation of PV the government refunds 3.50 Euros for each Wp and gives a 25\% discount on the price of the system (not for newly build houses) (Duurzame Energie 2002b, Duurzame Energie 2003a). In September 2003, the announcement of the Ministry of Environment that the EPR will be stopped within one month caused a rush on subsidies by actors in the PV sector to obtain this subsidy (Duurzame Energie 2003a). In the last month about 90,000 PV panels have been sold to households (about 8 million kWh per year, corresponding to a consumption of 2,500 households), for a value of 99 million Euros (YourEnergy.net).

\section{MEP}

In 2003, the 'Environmental Quality of the Electricity Production' (MEP) was introduced in order to improve the environmental quality of the Dutch electricity supply. The main aim of the MEP was to stimulate the production of renewable energy in the Netherlands (SenterNovem n.d./2010). The level of support was differentiated by technology. The highest level of support, $0.068 \mathrm{EUR} / \mathrm{kWh}$, was given to offshore wind energy, PV, small stand-alone biomass installations, hydro, wave and tidal energy. However, this tariff for PV was limited, lower than the 0.123 EUR/kWh under the EPR (Negro, Sinke et al. 2008). Without any prenotice the Ministry of Economic Affairs stopped the MEP subsidy in 2006. The official reason given for this is that the goal of $10 \%$ renewable energy in 2010 will be achieved easily without subsidies (Energie+ 2006).

\section{$S D E$}

In 2008, the government launched a new market implementation programme for renewable energy called 'Stimulation of Renewable Energy Production' (SDE) based on tariffs. The tariffs for PV are set to 0.33 EUR/kWh (for small-scale systems between 0.6 $\mathrm{kWp}-3 \mathrm{kWp}$ ) for a period of 15 years (see Table 9). The total new power to be installed in this Cabinet period (2008-2011) is expected to be $78 \mathrm{MW}$, on top of the almost 60 MW installed end 2008 (IEA-PVPS 2009). May 2008 there were more applications than money available, i.e. about 8000 applications with a capacity of $17.8 \mathrm{MW}$, whereas the budget is only available for 10 MW (NWEA 2008, ODE 2009). Due to this overwhelming public interest, an additional budget was allocated in 2009 to allow for another $11.8 \mathrm{MW}$ installed capacity over the coming years. The adjusted SDE granted also larger PV installations (15 kWp - $100 \mathrm{kWp).} \mathrm{For} 2010$ a total budget is planned of 93 MEUR of which 69 MEUR is allocated for small PV installations and 24 MEUR for larger PV installations (Senternovem 2010). 
Table 9. Overview SDE 2008 - 2010 (Polder-PV 2010).

\begin{tabular}{llllll}
\hline & SDE 2008 & SDE 2009 & \multicolumn{3}{c}{ SDE 2010 } \\
\hline Scale $(\mathrm{kWp})$ & $0.6-3.5$ & $0.6-3.5$ & $15.0-100.0$ & $1.0-15.0$ & $15.0-100.0$ \\
Basic $(€ / \mathrm{kWh})$ & 0.564 & 0.526 & 0.459 & 0.474 & 0.430 \\
Returned by utility (€/kWh) & 0.234 & 0.273 & 0.076 & 0.225 & 0.053 \\
Actual subsidy (€/kWh) & 0.330 & 0.253 & 0.383 & 0.249 & 0.377 \\
\hline
\end{tabular}

Financial considerations resulted in a change in the programme by the new government. Under the new SDE there will be significantly less money. For 2010, the SDE budget was 2.216 billion Euros (excluding the budget for wind at sea), while only 100 million Euros will be provided in 2011 (AgentschapNL 2010, Rijksoverheid 2010).

\section{Policy comparison}

In this section we will compare the support given to PV investments in Germany and the Netherlands. Given that the public budgets for market stimulation for PV in Germany is provided in the form of a feed-in tariff, the German market stimulation is not directly comparable with the one in the Netherlands. Therefore, the feed-in tariff for Germany and the subsidy tariff for the Netherlands are used to compare both countries. The tariff data used in the following figures is earlier mentioned in the policy overview section. The installed PV power data used in the figures were derived from the annual Trends in Photovoltaics Application reports of the IEA-PVPS (IEA-PVPS 2010a).

An overview of the development of the German feed-in tariff and the installed PV power per year is given in Figure 13. Apart from 2004, the feed-in tariffs are lower for each consecutive year. We observe a steady increase in the newly installed PV power per year. Throughout the years, the German government provided uniform, consistent, and long-term support for PV through the use of special feed-in tariffs for PV, with levels high enough to make PV investments profitable. We can see that until 2003, the growth of the German installed PV power was more or less constant. In that period, the feed-in tariffs meant that PV only has to compete within the PV market with other PV sources, and not with cheaper sources like wind and biomass. The system provided investors with long-term security through guaranteed and fixed tariffs for a period of 20 years on a relative high level. This is the longest security of all policies within the world (Reiche and Bechberger 2003). 


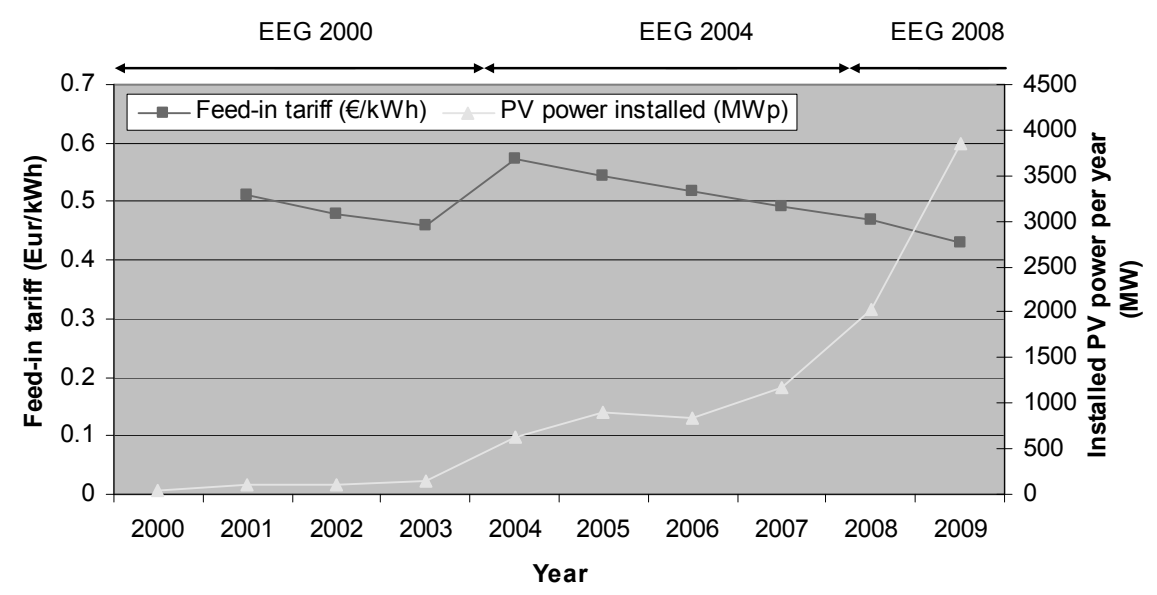

Figure 13. The historic development of the feed-in tariff and the installed PV power in Germany.

Because of the clarity of this policy and the safety it provides for investing in PV, it has become a great success increasing the installed PV power in Germany (interviews 1,4 and 7$)^{37}$. The rapid growth after 2004 is related among other things to the lifting of the restriction that PV systems could not be larger than $100 \mathrm{kWp}$. It encourage the uptake of larger systems, on barns and other buildings, making up about $70 \%$ of the installed PV power in 2009, against about 40\% in year 2005 (Staiß 2007, Dewald and Truffer 2010, PhotonInternational 2010).

An overview of the development of the Dutch subsidy tariff and the installed PV power per year is given in Figure 14. We see that the installed PV power peaked in 2003, was very low in the years 2005-2007, picking up again in 2008 and 2009. The main reason for this erratic pattern is the discontinuities in policy according to various sources (Montfoort and Ros 2008, Negro, Sinke et al. 2008) and (interviews 2, 5 and 6). The Netherlands has a system where support policies for renewable energy can change from year to year which offers no (long-term) security at all (Reiche and Bechberger 2003). Following the elimination of the EPR, the installed capacity of PV per year in the Netherlands drops from 19.3 MW in 2003 to almost zero for the next three years (see Figure 14). Support through the MEP was insufficient to stimulate PV investments, because the tariffs of the MEP were lower than the ones of the EPR, (0.068 EUR/kWh compared to 0.123 EUR/kWh under the EPR (Negro, Sinke et al. 2008). In 2007, there was no market stimulation program. From 2008 on, the installed PV power is growing due to the introduced SDE program (in 2008) which aims to develop a large-scale PV market. But SDE was scaled down in 2010 for budgetary reasons, the consequences of which we do not know yet. Though the government has supported market introduction in the past and

\footnotetext{
${ }^{37}$ The feed-in system has also been associated with a large growth in PV in Spain.
} 
again through the SDE arrangement, support has not been constant over the years (switches in subsidy programs and sudden discontinuation of subsidy schemes), both end-users and manufacturers are unsure if they can trust new schemes, which will have negative effects on the formation of a domestic market (see Figure 14).

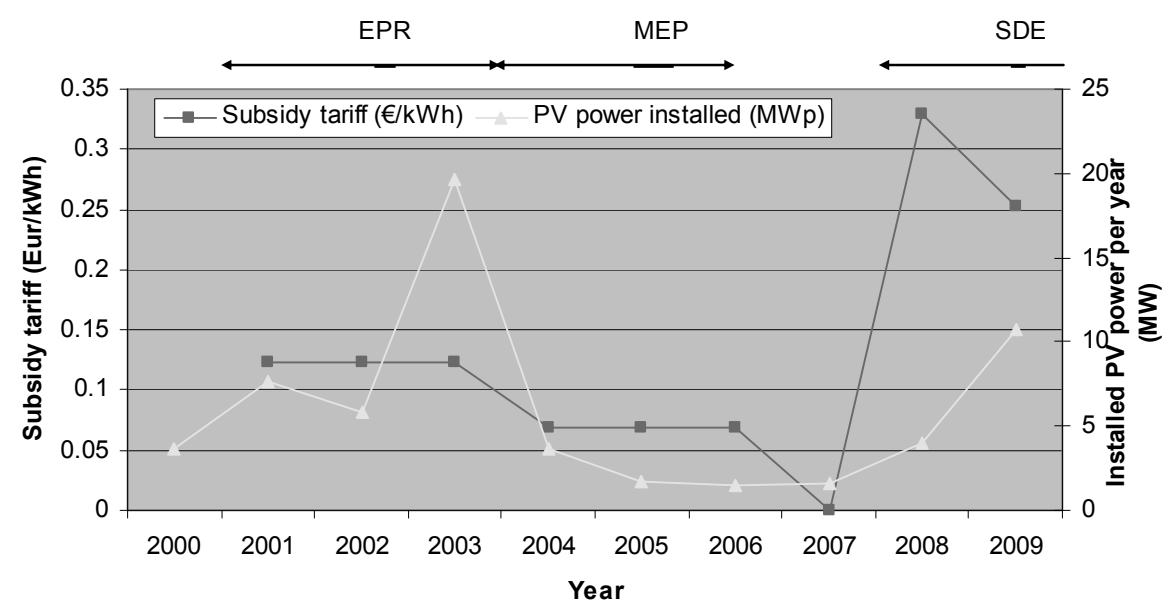

Figure 14. The historic development of the subsidy tariff and the installed PV power in the Netherlands.

The results (see Figure 13 and Figure 14) show also the difference between the basic PV feed-in tariff provided by the EEG and the subsidy tariff provided by different stimulation programmes in the Netherlands. The Dutch tariffs are in sharp contrast to German tariffs, in 2001 the Dutch tariffs were less than one-fourth of the German tariffs $(0.123$ compared to 0.51), in 2007 there was no Dutch tariff and in 2009 the difference was around 50\% (0.25 compared to 0.43). The Netherlands opted for a system where the policies were paid directly by the government. As the introduced policy becomes more successful than expected, it can cause an unexpected huge expenditure for the government. (e.g. the EPR exceeded the government budget by approximately 99 million Euros due to its own success). From this, we can conclude that the Dutch government did not create the right enabling conditions for the development of the PV market, the policy support created windfall profits.

An important difference between the support policies is that the Dutch policies relied on (non-hypothecated) taxes and the German policies did not. In Germany the government has only some costs for creating and implementing the legislation, the costs of renewable energy are spread among all consumers who buy electricity in Germany and the grid owners take care for the calculations and remunerations. Thus in Germany electricity consumers are responsible for the costs of this feed-in system. The costs of the German system are quite substantial. In 2009 they amounted to 3.2 billion (compared to 1 billion in 2000) (Aan den Brugh 2009, Segaar 2010). The growing costs resulted in opposition 
from German industry who were given discounts. In the Netherlands PV also lobbied for this feed-in system, unsuccessfully.

\section{Statistical results}

We also undertook a correlation analysis to establish the link between deployment support and PV investments. We applied the non-parametric Spearman's correlation analyses, as not all variables showed a normal distribution (Shapori and Wilk 1965) ${ }^{38}$. What we found is that the Dutch subsidy tariff has a statistically significant positive correlation of 0.725 (at $\alpha=0.05$ ) with the installed PV power. In contrast to the Netherlands, in Germany there is no statistically significant correlation between the indicators. Our explanation for this is that the diffusion of PV in Germany is governed by the lower costs of PV modules in combination with the feed-in tariffs.

\subsection{The technological innovation systems for PV in Germany and the Netherlands}

This section describes the technological innovation systems for PV in Germany and the Netherlands, focusing on 3 elements: i) research activities and public research funding, ii) patent statistics, iii) number of companies active in the PV market and the range of their activities. In the section, we investigate the link between each of those.

\section{Research activities and public research funding}

Both countries have strong research capabilities in PV solar, according to industry analysts and according to patent statistics. Of the two countries, Germany has the highest patents in PV research: 44.7E-07 per capita compared to 5.44E-07 in the Netherlands ${ }^{39}$. In Germany research institutes such as Forschungszentrum Jülich, the Max Planck Institute, Fraunhofer Institute and universities such as Karlsruhe and Frankfurt gathered particular knowledge of PV technology in various different technology areas. The research concentrates on improving existing solar cells, modules and system components, as well as on developing new types of solar cell in the thin-film sector. From 2006 on, PV

\footnotetext{
${ }^{38}$ The following tests have been used to assess whether the indicators used display a normal distribution: Frequency histograms (for a graphical assessment of normality of distribution); P-P plots and Q-Q plots (have been used as a complementary graphical assessment tool for the normality of the distribution of the variable, thus in addition to the frequency histograms); Boxplots (to graphically check for outliers and skewness); the Shapiro-Wilk's W-test (as a formal test for normality has been used (Shapiro and Wilk 1965). However, results of the $\mathrm{W}$-test have been treated with care and placed within the context of the insights gained from all the other normality tests performed); descriptive statistics have been used to numerically assess skewness and kurtosis (criterion used for skewness: the skewness-statistic must lie between +2 and -2 ; criterion used for kurtosis: the kurtosis-statistic must lie between +2 and -2) (Garson, 2009).

${ }^{39}$ The number of patents is visible in Figure 18 and Figure 19, this number is divided through the total population of Germany/the Netherlands. The total population data used was derived from the World Bank database.
} 
RTD is brought under the aegis of a special programme called Innovation and New Energy Technologies. Under this framework the Federal Ministry for the Environment, Nature Conservation and Nuclear Safety (BMU) as well as the Federal Ministry of Education and Research (BMBF) support R\&D on different aspects of PV (BMWA 2005).

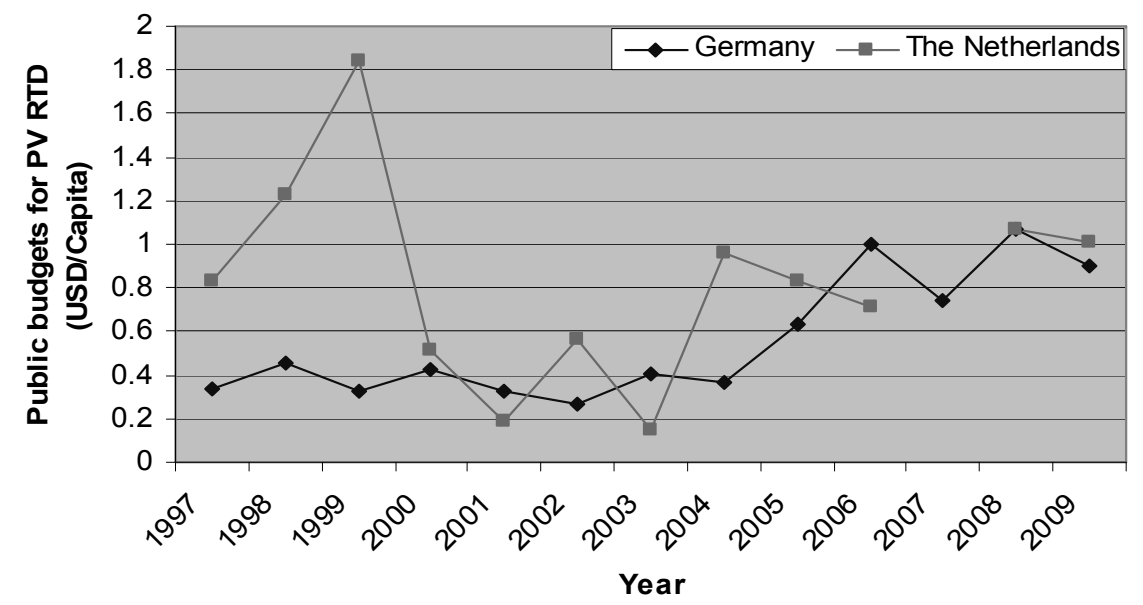

Figure 15. Public budgets for PV RTD per capita.

The main players in the Dutch PV RTD activities are research institutes (such as ECN, TNO and FOM-AMOLF) and universities such as the Technical University of Eindhoven (TU/e), Technical University of Delft (TUD), and Utrecht University (UU), who continue their research and focus on cost reduction and quality improvement of polycrystalline silicon cells and thin film silicon cells (first and second generation PV) with some research on the third generation of PV. The research and development in the Netherlands is mainly relying on European support programmes (Duurzame Energie 2003b, Senternovem 2010).

The absolute level of public RTD support ${ }^{40}$ was five times higher in Germany but in relative terms (per capita) RTD spending for PV is one and a half times higher in the Netherlands $^{41}$ (see Figure 15) in the 1997-2009 period. From 2000 on, the public budgets for PV RTD per capita have been more or less equal in both countries.

\footnotetext{
${ }^{40}$ In this analysis only public budgets for PV RTD are taken into account. Private energy RTD data is hardly accessible, due to the private sector is more dynamic.

${ }^{41}$ Measured over the last ten years, 2007 is not taken into account.
} 


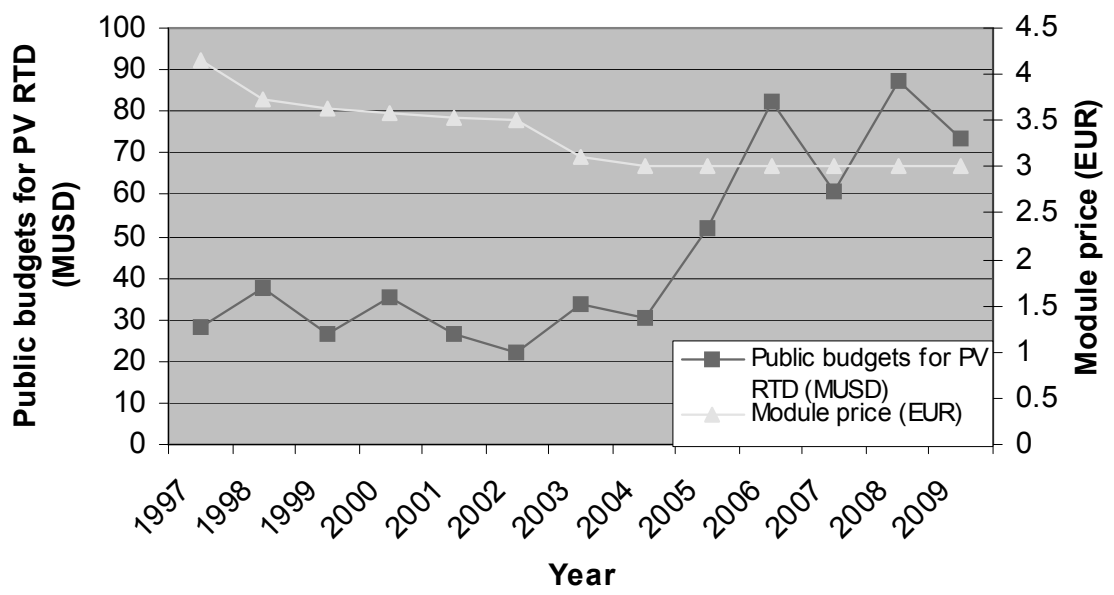

Figure 16. The historic development of the public budgets for PV RTD and the module price in Germany.

Over the past years, large improvements in cell efficiency have been realized and new types of solar cells have been introduced. However, it is difficult to compare efficiencies of solar cells since it is not country specific. For example, one of the objectives of European Crystal Clear project is to enhance the cell efficiency. Germany and the Netherlands are both involved in this project which means that the efficiencies reached counted for both countries. An interesting question is whether there is a relationship between public budgets, module prices and patents. We found a positive relationship between the rising budgets for PV RTD and falling module prices in Germany but no such relationship for the Netherlands. The observed relationship for Germany may be spurious because the link between module prices and public RTD is more long-term. Module prices can be expected to depend more on private RTD on which we have no information.

The increase in the German RTD budget from 2005 (see Figure 16) is related to R\&D roadmap, which was developed during the $9^{\text {th }}$ BMU R\&D strategy meeting by representatives from industry and research institutes. This national R\&D roadmap was developed in order to put emphasis on a stable decrease of the costs of electricity from PV, higher efficiencies and long-term stability of all system components (PV ERA NET 2009). In the Netherlands, the PV industry and research institutes also produced a R\&D roadmap for PV but this was not used by the government, despite PV being an official transition path of the Dutch energy transition (Negro, Sinke et al. 2008). 


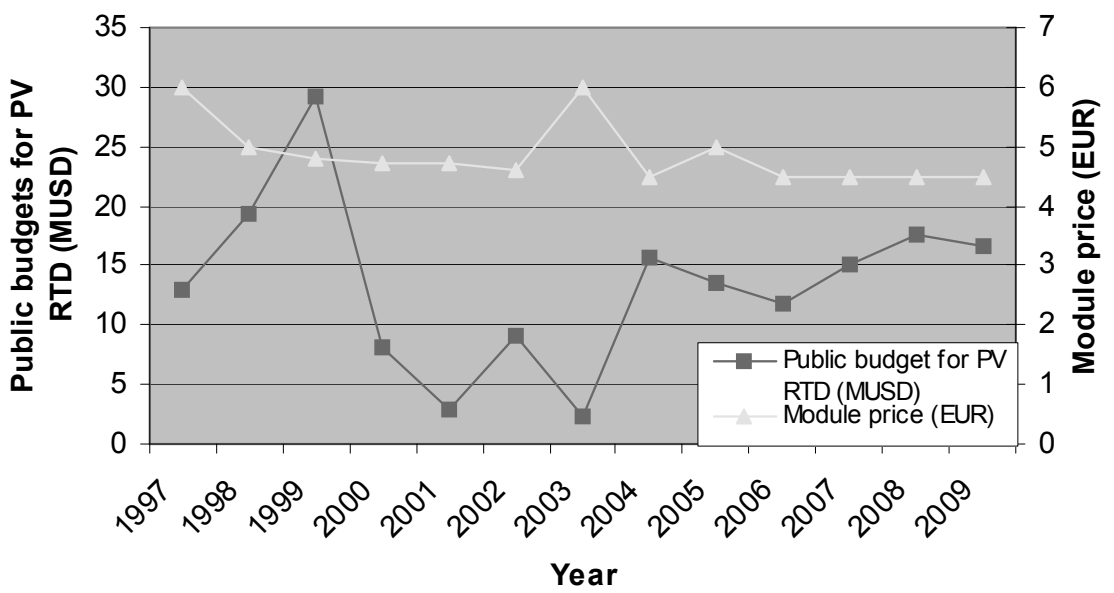

Figure 17. The historic development of the public budgets for PV RTD and the module price in the Netherlands.

In the Netherlands the public budgets for PV RTD fell from a very high level in 1999 to very low levels in 2001 and 2003, picking up in 2004 and 2008 (see Figure 6). In Germany RTD policy is more an element of industrial policy than it is in the Netherlands. This may explain the greater continuity but further research is needed to ascertain this.

\section{Statistical results}

The results show that German public budgets for RTD have a statistically significant positive correlation (at $\alpha=0.05$ ) of 0.636 with the module price in Germany. In contrast to Germany, in the Netherlands there is no statistically significant correlation between the indicators.

\section{Patent statistics}

The causal relationship between the number of patents for PV and the public budgets on PV RTD is also analysed. If we compare Germany with the Netherlands we see that the number of patents per capita is higher in Germany (44.7E-07 compared to 5.44E-07). Most patent activity is in PV cells and modules. Applications for cells and modules account for $72 \%$ of applications for PV technologies. Nanotechnologies are increasingly gaining ground in solar cell research, for instance, to produce dye-sensitized solar cells or multi-junction thin-film solar cells (WIFO 2009).

For patents we used data from esp@cenet, a free database offered by the European Patent Office (EPO). The use of the EPO patent data rather than national data bases helps to eliminate relatively minor patents and correct for national differences in databases. 
To delineate the PV research field we used the European classification scheme (ECLA) ${ }^{42}$ established by EPO. It can be used to determine the state of the art of patents applications. We used the ECLA code Y02E10/50, which refers to Photovoltaic (PV) energy, as criterion in our search for patents (espacenet.com). The public budgets for PV RTD were derived from the IEA-PVPS website.

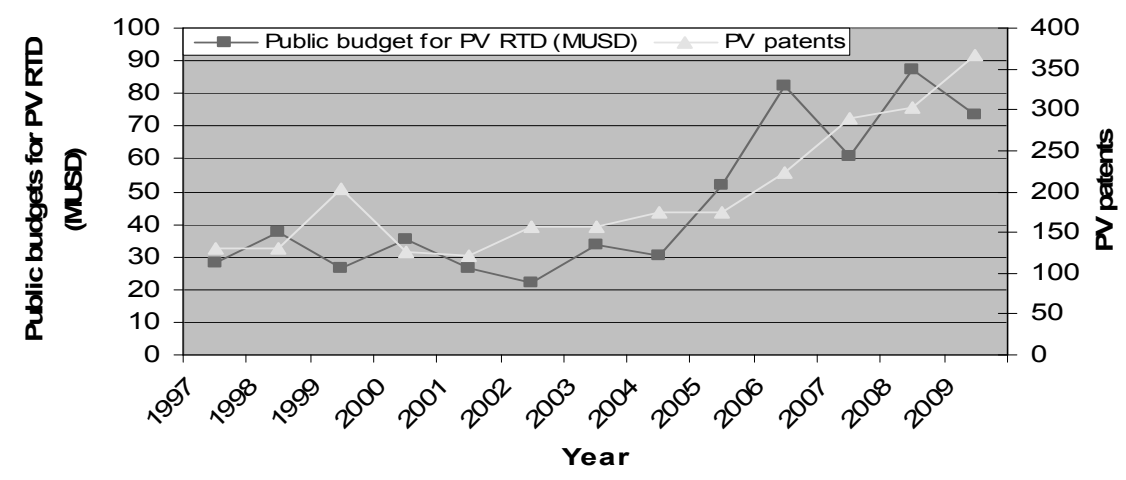

Figure 18. The historic development of public budgets for PV RTD and the number of PV patents in Germany.

In Figure 18, we show the number of patents for the PV as a function of the public budgets for PV RTD in Germany. It can be seen that high expenditures for RTD tend to have a higher number of patent applications.

The causal relation between the development of the public budgets for PV RTD and the number of PV patents for the Netherlands is given in Figure 19. A peak in patenting can be observed in 2002, 2006 and 2009 with some year of time lag after peaks in RTD budgets in 1999, 2004 and 2008. Despite the generally low number of patents a statistically reliable relation can be obtained (see Table 10). We also undertook a linear regression analysis, using public budgets for RTD and newly installed PV power as explanatory variables. The regression helps us to assess the relative influence of government-funded science push and market pull on patents.

\footnotetext{
${ }^{42}$ Another possible classification system is the International Patent Classification (IPC) which is a hierarchical classification system applied to published patent documents. The ECLA is based on the IPC but more detailed; the IPC consists of 70,000 groups while the ECLA has 134,000 groups.
} 


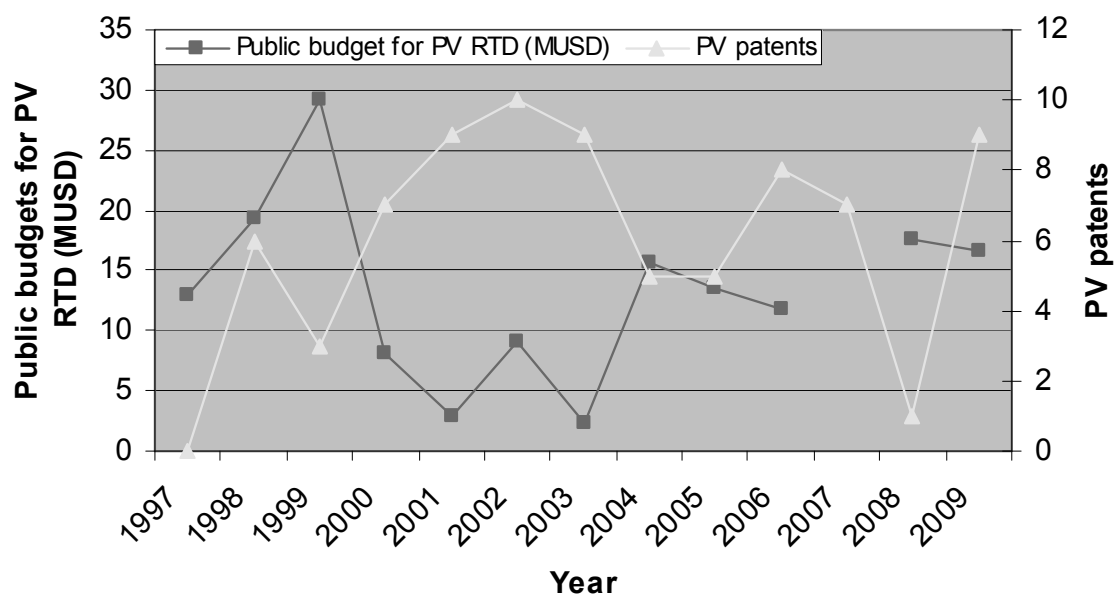

Figure 19. The historic development of public budgets for PV RTD and the number of PV patents in the Netherlands.

\section{Statistical results}

Table 10 shows the Spearman's correlation and simple linear regression outcomes.

Table 10. Spearman's correlation and linear regression coefficient between public budgets for PV RTS and PV patents.

\begin{tabular}{ll}
\hline \multicolumn{2}{l}{ Spearman's correlation between public budgets for PV RTD and PV patents } \\
\hline DE: Public budgets for RTD (MUSD) & $0.799^{*}$ \\
NL: Public budgets for RTD (MUSD) & $-0.582^{* *}$ \\
\hline Linear regression coefficients between public budgets for PV RTD, installed PV power per year and PV patents \\
\hline DE: Constant & $106.430 \pm 24.022(0.003)$ \\
DE: Public budgets for RTD (MUSD) & $1.069 \pm 0.569(0.102)$ \\
DE: Installed PV power per year (MW) & $0.050 \pm 0.012(0.004)$ \\
DE: R Square & 0.903 \\
NL: Constant & $9.323 \pm 2.958(0.020)$ \\
NL: Public budgets for RTD (MUSD) & $-0.268 \pm 0.186(0.200)$ \\
NL: Installed PV power per year (MW) & $0.092 \pm 0.184(0.635)$ \\
NL: R Square & 0.413
\end{tabular}

\footnotetext{
* Correlation is significant at the 0.01 level (2-tailed).

** Correlation is significant at the 0.05 level (2-tailed).

Independent variable: public budgets for RTD (MUSD) and installed PV power per year; Dependent variable: PV patents; Standard Error between brackets.
}

The results show that the German public budgets on PV RTD have a statistically significant positive correlation (at $\alpha=0.01$ ) with PV patents. The correlation is 0.799 , in other words, the number of PV patents increases as the RTD spending increases. In the Netherlands there is a statistically significant negative correlation (at $=0.05$ ). One possible 
explanation is the absence of market pull. When we introduce a market pull variable into the equation the significant positive and negative effect of public RTD support on patents disappears in both countries. Installed capacity has a significant positive effect on patents in Germany (at $\alpha=0.05$ ). For the Netherlands neither public RTD budget and installed PV power has a significant effect. We should note that Dutch countries are exporting to Germany, so installed capacity in the Netherlands only captures a part of the market sales. $90.3 \%$ of the variation in PV patents in Germany can be explained by public budgets for PV RTD and installed PV power per year. In the Netherlands only $41.3 \%$ of the variation can be explained.

However, there are some limitations to this analysis that have to be kept in mind. First, not all the innovations are patented, firms, for example, can choose other strategies to protect their innovations. Second, only public budgets for PV RTD are considered here, while it may be expected that the private RTD funding has increased significantly especially in Germany because of the rapidly growing PV market. To our knowledge there are no reliable estimates for private budgets for PV RTD.

Number of companies active in the PV market and the range of the activities

It is interesting to compare the technological innovation system for PV in Germany with that of the Netherlands and to relate this to policy to the extent this is possible. In Germany, more companies are active in the PV market than in the Netherlands (see Table 11). Dutch companies are active only in certain segments of the PV chain (solar cell and module production and thin film and CIS technologies). In Germany PV activities cover the whole value chain, ranging from a feedstock silicon company (Wacker), some solar cells production companies (RWE Schott Solar, Shell Solar, Deutsche Cell, ErSol Solar Energy, Q-cells, Sunways) and modules production companies with a production more than $5 \mathrm{MW}$ (RWE Schott Solar, SMD, Solara, Solon AG). The activities cover all fields of the PV technology, for example RWE Schott Solar is active in ribbon and sheet production using the EFG-technology and Würth Solar and Shell Solar produce CiS-modules in pilot plants. German manufactures are the world market leaders, especially the BOS field like inverters (SMA and Sunways) and battery chargers (Wissing 2009). 
Table 11 Number of active companies and PV production capacities for 2010.

\begin{tabular}{|c|c|c|c|c|}
\hline & \multicolumn{2}{|l|}{ Germany } & \multicolumn{2}{|l|}{ The Netherlands } \\
\hline & $\begin{array}{l}\text { Number of active } \\
\text { companies }\end{array}$ & $\begin{array}{l}\text { Production capacity } \\
2010\end{array}$ & $\begin{array}{l}\text { Number of active } \\
\text { companies }\end{array}$ & $\begin{array}{l}\text { Production Capacity } \\
2010\end{array}$ \\
\hline \multicolumn{5}{|c|}{ Silicon Wafer Technologies } \\
\hline Silicon feedstock & 4 & $28190 t$ & - & - \\
\hline Wafer production & 2 & $300 \mathrm{MW}$ & - & - \\
\hline Solar cell production & 7 & $1223 \mathrm{MW}$ & 2 & $170 \mathrm{MW}^{43}$ \\
\hline Module production & 19 & $1569 \mathrm{MW}$ & 2 & n.a. \\
\hline \multicolumn{5}{|l|}{ Thin-film Technologies } \\
\hline Silicon thin film & 10 & $405 \mathrm{MW}$ & 1 & Pilot \\
\hline CIS technologies & 11 & $320 \mathrm{MW}$ & 1 & Pilot \\
\hline CdTe & 3 & $237 \mathrm{MW}$ & - & - \\
\hline Poly-Si & 1 & n.a & - & - \\
\hline GaAS & 1 & $100 \mathrm{MW}$ & - & - \\
\hline OPV & 1 & - & - & - \\
\hline \multicolumn{5}{|c|}{ Concentrated PV (CPV) } \\
\hline CPV cells & 2 & $25 \mathrm{MW}$ & - & - \\
\hline \multicolumn{5}{|l|}{ Fully integrated } \\
\hline Wafer/Cell/Module & 4 & $1780 / 1$ 110/475 MW & - & - \\
\hline \multicolumn{5}{|l|}{ PV \& Thermal } \\
\hline PV \& Thermal & 4 & n.a. & - & - \\
\hline \multicolumn{5}{|l|}{ System Technology } \\
\hline $\begin{array}{l}\text { Inverter for grid } \\
\text { connection }\end{array}$ & $>15$ & $>4000 \mathrm{MW}$ & $>3$ & n.a \\
\hline
\end{tabular}

Source: the data used in the table were derived from German Trade \& Invest and from websites of Dutch companies

Most of the Dutch companies are new entrants into the PV industry; many of the current companies have been founded in the last 6 years. As the Dutch market is small, the manufacturers are focussing on foreign markets (in particular Germany), e.g. Scheuten Solar has supplied products to the German market since 2003. Dutch companies are also benefiting from the German tariff systems and innovation policies. Solland Solar for example, is located in Heerlen/Aachen on the border between the Netherlands and Germany and obtaining subsidy from two countries.

It is difficult to relate the differences to policy. The wider scope of market activity in Germany is probably related to the size of the market. As Germany did not have an ac-

\footnotetext{
${ }^{43}$ This capacity represents only the production of Solland Solar, APA has a pilot plant.
} 
tive policy for expanding the scope of PV business it can be viewed an indirect effect of German deployment policy for PV.

\subsection{Conclusion and discussion}

In this paper we examined the role of policy in the evolution of technological innovation system and diffusion of PV in Germany and the Netherlands. The main conclusions from our analysis about the role of policy are as follows.

First, the creation of a strong technological innovation system for PV requires market pull besides RTD support. RTD support in the Netherlands was quite considerable; for a certain period RTD support in the Netherlands was significantly higher in relative terms (per capita) than in Germany. A large-scale market is necessary to provide the investment that will make a new technology cost competitive in the long-term and create a technology innovation system around it.

Second, policy support should be consistent and not be erratic. German policies were consistent with the feed-in tariff system offering guaranteed tariffs for a period of 20 years. The "stoplight" policies of the Netherlands were very harmful for the PV sector which oriented themselves to the German market. The fact that the support for PV in Germany was not organised through the government budget, but was paid by consumers of electricity, was an important factor behind the continuity. The financial claims on the government budget made PV support vulnerable to budget cuts in the Netherlands. Support is thus better organised outside the government budget. Interestingly the feedin system was not specially created for PV but was already in place for other technologies. PV benefited from the existence of feed-in tariffs created for small hydropower and wind power (positive spillover). In the Netherlands PV actors also lobbied for a feed-in system, unsuccessfully. Perhaps if they had joined forces with other renewable energy technology actors they would have been more successful.

Third, when giving support to a fledging technology the regulator should make sure that the level of support is not too low or too high. A too high level of support will result in windfall profits, whereas too low levels will result in very low levels of investment. In a dynamic world in which energy prices are changing and technologies are improving (thanks to innovation) policy support should be dynamic. Germany had a more sophisticated system of adjusting support. To this we should add that the German system of feed-in tariffs has been criticised for being a very expensive system for achieving carbon reductions and creating jobs.

Fourth, policy should be mindful about interaction effects. In Germany PV development is partly promoted for industrial policy reasons, which helped to make the support sys- 
tem more consistent and less erratic. Dutch fiscal policy is constant a source of disruption. In Germany PV development was insulated from government budget decisions.

Fifth, the Dutch experience suggests that innovation policy should go beyond research and development and should be oriented towards the creation of a technological innovation system. Possible ways to do this are the fostering of collaboration between research institutes and companies, stimulate knowledge exchange, assist in the creation of strategic intelligence, fund targeted programmes for research and promote the development of skills and knowledge in the education system. PV actors managed to get a privileged position in the Dutch energy transition, but little was done with the road map they produced.

Sixth, the analysis demonstrates the importance of taking into account policy design aspects and the importance of doing a longitudinal analysis for studying the link between innovation and policy. The analysis clearly demonstrates that the details of policy instrument really matter. Interestingly, the source of funding proved to be an important factor for the policy continuity. We also found that innovation policy is coordinated with industry and that the feed-in tariffs are carefully set so as to promote PV and support the fledging PV industry. Future research may want to focus more on the policy making processes (the actors involved, concerns of the different actors, integration of various concerns). 



\section{Chapter 6:}

\section{A comparative analysis of PV innovation systems including international dimensions - \\ The cases of Japan and the Netherlands}





\subsection{Introduction $^{44}$}

One of the main challenges facing our world today is climate change. To reduce the main cause of climate change, $\mathrm{CO}_{2}$ emissions, renewable energy technologies (RETs) should be developed and diffused. However, even though many years of public efforts and government money have been invested in order to speed up the development, diffusion and implementation of renewable energy technologies (RETs), experiences in different countries show that this can be a very slow and tedious process (Negro, Alkemade et al. 2012). As Rosenberg (1976) puts it, at the beginning the new technology is crude, expensive, inefficient, and badly adapted to the existing institutional setting and the ultimate use, which leads to slow diffusion. To accelerate the diffusion of RETs in society it is necessary to break through the current situation of carbon lock-in, and have more detailed knowledge of how the development and diffusion of RETs takes place (Unruh 2000).

In this paper we focus on the development and diffusion of Photovoltaic solar energy (PV) in Japan and the Netherlands. PV is one of the most promising renewable energy technologies (Verbong, van Selm et al. 2001, Aberle 2006, Jacobson and Delucchi 2009). For years, Japan has been a frontrunner in the development and implementation of PV being the global leader in solar cell shipment and cumulative installed capacity ${ }^{45}$. This is in sharp contrast to the Dutch situation which knows a long history of policy efforts to stimulate the PV industry and implementation of PV, but the results in terms of diffusion of PV panels is low (Negro, Vasseur et al. 2012). Both countries have the goal to create a strong economic sector around PV that contributes to sustainable energy production. The target for PV installed capacity in Japan by 2020 is $28 \mathrm{GW}$ (Yamamoto and Ikki 2010). In the Netherlands, the goals for 2020 are an overall emission reduction of $30 \%$ in 2020 as compared to 1990 , a $20 \%$ share of renewables and 100,000 roofs must be fitted by solar panels (AgentschapNL 2009).

We will compare the strengths and weaknesses of both countries and draw lessons from the Japanese case for the Dutch case. To compare the performance of an emerging technology in two different countries the perspective of technological innovation systems (TIS) will be used as described by Markard and Truffer (2008). The purpose of analysing a TIS is to evaluate the development of a particular technological field in terms of the structures and processes that support or hamper it (Hekkert, Suurs et al. 2007, Bergek, Hekkert et al. 2008, Markard and Truffer 2008). A TIS is especially suitable for the analysis of emerging technologies as it allows to study how the configuration of

\footnotetext{
${ }^{44}$ Since the chapter was originally written in article-format, the theoretical section, methodological section and the description of the PV case partly overlap with Chapter 3 and Chapter 4. However, by combining the Dutch PV case with the new Japanese PV case, the chapter reveals an interesting picture of the influence of international factors in the development of this emerging technology.

${ }^{45}$ In the year 2011 Japan was surpassed by Italy and the USA in terms of cumulative installed capacity while solar cell production and exports were taken over more and more by China (IEA-PVPS, 2011).
} 
actors, networks and institutions changes over time as the technology develops (Carlsson 1997, Coenen and Diaz Lopez 2010). A dynamic approach has been developed where the key processes within the TIS are mapped over time. This approach is called the 'Functions of the Innovation Systems approach' (Johnson 1998).

In our paper we will show how a TIS study can have a national TIS as a focal point but include relevant international factors that influence the system.

By mapping and measuring the key processes within a TIS we can identify the drivers and barriers that trigger or hamper the development, diffusion or implementation of innovations. This approach was adopted by Dutch policy makers that seek to induce and accelerate the diffusion and adoption of RETs (Min Ez 2008, AgentschapNL 2010).

This brings us to the following research question:

How did the Japanese PV TIS develop and which lessons can be drawn for the Dutch PV TIS?

The paper is structured as follows. An overview of the background of the TIS approach and the system functions concept is given in section 2. The methodology applied is then described in section 3. In section 4 the functioning of the Japanese and Dutch PV TIS will be described. These systems are then assessed and compared in section 5 . Section 6 concludes with the lessons learned from the Japanese case for the Dutch case and some points for discussion.

\subsection{Theoretical framework}

The most important insight that has dominated the field of innovation studies in recent decades is the fact that innovation is a collective activity. It takes place within the context of a wider system. This wider system is coined 'the innovation system' or 'the innovation ecosystem'. In the literature innovation systems have been defined with different foci (Markard and Truffer 2008, Coenen and Diaz Lopez 2010). The sectoral system of innovation (SSI) as defined by Malerba (2004) includes multiple technologies and transcends geographical boundaries; the boundaries are set on the basis of existing products and product groups. However, for an emerging field such as renewable energy technologies, where the technology and market are uncertain, boundaries cannot be set ex-ante as important factors and actors driving innovation would be missed out as they still need to develop/come in place (Coenen and Diaz Lopez 2010). The technological innovation system (TIS) approach appears to be better equipped to deal with this state of emergence (Nygaard, Pogutz et al. 2008, Coenen and Diaz Lopez 2010).

A TIS can be defined "as the set of actors and rules that influence the speed and direction of technological change in a specific technological area" (Hekkert, Suurs et al. 
2007, Bergek, Hekkert et al. 2008, Markard and Truffer 2008). The success of innovations, or in our case, PV technology46, is to a large extent determined by how the TIS is built up and how it functions (Hekkert, Suurs et al. 2007, Bergek, Jacobsson et al. 2008). A technology, or the knowledge it embodies, is hardly ever embedded in just the institutional infrastructure of a single nation or region, since - especially in modern society - the relevant knowledge base for most technologies originates from various geographical areas all over the world (Hekkert, Suurs et al. 2007). Technological systems typically cross geographic as well as sectoral boundaries (Hekkert, Suurs et al. 2007), and can sometimes have more international than national characteristics. However, country boundaries remain important since, especially in a newly developing TIS, national policies and knowledge exchange with other actors within the same region or country are required to develop the technology further and bring costs down. As (e.g. Kamp, Smits et al. 2004) show, a home market and proximity to other relevant actors is an important facilitator for knowledge exchange and therefore for innovation. Furthermore, when, within an international TIS, in a specific country both R\&D, production and implementation of a technology take place, in our view this can be conceptualised as a national TIS (as part of an international TIS).

Also for the case of PV in Japan and the Netherlands, the technology is still in development, which makes government support and knowledge exchange with local and national actors important. Also, in both countries both R\&D, production and implementation of PV technology take place and there are explicit national goals and policies. However, especially in recent years, international competition between PV companies is increasing, and new export markets are opening up. For our analysis we therefore choose to focus on TIS within a specific nations, Japan and the Netherlands, in order to be able 'to compare the performance of technological systems ${ }^{47}$ in different countries' (Markard and Truffer 2008, p 601), but to also include international aspects in our theoretical framework. We conceptualise PV within a specific country as a national TIS with input and output flows into and out of the TIS to the international context. The input and output flows we consider, based upon (Binz, Truffer et al. 2012, p 158), are import and export of the technology, foreign direct investment and knowledge exchange in international joint ventures, international research cooperation, and international conferences. The explicit inclusion of international dimensions is new to the TIS approach and has only been applied once before in Binz et al (2012). In the conclusion and discussion section

\footnotetext{
${ }^{46}$ There are several varieties of solar cell designs with different performance and cost features. The so-called first generation technology uses the crystalline silicon (c-Si) cell. It is reliable and typical conversion efficiencies are $15-20 \%$, while costs are high due to the need of large amounts of very pure silicon. Second generation PV technology denotes the use of thin-films, and is aiming at reaching low-cost devices with acceptable efficiencies (e.g. amorphous silicon, cadmium telluride, dye-sensitized solar cell. Third generation solar cells are mostly existing in the research laboratories only.

47 'Technological systems' is here referred to as TIS.
} 
we will show the added value of the inclusion of the international dimension for understanding the dynamics of a national TIS.

According to Carlsson and Stanckiewicz's (1991) definition of a TIS, Bergek et al (2008) claim that 'the TIS consists of three structural components: actors, networks and institutions' (p.81). The actors include firms within the whole value chain (Porter 1985), as well as universities, industry organisations, intermediary organisations, NGOs and government bodies and by entering the TIS each actor brings its specialised knowledge (Bergek, Hekkert et al. 2008). The networks can be both 'learning networks', which can link suppliers with users, related firms, competitors or researchers, and/or 'political' networks or advocacy coalitions (ibid.). The networks are important because they link the different actors, but also influence the expectations of the future, share a set of beliefs and seek to influence the political agenda. These are important processes because a new technology needs to gain ground and engage in the wider political debate in order to be successfully diffused and implemented. The third component, institutions, is at the heart of the process whereby new technologies gain ground (ibid.). As Van de Ven and Garud (1989) put it: 'firms compete not only in the marketplace, but also in the political institutional context. Rival firms often cooperate to collectively manipulate the institutional environment to legitimise and gain access to resources necessary for collective survival' (p.210). The formation of a new TIS involves the build-up of these three structural processes (Bergek, Hekkert et al. 2008, p.82): (1) entry of firms and other organisations, (2) formation of networks and (3) institutional alignment, which implies changing the institutional context in such a way that it legitimises the TIS and provides access to resources necessary for the survival and growth of the TIS (Van de Ven and Garud 1989). However in order to assess the 'goodness' of a particular structure other than relating it to an outcome in terms of diffusion (e.g. cumulative PV panel installation), the weaknesses within a TIS need to be identified (Bergek, Hekkert et al. 2008). Only then can appropriate guidelines for the various actors be identified. Therefore to assess the performance of a TIS a second level of key processes needs to be introduced that bridges the gap between structure and performance: the 'functions of innovation systems' or in short 'system functions' (Hekkert, Suurs et al. 2007, Bergek, Hekkert et al. 2008). The system functions address what actually happens in the TIS and have a direct influence on the ultimate performance of the system (ibid.). This paper uses the list of system functions developed at Utrecht University that has been derived from literature and applied to many empirical studies (see Hekkert, Suurs et al. 2007 for a more elaborate description) and which relates closely to the list used by other researchers (Bergek, Jacobsson et al. 2008).

Entrepreneurial activities refer to the process of technological variety creation by means of experimenting with and producing new technology. Knowledge development is necessary in the innovation system to feed entrepreneurial experimentation and to learn how 
technological options can be developed for optimal success in the market. This learning process often involves multiple actors and therefore knowledge exchange is another key process. Guidance of the search relates to goals, targets and expectations and is important to align the visions of different actors in the innovation systems regarding the desired future. This reduces uncertainties and stimulates focus and mass. Market formation is necessary since the initial advantages of new technologies tend to be small due to high costs and technological imperfections. The process of mobilisation of resources refers to financial, human and physical capital resources that are critical inputs for innovation processes. Creation of legitimacy refers to increasing the legitimacy of new technological trajectories in order to overcome inertia in institutional structures and resistance by actors that benefit from the current status quo.

Both the individual fulfilment of each system function and the interaction dynamics between them are of importance, as well as the structural processes explained above. When more system functions are fulfilled the expectation is that there will be a better performance of the TIS which results in higher chances for successful development, diffusion and implementation of new technologies. However if the system functions are not fulfilled the performance of the TIS will be hampered. By identifying the malfunctioning system functions, handholds can be identified in order to develop policy instruments that accelerate the diffusion and implementation of RETs (Hekkert, Suurs et al. 2007, Bergek, Jacobsson et al. 2008).

\subsection{Methodology}

The methodology that is used in this paper to put the TIS theory into practice is divided into three steps. The first step consists of investigating the structural components of the PV TIS within both countries in terms of the character and constellation of actors, networks and institutions.

In the second step the focus shifts towards the fulfilment of the individual system functions. Basically, the approach consists of collecting events and to allocate those by indicators to the respective system function, see Table 12. This list varies slightly from previous studies (e.g. the studies of Negro (2007) and Suurs (2009)) as international aspects are also taken into account. These international aspects are, as explained in section 2, conceptualised as the following input and output flows: import and export of the technology, foreign direct investment and knowledge exchange in international joint ventures, international research cooperation, and international conferences. These input and output flow are attributed to the system functions through adding them as indicators: export activities as an indicator for entrepreneurial activities, import shares as an indicator for market formation, international knowledge exchange during joint research projects, conferences and seminars as an indicator for knowledge exchange, foreign direct investment as an indicator for resource mobilisation. As mentioned above, the 
structural components identified in the paper are those within the borders of each country.

Data is collected via desk research (academic and professional journals, newspapers, reports, and websites) and interviews with companies, organisations and experts in the field. This paper builds partly on the same data as Negro et al (2012) ${ }^{48}$, but extends data and analysis on more recent events (2011-2012) such as institutional conditions and international factors have also been included in this paper. The data on the Japanese PV TIS is new and not earlier published and runs from 2000 till 2011. In this paper a short overview of the individual system functions fulfilment for the Dutch PV TIS will be highlighted. By presenting the material per system function a direct comparison with the Japanese data and lessons learned will be possible.

In the third step the assessment of innovation systems and the comparison is provided; here the link is made between the results of the analysis of the structure and the functioning of the TIS. The interrelation between the system functions is investigated by observing positive and negative interactions; we determine the presence of virtuous and vicious cycles and their main causes. Then we compare the two cases and represent the main similarities and differences in table 3. Based on the differences in the cases we draw lessons learned from the Japanese case for the Dutch case.

Table 12. Table of indicators per system function.

\begin{tabular}{llc}
\hline Function & Indicator & Sign \\
\hline Function 1: & Organisations or companies entering/leaving the market & + /- \\
Entrepreneurial activities & Size of companies & + /- \\
& Export activities & + - \\
Function 2: & Research and technological projects & + -- \\
Knowledge development & Demonstration and pilot projects & + -- \\
& Learning by doing and learning by using & + -- \\
Function 3: & National knowledge exchange between organisations (e.g. via & + \\
Knowledge exchange & workshops, conferences, joint projects) & + \\
& International knowledge exchange (e.g. in joint research projects, & + +- \\
Function 4: & international conferences or seminars) & + - \\
Guidance of the search & Targets set by the government of industry & + Expectations and opinion of experts (positive/negative) \\
Function 5: & Financial market incentives (regulation/stimulation programmes) & + +- \\
Market formation & Regulations / tax regimes & + -
\end{tabular}

\footnotetext{
${ }^{48}$ In that paper the development and diffusion of the PV TIS are investigated over time and functional patterns are identified over time. The data are in a narrative storyline over several time periods $(1970-2010)$ and not per individual system function. Motors of innovation as labeled by Suurs (2009) are analysed by observing reoccurring sequences of events.
} 


\begin{tabular}{|c|c|c|}
\hline Function & Indicator & Sign \\
\hline & Import share & $+/-$ \\
\hline \multirow[t]{4}{*}{$\begin{array}{l}\text { Function 6: } \\
\text { Resource mobilisation }\end{array}$} & $\begin{array}{l}\text { Financial resources (e.g. subsidies for and investments in the } \\
\text { technology) }\end{array}$ & $+/-$ \\
\hline & Human resources & $+/-$ \\
\hline & Physical resources & $+/-$ \\
\hline & Foreign direct investment & + \\
\hline \multirow[t]{2}{*}{$\begin{array}{l}\text { Function 7: } \\
\text { Creation of legitimacy }\end{array}$} & $\begin{array}{l}\text { Extent to which the technology is promoted by organisations, } \\
\text { government (awards, brochures, competitions) }\end{array}$ & \\
\hline & Lobby activities for/against the technology & $+/-$ \\
\hline
\end{tabular}

\subsection{Results}

PV in Japan

\section{TIS structure}

In Japan a very large number of actors are active in the PV TIS. The system includes about 41,300 jobs (about 800 in R\&D within research organisations, about 8,500 in manufacturing of products throughout the value chain, and about 32,000 other jobs) (Yamamoto and Ikki 2011). The main companies involved are large and strong companies such as Sharp Corp., Kaneko, Fuji Electric Systems, Hitachi, Kyocera, Mitsubishi Group. Since a dip in the growth of the Japanese PV market in the years 2006-2008 Japanese entrepreneurs have turned towards foreign markets. However, their dominant position is increasingly challenged by successful new international entrants both in China and Europe. PV has a large research base in Japan. A large part of this research is performed by the large manufacturing companies, sometimes in collaboration with manufacturing equipment companies. The main organisations that perform research into crystalline silicon are: AIST (national research institute), several universities, Mitsubishi, Kyocera, Hitachi and Sharp Corp. (RTS Corporation 2008, Yamamoto and Ikki 2011). The national government's energy policy is executed by the Ministry of Economy, Trade and Industry (METI). Within METI the Agency for Natural Resources and Energy (ANRE) is responsible for maintaining a stable energy supply. The New Energy and Industrial Technology Development Organisation (NEDO) is the main subsidy provider of the government, for the most part research subsidies. The demand side is composed of residential home owners (85\% in 2011), housing companies and a number of other companies (Yamada and Ikki 2012).

Political networks, advocacy coalitions that lobby to the government, are formalised in Japan. The government mostly receives input from outside actors such as industry through advisory committees. The main intermediary actor is the Japanese PV branch organisation, JPEA, which plays an important role in these networking and lobbying ac- 
tivities (JPEA 2012). Learning networks are strong, consisting of research organisations and companies, and have had a very positive effect on PV development in Japan.

The institutions have played an important role during the last decades with strong and consistent policies. The Japanese 'PV 2030 Roadmap' provides specific research goals for each PV technology, in the form of conversion efficiency targets and production cost of modules. The Roadmap's overall target is to make PV generation cost equal to the level of thermal power generation by 2030, so-called grid parity. The target for PV installed capacity in Japan by 2020 is $28 \mathrm{GW}$ (Yamamoto and Ikki 2010).

\section{System functions fulfilment}

\section{Function 1 Entrepreneurial activities}

Over 3,710 MW of solar cells and modules are produced by Japanese companies in 2010, providing 41,300 labour places (Yamamoto and Ikki 2011). Though the Japanese PV production volume is enormous, a relatively small number of companies are involved in production. The Japanese companies are listed as important PV cell and module manufacturers (see Table 13 for an overview) (Yamamoto and Ikki 2010). These companies are subsidiaries of large group companies such as Sharp Corp., Mitsubishi Group and the Kyocera Group. The growing market has attracted new firms, such as Sanyo (1997) to the development and production of PV (IEA-PVPS 2007). Despite the large domestic market, practically all of the companies are currently focusing on foreign markets, in particular Germany, due to the highly profitable large-scale market present there (Kaizuka 2008, Vasseur and Kemp 2011). However, on the international market and on their home market, Japanese producers are also losing ground to new players such as companies from mainly China and Germany (Marketbuzz 2008, Yamada and Ikki 2012). Export shares decreased between 2009 and 2011 from 79\% of production to less than $50 \%$ (Movellan 2012). In order to bring production costs down, some Japanese manufacturers outsourced their production facilities to countries such as China and Malaysia (Movellan 2012).

Table 13. Production capacities by solar cells and PV module manufacturers (Yamamoto and Ikki 2010).

\begin{tabular}{|c|c|c|c|}
\hline & \multirow[t]{2}{*}{ Technology } & \multicolumn{2}{|c|}{$\begin{array}{l}\text { Maximum production capacity } \\
\text { (MW/year) }\end{array}$} \\
\hline & & Cell & Module \\
\hline \multicolumn{4}{|c|}{ Silicon Wafer-based manufacturers } \\
\hline Sharp & $\mathrm{sc}-\mathrm{Si} ; \mathrm{ms}-\mathrm{Si}$ & 550 & - \\
\hline Kyocera & ms-Si & 500 & 500 \\
\hline SANYO Electric & a-Si / sc-Si ; a-Si & 345 & 140 \\
\hline Mitsubishi Electric & $\mathrm{ms}-\mathrm{Si}$ & 220 & 220 \\
\hline Space Energy & Bifacial sc-Si & - & - \\
\hline Clean Venture 21 & Light-collecting spherical Si & - & - \\
\hline
\end{tabular}




\begin{tabular}{|c|c|c|c|}
\hline & \multirow[t]{2}{*}{ Technology } & \multicolumn{2}{|c|}{$\begin{array}{l}\text { Maximum production capacity } \\
\text { (MW/year) }\end{array}$} \\
\hline & & Cell & Module \\
\hline MSK (Suntech Power Japan) & $\mathrm{C}-\mathrm{Si}$ & - & - \\
\hline Fujipream & $\mathrm{sc}-\mathrm{Si} ; \mathrm{ms}-\mathrm{Si}$ & - & 24 \\
\hline Choshu industry & $\mathrm{sc}-\mathrm{Si} ; \mathrm{ms}-\mathrm{Si}$ & - & 5 \\
\hline \multicolumn{4}{|l|}{ Thin-film manufacturers } \\
\hline Sharp & $\mathrm{a}-\mathrm{Si} / \mu-\mathrm{Si}$ & 160 & \\
\hline Kaneka & a-Si ; a-Si / poly-Si hybrid & 70 & 70 \\
\hline $\begin{array}{l}\text { Mitsubishi Heavy Industries } \\
\text { (MHI) }\end{array}$ & $\mathrm{a}-\mathrm{Si}$ & 68 & 68 \\
\hline Fuji Electric Systems & $\mathrm{a}-\mathrm{Si}$ & 17 & 17 \\
\hline Solar Frontier & $\mathrm{CIS}$ & 80 & 80 \\
\hline Honda Soltec & CIGS & 27.5 & 27.5 \\
\hline
\end{tabular}

\section{Function 2 Knowledge development}

Japan spent 32 million Euros on R\&D in 2009, third place after the United States and Korea (IEA-PVPS 2010a). The country has been investigating solar cells since the Sunshine Project was initiated in 1974, and has established quite a reputation for its PV research. Most of the research is performed by the PV manufacturers, including basic research. Most PV companies are large consortia who each have their own research centre. PV research is funded through the government-sponsored NEDO research projects, which include basic and applied research (learning by searching). In 2009, four projects under the control of the Ministry of Economy, Trade and Industry (METI) were conducted by NEDO; i) Research and Development of Next-generation PV Generation System Technologies, ii) Research and Development of Common Fundamental Technologies for Photovoltaic Generation Systems, iii) Development of Technologies to Accelerate the Practical Application of Photovoltaic Power Generation Systems, and iv) Research and Development on Innovative Solar Cells (Yamamoto and Ikki 2010, IEA-PVPS 2010a, IEA-PVPS 2010b). In 2011, the Japanese were ranked second world wide concerning patents for photovoltaics (Ecofys 2012).

In Japan a lot of knowledge has also been gained from solar cell manufacturing. Production of solar cells has been going strong for 50 years in Japan, since Sharp started massproduction in 1963 (Watanabe 2007). Large production cost reductions have been achieved in this time. Between 1994 and 2009 the system price per killowatt dropped over 75\% (resp. 23.13 and 5.,06 Euro/W) (Yamamoto and Ikki 2010). This reduction suggests that learning by doing processes have taken place.

Learning by using is promoted through the large domestic market of 9,845 MW total installed PV capacity in 2009 (IEA-PVPS 2010a), the international market and the NEDO Field Test projects, in which end user feedback in the form of operational data is gathered and published. 


\section{Function 3 Knowledge exchange}

In Japan, interest in research collaboration between companies is decreasing as the main PV technologies have become more advanced. However, collaboration in governmentsponsored NEDO research projects is continuing. The projects' patenting structure is beneficial to knowledge exchange while keeping in line with companies' secrecy requirements $^{49}$ (Kushiya 2008). Formalised knowledge exchange methods such as publishing in and reading scientific journals, and visiting seminars and symposia are plentiful in Japan. The seminars and symposia are important, not just for the presented information, but also the opportunity to get in touch with other researchers. Also the monthly meetings of the 'society for PV systems' are big events that attract about 200 - 300 people from industry and universities (Yoshikawa 2008 ). International knowledge exchange in the form of international project collaboration and participation in international conferences is limited, however. The 'Japanese PV branch organisation' JPEA has an important role in the exchange of information within Japan. It organises many seminars and events on a wide variety of topics, it promotes collaboration between actors in the system and provides many opportunities for actors to meet one another and is an important sparring partner for the government (JPEA 2008).

\section{Function 4 Guidance of the search}

Japan is internationally well-known for its reduction goals such as those described in the Kyoto Protocol. In 2007, the prime minister declared a new goal of cutting greenhouse gas emissions by $60-80 \%$ from current levels by 2050 , which goes further than any other country (Reuters 2008). Also the expectations for the development and diffusion of PV in Japan are high. There is high confidence in the continuation of the government's research projects towards its 2030 goal of grid parity (Smets 2008) ${ }^{50}$.

The government has a strong research policy for renewable technologies, in particular for PV in the form of the 'PV 2030 Roadmap', which provides specific research goals for each PV technology, in the form of conversion efficiency targets and production cost of modules. As mentioned above, the Roadmap's target is grid parity by the year 2030. It is also incorporated in the government's New National Energy Strategy ${ }^{51}$ and is used as a basis for the NEDO research projects (ANRE 2006). It is widely supported by government, academic and industry circles. NEDO reviewed the PV Roadmap 2030 to establish new

\footnotetext{
${ }^{49}$ NEDO projects are national projects and as such in general the research results need to be made public. However, with patents from NEDO projects the situation has changed over the years. Before 1992, all patents that came out of NEDO projects belonged 100\% to NEDO. In the period 1992-1996 the patents were owned $50 \%$ by the company and $50 \%$ by NEDO. Since the Baido law of 1996 the patents are $100 \%$ entrusted to the company (Kushiya, 2008).

${ }^{50}$ By 2013, parts of Japan are expected to reach grid parity (Breyer and Gerlach, 2012).

${ }^{51}$ The government's New National Energy Strategy aims at energy security and sustainability and includes the New Energy Innovation Plan.
} 
projects from 2010 and released a new roadmap, PV 2030+, in June 2009. This new roadmap has postponed the target year by three to five years ahead of schedule originally set in PV 2030, looking towards 2050. The government also increased the target for PV installed capacity in Japan by the year 2020 from 14 GW to 28 GW (IEA-PVPS 2010a, IEA-PVPS 2010b).

\section{Function 5 Market formation}

The Japanese domestic market is one of the largest in the world. In 2011, cumulative installed capacity was $4.9 \mathrm{GW}$ and during that year an additional $1295.8 \mathrm{MW}$ was installed (Yamada and Ikki 2012). The residential market is by far the largest of part of the market for PV and has increased enormously under the government's installation subsidy, the 'Residential Dissemination Programme', which ran from 1993 up to 2005 (JPEA 2006). The scheme provided home owners with an installation subsidy; however, the amount decreased as production costs decreased. As such the price that home-owners had to pay for a PV installation has barely changed under the scheme. Even with the voluntary buy-back of power by the utilities since 1992, the expected pay-back period for a PV installation remained 20 years. For reference, the expected lifespan of a house in Japan is also 25 - 35 years (Jäger-Waldau 2007).

The industrial and public markets have some procedural and installation difficulties, which might be solved through the Field Test projects ${ }^{52}$. There are good prospects for businesses however large-scale projects and power plant type installations are rare. The public market is mainly being promoted through several government projects. An important government law which promotes renewable energy use is the 'Renewable Portfolio Standard' (RPS) law, enacted in 2002. It obliges electric power companies to expand the use of electricity generated from new and renewable energy. The required amount is set every year, for instance 0.73\% in 2006 (Watanabe 2007). In 2007 the RPS law was revised in order to become more beneficial for PV; an especially preferred measure for PV was added, where electricity generated by PV was counted double (Ikki and Matsubara 2007).

\footnotetext{
52 Field Test Projects such as the "Field Test Project on New Photovoltaic Power Generation Technology" project are aimed at the adoption of new technologies into PV systems for public and industrial facilities and accelerating further developments while promoting further introduction of medium and large-scale PV systems and acquiring feedback from end users (IEA-PVPS 2007).
} 


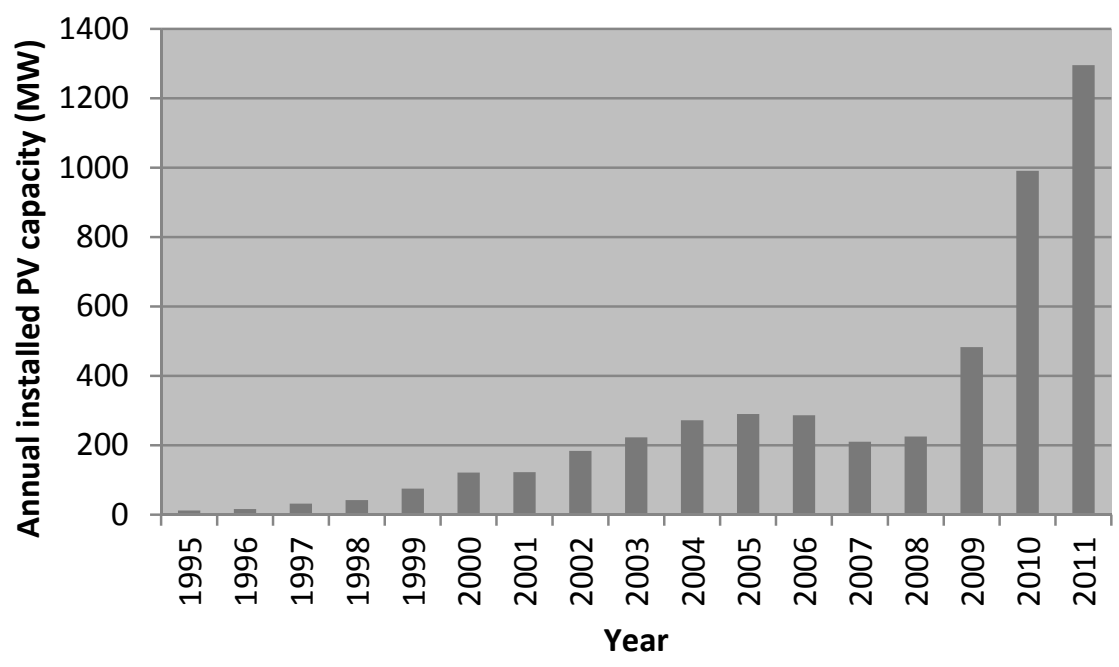

Figure 20. Annual installed PV capacity in Japan 1995-2011.

The overall market growth decreased after 2005 as can be seen in Figure 20 This decline can be explained by the stop of the residential dissemination programme and the price increases due to material shortages (e.g. silicon) (Hasan 2009). In January 2009, a new residential subsidy programme for residential PV systems with a budget of 9 billion yen (around 76 million Euros) for 35,000 systems was announced. The accelerated growth in 2009 (see Figure 20) can be explained by the restart of this subsidy programme and by the start of a new programme to purchase surplus PV power (July 2009), based upon the 'Act on the Promotion of the Use of Non-Fossil Energy Sources and Effective Use of Fossil Energy Source Materials by Energy Suppliers' (Photon International 2009, IEA-PVPS 2010a). In response to the resumption of the subsidy programme for residential PV systems by the Ministry of Economy, Trade and Industry (METI), over 500 municipalities started implementing their own support programmes for residential PV systems (IEAPVPS 2010a) and consequently, installed capacity has grown fast again in 2009 and 2010 (Yamamoto and Ikki 2010, Yamamoto and Ikki 2011). On this home market Japanese companies are facing growing competition from foreign manufacturers, especially Chinese (Yamada and Ikki 2012). In the period 2008-2011, the import share of the modules installed in Japan increased from 0\% to almost 20\% (Movellan 2012).

\section{Function 6 Resource mobilisation}

Regarding financial means, the main PV manufacturing companies are subsidiaries of large holdings and as such can bear the financial burden of research and development. Long-term government research projects (e.g. the Sunshine Project) have proven to be good sources of funding (Kurokawa 2008). These projects have helped to overcome the expensive development period between research results and prototype or product, as 
all of the main PV companies, with the exception of Honda, developed their product in a government-sponsored project (NEDO) (Tanaka 2007). In recent years, foreign direct investment (FDI) into the Japanese PV sector has increased significantly (Nagashima 2011).

Japan seems to have no major problems with the supply and quality of staff in research organisations and companies. Companies train nearly all their researchers in-house (Kaneka 2008). A future problem in the availability of human capital may lie in Japan's low birth-rate (Head 2004).

The main physical resources which are or might become scarce in the market are silicon and indium. The silicon shortage was a major issue for several years for companies and has already led to problems for several companies. Sharp Corporation saw its production slump due to its inability to acquire a sufficient silicon supply (Kurokawa 2008). However the shortage is largely resolved as four companies manufacture polysilicon for the feedstock for solar cells ${ }^{53}$. Indium is a rare metal but is of vital importance for the creation of $\mathrm{CIS}$ solar cells. The amount of Indium required by the solar cell industry is still very small as compared to flat panel displays (Kushiya 2008). However some experts say the supply will become a constraint if production is increased rapidly (Smets 2008).

\section{Function 7 Creation of legitimacy}

Lobby activities mostly take place behind closed doors (Arakawa 2008, Kurokawa 2008). There are no large well-known customer organisations or 'green' political parties; however there are no indications that this lack forms a problem. Government regularly receives input from outside actors such as industry and academia through ever-present advisory committees (Arakawa 2008, Kurokawa 2008). The government's goals and policies in general are not top-down but are made in conjunction with relevant parties. A good example of the way advice-giving is incorporated in the structure of government offices can be found in the government's subsidy provider: NEDO. NEDO is not staffed with specialists from specific technological fields. As such the institute does not have the necessary knowledge to judge the highly technical proposals that come in. These evaluations are done by committees of experts which are made up of academic and company researchers. This automatically gives academic and industry researchers a significant influence over the future direction of PV in Japan (Arakawa 2008, Kurokawa 2008).

The main organisation which brings Japanese PV parties together, the JPEA, consists of a wide range of organisations including: PV manufacturers, equipment manufacturers, engineering companies, research institutes, power companies and raw material suppliers. The JPEA has an important role within the lobby activities of the PV sector. However, consumers and representers of the general public do not appear to be part of the JPEA

53 (1) Tokuyama (production capacity: 9,200 t/year), (2) Mitsubishi Materials (production capacity: 1,800 t/year), (3) OSAKA Titanium technologies (production capacity: 1,400 t/year), and 4) M. SETEK (production capacity: 3,000 t/year). 
(JPEA 2012) which implies that they do not have a say in the development of visions and goals related to $\mathrm{PV}$.

\section{Assessment of the Japanese PV TIS}

Two virtuous cycles can be distinguished in the Japanese PV TIS: a knowledge development cycle and an implementation cycle. The knowledge development cycle is as follows: Firstly, there is strong guidance (F4) in Japan for PV research activities through the PV2030 Roadmap and financial resources (F6) are made available for knowledge development (F2). The performed research and insights from test projects (F2) increases support for the technology (F7) and expectations of the technology's capabilities to fulfil the government's reduction targets (F4). This reinforces government support for further financial endorsement (F6) for knowledge development (F2).

The implementation cycle, which runs parallel to the knowledge cycle, also starts with government goals for implementation of the technology (F4), which are supported by market stimulation measures (F6) resulting in the growth of the home market (F5). This growing market, and growing export markets, increase entrepreneurial activities in terms of new companies entering the TIS and existing companies expanding their production activities (F1). It also attracts companies from outside Japan. This growing number of firms on the one hand leads to more input into the governmental target setting and formulation of support programmes (F7), which stimulates availability of support programmes and stimulation measures (F6) for a further market growth (F5). On the other hand, the growing number of firms also directly leads through marketing strategies, to expansion of both domestic and Japanese export markets (F5). Furthermore, growth in the Japanese home market attracts foreign companies, which also increases the implementation of PV within Japan and the competition between the firms (Kamp, 2008a).

PV in the Netherlands

\section{TIS structure}

A multitude of actors are involved in basic research on and the development of the PV sector. The Dutch PV innovation system included about $622 \mathrm{fte}$ job opportunities in 2010 with approximately̌EUR 0.5 billion turnover and 90\% export (Ecofys 2012). The industry (manufacturing and production) and research (all Universities in the Netherlands are involved in PV research and research organisations TNO and ECN are involved in EU projects on PV) sectors are particularly well developed in the Netherlands. There are several companies, such as Solland Solar, Scheuten Solar, HyET Solar, APA/AST, The Silicon Mine, Mastervolt, Stroomwerk and theSun factory, that are very active within the Netherlands, but are primarily focussed on export ${ }^{54}$. The Netherlands has a strong posi-

\footnotetext{
${ }^{54}$ HeYt Solar has acquired Helianthos in 2012 and will continue to develop the thin-film production technology.
} 
tion in the PV equipment supply industry (Smit Ovens, OTB Solar, Tempress). The main branch organisation is Holland Solar ${ }^{55}$. The national government's energy policy is executed by the Ministry of Economic Affairs Agriculture and Innovation (EL\&l). Within EL\&l, AgentschapNL is responsible for information, financing, networking and implementation of laws and regulations. The Ministry of Education, Culture and Science (OCW) is responsible for funding of research in the Netherlands, mainly through several research councils (such as $\mathrm{NWO}^{56}, \mathrm{STW}^{57}$ and $\mathrm{FOM}^{58}$ ) and the Royal Academny of Sciences $\left(\mathrm{KNAW}^{59}\right.$ ). The demand side is mainly composed of residential home owners and housing companies, 93\% of the total installed capacity is grid connected decentralised in 2010 (Ecofys 2012).

Learning networks are much more prominent than political networks. PV companies, research institutes and universities often interact in specific pilot plant projects or even in commercial applications, thereby strengthening the learning networks. Examples of current learning networks are the Joint Solar Programme (FOM, Shell, Nuon, CW) and Solliance (ECN, TNO, TUe and Holst Centre). A positive aspect of the learning networks is the increased international orientation, allowing more international exchange of knowledge and experience. In contrast, a formal political network cannot be identified in the Netherlands.

The main institutions that are of importance for the future success of PV in the Netherlands are policy goals and programmes. Their inconsistent nature is a severe hindrance for a successful build-up of a PV TIS. The current policy goal of the Netherlands is to develop a strong economic PV sector that in the future will contribute to the environmental and energy goals set for 2020 where an overall emission reduction of $30 \%$ as compared to 1990, a 20\% share of renewable energy must be achieved and 100,000 roofs must be fitted with solar panels (AgentschapNL 2009, Eveleens, de Boer et al. 2011).

\section{System functions fulfilment}

\section{Function 1 Entrepreneurial activities}

Dutch entrepreneurs are small- to medium-sized (SME) companies which are mostly new entrants into the PV industry. Dutch companies are starting and/or expanding pro-

\footnotetext{
${ }^{55}$ The members of the association are companies or organisations active in the field of solar thermal energy or photovoltaic solar energy for small- and large-scale applications; they lobby strongly to the government.

${ }^{56}$ Dutch Organisation for Scientific Research; in Dutch: Nederlandse Organisatie voor Wetenschappelijk Onderzoek.

${ }^{57}$ Technology Foundation; in Dutch: Stichting Technische Wetenschappen.

${ }^{58}$ Foundation for Fundamental Research on Matter; in Dutch: Stichting voor Fundamenteel Onderzoek der Materie.

${ }^{59}$ Royal Dutch Academy of Sciences; in Dutch: Koninklijke Nederlandse Akademie van Wetenschappen.
} 
duction for solar cells and modules and are focusing on foreign markets, in particular Germany due to its large-scale market and favourable financial schemes ${ }^{60}$. Dutch companies also benefit from the German tariff systems and innovation policies. Solland Solar, e.g., is located in Heerlen/Aachen on the border between the Netherlands and Germany and obtains subsidy from two countries (Vasseur and Kemp 2011). Furthermore, there is a strong PV equipment industry in the Netherlands (e.g. manufacturing of semiconductors, glass, coatings, and flat panel displays) (Ecofys 2012).

The export activities are estimated to be three quarters of the Dutch turnover, generated by the solar cell production and machine supplying industry and to a lesser extent production of PV modules and other PV components. More than 95\% of all Dutch power produced by the solar cell industry is exported; the total export value of PV panels is estimated between 191 and 293 million euros (KEMA 2010, Eveleens, de Boer et al. 2011). On the international market, the Dutch companies face fierce competition from countries like China, Korea and Japan. Only the Dutch PV equipment industry and the innovative PV module manufacturer Solar Modules are strongly holding their ground (Ecofys 2012).

\section{Function 2 Knowledge development}

The R\&D based knowledge quality and quantity is high in the Netherlands, as well as being so at an international level (Negro, Vasseur et al. 2012). In 2011, the Netherlands were ranked seventh world-wide concerning patents for PV (Ecofys 2012). Since the construction of the first PV plant in the Netherlands in 1981, many entrepreneurs have set up manufacturing sites and have managed to achieve significant price reductions, which indicates that learning by doing processes have taken place. However as their production volumes are still fairly small, the market cannot yet benefit from reduced prices due to economies of scale. Also learning by using is limited since the number of PV pilot projects and evaluations of the existing solar panels are limited (Negro, Vasseur et al. 2012).

\section{Function 3 Knowledge exchange}

Within the Dutch research community an increasing amount of collaborations is taking place, especially research projects between knowledge institutes (universities and research institutes) and entrepreneurs, both on national and international level. New networks are created to further increase the speed of development and alignment of research activities. These include Solliance (ECN, TNO, TUe and Holst Centre) and the Joint Solar Programme (FOM, Shell, Nuon, CW). The international knowledge exchange is good. ECN, for example, is an important player in international research projects such

\footnotetext{
${ }^{60}$ The wider scope of market activity in Germany is probably related to the size of the market. As Germany did not have an active policy for expanding the scope of PV business it can be viewed as an indirect effect of German deployment policy for PV.
} 
the EU projects Crystal Clear ${ }^{61}$ and PV-TRAC ${ }^{62}$ (Photon International 2004, Duurzame Energie 2004a, Sinke 2008). However, the essential cooperation with the end user is missing (Negro, Sinke et al. 2008) which is a large bottleneck for knowledge exchange. Internationally, Solarplaza (Rotterdam) ${ }^{63}$ has built a worldwide network which has inspired the solar industry to set up an international PV trade mission and expert conferences in e.g. Germany, China, California and India (Sam 2010, Solarplaza 2012).

\section{Function 4 Guidance of the search}

Despite the positive perception of PV and wide range of applications, PV implementation in the Netherlands has been limited so far. The Dutch public is enthusiastic about the self-supplying possibilities of PV but finds the systems expensive and aesthetically unappealing (Vasseur 2012).

A wide variety of support policies for renewable energy has existed over the years, each with a different set-up and budget (Vasseur and Kemp 2011, Negro, Vasseur et al. 2012). However, the support has not been constant over the years which offers no (long term) security at all. This leads to a lot of criticism by industrial actors as they need a stable and long-term policy support to build-up their business strategies and to attract investors.

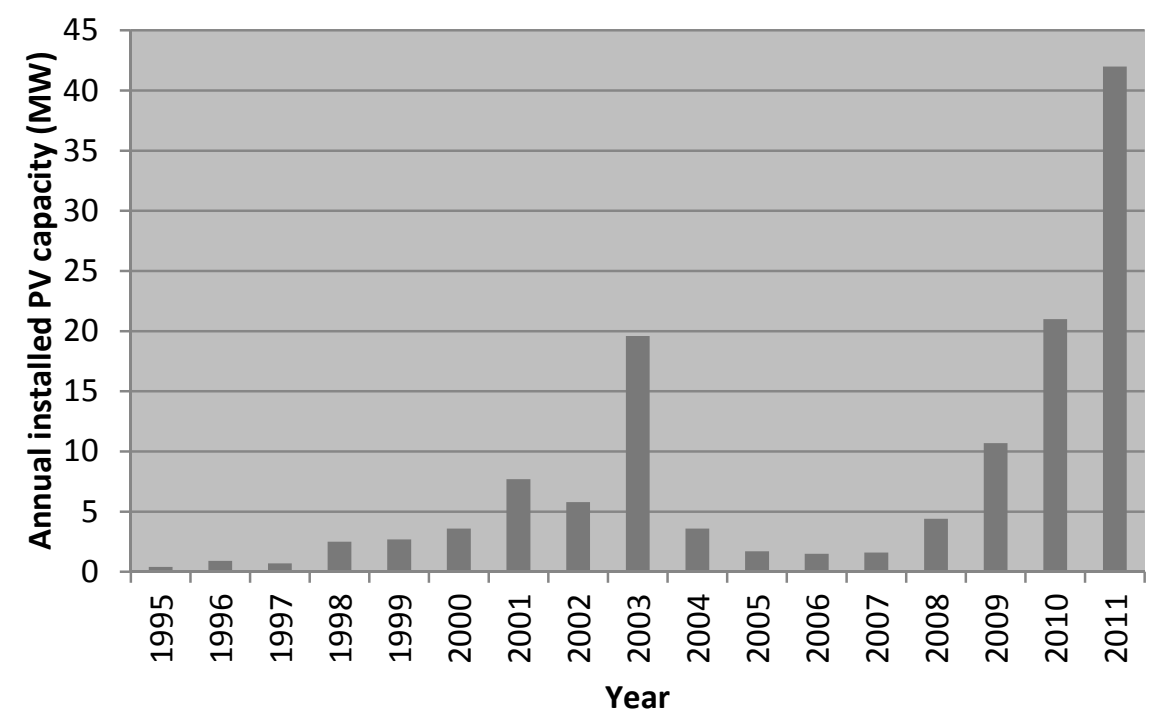

Figure 21. Annual installed PV capacity in the Netherlands 1995-2011.

\footnotetext{
${ }^{61}$ The aim of the programme (2004 - 2009) is to research, develop and integrate crystalline silicon technologies that allow PV modules to be produced at module costs below €1/Wp (Photon International 2004).

62 The aim is to contribute to a rapid development of a world-class cost competitive European PV for a sustainable electricity production (Duurzame Energie 2004a).

${ }^{63}$ Solarplaza is a free platform for the solar industry, providing (free) information and trade, promotion and matching services.
} 


\section{Function 5 Market formation}

Inconsistent national subsidy schemes create uncertainty which is perceived as a major barrier for successful market development of the Dutch PV-market. As a result, Dutch companies move abroad when market opportunities for PV are better and operate predominantly on international markets, as described in Function 1 - Entrepreneurial activities, or they stop their PV activities (KEMA 2010, Van den Akker 2012). Market development has been fairly erratic and the Dutch PV market is seen as a small niche market which mainly attracts small players with a low level of experience (Eveleens, de Boer et al. 2011). However, positive signs are visible, since a total of $43 \mathrm{MW}$ of PV were installed in the Netherlands in 2011, which is a 50\% increase compared to the 2010 level (see Figure 21) (Ecofys 2012). A substantial part of the PV cells and panels sold in the Netherlands are imported (Ecoys, 2012).

PV systems are mostly installed on private houses but also companies that receive subsidy, e.g. SDE ${ }^{64}$, install PV systems on their roofs. In addition to national subsidy schemes, the market for small-scale PV systems is boosted by dedicated Dutch provinces and municipalities that offer extra subsidies (KEMA 2010). Furthermore, a number of new bottom-up initiatives have been set up in 2011 to collectively buy PV panels independent of governmental subsidies. Because of the large amounts of panels bought the price per panel is reduced (Ecofys 2012).

\section{Function 6 Resource mobilisation}

An important problem for Dutch entrepreneurs is the lack of available venture capital (Negro, Sinke et al. 2008). There is sufficient venture capital for relatively large entrepreneurs to do research or to open a factory, but not for small start-ups. The fund from the national subsidy programme (SDE) is insufficient to develop a PV market. Solar cell research is funded through national and international research programmes (e.g. Crystal Clear, PV-TRAC, European PV Technology Platform ${ }^{65}$ and the Joint Solar Programme ${ }^{66}$ ) (eupvplatform.org). The availability of skilled people creates uncertainty as they are in short supply in the Netherlands, due to the discontinuity of subsidies and market growth, and as installers loose know-how and skills if their services are not required.

\footnotetext{
${ }^{64}$ A market implementation programme for renewable energy called 'Stimulation of Renewable Energy Production'. The tariffs for PV are set to 0.33 EUR/kWh (for small-scale systems between $0.6 \mathrm{kWp}$ and $3 \mathrm{kWp}$ ) for a period of 15 years (Vasseur and Kemp 2012).

${ }^{65}$ Aims to mobilise all the actors sharing a long-term European vision for PV e.g. by expressing and explaining the county specific PV Policy.

${ }^{66}$ Aims to carry out fundamental and exploratory research to PV conversion of solar-energy in the NL, and to increase the efficiency.
} 


\section{Function 7 Creation of legitimacy}

The perception of investors is ambiguous towards PV. The green image and the selfsupplying model are seen as positive but the costs are considered as too high (Vasseur 2012). The PV lobby activities in the Netherlands appear to lack strength. There is a shared industry vision for the future of the PV industry which is collected in the Roadmap 'Zon op Nederland'. The roadmap maps the main technologies in the field of solar energy, the largest players, the competitive relations and promising products and market segments (Berenschot 2011). However, the government did not include it in their policies, and the industry appears unable to counteract the governments' inconsistent behaviour.

\section{Assessment of the Dutch PV TIS}

In the case of the Netherlands, we see that not all system functions are equally well fulfilled. The knowledge basis in terms of quality, quantity and exchange (F2, F3) is high in the Netherlands, also caused by the strong international aspects, but there is a lack of guidance of the search (-F4), creation of legitimacy (-F7) and mobilisation of resources (F6) and a small home market (-F5). In addition, entrepreneurial activities are limited because there are a small number of SMEs and (pilot) projects. A learning network and a positive knowledge development cycle can be found in the Netherlands: research subsidies (F6) trigger research in the respective institutes and learning networks (F2, F3) and positive outcomes of these studies (F4) result in further research subsidies that are in turn allocated to PV research (F6). The outcome of this cycle is that the Netherlands has a strong knowledge base, however, no positive implementation cycle and no growing Dutch PV industry can be found. This is due to the lack of guidance of the search (-F4) and inconsistent market formation instruments (-F5) in the Netherlands. As a result, the demand for PV remains low and entrepreneurs (mainly SME's) and investors are reluctant to invest in a Dutch PV market. The result is that entrepreneurs shift their focus to export markets or move abroad or stop their PV activities (-F1). Only the Dutch PV equipment industry is going strong. The sector's attempts to lobby for more government support have very limited success (-F7) and have not led so far to more stable support policies and long-term goals for PV (-F4).

\subsection{Comparison of the Japanese and Dutch PV innovation systems}

In this paper we have examined how Japan and the Netherlands have differed in the build-up of a successful PV TIS. As a result of continuity and cohesion in the system, Japan is found to have a well-functioning PV TIS with a strong industry and a large market for PV, whereas the Dutch have a considerably less established TIS. In Table 14 we make a comparison of the PV TISs in both countries, based on the analysis of the structural TIS components and the fulfilment of and interactions between the system functions. Then, based upon this comparison we formulate four lessons for the Dutch PV TIS. 
Table 14. Comparison between PV TIS in Japan and in the Netherlands.

\begin{tabular}{|c|c|c|}
\hline & Japan & The Netherlands \\
\hline Actors & $\begin{array}{l}\text { Large, multinational firms that have substantial } \\
\text { resources and capabilities. } \\
\text { Feedback from end-users to other actors } \\
\text { through the NEDO Field Test projects. }\end{array}$ & $\begin{array}{l}\text { Small number of SMEs that primary focus } \\
\text { on export. } \\
\text { Lack of feedback from practice to } \\
\text { researchers and policy makers is due to the } \\
\text { missing cooperation with the end-user. }\end{array}$ \\
\hline Institutions & $\begin{array}{l}\text { Strong and consistent policies with a long-term } \\
\text { strategy, which are supported by } \\
\text { market stimulation measures. }\end{array}$ & $\begin{array}{l}\text { Inconsistent and short term regulations and } \\
\text { subsidy schemes. }\end{array}$ \\
\hline Networks & $\begin{array}{l}\text { Strong political network that put PV on the } \\
\text { political agenda and formulates uniform } \\
\text { messages to the government. Learning } \\
\text { networks which facilitate the build-up and } \\
\text { exchange knowledge are also strong. }\end{array}$ & $\begin{array}{l}\text { Build-up of a political networks is missing. } \\
\text { However, learning networks are more } \\
\text { prominent than political networks and } \\
\text { facilitate national and international } \\
\text { exchange of knowledge and experience. }\end{array}$ \\
\hline $\begin{array}{l}\text { Entrepreneurial } \\
\text { activities }\end{array}$ & $\begin{array}{l}\text { Many strong firms within the PV TIS and } \\
\text { many test projects. Large but declining } \\
\text { export share. }\end{array}$ & $\begin{array}{l}\text { Few pilot projects set up. Small amount of } \\
\text { SMEs that mainly focus on foreign markets. } \\
\text { PV equipment manufacturers are doing } \\
\text { well. }\end{array}$ \\
\hline $\begin{array}{l}\text { Knowledge } \\
\text { development and } \\
\text { diffusion }\end{array}$ & $\begin{array}{l}\text { Strong knowledge development and } \\
\text { diffusion within Japan. International knowledge } \\
\text { exchange limited. } \\
\text { 2nd position world-wide regarding PV patents. }\end{array}$ & $\begin{array}{l}\text { Good knowledge base and good domestic } \\
\text { and international knowledge exchange } \\
\text { between researchers. However knowledge } \\
\text { exchange with users severely limited. 7th } \\
\text { position world-wide PV patents. }\end{array}$ \\
\hline $\begin{array}{l}\text { Guidance of the } \\
\text { search }\end{array}$ & $\begin{array}{l}\text { Vision and goals of roadmap trigger } \\
\text { researchers, entrepreneurs and investors } \\
\text { to engage in PV }\end{array}$ & $\begin{array}{l}\text { Inconsistent and short term policy } \\
\text { measures confuse and discourage } \\
\text { entrepreneurs and investors }\end{array}$ \\
\hline Market formation & $\begin{array}{l}\text { Favourable market stimulation instruments } \\
\text { create a large home market. Import share } \\
\text { is relatively small but growing. }\end{array}$ & $\begin{array}{l}\text { Small home market and hardly any market } \\
\text { stimulation instruments. However, some } \\
\text { recent subsidy independent bottom-up } \\
\text { initiatives. Majority of PV sold on Dutch } \\
\text { market is imported. }\end{array}$ \\
\hline $\begin{array}{l}\text { Resource } \\
\text { mobilisation }\end{array}$ & $\begin{array}{l}\text { Financial and human resources are } \\
\text { abundant and investors invest in PV; } \\
\text { also growing amount of FDI. }\end{array}$ & $\begin{array}{l}\text { Lack of human resources and financial } \\
\text { resources to stimulate the market. } \\
\text { However good availability of research } \\
\text { subsidies. }\end{array}$ \\
\hline $\begin{array}{l}\text { Creation of } \\
\text { legitimation }\end{array}$ & $\begin{array}{l}\text { Support programmes by the government } \\
\text { increase confidence of entrepreneurs } \\
\text { and investors in the technology. }\end{array}$ & $\begin{array}{l}\text { Very little support for PV by government } \\
\text { and investors. Lobby groups do not } \\
\text { haveenough impact to put PV on the } \\
\text { political agenda. }\end{array}$ \\
\hline $\begin{array}{l}\text { Interaction } \\
\text { betweem system } \\
\text { functions }\end{array}$ & $\begin{array}{l}2 \text { virtuous cycles: knowledge development } \\
\text { cycle and implementation cycle. }\end{array}$ & $\begin{array}{l}1 \text { virtuous knowledge development cycle } \\
\text { and } 1 \text { vicious cycle due to the lack of } \\
\text { guidance of the search and inconsistent } \\
\text { market formation instruments. }\end{array}$ \\
\hline
\end{tabular}


First, the presence and capability of the actors present in the PV TIS are important. We observe that there is a lack of expertise and skills among actors (entrepreneurs, installers, policy makers) in the Netherlands. Due to the inconsistent institutional setting, where subsidies are introduced and removed every few years, the continuity for actors to obtain practical skills and learn from long term projects is missing. Moreover, the essential cooperation with the end user is lacking which creates a large bottleneck for knowledge exchange. On the contrary, in Japan end user feedback is gathered and published via the Field Test projects. In addition, feedback from practice to researchers and policy makers the Netherlands has been missing. It is therefore important that consistent long-term goals are formulated and that these goals are maintained. By translating these goals into long-term policies and stimulation measures a gradual build-up of networks and skills and expertise will occur.

Furthermore, in the Japanese PV TIS a great variety of actors are present that form strong networks. Both learning networks, which build-up and exchange knowledge, and political networks that formulate uniform messages to the government and put PV on the political agenda play an important role in the Japanese PV TIS. In the Netherlands national and international learning networks are present but the build-up of strong political networks is missing, and because of the lack of unanimity between the actors, lobbying activities have little impact on the political agenda. In order to stimulate a positive build-up of the Dutch PV TIS, system functions such as guidance of the search (F4) and advocacy coalitions (F7) need to be strengthened in order to reinforce each other in a positive manner.

Thirdly, we observe that the firms involved with PV in Japan are mostly large, multinational firms that have substantial resources and capabilities. In the Netherlands only the PV equipment suppliers are strong businesses; the remainder of the PV sector consists of a small number of SMEs. This limited industrial basis is more vulnerable to changes in investments and subsidies. Thus it is imperative to maintain a climate that attracts investors and allows room for failure and the manoeuvrability to learn from it. It is also important that the technology has advocates that can lobby for the technology and that there is legitimacy for it within the institutional setting.

Fourthly, in the Japanese case practically all PV manufacturers targeted foreign markets. On one side this was possible due to a strong national market, but also due to its leading position that the Ministry of Economy, Trade and Industry wanted to continue maintaining. In terms of import shares, in Japan the import share is relatively small while a substantial part of the PV cells and panels sold in the Netherlands are imported. In addition, $P V$ entrepreneurs in the Netherlands focus on foreign markets more and more. However, the Dutch PV companies have a weaker starting position than the Japanese for example; they have a much stronger resource base in terms of capital and capabilities, 
which they have built up in the last decades. Moreover, the increased competition of the Chinese with their much cheaper products creates a problem for the Dutch companies that do not have competitive products. If the Netherlands wants to be able to compete with such strong foreign competitors, the Dutch PV TIS needs to be strengthened in order for the SMEs to grow in terms of capital and capabilities.

\subsection{Conclusion and discussion}

In this paper we compared two PV TIS, delineating the systems on a national basis but including also their international dimensions. The main message from the Japanese case is that a successful TIS needs time to build-up, where actors are supported by stable institutional conditions to obtain knowledge and skills from experimenting with the technology, form strong networks that have an impact on learning processes and policy making and build-up and maintain legitimacy and support from investments. Based on the main differences between the Japanese and the Dutch PV TIS we formulate four lessons for the Dutch PV TIS: 1) system functions such as guidance of the search (F4) and advocacy coalitions (F7) need to be strengthened in order to reinforce each other in a positive way; 2) formulate, maintain and translate consistent long-term goals into longterm policies and stimulation measures in order to allow a gradual build-up of networks and skills/expertise; 3) build-up and maintain legitimacy within the institutional setting; and 4) strengthen the TIS in order for the SMEs to grow in terms of capital and capabilities.

However, what has become clear from the analyses is that the Dutch PV industry has a much weaker international position than e.g. the Chinese with their much cheaper products and the Japanese with their much stronger and more established resource bases and competences. Following Porter (1990) one might ask whether the small Dutch PV sector has the potential grow into a competitive force on the international market. Two aspects of the Dutch PV TIS that have shown in the analyses to be strong and competitive are the PV equipment supply industry and innovative PV modules. These findings, in combination with the growing transport costs for shipment of PV modules from countries like China, Korea and Japan to Europe, imply promising opportunities for the Netherlands.

From the cases in this paper, it becomes clear that for the breakthrough of technologies the international dimension is very important. For the Dutch case, export is found to be attractive since the Dutch home market is suffering from inconsistent policies and lack of investment and commitment. In foreign markets, Dutch actors find favourable and consistent institutional settings and consistent demand. International knowledge exchange appears to be important for Dutch R\&D in order to stay in a leading position worldwide with respect to research. International markets appear to be just as attractive for the Japanese firms, but are not as vital since there is already a large domestic market. Col- 
laboration and involvement of multiple actors in the home market that exchange knowledge with each other (i.e. entrepreneurs with governments as well as with research institutes) remains important for learning processes within both countries.

The international aspects that we use in this research are conceptualised as input and output flows and attributed to the systems functions by defining additional indicators. However, factors that are external to a specific TIS are important as well as these factors can affect the dynamics of the TIS (Kamp 2008, Markard and Truffer 2008). Successful technological applications or technological breakthroughs in other countries may, for example, raise the expectations of actors within a national PV TIS. Also, on the national level there are external influential factors that affect the PV TIS dynamics, for example domestic economic policies that affect the distribution of funds between sectors. Such external factors could be included into the analysis by adding a multi-level perspective (MLP) analysis (Geels 2002) to the TIS analysis, as done by (Kamp 2008), or integrating the two, as suggested by (Markard and Truffer, 2008). However, Stirling (2011) points out that these two frameworks build upon fundamentally different and therefore unreconcilable ontological assumptions that can therefore not be combined. In this paper we chose not to combine these two, but included external factors either as international dimensions or in the system function descriptions. Each case was delineated as a national TIS but external and international factors were included that provided useful insights and explanatory factors for the differences in the dynamics of the respective TIS.

This paper is meant as a first step on how to include international dimensions when investigating a national TIS. Further research remains necessary on how to further integrate these international dimensions, and on how and when to delineate a national TIS within an international TIS. 



\section{Intermezzo 1}

In the previous chapters (Chapter 4, Chapter 5, and Chapter 6), the empirical outcomes of the technology innovation system have been reported. This was step one of the research approach: development and diffusion of innovative technologies.

The three PV cases studied, the Netherlands, Germany and Japan, shed an ambivalent light on the build-up of the TIS. On one hand I have seen a continuously increasing knowledge base and a rise in entrepreneurial activities related to PV production. These are important indicators for a well-functioning innovation system. On the other hand I observed a strongly fluctuating market formation function. Periods where market formation stopped resulted in 'motors of decline' that deteriorated the state of the TIS. From previous studies (Negro, Hekkert et al. 2007, Negro and Hekkert 2008, Negro, Hekkert et al. 2008, Negro, Suurs et al. 2008, Suurs 2009) I observed that strongly fluctuating guidance of the search and lack of market formation proved to be very damaging for innovation system build-up. Surprisingly, two very important functions (knowledge development and entrepreneurial activities) were not very much affected by the periods of poor market formation. A stable home market is normally an important factor that increases of the chances of success for entrepreneurs. As Porter (1990 p.70-71) has put it: a nation can only achieve international success in a particular industry if their home base (the national innovation system) "...allows and supports the most rapid accumulation of specialised assets and skills, affords better ongoing information and insight into product and process needs, and when the goals of owners, managers, and actors in the field support intense commitment and sustained investment". Furthermore, Sagar and van der Zwaan (2006) argued that R\&D and 'learning-by-doing' are the main contributors (complementary to each other and interlinked) to technological change. Thus, targeted efforts are needed to promote deployment of new energy technologies by translating the results from R\&D activities to 'learning-by-doing' in order to achieve changes in the trajectory of the country's energy system (Sagar and Van der Zwaan 2006). However, as the Netherlands did not pursue consistent efforts to promote deployment, one could think that they left this role over to the neighbouring German market. The German market was a good enough substitute for the home market to keep the sector going also in times when Dutch policy was not in favour of creating a market for solar energy. This has implications for TIS analysis and policy (see Chapter 5). Earlier, Hekkert et al. (2007) claimed that a TIS crosses national boundaries, especially for system functions such as knowledge development and knowledge diffusion. However, much of the guidance and many favourable institutions were often claimed to be local, which was an argument for delineating the TIS under study to the level of a nation. From this example it became clear that also for the market breakthrough of technologies the international dimension 
is very important (see Chapter 6). Therefore, the (policy) implication might be that a government may decide not to strengthen some parts of the innovation system when neighbouring countries fulfil these functions sufficiently.

In the following part, the empirical results of the user perspective are introduced. It focuses on the user as a consumer-citizen who consciously chooses for using one technology or the other, and on the fact that there is a great variety in users. The goal of this part is threefold: (1) to analyse the differences between adopters and rejecters of a PV system in terms of their values and beliefs, socio-economic and demographic characteristics and environmental lifestyle; (2) to gain insight in and to understand the adoption of PV from a user perspective; (3) to analyse how individuals interact with each other to learn about PV and what decisions they reach in term of adoption and non-adoption. 
Part 3:

Consumer behaviour 



\section{Chapter 7: \\ A segmentation analysis - \\ The case of PV in the Netherlands}

This chapter is based on Vasseur, V. and Kemp, R. (Revised and resubmitted). "A segmentation analysis - The case of photovoltaic in the Netherlands.", Energy Efficiency. 



\subsection{Introduction}

Solar energy systems, i.e photovoltaic (PV), continue to gain attention in the Netherlands as consumers seek alternatives to increasingly expensive conventional energy sources. Concerns about energy usage and energy costs is expected to further the consumer demand for PV, accompanied by a rapid expansion in the acceptance of these systems in the future years. The adoption of PV is driven by this consumer demand and is characterized by the number of individuals or households that decide to adopt or reject this technology. We are interested in the pioneers who have adopted a PV system, which kind of people adopt it and what are for example their demographic characteristics. But also the people who rejected a PV system are of importance. What kind of people are they? Given the current activity and interest in solar energy and the future growth expected in this industry, it is important that we are able to identify these people to create insight in the adoption process. Little scientific research is presently known concerning the individuals adopting a PV system.

To our knowledge, there are some studies which investigate how and why consumers may transition toward adopting sustainable energy technologies. Most interesting is the study of Axsen et al. (2012), who grouped their sample into the greens that are 'engaged', those who are 'aspiring' and those who are 'low-tech', and the nonenvironmental groups, whereby it is distinguished between the 'traditional' and the 'techies'. However, in our opinion it highly depends on the technology in question whether people are willing to adopt, even within a group 'green - engaged' it is impossible to predict the decision. A study by Pedersen (2000) showed that even inconsistency in the purchase of various green products and/or technologies exist. He contends that the purchase of a green product can not be predicted based on the purchase of another green product (Faiers and Neame 2006). Thus, it is not because, for example, buying an electric vehicle that one will also buy solar panels for example. The opposite is obviously also true: it is not because a polluted product (e.g. a plane trip) that one does not buy green products (e.g. solar panels).

Drawing on the theory of market segmentation, we introduce a typology which can be used for analyzing the adoption of technological innovations, in particular PV. Different typologies to classify people exist. Some researchers prefer to highlight the connectedness of different sub-typologies within a typology, then the term segmentation instead of typology is often used. Segmentation is defined as a process of dividing one population into smaller sub-populations (i.e. segments or groups), which are characterized by different needs, characteristics or behaviors, including their response to the way they are approached and affected (Geest, Jansen et al. 2008). In this research, we are interested in the different ways of thinking, beliefs and perception of people which make the concept of segments more practical as it highlight the interconnectedness of parts related to a larger populace (the Dutch population). So, the objective of this study is to introduce a segmentation model which allows us to answer the question whether adopters and rejecters of a PV system consider the same or different values/attributes. The model 
gives more specific insight in the adoption of PV but can also be used to insight in the adoption of other technologies and/or in other countries. Moreover, the research method is accessible and workable for other researchers who such to gain insight in adoption processes.

Section 2 offers a theoretical background, we discussed the theory of market segmentation. Section 3 offers the research method and data collection. Based on the gained insights in segmentation literature, we introduce a new model in section 4 which can be used for analyzing the diffusion and adoption of PV in the Netherlands. The overall purpose of this section is to determine empirically how the groups differ from each other. We take the demographic characteristics, geographical characteristics, physiographical characteristics and behavioral characteristics into account. Section 5 offers a reflection of our segmentation model, we analyze how the model met different criteria for good segmentation. Finally, section 6 provides a discussion and conclusion.

\subsection{Theoretical background}

\section{Technology adoption cycle}

Consumers have different personal characteristics and traits, and do not all adopt innovations (a new technology) at the same time (Beal and Bohlen 1957). Beal et al. (1957) divide the diffusion of new ideas into five stages; awareness, interest, evaluation, trial, and adoption. Interesting in Beal and Bohlen's discussion of these five stages is how the most common way for people to learn about new technologies change at each step in this process. When it comes to individuals, Beal, Rogers and Bohlen (1957) introduced a technology adoption lifecycle which divided people into categories that are determined by how soon they adopt new technologies. This is where they divided people into the categories of innovators, early adopters, early majority, (late) majority and laggards or non-adopters. The innovators, early adopters or early majority are individuals or firms investing at an early stage of the diffusion of new technologies. They have a large network, access to information, investment capital, an educational level or experience above average. The (late) majority and non-adopters or laggards are people investing on a later stage, they are older than people investing at an early stage of the innovation diffusion and they have a smaller network and are less educated. See Table 15 for a more elaborated description of the different categories. 
Table 15. Categories of technology adoption cycle (Beal, Rogers et al. 1957, Rogers 2003)

\begin{tabular}{ll}
\hline Name & Description \\
\hline Innovators - 2.5\% & $\begin{array}{l}\text { First to adopt in a very early stage of the innovation process. They are willing to } \\
\text { take risks, often have substantial financial resources and a technical knowledge }\end{array}$ \\
Early adopters - 13.5\% & $\begin{array}{l}\text { Role model for other members of the social system. They are aware of their } \\
\text { important position and try to maintain this position by making quick judicious } \\
\text { decisions which will trigger the mass to adopt an innovation }\end{array}$ \\
Early majority -34\% & $\begin{array}{l}\text { Adopt a new technology when they see that the implementation was successful } \\
\text { in the early adopters group. This group takes its time to make a deliberate } \\
\text { decision in order to avoid the start-up problems of an innovation } \\
\text { Adopt an innovation when there is a pressure from the environment or when the } \\
\text { innovation has proven higher performance. This group has a lower socio- } \\
\text { economic status } \\
\text { Laggards / non-adopters - }\end{array} \quad \begin{array}{l}\text { Last to adopt an innovation, for who technology is unatractive. They are very } \\
\text { conservative, isolated from the rest of the social system and often have limited } \\
\text { resources }\end{array}$ \\
\hline
\end{tabular}

The technology adoption cycle should be viewed as a relative concept. It seems to be straightforward that the group of innovators depends on the technology in question, it does hardly account for differences in the circumstances of users and difference of the preferences.

\section{Market segmentation}

Market segmentation is a marketing strategy which refers to the process of dividing a potential market into distinct subsets of consumers who have common needs and priorities and selecting one or more segments as a target market to be reached with a distinct marketing mix. The basic idea behind market segmentation is that consumers are not all the same and that one strategy will not work for all customers. This has led to break down large markets into smaller segments, each of which is more narrowly-defined than the overall target market. Different authors have discussed market segmentation e.g. Abell and Hammond (1979), Gankema and Wedel (1992), Hessing and Reuling (2003), Schiffman and Kanuk (2010). It is a common view that a good segmentation has to comply with seven criteria (Abell and Hammond 1979, Gankema and Wedel 1992, Hessing and Reuling 2003, NetMBA 2010).

- Identifiable; it should be clear to which segment somebody belongs

- Accessible; people should have the opportunity to move to another segment

- Substantial (size); the segments should be sufficiently large and there should not be too much groups consisting of only a few people

- Unique needs / heterogeneous; the segments should differ clearly and with clear differences between the segments

- $\quad$ Stable (durable); the segments should be relatively stable (minimize often and/or easily changes between segments) 
- Homogeneous response; members within a segment should react in a comparable way to arousals, e.g. advertising and information

- Conducive to steering / affecting behavior (influential); the typology should offer ideas on how human behavior within each segment can be steered

With these criteria in mind, there are many conceivable ways in which a market can be segmented. Think about where consumers are located, who is purchasing a product or service, why consumers buy what they do, and so on. However, the segmentation itself is based on a limited number of characteristics. Four commonly seen characteristics are found in the market literature ${ }^{67}$ e.g. Beane and Ennis (1987), Wedel and Kamakura (2000), Doornbos (2004), Schiffman and Kanuk (2010). Demographic characteristics ${ }^{68}$ refer to age, gender, family composition, education level, housing type and income. Understanding who consumers are (middle aged woman, high educated) will enable you to more closely identify and understand their needs, product and services usage rates and wants. Geographical characteristics divide the total potential market into smaller subgroups on the basis of geographic variables (e.g. city, region, province, postal code and population density. Psychographic characteristics, or lifestyle characteristics, refer to activities, interests, opinions, attitude and values. Segmenting consumers into lifestyles is based on the notion that a person's lifestyle has a direct impact on their interests in products and services. Behavioral characteristics divide consumers into groups according to their motive to buy / benefits sought (price, esthetic, functionality, idiosyncratic preferences), readiness to buy, and occasions (event that stimulate the purchase).

Other consumer-rooted characteristics used to segment markets are personality traits and socio-cultural values and beliefs. The key consumption-specific segmentation factors are usage behavior (including usage rate and situation), benefit segmentation, and brand loyalty and relationship (Schiffman L G and Kanuk L L 2010).

The most common category used in market segmentation is demographics. However, this group does not probe into why consumers buy what they do, hence it does not offer an understanding of what motivates consumers to buy certain services or what types of personalities favor a product or brand over another. Answers on these question combined with demographic data is even more valuable. That is also the reason why a single characteristic is almost never used alone. Practically all segmentation models are in the form of hybrid segmentation. Hybrid segmentation, also referred to as multivariate segmentation, refers to using multiple segmentation characteristics in order to determine

\footnotetext{
${ }^{67}$ It is important to note that sometimes textbooks classify the characteristics differently. For example, we integrate 'benefits sought' as being a 'behavioral characteristic' while some textbooks reported that they should be separated out. And some textbooks will list geo-demographics - a combination of geographic and demographic measures - as a separate category.

${ }^{68}$ Socio-economic characteristics are covered by this group.
} 
the market segment (Schiffman L G and Kanuk L L 2010). Below some primary examples of hybrid segmentation models are described. Important to keep in mind, it is not our purpose to be exhaustive but rather to broaden insight in combining different segmentation categories.

\section{Geo-demographic segmentation - PRIZM}

Geo-demographic segmentation involves a combination of geographic and demographic factors. This segmentation is based on the notion that people who live close to one another are likely to have similar financial means, tastes, preferences, lifestyles and consumption habits (Schiffman $L G$ and Kanuk $L$ L 2010). Jonathan Robbin, the founder of Claritas Inc., is seen as the father of geo-demographic segmentation, and introduced in 1974 the PRIZM (Potential Rating Index for ZIP Markets) segmentation system. PRIZM divides the US population into 15 social groups (e.g. Landed Gentry, 2nd City Centers, Urban Cores) based on differences in socioeconomic status and urbanization. Those 15 groups are further subdivided by measurable differences in household composition (e.g., family structure), mobility, ethnicity, and housing. It defines every U.S. household in terms of 66 segments to help marketers discern those consumers' likes, dislikes, lifestyles and purchase behaviors (Wedel M and Kamakura W A 2000, Heitgerd J L and Lee C $\checkmark$ 2003). The segment names are meant to catch interest and convey a general sense of the character of an area; however, they should not be interpreted literally.

\section{Psychographic/lifestyle segmentations - VALS and LOV}

One of the most widely popularized approaches to lifestyle research for market segmentation is the values and lifestyles (VALS) segmentation model developed at Stanford Research Institute (SRI) by Mitchell (1983), drawing on the theoretical base of Maslow's (1954) needs hierarchy and the concept of social character (Reisman D, Glazer N et al. 1950). The VALS model is developed to determine different classes of people who had varying values, attitudes and lifestyle. This typology classifies the American adult population into eight distinct subgroups based on a specific set of attitudinal and demographic questions that drive consumer behaviour. The model illustrates two critical concepts for understanding consumers: primary motivation and resources (e.g. income, education). The combination of motivations and resources determines how a person will express himself or herself in the marketplace as a consumer (Kahle L R, Beatty S E et al. 1986, Wedel M and Kamakura W A 2000, Schiffman L G and Kanuk L L 2010). The eight VALS segments are: innovators, thinkers, believers, achievers, strikers, experiencers, makers and survivors.

One alternative to VALS is the List of Values (LOV) which was developed by researchers at the University of Michigan Survey Research Centre (Kahle L R, Beatty S E et al. 1986). LOV was developed from a theoretical base of Feather's (1975), Maslow's (1954), and Rokeach (1973) work on values in order to assess adaptation to various roles through value fulfilment. A list of nine values is used to classify consumers, including self-respect, 
security, warm relationships with others, sense of accomplishment, self-fulfilment, sense of belonging, being well respected, fun and enjoyment in life, and excitement. These values are used to classify people on Maslow's hierarchy and they relate more closely to the values of life's major roles than the values in Rokeach Value Survey (ordered value system). Respondents have been asked to identify their two most important values or to rank the values (latent value system) (Kahle L R, Beatty S E et al. 1986, Schiffman L G and Kanuk L L 2010).

Some similarities are found between both segmentation models: (1) VALS segmentation of achievers and the LOV segmentation of sense of accomplishment, and (2) VALS classification of believers and the LOV classification of sense of belonging. Whereas in VALS the individual is viewed as going from worse to better, within the LOV framework no such expectation exists. Comparisons of the VALS and LOV model of segmenting consumer markets have indicated that the LOV method has certain advantages over VALS, and the LOV has been found to predict consumer behaviour more often than VALS across a range of brands (Kahle L R, Beatty S E et al. 1986).

\section{MindBase}

The segmentation methodology, Mindbase, is created by Yankelovich researchers who examined four years of in-depth data on American values and attitudes from its annual monitor surveys comprehensive study of American opinions on topics such as government, health, sex, business, and religion, which it has carried out since 1971. From this data, Yankelovich identified eight major consumer groups with shared life attitudes and motivations: up \& comers, aspiring achievers, realists, new traditionalists, family centereds, individualists, renaissance masters, and maintainers. These eight groups were further divided into 32 distinct sub-segments for greater differentiation and clarification (Hawkins D, Mothersbaugh D et al. 2007).

\section{Commercial segmentation models}

In the Netherlands six major research centers have each developed a segmentation model based on personal values and lifestyle. The different segmentation models are: valuebox-model of NFO-trendbox; metality-model of motivaction; mosaic-model of Experian; win-model of TNS/NIPO; censydiam-model of synovate;and BSR-model of SmartAgent Company. Every segmentation model is already used in a case related to the building market, e.g. municipality Almere by Experian. These research centers used the models to help their customers with the segmentation. In the past, a disadvantage of these models was that there was almost no connection possible to reach segments of the market. In recent years, research centers have coupled their segmentation model with large address files or large self-made databases. In this way, the translation of the results to reach potential customers is easier. However, the research methods are not communicated since this is confidential. 
To sum up, market segmentation is all about identifying specific groups of people based on common characteristics. There are virtually dozens of ways that a market might be segmented and the segments chosen will depend on the products or services it offers. It is important to keep in mind that with the identified segments one will decide which strategy is best for a given product or service, and now and then the best option arises from using different strategies in conjunction.

\subsection{Research method and data collection}

With the theoretical background of market segmentation in mind, it is intended to introduce a segmentation model which can be used for analyzing the adoption of technological innovations. We focus on PV as it is one of the most promising low carbon energy sources. While the worldwide application of PV is growing fast the Netherlands is lagging behind which clearly constitutes a case of slow diffusion. By studying this case, we find out which kinds of people use the technology already and which kind of people rejects the technology. We can use these insights to prevent similar tragedies of slow technology diffusion for other technologies and/or in other countries.

Empirically our research is based on original data on the perception on solar energy in the Netherlands collected via an internet questionnaire. The data gathering took place in September 2011 and the response consisted of 817 completed and usable questionnaires. The data is used to determine empirically a new segmentation model for technological innovations.

After some trial and error, we figured out that it is impossible to group our sample into different lifestyle groups based on VALS, PRIZM or the like. For that a much bigger sample and much more questions on attitudes and values would be required. But the strength of the survey that could be exploited in more detail is that it measures the environmental attitudes and concerns of adoption/non-adoption of PV of the respondents pretty well. We explored the use of a factor analysis, a cluster analysis, a principal components analysis and CHAID analysis. All techniques are used (1) to see the relationship between the items in the questionnaire and underlying dimensions, but also (2) to reduce a larger set of variables to a smaller set of variables that explain the important dimensions of variability. A factor analysis aims to find underlying latent factors ${ }^{69}$, whereas principal components analysis aims to summarize observed variability by a smaller number of components. Cluster analysis divides people into groups that are meaningful and interesting, however, these groups are not associated either with an outcome measure such as likelihood of purchasing a product, or with background data

\footnotetext{
${ }^{69}$ Doing the factor analysis to group the different behaviours and thereby increase the reliability is very difficult given that correlations are fairly low between behaviours.
} 
that would allow them to be identified so that specific messages can be addressed to them. Finally, CHAID identify segments that are related to an objective and easily identifiable. However, this method does not work very well with attitudinal data as the segments tend to lack depth and complexity, or their complexity is uninterpretable. As such, we observed that these analyses are not useful for the aim of our research as we will gain specific insights into the adoption and non-adoption of solar PV in Dutch households. Therefore we decided to cluster some specific questions in order to reduce the large set of items into a smaller number of dimensions.

In this research we propose a hybrid segmentation model which we introduce in the next section to analyze whether PV users are identifiable as small number of relatively homogeneous groups of technological users, based on their adoption or rejection of a specific technological innovation. The introduced model is tested with the criteria of o.a. Gankema and Wedel (introduced in section 2), namely identifiable, accessible, size, unique needs (heterogeneous), stable, homogeneous response, and conducive of steering. Our focus is placed on demographic, - geographic, - psychographic characteristics and motivations (behavior characteristics) rather than on feelings or intentions. We are interested in the personal characteristics of Dutch citizens in relation to sustainable energy sources and in particular PV. In order to gain insight in PV users the following dimensions are important.

- Demographic characteristics. In our questionnaires we included questions about age, possibly income, education and gender to analyze if some characteristics occur more often in a specific group.

- Geographic characteristics include the housing type, housing situated, ownership and number of residents per dwelling as these characteristics influence where PV systems appears. The domestic sector in the Netherlands is divided over three types of ownership. Each represents a different type of decision maker with respect to the purchase of PV: (1) owner-occupied sector in which the residents themselves are the decision makers; (2) private rental sector in which private landlords make the investment decision; (3) public rental sector in which housing associations make the investment decision. Broadly five types of houses can be distinguished in the Dutch domestic sector: (1) detached (free standing), (2) middle of a row, (3) semi-detached, (4) apartment, (5) farms. Furthermore, a house can be situated in a city, village or countryside.

- Psychographic characteristics include activities, opinions and values in our questionnaire. Activities give an insight into attitudes, norms and values of people. More specifically, it attempts to predict specific buying habits and preferences of consumers. Often there is a discrepancy between what people say they wish to do and their actual behavior. Activities used in this research are: recycling of paper, avoidance of unaddressed advertising, energy efficient equipment (A-label), avoidance of car use and water conservation. We asked the respondents to indicate their contribution with regard to sustainability 
within their own lifestyle with a number of indicators using 4-points Likert-scale ranging from (almost) always to never. The respondents which answer the question with (almost) always or regularly are seen as people who behave sustainable on that question. Opinions and attitude includes the reliance on other people's advice and approval. To what extent people make decisions alone or dependent of others, have neighbors, family or friend an important role in decision making and / or in their behavior. It also includes to what extent behavior is determined by habits that exist for decades. Another characteristic is being traditional or modern. Traditional means that people conform themselves to habits, rules and expectations from a group. The opposite, modern, refers to societies in which not a lot of habits, rules and expectations exist. Nineteen questions regard personal preference were asked. Answering each question implied making a choice between two opposite possibilities, agree or disagree. Finally, values can pertain to how a group of individuals feels about certain characteristics/ attributes. Depending of these attributes, people decide to adopt or not adopt a PV system, therefore it is interesting to know what people consider as important product attributes for a PV system and how these attributes are ranked. Based on focus group discussion ${ }^{70}$ we proposed that a PV system have five predominant attributes. These are price, efficiency, lifetime, integration and attractiveness. We asked the respondents to rank, from very important to not important, these attributes which are important in the decision process to adopt or not adopt a system.

- Behavioral characteristics include the motivations and the barriers to adopting a PV system. We asked the respondents who have adopted a PV system themselves to rate several aspects in deciding to adopt a PV system by importance, maximum three answers were possible. There is also a section in the questionnaire which aimed to find out which aspects non-adopters of PV find important in order to observe the barriers for and during adopting a PV system. Different product benefits and costs are taken into account.

\subsection{A segmentation model for PV in the Netherlands}

At the moment, an investment in PV requires a considerable run of money. Citizens need an average to above average income for the purchase of PV. The payback of PV is around ten years, the ideal situation is that the citizen has this time still in prospect. The dimension life situation is not straight forward, in both situation you can buy a system. However, the context of being single of having a family can make a difference, for example a well-educated single can afford a system while a single earner family-man can not afford the same system. Also the other way around is possible. As a citizen has a home in the private or public rental sector, it is likely that these people do not buy PV panels by

\footnotetext{
${ }^{70}$ Within the Organext project, expert interviews with members of the project amongst which are R. Kemp (Maastricht UIniversity) and J. Manca (Hasselt University) were conducted led by S. Lizin (Hasselt University).
} 
themselves while for an owner of a house it can be profitable. The difference in type of citizen has an influence on the purchase of such innovative technologies; a modern citizen shall easier buy an IPOD than a traditional citizen.

To reduce the large set of items in our questionnaire to a smaller number of dimensions and components (groups), we explored the use of different analysis (see section research method and data collection). We observed that these analyses are not useful for the aim of our research as we will gain specific insights into the adoption and nonadoption of PV in Dutch households. The purchase of a green product can not be predicted based on the purchase of another green product, therefor we decided to cluster some specific questions in order to reduce the large set of items into a smaller number of dimensions. In order to understand the meaning of technology for an individual it is not sufficient to only look at the above mentioned dimensions (e.g. income, age), more important is to obtain insight into the usage of sustainable technologies and the sustainable mindedness of people. Therefore, the attitude of the citizens we are dealing with is a strong determining dimension in this research, vertical axis in Figure 1. This dimension refers to the attitude citizens have on the technology, positive versus neutral or negative, while the above mentioned dimensions are largely influenced by external circumstances in which the attitude plays no role. Income, life phase and home ownership may in itself be decisive factors. The second determining dimension in this research refers to the decision making process of major technological innovations, see horizontal axis in Figure 22. An important aspect is the consideration of the adopters and non-adopters.

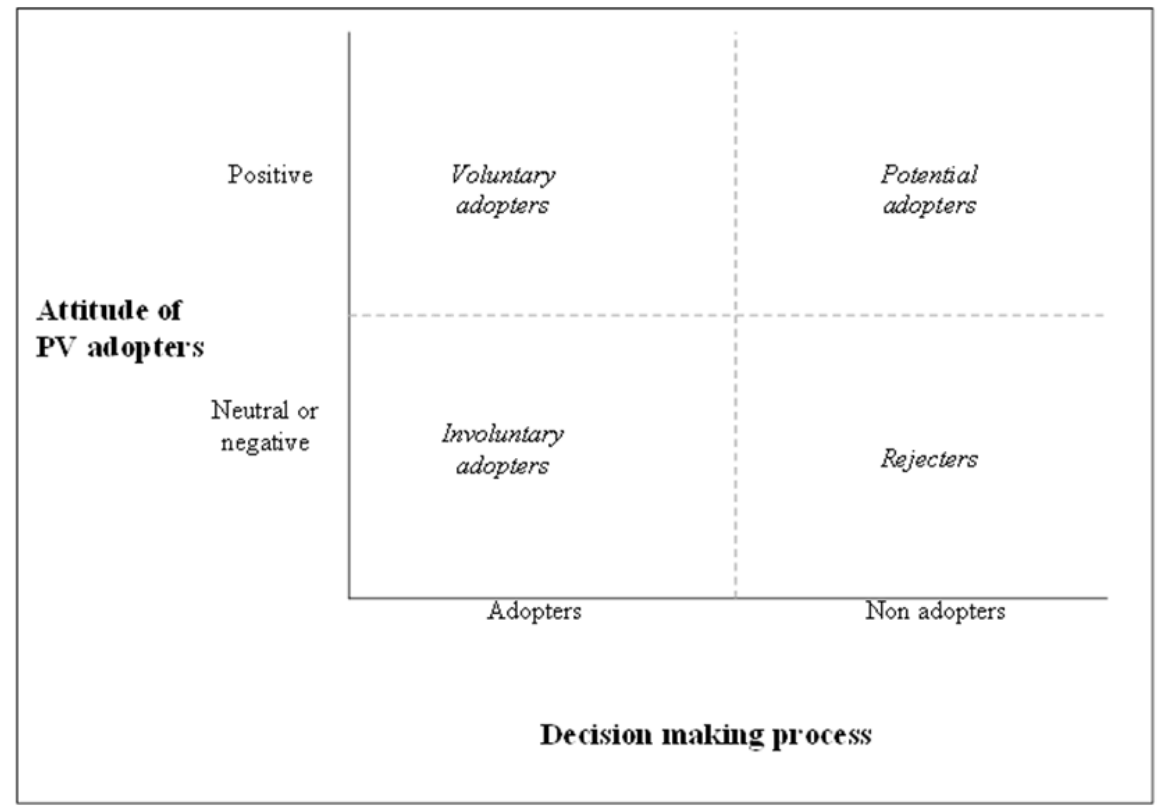

Figure 22. Segmentation model for PV in the Netherlands. 
In this research, the attitude of PV adopters and individual preferences (adoption or not) is determined by using different questions. First we asked whether the respondents have a PV system in their possession. If they have, then we asked who the purchase of the system has decided. If the respondent decided the purchase by themselves we label this respondent with a positive attitude, if not, we label this respondent with a neutral or negative attitude. If they have not a PV system in their possession, a distinction is made between respondents who are willing to purchase a system (they indicated that they are in the orientation phase or that they will consider the purchase when more people decided to opt for a system) or not, we label these respectively as non-adopters with a positive attitude and non-adopters with a negative/neutral attitude.

Taking these dimensions together, we constructed a segmentation model for PV in the Netherlands, see Figure 22. The number of segments is determined by the number of axis used which corresponds with segmentation literature. The figure shows that different attitudes and individual preferences (adoption or not) can be distinguished in four groups: voluntary adopters, involuntary adopters, potential adopters and rejecters.

Better understanding of the adopters (voluntary and involuntary) and non-adopters (potential adopters and rejecters) allows us to determine how the groups differ from each other. In this way, we can compare the choices and considerations for the different adopters. In the section below, the different adopters are discussed according to the characteristic groups. An overview of the characteristics is also given.

\section{Demographical characteristics}

The age spider diagram (see Figure 23) suggests that the majority of the voluntary adopters are located in the category 50- 59 year while the involuntary adopters are concentrated around age 40. Non adopters appear more concentrated from categories 40 to 59.

Concerning income, the majority of the respondents have an income between 15000 and 36000 euro per year. As expected, the respondents with an income less than 15000 euro per year are respectively represented by the group rejecters, involuntary adopters, potential adopters and finally voluntary adopters. So the attitude of the people with the lowest income is more negative or neutral than the people with an income between 36000 and 60000 euro per year. This latter group is more represented by the respondents who have a positive attitude for PV, the group voluntary and potential adopters. These results show that voluntary adopters of PV have higher income than the average population. This is in line with the results of Labay and Kinnear (1981), who examines PV within an adoption and diffusion of innovation frameworks in the State of Maine. A case study on the city of Groningen from Jager (2006) comes also to similar findings. This study analyses factors that lead to a faster diffusion of PV in society from a behavioral perspective. 


\section{Income}
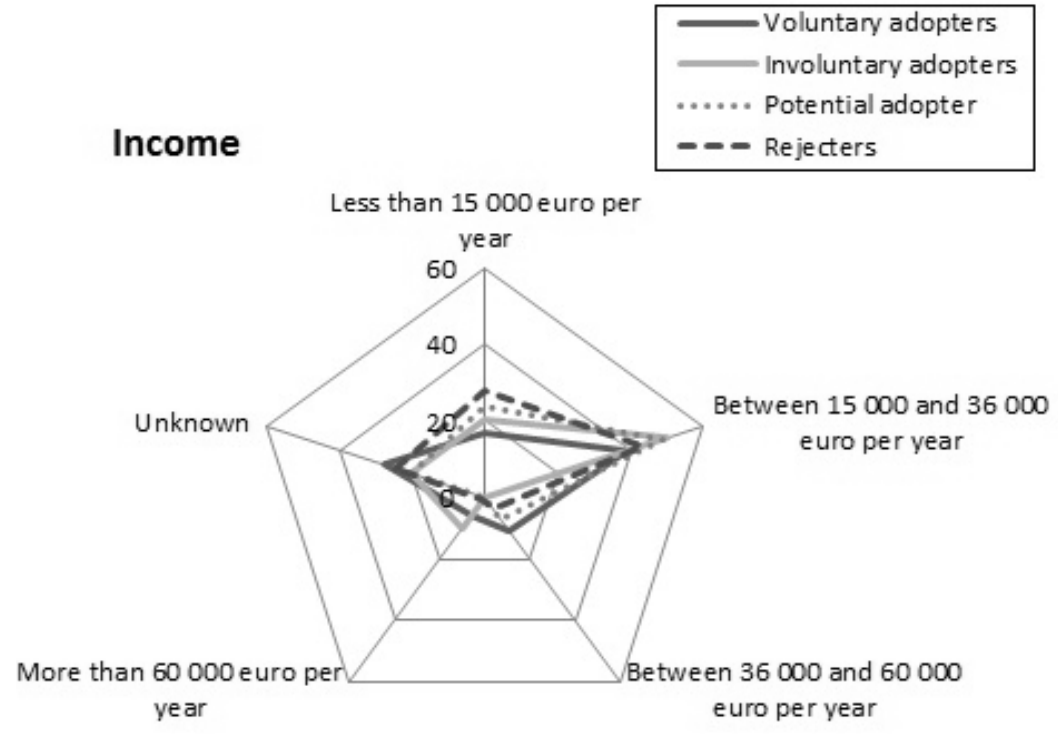

Age
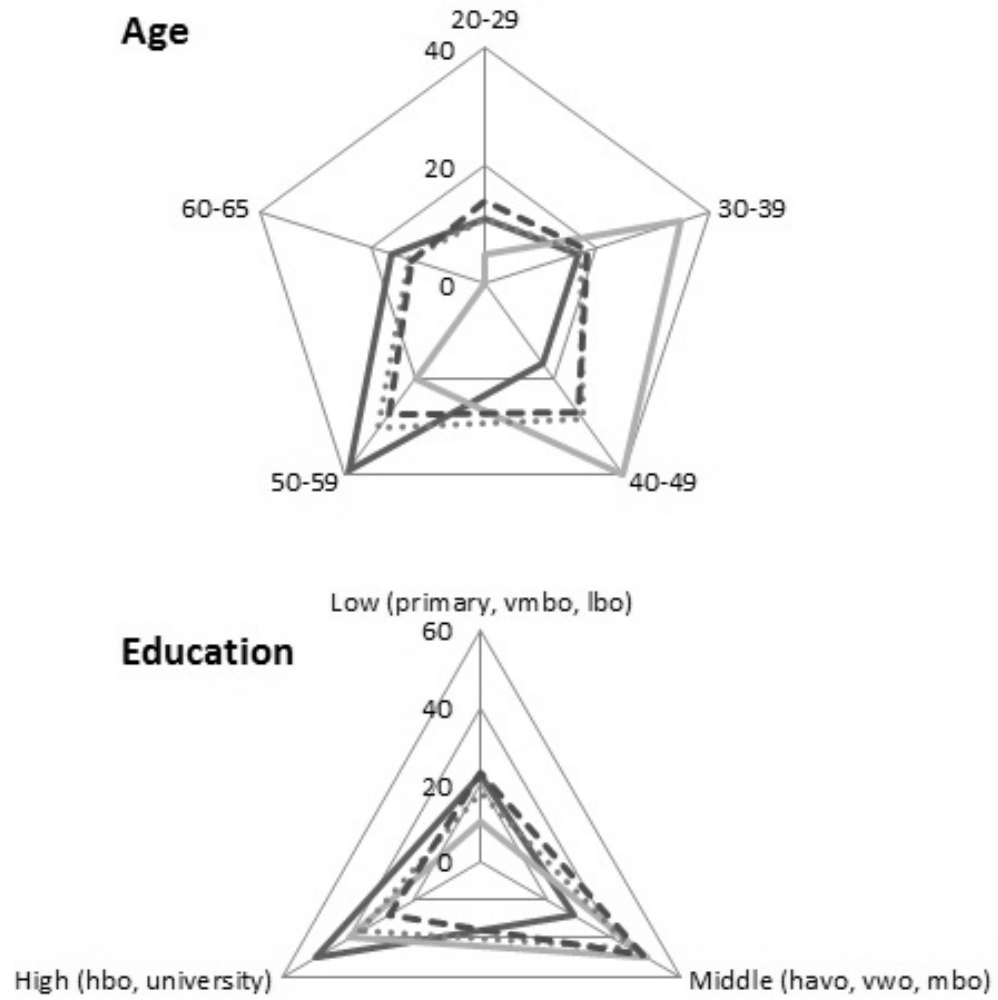

Figure 23. Age, income and education of all respondents divided over the different adopter groups. 
With regard to education, we found that adopters, especially voluntary adopters, have a higher education than the non-adopter. Potential adopters and rejecters appear to be very similar. In gender, the adopter and non-adopters appear to be also very similar.

\section{Geographical characteristics}

In Figure 24 the spider diagram of the different geographical characteristics is given.

We see that the respondents who have an own house has a more positive attitude than the respondents who rent (public or private). The majority of the home-owner is voluntary or potential adopter. The majority of the group of adopters (voluntary and involuntary) lives in a village while the group of non-adopters (voluntary adopters and rejecters) lives in a city. Concerning housing type, the majority of the respondents in every group lives in a middle of row dwelling (non-detached dwelling). But, detached dwellings are even popular for the group voluntary adopters, and semi-detached dwellings are almost even popular for the group involuntary adopters. The second selected housing type of the group rejecters is the apartment which can be identified as physical barrier as it is assumed that this group of people does not consider the option of solar PV panels individually. The last characteristic we discuss is the number of residents. The majority of the voluntary adopters live with two people in a dwelling while the group of involuntary adopters lives with 3 or 4 people. Potential adopters and rejecters appear to be also very similar.

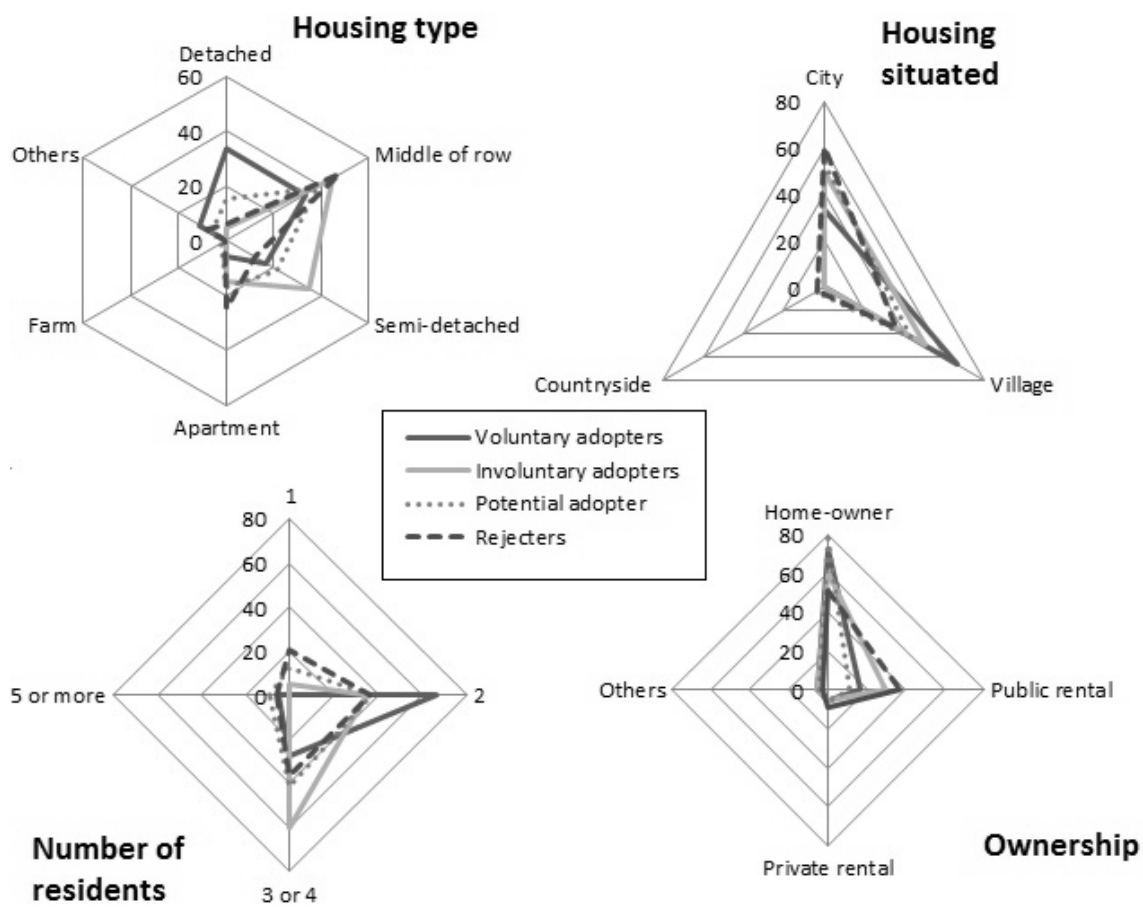

Figure 24. Housing type, housing situated, ownership and number of residents of all respondent divided over the different adopter groups 


\section{Psychographic characteristics}

The opinion spider diagram (Figure 25) suggest that climate change is a concern for people with a positive attitude for $\mathrm{PV}$, thus the voluntary and potential adopters seem fairly similar to each other and fairly different from the involuntary adopters and rejecters. Comparing the decision making process of adopters with non-adopter, we see that voluntary adopters take big decisions independent of others and that this group of adopters do not take considerable time for big decisions, yet quit different form the other three groups. Finally, all the respondents answered that rules are necessary in daily life, but the adopters with a positive attitude score a little bit higher than the respondents with a neutral or negative attitude. The majority of the respondents answered that traditional norms and values are import.

Furthermore, the findings in the activity spider diagram indicate that recycling paper, buying energy efficient equipment (A-label) and use water wisely are major activities performed by all the respondents. Remarkable, the avoidance of unaddressed advertising is notified as not common by the majority of the respondents. With regard to the different adopter groups, we see that the adopters are more sustainable minded than the non-adopters. Within the group non-adopters, rejecters have indicated that they are less sustainable minded on all the analyzed characteristics than the potential adopters. In conclusion, the adoption of PV did not appear to vary between the respondents based on their level of environmental consciousness.

Finally, the value spider diagram suggests that the price of a system is a major issue perceived by all the respondents. Remarkable, the efficiency is mentioned as more important for the voluntary and potential adopters, thus for PV respondent who have positive attitude, while the visual representation is mentioned by the involuntary adopters and rejecters, the group respondents with a neutral or negative attitude on PV. The integration is more important by the group involuntary adopters and quite different from the other groups.

\section{Behavioral characteristics}

Figure 26 gives an overview of the behavioral characteristics, important aspects for this group of characteristics are particular asked to adopters or non-adopters (see research method and data collection) and therefor it was not possible to include all adopter groups in this analysis, nevertheless we can describe these characteristics. Both spider diagrams consist of the most import barriers and motives, more aspects are included in the questionnaire but the results indicated that these aspects have not a role for the adoption or rejection of PV. 


\section{Opinion}
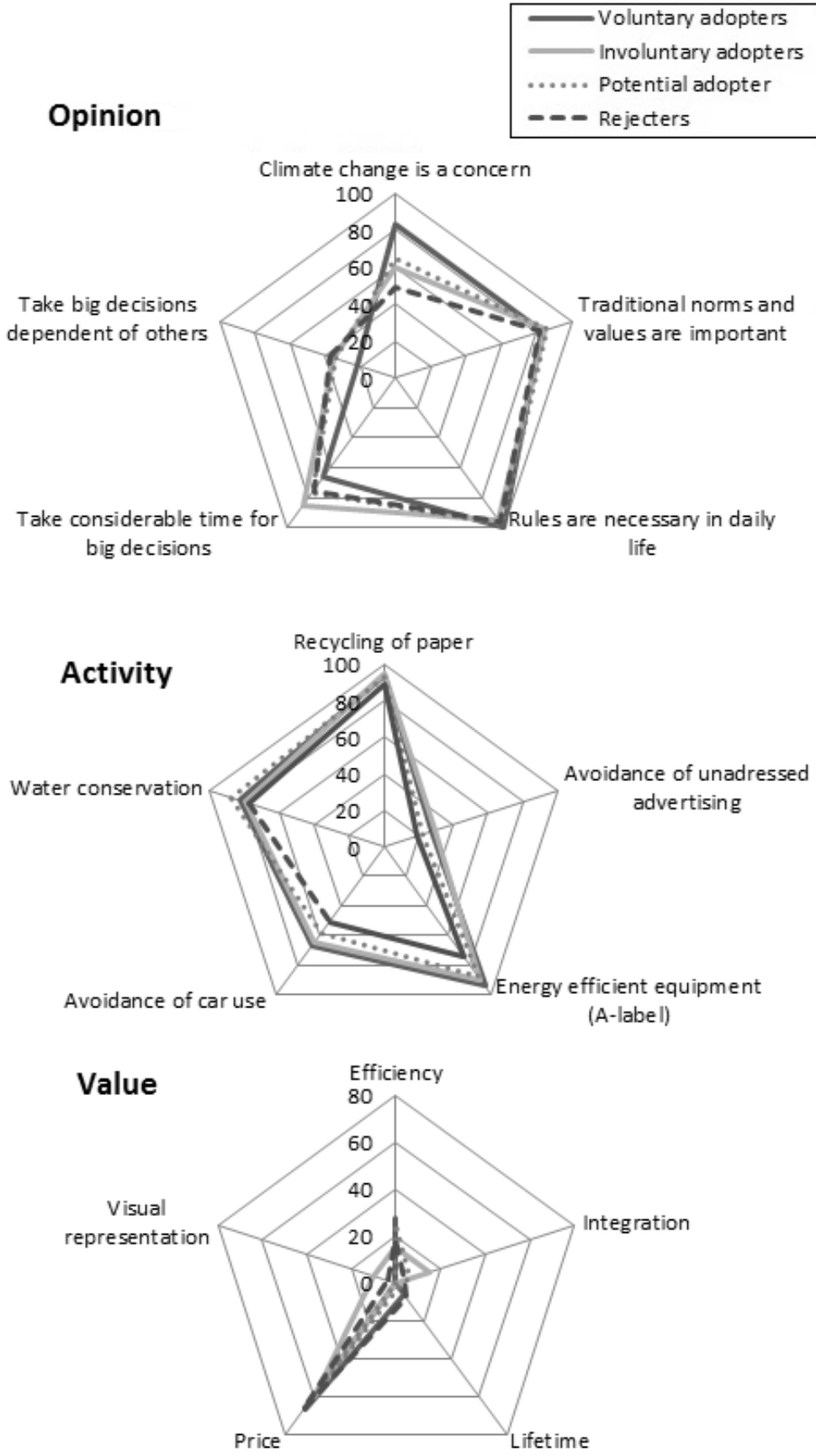

Figure 25. Cultural beliefs and lifestyle characteristics of all respondent divided over the different adopter groups 
The barrier spider diagram suggests that for the vast majority non-adopters (potential adopters and rejecters) the high investment costs of PV is the most important aspect followed at a large distance with low energy yield. With regard to the efficiency of a PV system, we see that potential adopters have more fear for gaining promised efficiency than the group rejecters. In line with our expectations, many rejecters indicated that they are not interested in adopting a PV system.
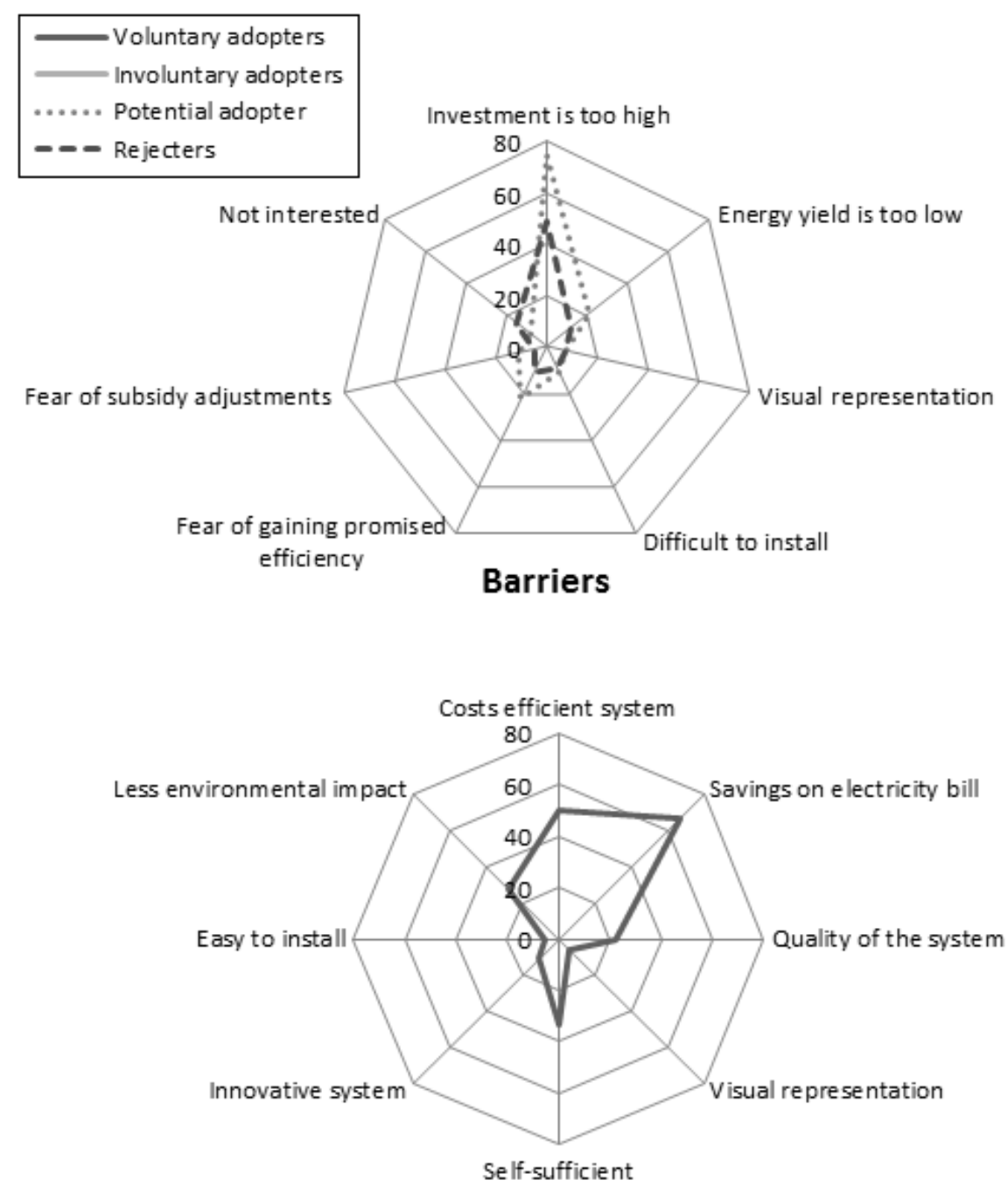

Motives

Figure 26. Behavioural characteristics of all respondents divided over the different adopter groups. 
Concerning motivation of adoption of PV, for the majority of the voluntary adopters the saving of electricity costs is the most import aspect together with the costs of a PV system. The possibility to be self-sufficient and the contribution to a better natural environment are also important motivations for adoption. The visual representation and innovativeness of the system are not seen as an important aspect. This is against our expectations because the visibility of the technology can function as a status symbol or serve as a symbol to communicate a certain identity or value orientation. An elegant and aesthetically integrated system should be used to convince neighbors, friends and family of the positive role that PV can play.

Finally, discussion with other adopters to convince adoption is not an issue, the nonadopters do not feel pressure from their social environment.

\section{Overview of the characteristics}

Table 16 gives an overview of the demographic characteristics, geographic characteristics, psychographic characteristics (cultural beliefs and the importance of the different attributes for PV of the different lifestyles) and behavioral characteristics (motives and barriers to adopt PV).

Table 16. Characteristics of the different lifestyles.

\begin{tabular}{|c|c|c|c|c|}
\hline & \multicolumn{2}{|l|}{ adopters } & \multicolumn{2}{|l|}{ non-adopters } \\
\hline & voluntary & involuntary & potential adopters & rejecters \\
\hline \multicolumn{5}{|l|}{ Demographic characteristics } \\
\hline Age & $50-59$ & $30-49$ & $40-59$ & $40-59$ \\
\hline Income & On average higher & On average higher & On average lower & On average lower \\
\hline Education & high & high-middle & middle & middle-low \\
\hline Gender & similar & similar & similar & similar \\
\hline \multicolumn{5}{|l|}{ Geographic characteristics } \\
\hline Home-owner & me & rental & me & rental \\
\hline Housing situation & more in a village & more in a village & more in a city & more in a city \\
\hline Housing type & $\begin{array}{l}\text { middle of row / } \\
\text { detached }\end{array}$ & $\begin{array}{l}\text { middle of row / } \\
\text { semi-detached }\end{array}$ & $\begin{array}{l}\text { middle of row / } \\
\text { semi-detached }\end{array}$ & $\begin{array}{l}\text { middle of row/ } \\
\text { apartment }\end{array}$ \\
\hline Number of residents & 2 & 3 or 4 & similar & similar \\
\hline \multicolumn{5}{|c|}{ Psychographic characteristics (opinion) } \\
\hline Climate change & more important & less important & more important & less important \\
\hline $\begin{array}{l}\text { Traditional norms and } \\
\text { values }\end{array}$ & important & important & important & important \\
\hline Rules & $\begin{array}{l}\text { necessary in daily } \\
\text { life }(100 \%)\end{array}$ & $\begin{array}{l}\text { necessary in daily } \\
\text { life (98\%) }\end{array}$ & $\begin{array}{l}\text { necessary in daily } \\
\text { life (95\%) }\end{array}$ & $\begin{array}{c}\text { necessary in daily } \\
\text { life }(96 \%)\end{array}$ \\
\hline $\begin{array}{l}\text { Time needed for making big } \\
\text { decisions }\end{array}$ & less considerable & considerable & considerable & considerable \\
\hline Taking big decisions & independent & more dependent & more dependent & more dependent \\
\hline
\end{tabular}




\begin{tabular}{|c|c|c|c|c|}
\hline & \multicolumn{2}{|l|}{ adopters } & \multicolumn{2}{|l|}{ non-adopters } \\
\hline & voluntary & involuntary & potential adopters & rejecters \\
\hline \multicolumn{5}{|l|}{ (in)dependent of others } \\
\hline \multicolumn{5}{|c|}{ Psychographic characteristics (activity) } \\
\hline Recycling of paper & (almost) always & (almost) always & (almost) always & (almost) always \\
\hline $\begin{array}{l}\text { Avoidance of unaddressed } \\
\text { advertising }\end{array}$ & occasional & occasional & $\begin{array}{l}\text { occasional to a } \\
\text { lesser extent }\end{array}$ & $\begin{array}{l}\text { occasional to a } \\
\text { lesser extent }\end{array}$ \\
\hline Energy efficient equipment & (almost) always & (almost) always & (almost) always & regularly \\
\hline Avoidance of car use & regularly & regularly & $\begin{array}{c}\text { regularly to a lesser } \\
\text { extent }\end{array}$ & $\begin{array}{c}\text { regularly to a lesser } \\
\text { extent }\end{array}$ \\
\hline Water conservation & (almost) always & (almost) always & (almost) always & (almost) always \\
\hline \multicolumn{5}{|c|}{ Psychographic characteristics (value) } \\
\hline $\begin{array}{l}\text { Efficiency - amount of } \\
\text { energy }\end{array}$ & more important & less important & more important & less important \\
\hline Integration & not important & more important & less important & less important \\
\hline Lifetime of the system & less important & not important & less important & less important \\
\hline Price & most important & most important & most important & most important \\
\hline Visual representation & not important & important & not important & Important \\
\hline \multicolumn{5}{|c|}{ Behavioural characteristics (motive) } \\
\hline Costs efficient system & most important & - & - & - \\
\hline Savings on electricity bill & most important & - & - & - \\
\hline Quality of the system & less important & - & - & - \\
\hline Visual representation & less important & - & - & - \\
\hline Self-sufficient & more important & - & - & - \\
\hline Innovative system & less important & - & - & - \\
\hline Easy to install & less important & - & - & - \\
\hline Less environmental impact & more important & - & - & - \\
\hline \multicolumn{5}{|c|}{ Behavioural characteristics (barrier) } \\
\hline Investment is too high & - & - & most important & most important \\
\hline Energy yield is too low & - & - & more important & more important \\
\hline Visual representation & - & - & less important & less important \\
\hline Difficult to install & - & - & less important & less important \\
\hline $\begin{array}{l}\text { Fear of gaining promised } \\
\text { efficiency }\end{array}$ & - & - & more important & less important \\
\hline Fear of subsidy adjustments & - & - & less important & less important \\
\hline Not interested & - & - & less important & more important \\
\hline
\end{tabular}

Results show that voluntary adopters are on average middle-aged, high educated, take big decision independent of others and take care of the environment by for example recycling paper and avoiding the car on a regularly basis. The opposite are the rejecters who have on average a lower income, take big decisions dependent on others and need also considerable time for big decisions. These characteristics help to construct a picture 
of which kind of people adopt or reject a system, however, we can not do predictions based on these characteristics. Therefore we indicate some determining factors which correspond with some psychographic and behavioral characteristics. Especially characteristics regarding the cost and benefits of adoption are of importance. In this research, the price of a system is indicated as the most important issue perceived by the different groups. It is the most important motive to adopt but also the most important barrier to reject (potential adopter and rejecter). The financial arguments for PV are complicated by amongst others the uncertainty of electricity prices over the 20 to 30 year system life. Many respondents felt that prices would inevitably rise and therefore PV could provide a good option and a degree of self-sufficiency. While self-sufficiency is an important part of owning a PV system, PV did not provide the level of independence that we expected (see behavioral characteristics, only $+/-30 \%$ of the adopters citing the importance of self-sufficiency). The motive to contribute to a better natural environment appeared to be more important for the group voluntary adopters than the symbolic investment. Regarding the non-adopters, we can conclude that for the potential adopters next to the costs of a PV system the efficiency and energy yield are important determining factor. This is different for the group rejecters, they indicated the visual representation as a barrier for the adoption of PV while this aspect is pointed out as an important aspect by analyzing the psychographic characteristic. These findings suggest that the visual representation is not a determining factor for this group of adopters. As a barrier, they indicated next to the costs and the energy yield that there are not interested. To conclude, PV specific characteristics are more important for the analysis of the adoption or rejection process of a PV system than characteristics regarding demography and geography. Interestingly, other than demographic and geographic characteristics, the different groups exhibit more similar psychographic characteristics. These similarities show us how intertwined or entangled self-concept and personal interest is with actual and perceived knowledge and competence and the actual and reported performance of a practice.

Our results are different in several ways from those found in classic diffusion research such as the theory of Beal and Bohlen (1957) and Rogers (2003). People with the highest socio-economic status who are the least guided by others in their decision making do not necessarily fall into the first groups of adopters (innovators) as defined by Rogers. In this research the group of voluntary adopters is in line with this thought, but the involuntary adopters not. Also, Rogers' group of households that never will adopt a system (laggard / non-adopters) is not in line with our research. This group should have a low socio-economic status which are set to belong to the group of households that is least guided by others in their decision making. In this research, the group of rejecters is more guided by others in their decisions and has middle to low socio-economic status, compared to Rogers' middle groups (early and late majority). 


\subsection{Reflection}

To test whether the introduced segmentation models can be used as a good segmentation for technological innovations, we analyze how the segmentation model met the seven criteria of Gankema and Wedel (identifiable, accessible, size, heterogeneous, stable, homogeneous response, and conducive of steering). The typology scored well on most of the criteria. It is clear to which segment somebody belongs, the segments were easy to distinguish (heterogeneity) and stable, the groups are big enough and gave in general homogenous responses in the questionnaire. The criteria which was met least, was the criteria of accessible, which says that people should have the opportunity to move in and move out a certain group. It is obvious that it is not logical to move from the group voluntary adopter to the group potential adopters, expect when you moved to another dwelling. However, to a certain extent it is possible to move in another group. Potential adopters, for example, can become adopters of the technology and rejecters of the technology can also become potential adopters which in turn can become adopters of the technology, see Figure 27. Moreover, it is also possible to move from involuntary adopters to voluntary adopters. Involuntary adopters, who do not decide the purchase of the system themselves, can be very positive of the system and can decide to adopt more panels and in this way become a voluntary adopter. The other way around is less obvious (from voluntary to involuntary adopters) as the purchase decision of the panels can not be changed from themselves to another person who decided.

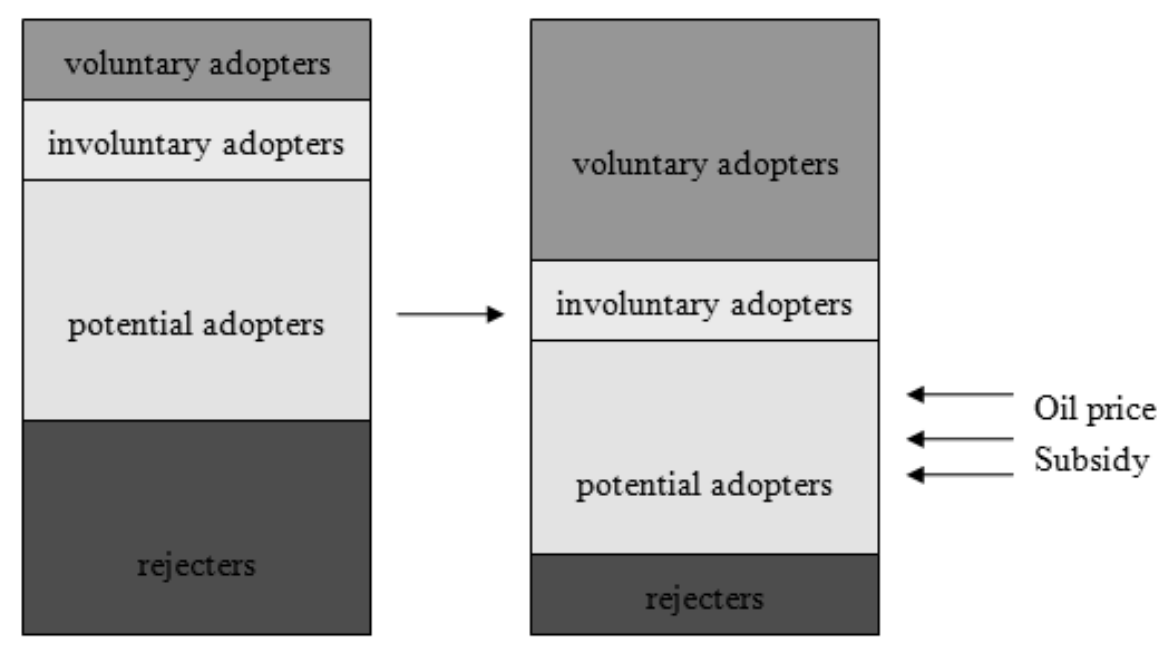

Figure 27. Accessibility and influentially of the different groups.

The last criterion, conducive of steering, is more or less connected to the accessibility of the typology. Every group should give a description about preferred policy-options and/or aspects where people in the group strive for. A favorable grant, for example, can 
have an influence on the behavior of people within a certain group. The grant can stimulate potential adopters to become voluntary adopters.

Our segmentation model is constructed on survey research and on scientific insights, and offers opportunities for analyzing, exploring and visualizing beliefs and perspectives of people who are in the adoption process of PV. It gives more specific insight in the different beliefs and perceptions of the adoption of PV, however, the model can also be used to gain insight in the adoption of other technologies and/or in other countries. The segmentation method can be used to classify, interpret and analyze these different beliefs and perspectives. In this way they can be used to analyze the response in order to contribute to the Dutch energy system in the years ahead and the future social acceptance of different technological innovations. By doing this, insights can be provided how the government's policy or service can align the needs of the customer (citizen) as well as how suppliers of this technology can optimize their product based on identified consumer beliefs and preferences.

Furthermore, a first attempt is made to include innovation specific characteristics during the segmentation of a larger populace. Characteristics (more in particular psychographic and behavioral) related to the cost and the benefits are taken into account. The benefits of an innovation obviously refer to the positive consequences (e.g. environmental benefits), while the costs refer to the negative consequences (e.g. financial uncertainty). In this way, our segmentation model can be distinguished from the segmentation models we compared from the different research centers as their segmentation is not product or service specific.

\subsection{Conclusion and discussion}

The overall purpose of this paper was to introduce a segmentation model which can be used to determine empirically groups of PV technology adopters. The use of questions about beliefs and attribute preferences helped to group people into different groups and compare the choices for such groups. The empirical analysis, based on a questionnaire among 817 Dutch households, resulted in new introduced segmentation model. The model consists of four segments which is determined by two axis: the view citizens have on the technology (positive versus neutral or negative) and the decision making process of major technological innovations. The four segments are voluntary adopters, involuntary adopters, potential adopters and rejecters. The groups (segments) met the set criteria for good segmentation and differ from each other with respect to the demographical, geographical, physiographical and behavioral characteristics. We split our results in non-determining and determining factors to explain how the groups differ from each other. Regarding the determining factors, the costs of a PV system are included as a benefit of having PV for voluntary adopters which obviously refer to the positive 
consequences of having a system (e.g. self-sufficiency and environmental benefits), while for non-adopters the benefits of $\mathrm{PV}$ which also refer to the positive consequences of having a system do not outweighed the costs of a system which refer to the negative consequences (e.g. price and financial uncertainty). Regarding the non-determining factors, voluntary adopters are on average middle-aged, high educated, take big decision independent of others and take care of the environment by for example recycling paper and avoiding the car on a regularly basis. The opposite are the rejecters who have on average a lower income, take big decisions dependent on others and need also considerable time for big decisions.

After this analysis it becomes clear that for the breakthrough of technologies the innovative specific characteristics are more important than characteristics regarding demography and geography. However, the cost and benefits we used in this analysis is a first attempt and can be extended. For example, we do not asked people about the relative importance of the several aspects of the price, for example purchase price, operating costs, maintenance costs, and insurance rates. Also the expected future price of electricity has to be taken into account. Including these aspects make it possible to determine which costs are perceived as most important. Furthermore, the social influence and the effort people must do to adopt a system is not thoroughly considered in this research. Thus, further research remains necessary on how to further integrate this cost-benefit dimensions and the social influence in segmentation analysis, and on how and when to include these aspects.

Insights regarding both adopters (voluntary and involuntary) and non-adopters (potential adopters and rejecters) of PV are provided in this research. Four major groups of characteristics are taken into account: the demographical characteristics, the geographic characteristics, the physiographical characteristics, and the behavioral characteristics. Overall, the link between the characteristics/attitudes we see in this research and the actual adoption behavior are found not to be strong enough. Therefore, it would be beneficial to study the fourth group, behavioral characteristics, in more detail to better understand their motivations to (not) purchase a system. The perceived advantage a PV system have, but also the complexity people perceive are two example concepts which have to be taken into account to help gauge people perception of PV which shape the adoption process. By doing this, insights can be obtained about useful government's policies fitting in with the needs of the customer (citizen) and how suppliers of this technology can optimize their product based on identified consumer preferences and frames.

It is important to notice that the case analyzed in this paper deals with a particular sustainable energy technology. The behavioral response related to this technology might be quite specific, and response related to other sustainable energy technologies may be 
quite different. Also the composition of the respondents may be quite different. In the case of PV, we expect that the potential adopters may become less common in the near future, particularly as the government and municipalities encourage installation of PV in social housing or other large development. As such, the potential adopters may have markedly different socio-economic, attitudinal and value characteristics, and hence behavioral responses. Nevertheless, describing segments in a systematic way allows us to compare different cases and to identify typical responses that may be associated with success or failure. This provides insights regarding the adoption of a technology and provides insights for policymakers especially when considering the implementation of market formation policies for sustainable technologies. Further research is therefore necessary to expand the empirical cases to different technologies, but also to different sectors and countries. In order to generalize research findings, it is important to use the same segments and take the different characteristic groups into account.

It is possible that a small number of the respondents who do not adopt a system have for example not enough knowledge to fill in the questionnaire, because they do not want it, can not afford it or do not understand it. These people are also included in this research and impossible to omit. This is seen as a limitation to this research. 



\section{Chapter 8: The adoption of PV in the Netherlands: A statistical analysis of adoptions factors}

This chapter is based on Vasseur, V. and Kemp, R. (Forthcoming). "The adoption of PV in the Netherlands: A statistical analysis of adoption factors." Renewable \& Sustainable Energy Reviews. 



\subsection{Introduction}

Although there have been ongoing debates- inside and outside the scientific communityabout the reality of a changing climate, the Intergovernmental Panel on Climate Change (IPCC 2013) clearly stated in September 2013 that warming in the climate system is unequivocal, human influence on the climate system is clear, and that the continued emissions of greenhouse gasses (GHG) will cause further warming over coming decades. The IPCC's fifth assessment report (IPCC 2013) further stressed that limiting climate change will require substantial and sustained reductions of greenhouse gas emissions. This requires a fundamental transformation of the energy supply system, including the longterm substitution of fossil fuel conversion technologies by low-GHG alternatives such as renewable energy (IPCC 2014). In a broad sense renewable energy sources refer to hydropower, bioenergy, solar energy, geothermal energy, ocean energy, and wind energy (Twidell J and Weir T 2006). Of these sources, solar energy (CSP -concentrated solar power and PV - photovoltaic) is by far the largest followed by wind and ocean energy (Hoogwijk M and Graus 2008). Fischedick et al. (2011) reports that the technical potential of renewable energy as a whole is at least 2.6 times as large as the 2007 total primary energy demand in all regions of the world. He further reports that the long-term percentage contribution of some individual sources to climate change mitigation may be limited by the available technical potential if deep reductions in GHG emissions are sought (e.g. hydropower, bioenergy and ocean energy), while even sources with seemingly higher technical potentials (e.g. solar, wind) will be constrained in certain regions (Fischedick M, Schaeffer R et al. 2011). However, an estimation of the potential (resource, technical, economic, market) of these individual renewables is a difficult task due to the challenges of unifying assumptions for all geographic areas, technologies, politics, human behavior, etc. (Verbruggen A, Fischedick M et al. 2010, IPCC 2014). On a global scale some studies are available that assess the potential of renewable energy sources (Hofman Y, de Jager D et al. 2002, Hoogwijk M 2004, Johansson T B, McCormick K et al. 2004, Byrne J, Zhou A et al. 2007, de Vries B, van Vuuren D P et al. 2007, Gostelie, Maas et al. 2010, Verbruggen A, Fischedick M et al. 2010, Bakker S, de Coninck H et al. 2010 , Carbo M C, Smit R et al. 2011, de Castro C, Mediavilla M et al. 2011, Jacobson M Z and Archer C L 2012, Moriarty P and Honnery D 2012, Rogner H, Aguilera R F et al. 2012). The outcomes of these studies show that solar energy has a large potential (as per unit of area the output is relatively high) that allows it to become one of the main sources of renewable energy in the long-term future. Despite the large technical potential of PV compared to other renewable energy sources, the total global capacity for PV - $139 \mathrm{GW}$ worldwide in 2013 (REN21 2014) - is rather low, compared to other renewable energy sources as hydropower or wind (Twidell J and Weir T 2006). This raises the question why solar PV did not diffuse more. It is believed that the answer to this question has to do with the multiplicity of human valuation. In this paper we focus on the multiplicity of human valuation by examining the reasons for adoption and non-adoption of solar PV in the Netherlands for a sample of 817 households. In our analysis, the influence of the 
following four factors is studied: perceived relative advantage of the technology, perceived complexity as a negative factor, social influence and knowledge of grants and costs. For each of the variables, different proxies are being used in an attempt to study individual components. The influence of the four adoption factors are studied for 4 groups: voluntary adopters, involuntary adopters (people who bought a house equipped with solar PV), rejecters and potential adopters.

This paper tests theoretical propositions about adoption variables for the case of solar $\mathrm{PV}$ in the Netherlands and offers a novel contribution to the literature through the use of a segmentation model. The propositions about adoption variables are based on a review of the literature on adoption of innovation.

The structure of this paper is as follows. Section 2 offers a discussion of the theoretical models of technology acceptance and innovation diffusion (adoption). After describing the theoretical propositions from the innovation diffusion and adoption literature, we examine the empirical literate on adoption of solar PV. This is done in section 3. Section 4 presents the research data and the segmentation model that is used in the empirical investigation. Section 5 presents the results of our empirical analysis and analyses the implications of the results for PV stimulation policies. The final section describes how our findings compare to those of others and offers a theoretical reflection.

\subsection{Theoretical background}

The characteristics of an innovation generally affect the likelihood and speed of its diffusion (Gatignon and Robertson 1985, Rogers 1983). Ostlund (1974) applied diffusion theory to two new consumer products and discriminate buyers from nonbuyers using the personal characteristics of respondents and their perceptions of each new product. In both studies perceptual variables are found far more successful as predictors of the purchase outcome than respondent personal characteristics (Ostlund 1974). Similar findings are reported by Labay and Kinnear (1981), who examines PV within an adoption and diffusion of innovation frameworks in the State of Maine. Relative advantage is indicated as an important characteristic which refer to the "degree to which an innovation is perceived as superior to ideas it supersedes (both economic and noneconomic considerations)" (Ostlund 1974 p 24). The greater this characteristic is, the faster the rate of adoption will be (Ostlund 1974, Rogers 2003). Not all users, of course, perceive the same levels of relative advantage at the same time. Before elaborating on this, we will first elaborate on different categories of characteristics that influence the adoption and/or diffusion of an innovation. Kemp and Schot (1996) discussed the determinants of adoption decision with respect to environmental technologies. They divided the adoption determinants into three categories: (1) the system of information transfer, (2) the characteristics of the technology (economic and technical) and (3) the characteristics of 
the adopter environment. The last category is further divided into environmental policy, price and cost structure, availability and costs of complementary techniques, age of existing consumer goods, competiveness, environmental awareness and attitude, social pressure, availability of financial resources, and resistance to change and acceptation. The importance of these factors is different for each technique and in the time (Kemp and Schot 1996). The proposed categories focuses strongly on the adoption environment and the characteristics of the technology in question, however the characteristics of the individual is missing. Therefor we introduce the work of Straub (2009), who identified three categories of characteristics. Like the categories of Kemp and Schot, Straub focuses on the technological characteristics and contextual characteristics (corresponds to Kemp's characteristics of the adopter environment), but instead of taking the system of information into account, he added a category of individuals who perceived a technology in different ways and thus are more or less inclined to adopt new technologies. Straub (2009) described the categories as follow. Individual characteristics are individual differences, state- or trait-based characteristics that predispose a person to seek out or shun change. Innovation characteristics are specific to the particular innovation, how easy an innovation is to use, how the use of an innovation is compatible with the lifestyle of an individual. Lastly, contextual characteristics make up the environment and surroundings of an individual during the adoption process (Straub 2009).

However, every particular characteristic (e.g. relative advantage) can play several roles and thus occupy multiple positions in the system. We expect that a certain characteristic contains values, beliefs and needs which are even more likely stretched across different categories. Perceived characteristics are important because they show that potential adopters base their opinions of an innovation on a variety of characteristics, not just innovation characteristics. Therefore, we should try to think about how users will perceive their innovations in terms of all of the three categories, and not focus exclusively on the technical superiority of an innovation.

The most commonly used framework in the area of adoption and diffusion is Rogers' classical "Diffusion of Innovations" framework (Rogers 2003), rooted mainly in the domains of sociology and social communication. For Rogers diffusion is "the process by which an innovation is communicated through certain channels over time among the members of a social system" (Rogers 2003 p.5). Thus he organizes the diffusion process into four primary elements that influence the spread of a new idea: the innovation itself, communication channels, time, and a social system.

Rogers takes a social constructivist ontological view in claiming that it is the perceptions of actors that matter from the point of view of adoption and rejection. He also draws attention to the system of communication. He focuses on the human actors participating in the process, but instead of seeing them as "key players" for observed outcomes, he examines them as categories of individuals who perceive technologies in different ways and thus are more or less inclined to adopt new technologies. 
Roger's theory (2003) provides a useful tool that consists of five stages: knowledge, persuasion, decision, implementation, and confirmation. Each stage consists of different behaviors that are subject to different influences. This research focused on the persuasion stage of the diffusion process, this is when an individual forms a positive or negative attitude towards the innovation. The persuasion stage is crucial for an individual to be committed to adopt or reject an innovation. A key determinant of diffusion in this phase is the five perceived components of innovations: relative advantage, compatibility, complexity, trialability and observability (see Table 17 for definition of perceived attributes). The innovations that are perceived as having greater relative advantage, compatibility, trialability, observability and less complexity will be adopted more quickly and easily than other innovations (Rogers 2003).

Table 17. Roger's five perceived components of innovations (Rogers 2003).

\begin{tabular}{ll}
\hline Attributes & Definition \\
\hline Relative Advantage & $\begin{array}{l}\text { the degree to which an innovation is perceived as better than the idea or technology } \\
\text { it supersedes by a particular group of users, measured in terms that matter to those } \\
\text { users, like economic advantage, social prestige, convenience, or satisfaction } \\
\text { the degree to which an innovation is perceived as being consistent with the existing } \\
\text { values, past experiences, and the needs of potential adopters } \\
\text { the perceived difficulty to understand and use the innovation } \\
\text { the degree to which the adoption of an innovation is experimented without making } \\
\text { Trialability }\end{array} \quad \begin{array}{l}\text { long-term commitments or incurring significant costs } \\
\text { Observability }\end{array}$ \\
\hline
\end{tabular}

The theory has been applied and adapted in numerous ways to model the diffusion of a range of innovations, for example agricultural methods, medical practice, IT solutions, educational innovations, and the use of solar power systems. Several similarities are found in these studies, for example, that technical compatibility, technical complexity, and relative advantage (perceived need) are important antecedents to the adoption of innovations and that innovations tend to diffuse following an S-Curve of adoption (Rogers 1995, Crum, Premkumar et al. 1996, Bradford and Florin 2003).

While Rogers's concern, for the most part, is about the specific type of adoption environment, Davis's emphasis is on a specific type of innovation. According to Davis Technology Acceptance Model (TAM) (1989), one's actual use of a technology system is influenced directly or indirectly by the user's behavioral intentions, attitude, perceived usefulness of the system, and perceived ease of the system. He also proposes that external factors affect intention and actual use through mediated effects on perceived usefulness and perceived ease of use. Davis defines perceived usefulness as "the degree to which a person believes that using a particular system would enhance his or her job performance" and perceived ease of use as "the degree to which a person believes that using a particular system would be free from effort" (Davis 1989). TAM is an adaptation of the 
Theory of Reasoned Action (TRA) developed by Fishbein and Ajzen (1975) and is extended to TAM2 by including subjective norm as an additional determinant of intention in the case of mandatory settings (Venkatesh and Davis 2000). Table 18 gives an overview of the key concepts used in the work of Davis.

Table 18. Key concepts of Davis's Technology Acceptance Model.

\begin{tabular}{ll}
\hline Key concepts & Definition \\
\hline Perceived usefulness & $\begin{array}{l}\text { the degree to which a person believes that using a particular system would enhance } \\
\text { his or her job performance (Davis 1989) }\end{array}$ \\
Perceived ease & $\begin{array}{l}\text { the degree to which a person believes that using a particular system would be free } \\
\text { from effort (Davis 1989) } \\
\text { Subjective norm }\end{array}$ \\
& $\begin{array}{l}\text { the person's perception that most people who are important to him think he should } \\
\text { or should perform the behaviour in question (Fishbein and Ajzen 1975) }\end{array}$ \\
\hline
\end{tabular}

TAM can be used in a wide variety of ways, but it is mainly used to explain factors that influence the use of information systems. A large number of studies have been conducted using the original TAM or an extended version of it. These studies confirmed the strong relationship (convergent and discriminant validity) between and among the two concepts and the significance of them in predicting system usage, however, little is understood about different user responses to information systems (Ozag and Jurkiewicz 2009).

Roger's and Davis both focus on the adoption stage, but the difference between the two theories is that Rogers describes this from a general perspective whereas Davis has the individual user as a starting point. More in detail, Rogers helps to explain and analyse how a new idea, object, or practice is communicated and accepted by others while Davis' model suggests that when users are presented with a new technology, a number of factors influence their decision about how and when they will use it. In order to provide a unified theoretical basis from which to facilitate research on adoption and diffusion, the Unified Theory of Acceptance and Use of Technology (UTAUT) was proposed and validated by Venkatesh (2003). The model is a synthesis of eight existing models of technology acceptance, including the work of Rogers' and Davis'. The model integrates elements from Theory of Reasoned Action (TRA), Motivational Model (MM), Theory of Planned Behaviour (TPB), Technology Acceptance Model (TAM), a combined Theory of Planned Behaviour/Technology Acceptance Model (C-TPB-TAM), Model of PC Utilization (MPCU), Innovation Diffusion Theory (IDT), and Social Cognition Theory (SCT).

The unification of these models provides UTAUT with seven constructs. The authors theorized that four constructs - performance expectancy, effort expectancy, social influence, and facilitating conditions - play a significant role as direct determinants of user acceptance and usage behavior (see Table 19 for definition of the concepts). Attitude toward using technology, self-efficacy, and anxiety are theorized not to be direct determinants of intention, mainly because they were found not to be significant in the pres- 
ence of effort expectancy. The theory also assumes that the effect of core constructs is moderated by gender, age, experience, and voluntariness of use (Venkatesh, Morris et al. 2003).

Table 19. Key determinants of innovation adoption according to the Unified Theory of Acceptance and Use of Technology (Venkatesh, Morris et al. 2003).

\begin{tabular}{ll}
\hline Key determinant & Definition \\
\hline Performance Expectancy & $\begin{array}{l}\text { the degree to which an individual believes that using the system will help him } \\
\text { or her to attain gains in job performance } \\
\text { the degree of ease associated with the use of the system }\end{array}$ \\
Effort Expectancy & the degree to which an individual perceives that important others believes he \\
Social Influence & or she should use the new system \\
the degree to which an individual believes that an organizational and technical & infrastructure exists to support use of the system \\
\hline
\end{tabular}

A systematic review of citations of UTAUT's originating article concludes that the UTAUT provides a useful tool by which to evaluate the potential for success of new technology initiation and helps identify factors likely to influence adoption of technology (Williams, Rana et al. 2011). Although the model was constructed to explain user intentions to use an information system and subsequent usage behaviour, the constructs and variables from the theory are very well applicable to explain the adoption of PV in the residential area. Therefore we have part of this framework taken, as well as some concepts from the framework of Kemp and Schot, Rogers and Davis, as a starting point in our analysis. Before elaborating on this, an overview of solar energy diffusion studies is given.

\subsection{Findings in solar energy diffusion studies}

Although many studies consider the diffusion of solar energy technology, few studies among them are dealing with solar energy from a consumer behaviour perspective. The following studies are contextually related and show some interesting issues in this area.

Thomas Sparrow is the first researcher who focused primary on the purchase decision of solar energy. He considered various socio-economic factors involved in the adoption of solar-energy technologies in a study of 45 owners-users of solar custom homes located throughout the United States in 1977. In his study, Sparrow emphasized that there are region-specific differences in consumer attitudes as well as in factors of importance for those adopting solar energy systems in different geographical regions.

However, the small and geographically diverse sample presents difficulties (Labay and Kinnear 1981). Another study conducted in the United States was undertaken by Cesta

\footnotetext{
${ }^{71}$ In the case of PV, there is no effort connect to use. The effort consists of obtaining relevant information about the products and applying for a grant.
} 
and Decker (1978) to determine and measure the attitudes of the public, including consumers. A two-stage Delphi research study identified some factors that may either inhibit or stimulate solar energy adoption and commercialization. The following factors were found to be important: product cost, lack of product knowledge, lack of governmental support, and public concern over the energy crisis. Cesta and Decker also found that governmental and business actions could help to initiate greater solar energy use and developmental efforts (Cesta and Decker 1978).

Several researchers used Rogers' diffusion of innovation theory as their theoretical framework. Labay and Kinnear (1981) used the theory to examine the purchase decision process of residential solar energy systems in one geographical region, the State of Maine. Multivariate nominal scale analysis is used to develop classification models based on both attribute perceptions of solar energy systems and demographic characteristics. They discovered that attribute perception data afford somewhat greater classification ability than demographic data. An important aspect in the work of Labay and Kinnear is the inclusion of knowledgeable non-adopters as a group worthy of attention, in addition to adopters and unaware non-adopters. They argued that the knowledgeable nonadopters evaluated the product and economic factors (e.g. quality of the system and payback period) higher (Labay and Kinnear 1981), which indicate the potential for adoption. Kaplan' (1999) research also used Rogers' diffusion of innovation theory to investigate why utilities not adopt solar power and what might help encourage their interest. The inclusion of motivation, experience and familiarity (e.g. whether the household has previously installed a similar technology, such as solar heating) are important variants which can influences the interest in PV. These findings have significant implications for commercialization efforts, as well as for management of utility operations. Kaplan emphasized that through small wins, experimentation, and groping along, solar power can be diffused far more effectively and with far greater ultimate success than is expected through the conventional wisdom of large-scale research and development (Kaplan 1999). The study conducted by Faiers and Neame (2006) also utilized Rogers' theory to investigates householder (using householders in central England as case) attitudes towards characteristics of solar systems and identifies some of the barriers to adoption. A group of 'early adopters', and a group of assumed 'early majority' adopters of solar power were surveyed and the results show that overall, although the 'early majority' demonstrate a positive perception of the environmental characteristics of solar power, its financial, economic and aesthetic characteristics are limiting adoption (Faiers and Neame 2006). In other words, the actual cost of an innovation is relatively unimportant; what matters is what it is worth to the adopters as individuals. Jager (2006) studied factors that lead to a faster diffusion of PV in society from a behavioural perspective. He discussed different consumer motives within a framework of underlying needs and the 
time sensitivity of various outcomes. Financial support and general problem awareness are found to be critical motives ${ }^{72}$ in the city of Groningen, but the positive effects of information meetings, technical support meetings and social networks are also identified. In terms of the factors affecting the speed and degree of diffusion (Rogers 1995), these meetings reduced the complexity of the decision problem as experienced by the buyers (Jager 2006).

Research that considers the behavioural responses to PV influenced by the broader socio-technical system is conducted by Keirstead (2007). He used PV households in the UK as case to investigate whether the use of PV could have a double divided effect, providing renewable energy as well as any changes in energy use. This research showed that the installation of PV encouraged households to reduce their overall electricity consumption by approximately $6 \%$ and shift demand to times of peak generation (Keirstead 2007). Palm and Tengvard (2011) also studied the adoption of PV from a broader sociotechnical perspective and embedded their work within the transition literature. Analysis of material from in-depth interviews with members of twenty Swedish households reveals that environmental concerns are the main motive for adopting PVs or microwind turbines. Other indicated motives were an ecologically aware lifestyles, a symbolic investment (provide a way to display environmental consciousness) a protest against "the system," with its large dominant companies, or a step toward selfsufficiency. Some households reject these installations because of financial considerations, respect for neighbours who might object, and/or difficulties finding an appropriate site (Palm and Tengvard 2011).

This state-of-the-art review showed that adopting PV requires more than simply interpreting its technical characteristics, the technology must also be compatible with the desires and frame for evaluation of the household. Therefore, attribute perception rather than objective date could significantly increase the insight in and the understanding of the adoption of PV, which is well beyond the state of the art.

\subsection{Research method}

Authors have made distinctions between studies of the diffusion and adoption of innovations. Although a certain degree of overlap between those concepts may exist, adoption analysis often take characteristics (individual, innovation as well as contextual) into account while diffusion analysis does not, or only to a very small extent. This study focused on the adoption of PV in Dutch households and examined properties that enhance or hinder this process by using perceived characteristics. In examining the adoption of $\mathrm{PV}$, we focus on the explanatory power of some the key concepts introduced by Ven-

\footnotetext{
${ }^{72}$ These motives can also be seen as facilitating factors.
} 
katesh, the five perceived components introduced by Rogers, the concepts introduced by Davis and some sub categories of the work of Kemp and Schot. The key concepts from the different models are taken into account to help gauge people's perceptions of $\mathrm{PV}$, so as to better anticipate their adoption processes.

As different individuals will have different practices but also different preferences for example for specific characteristics of PV. We used a segmentation model which is introduced for analysing the diffusion of technological innovations, in particular PV. The vertical axis refers to the attitude citizens have on the technology, positive versus neutral or negative. The horizontal axis refers to the decision making process of major technological innovations ${ }^{73}$.

This segmentation model is based on the adoption or rejection of PV. By using this model we are able to analyse how certain groups of people look at environmental issues and renewable energy, in particular solar energy, why do some people have already implemented this technology and why others do not. These insights can provide insight into how the government's policy or service can align the needs of the customer (citizen) as well as how suppliers of this technology can optimize their product based on these wishes. Especially in the domain of adoption of sustainable energy sources there is little scientific research from a user perspective. This urges the need for such research in which the adoption is studied from a user perspective.

The analysis is conducted via an internet questionnaire regarding the Dutch citizens. The majority of the questions were multiple choice questions with a few open questions. The data gathering took place in September 2011. 817 people out of 1371 have responded to the questionnaire, which is a response rate of $60 \%$. This is a representative sample over the Dutch population (21-65 year) regarding gender, age distribution, level of education and spatial distribution in the Netherlands. In order to classify the respondents, we used a segmentation model which is introduced. Four relatively homogeneous groups of technological users are determined based on their adoption or rejection of a specific technological innovation, in particular solar PV. The four groups are voluntary adopters, involuntary adopters (people who bought a house equipped with solar PV), potential adopters and rejecters. This segmentation allows us to answer the question whether adopters and non-adopters consider the same or different attributes for their

\footnotetext{
${ }^{73}$ The attitude of PV adopters and individual preferences (adoption or not) is determined by using different questions. First we asked whether the respondents have a PV system in their possession. If they have, then we asked who the purchase of the system has decided. If the respondent decided the purchase by themselves we label this respondent with a positive attitude, if not, we label this respondent with a neutral or negative attitude. If they have not a PV system in their possession, a distinction is made between respondents who are willing to purchase a system (they indicated that they are in the orientation phase or that they will consider the purchase when more people decided to opt for a system) or not, we label these respectively as non-adopters with a positive attitude and non-adopters with a negative/neutral attitude.
} 
decisions. These insights can provide insight into how the government's policy or service can align the needs of the customer (citizen) as well as how suppliers of this technology can optimize their product based on these wishes. Especially in the domain of adoption of sustainable energy sources there is little scientific research from a user perspective. This urges the need for such research in which the adoption is studied from a user perspective.

The questionnaire consists of a variety of questions. We started with questions about their impression on their own lifestyle in the view of sustainability. A description of sustainable development was given to all respondents through an information button to ensure everybody had the same information. We also asked the respondents whether they think that the implementation of PV should be stimulated, for example by providing subsidies, and how they think that actors in the field should take the lead in general. Furthermore, we asked to rank the importance of different characteristics of a PV system in deciding to adopt PV by importance. But there is also a section which aimed to find out which aspects non-adopters of PV find important in order to observe the barriers for and during adopting a PV system. We asked the respondents who did not have a PV system themselves to indicate their agreement and disagreement of different statements based on possible motives for purchasing a PV system. On the other hand we also investigate the different motives adopter of PV had for purchasing a PV system.

Descriptive analyses were conducted to analyse the perception of a representative sample of the Dutch population regarding solar energy, e.g. motives behind the adoption process. Although there are many ways to analyse the perception of people, in this paper we used an indicator-based approach. These respondents were provided with a questionnaire with different items, these items were indicators for analysing the adoption process of PV. To compare the differences, the four groups who have been formulated according to their decision to adopt or not adopt a PV system, are also studied statistically. We use logistic regression analysis to determine the predicting factors for adoption or not. We also categorized and quantified responses to the open-ended questions on positive and negative expectations and experiences.

\subsection{Results}

\section{Sample}

shows the findings regarding demographic characteristics obtained from the descriptive analysis. Comparing the adopters with the representative sample of the Dutch population, we see that the adopters are in general higher in income, younger and more highly educated than the general population. Comparing the adopters with the non-adopters, a few differences are apparent. The level of income does not appear remarkable similar which corresponds our expectations. We expected PV adopters to have higher incomes 
than non-adopters as PV systems are very expensive in purchase. Of the adopters, $31.6 \%$ have an income between $€ 22,500$ and $€ 36,000$ and $13.2 \%$ have an income above $€ 36,000$. For non-adopters these numbers are different, the majority have an income below $€ 22,500$ (47.0\%) and only 5.6\% have an income above $€ 36,000$. In age, the adopters and non-adopters appear quite similar in the Netherlands, but the adopter seems a little bit younger, however, this trend is not strong. Looking at education, the adopters appear more concentrated around the category high level of education while non-adopters have a middle level of education. Revealing the diffusion of innovation theory which suggests that the adopters might be "innovators" of PV technology and if so, they are likely to be well-educated (Rogers 2003).

These findings are in line with the results of Labay and Kinnear (1981), who conclude that adopters of PV are younger, more highly educated, higher in income, earlier in the family life cycle, and higher in occupational status than the general population. However, their observation that adopters are younger is not confirmed by the research conducted by Jager (2006). The research of Keirstead (2007) indicated that PV adopters do not represent an even mix of ages, instead favouring older ages. This significant difference from the national statistics may be explained by characteristics associated with older age such as higher income and owning one's own home (Keirstead 2007).

Table 20. Demographic findings.

\begin{tabular}{|c|c|c|c|}
\hline Income & Response (\%) & Adopters (\%) & Non-adopters (\%) \\
\hline$<22500$ & 46.3 & 31.6 & 47.0 \\
\hline $22500-36000$ & 25 & 31.6 & 24.6 \\
\hline$>36000$ & 6 & 13.2 & 5.6 \\
\hline Unknown & 22.8 & 23.7 & 22.7 \\
\hline Age distribution & Response (\%) & Adopters (\%) & Non-adopters (\%) \\
\hline $21-24$ & $4 \%$ & 5.2 & 4.0 \\
\hline $25-29$ & $9 \%$ & 2.6 & 13.5 \\
\hline $30-34$ & $9 \%$ & 10.5 & 9.1 \\
\hline $35-39$ & $9 \%$ & 15.8 & 8.7 \\
\hline $40-44$ & $13 \%$ & 13.2 & 13.1 \\
\hline $45-49$ & $14 \%$ & 15.8 & 14.4 \\
\hline $50-54$ & $14 \%$ & 13.2 & 13.5 \\
\hline $55-59$ & $15 \%$ & 15.8 & 15.1 \\
\hline $60-65$ & $13 \%$ & 7.9 & 11.0 \\
\hline Level of education & Response (\%) & Adopters (\%) & Non-adopters (\%) \\
\hline Low (primary, vmbo, lbo) & $28 \%$ & 15.7 & 28.2 \\
\hline Middle (havo, vwo, mbo) & $41 \%$ & 39.5 & 40.6 \\
\hline High (hbo, university) & $32 \%$ & 44.7 & 31.2 \\
\hline
\end{tabular}


Of the respondents in our sample, 38 respondents adopted a PV system, 18 respondents voluntary and 20 respondents involuntary. The latter group could also decide the adoption quasi-voluntary which in this research is also labeled as involuntary. Of the remaining 779 respondents, 293 (37.6\%) are in the orienting phase or will adopt a system when the majority adopt a system and/or when they see the usefulness of it. These respondents together are called the potential adopters. The majority of the non-adopters are rejecters, namely $62.4 \%$ (486 respondents).

Of the 38 respondents that adopted a PV system, a total of 25 reported having an own house and 11 reported having a rented house ${ }^{74}$, the remaining 2 reported others. There is not a specific type of house, but free standing house, semi-detached house and terraced houses are in favor. Given the selected technology in this study, one physical barrier can be identified: if a household is situated in a stacked building (e.g. apartment) it is assumed that they often do not consider the option of PV panels individually. The majority of the voluntary adopters live in a town. For an overview, see Table 21.

Looking at the non-adopters, 478 respondents reported that they are home-owner which could consider the option for PV panels individually. Remarkable, only 16 out of 779 respondents (2.1\%) live in the countryside and do not have the intention to adopt a PV system.

Table 21. Crosstab for the number of respondents having a PV system or not and housing conditions.

\begin{tabular}{|c|c|c|c|c|}
\hline & \multicolumn{2}{|l|}{ Adopter of PV } & \multicolumn{2}{|l|}{ Non-adopters of PV } \\
\hline & Voluntary adopters & Involuntary adopters & Potential adopters & Rejecters \\
\hline Frequency & 18 & 20 & 293 & 486 \\
\hline \multicolumn{5}{|l|}{ Home-owner } \\
\hline I & 13 & 12 & 228 & 250 \\
\hline Public rental & 3 & 6 & 34 & 181 \\
\hline Private rental & 1 & 1 & 17 & 43 \\
\hline \multicolumn{5}{|l|}{ Housing type } \\
\hline detached & 6 & 1 & 45 & 30 \\
\hline middle of a row & 6 & 9 & 112 & 234 \\
\hline semi-detached & 3 & 7 & 63 & 59 \\
\hline apartment & 1 & 3 & 49 & 122 \\
\hline farm & 0 & 0 & 6 & 1 \\
\hline others & 2 & 0 & 18 & 40 \\
\hline \multicolumn{5}{|l|}{ Housing situated } \\
\hline city & 6 & 10 & 157 & 295 \\
\hline town & 12 & 10 & 125 & 175 \\
\hline Countryside & 0 & 0 & 11 & 16 \\
\hline
\end{tabular}

\footnotetext{
${ }^{74}$ The domestic sector in the Netherlands is divided over three types of ownership. Each represents a different type of decision maker with respect to the purchase of PV: (1) private rental sector in which private landlords make the investment decision; (2) public rental sector in which housing associations make the investment decision; (3) owner-occupied sector in which the residents themselves are the decision makers.
} 


\section{Thresholds and benefits}

In this section we investigate the different thresholds and benefits (non) adopters of PV had to adopt a PV system. We asked them to indicate possible thresholds and motives in deciding to adopt a PV system by importance, maximum three answers were possible. We also asked the non-adopters to indicate under which condition they would adopt a system and which aspects have triggered the adopters in their decision. The latter was asked in the form of an open-ended question.

Table 22 shows the motives adopters had to adopt a PV system, ranked from important to unimportant. The most important motives to adopt PV are saving electricity costs (66.7\%), the costs of a PV system (50\%) and the possibility to be self-sufficient (33.3\%). The fact that with the use of a PV system one has less environmental impact has also been an important reason for people to adopt. The respondents also indicated that the innovativeness of a system, the visual aspect and the ease to install a system are less important motives for people to adopt a system. These results are not in line with the research of Jager (2006) and Palm and Tengvard (2011), who rated the contribution to a better natural environment as the most important motive for adoption. Palm and Tengvard (2011) also indicated the symbolic investment as an important aspect which is not in line with our findings.

Table 22 Motives and decisive factors to adopt a PV system, ranked from important to unimportant.

\begin{tabular}{|c|c|c|c|}
\hline Motives & $\begin{array}{c}\text { Percentage } \\
\left(1^{\text {st }}, 2^{\text {nd }} \text { or } 3^{\text {rd }}\right)\end{array}$ & Decisive factors & $\begin{array}{l}\text { Number of } \\
\text { respondents }\end{array}$ \\
\hline Savings on electricity bill & 66.7 & House improvement & 5 \\
\hline Costs efficient system & 50 & Subsidy programme & 4 \\
\hline Self-sufficient & 33.3 & Media & 2 \\
\hline Less environmental impact & 27.8 & Convenience & 2 \\
\hline Quality of the system & 22.2 & In combination with boiler & 2 \\
\hline Innovative system & 11.1 & $\begin{array}{l}\text { Cheaper in term of energy } \\
\text { consumption }\end{array}$ & 1 \\
\hline Visual representation & 5.6 & Interest and expertise & 1 \\
\hline Easy to install & 5.6 & Others & 1 \\
\hline
\end{tabular}

House improvements and subsidies were the decisive factors for adoption, repeated by respectively 5 and 4 respondents, followed by stories from the media and the convenience of having a PV system, both 2 respondents. It should be noted that house improvements is a broad concept. It contains the increased value of a home but also the decorative value of it. Since the questionnaire did not contain a question about the relative importance of these aspects it is impossible to determine which are perceived as more important. 
Apart from the motives and decisive factors, we also asked the voluntary adopters how they funded their PV systems. The results show us that the vast majority paid the PV system with their savings (66.7) and some with a mortgage (16.7). Remarkable, one respondent reported that the system was paid by an increase in rent of the building.

Table 23 shows the thresholds for non-adopters to adopt a PV system, ranked from important to unimportant. The results show us that the vast majority found the high investment cost of PV the most important aspect (58.3\%). This typically is a financial threshold. Many of these respondents mentioned that the financial arguments are the specific conditions which would be changed before they will consider the purchase of system. More in particular, $47.8 \%$ indicated that the investment has to drop significantly (ranked as the most important one) and $31.3 \%$ of the respondents would also adopt a system if there is an attractive subsidy program.

Table 23. Thresholds for making the step to adopt a PV system and the specific conditions to adopt a PV system, ranked from important to unimportant.

\begin{tabular}{|c|c|c|c|}
\hline Thresholds & $\begin{array}{l}\text { Percentage } \\
\left(1^{\text {st }}, 2^{\text {nd }} \text { or } 3^{\text {rd }}\right)\end{array}$ & Specific conditions & $\begin{array}{l}\text { Percentage }\left(1^{\text {st }}\right. \\
\left.\text { or } 2^{\text {nd }}\right)\end{array}$ \\
\hline Investment is too high & 58.3 & If the investment drops significantly & 47.8 \\
\hline I am not a home-owner & 28.8 & If the payback is 5 years max & 36.3 \\
\hline Energy yield is too low & 15.7 & $\begin{array}{l}\text { If there is an attractive subsidy } \\
\text { program }\end{array}$ & 31.3 \\
\hline $\begin{array}{l}\text { Fear of gaining promised } \\
\text { efficiency }\end{array}$ & 15.1 & Under no circumstances & 10.9 \\
\hline I live in an apartment & 15.0 & If the system is nicely integrated & 9.6 \\
\hline Not interested & 12.2 & If the system can easily be mounted & 6.7 \\
\hline Difficult to install & 9.6 & If the quality of the system improve & 5.9 \\
\hline Visual representation & 7.7 & & \\
\hline Fear of subsidy adjustments & 7.1 & & \\
\hline Plans to move & 6.7 & & \\
\hline
\end{tabular}

The fear of energy yield (15.7\%) and gaining the promised efficiencies (15.1\%) is also indicated as a reason to not adopt PV. A reduction in the payback period (maximum period of 5 years) is indicated as specific condition for making the step to adopt PV.

For many of the respondents, the physical non-accessibility and non-ownership of the house keeps them from adopting PV: 224 respondents indicated to not be a homeowner, 117 people is living in an apartment or flat and 52 respondents have plans to move. Technical complexity does not appear to be an important threshold. Only a small amount of non-adopters claim that the system is too difficult to install. Also the attractiveness of the system is not indicated as an important threshold, even a nicely integrated system is not ranked as a very important condition during the adoption process. Fi- 
nally, some respondents mentioned that they are not interested in adopting a system and will not adopt a system whether there are ideal or specific conduction available.

Apart from the thresholds above, we asked the respondents whether they think that the implementation of PV should be stimulated or not and how they think that actors in the field should take the lead in general, not per leader. In the importance of the different actors and aspects/instruments are ranked from important to unimportant.

Of the respondents in our sample, $90.5 \%$ indicated that PV should be stimulated. It was also explored to what extent actors in the field should play a role in the stimulation of solar energy. The government is seen as the actor who should take the lead (72.8\%), followed at a large distance by the municipality, gas and electricity companies and the European Union. Surprisingly, 155 respondents, 21.0\%, reported that they see themselves as the promising actor who should take the lead. This latter implies that for a reasonable group of people other actors has no or minimal impact on their decision to adopt a system.

Thus, different actors are expected to contribute to the implementation of PV, but the government is seen to be the most important actor who can make a difference by a vast majority of the respondents. According to the majority of the respondents, the government should create tax benefit (52.8\%), provide subsidies (legislation and regulation) (19.1\%), develop a vision (19.4\%) and set goals (9.3\%). The reason behind this, the implementation of PV is a long term trajectory depending on an enabling environment and coordinated action. Furthermore, the answers indicate that more information75 (31.6\%) is needed on solar energy. Although, public information on the ins and outs of PV seems to be important it will be not sufficient to stimulate the diffusion of PV. Coming back to the vision and goals, we have seen in previous work that this is a weak point in the implementation trajectory of PV and thus is definitely an area of concern.

\footnotetext{
${ }^{75}$ Information meetings can play a relevant role in the adoption process of people, providing information about the procedure for submitting a request or reducing their perception of the technical installation.
} 
Table 24. Actors and instruments/aspects by promoting the implementation of PV, ranked from important actor to unimportant actor.

\begin{tabular}{|c|c|c|c|}
\hline Actors & $\begin{array}{l}\text { Percentage } \\
\left(1^{\text {st }}, 2^{\text {nd }} \text { or } 3^{\text {rd }}\right)\end{array}$ & Instruments / aspects & $\begin{array}{l}\text { Percentage } \\
\left(1^{\text {st }} \text { or } 2^{\text {nd }}\right)\end{array}$ \\
\hline National government & 72.8 & Via tax benefit & 52.8 \\
\hline Municipality & 40.1 & By exchange of information & 31.6 \\
\hline $\begin{array}{l}\text { Gas and electricity } \\
\text { companies }\end{array}$ & 40.0 & By stimulation of innovations & 25.7 \\
\hline European Union & 38.1 & $\begin{array}{l}\text { By introducing a clear vision for the future which } \\
\text { show the effect of certain choices }\end{array}$ & 19.4 \\
\hline Provincial government & 22.1 & Via legislation and regulation & 19.1 \\
\hline $\mathrm{Me}$ & 21.0 & By limiting restrictive legislation & 11.8 \\
\hline Business & 16.0 & By introducing clear goals & 9.3 \\
\hline Science & 7.1 & $\begin{array}{l}\text { Through contracts with citizens, government and } \\
\text { industry }\end{array}$ & 9.3 \\
\hline Trade union & 1.5 & Others, e.g. lease construction, technology & 3.4 \\
\hline $\begin{array}{l}\text { Others, e.g. landlord, } \\
\text { housing cooperation }\end{array}$ & 1.5 & By addressing people with their responsibility & 3.0 \\
\hline
\end{tabular}

\section{Our explanatory variables}

Some key concepts from the different models are taken into account to help gauge people's perceptions of PV. From the work of Rogers, we will use the relative advantage and complexity as Rogers sees them as the two strongest predictors of successful adoption rates out of the five attributes as well as out of the diffusion literature as a whole (Rogers 2003). The concept complexity has substantial similarity among the construct definitions and measurement scales of perceived ease of use and effort expectancy (see Table 17, Table 18 and Table 19). The social influence towards the innovation and knowledge of grants and costs are included in the analysis as explanatory variables.

\section{Relative advantage}

The relative advantage refers to the perceived superiority of the innovation as compared with the existing values practices (Rogers 2003), in other words the degree that an innovation appears to be better than its preceding idea, practice, or object. An example of this is the adoption of mobile phones; potential users see the characteristics of mobility as an advantage thus the technology is perceived to be better than traditional telephones. Rogers theorizes that relative advantage is one of the strongest predictors of adoption rates to addresses the reduction of uncertainty. He argues that levels of uncertainty decrease when participants weight the benefits of a technology against the costs of adoption and perceive a low risk and high benefit (Rogers 2003). Similar findings are reported by Labay and Kinnear (1981), in their PV research relative advantage is indicated as an important characteristic (both economic and noneconomic considerations), the greater this characteristic is, the faster the rate of adoption will be (Ostlund 1974, Rog- 
ers 2003). Not all users, of course, perceive the same levels of relative advantage at the same time. Relative advantage is not something that can easily be measured. Different aspects are being weighed and compared. In the case of PV, the following aspects are important: the costs of adoption, the price of fossil fuels (which determine the economic value of solar power against fossil fuel alternatives), the esthetics of a roof with PV panels, and the wish to be environmentally responsible and to be seen as such. Rather than lumping these aspects together, we break down relative advantage in a number of components, as this will help us to determine which aspects are the most important ones. Our proxies are the expectation that solar energy will become cheaper than oil and gas (1), the expectation of increasing prices of oil and gas (2), the view that solar energy is the best available technology to be self-sufficient (3), the view that solar energy is the most sustainable energy source (4), the view that solar energy is environmentally benign (5) and the view that the investment of a system is affordable (6).

In this part we are interested in the factors that influence whether a respondent adopt a PV system. The outcome (response) variable is binary (0/1); reject or adopt. The predictor variables of interest are factors which refer to the (relative) advantage of having a PV system. The factors used in this analysis are given in Table 25

Table 25. We performed a Hosmer-Lemeshow test of goodness of fit. This test is similar to a Chi Square test, and indicates the extent to which the model provides a better fit than a null model with no predictors, or, in a different interpretation, how well the model fits the data, as in log-linear modelling. If chi-square goodness of fit is not significant, then the model has adequate fit. By the same token, if the test is significant, the model does not adequately fit the data. The Hosmer-Lemeshow test for the representative sample of Dutch population is not significant ( $\mathrm{Chi}^{2}$ 3.446; sig. 0.632) which indicates adequate fit (model prediction that is not significantly different from observed values) and therefore our model can be used to analyse whether there is an influence on the adoption of PV.

Table 25. The influence of relative advantage as a predictor for adoption of PV.

\begin{tabular}{|c|c|c|c|}
\hline \multicolumn{4}{|l|}{$\begin{array}{l}\text { Relative advantage - The perceived superiority of the innovation a } \\
\text { practices }\end{array}$} \\
\hline \multicolumn{4}{|l|}{ Logistic regression analysis ( 0 = rejecters; 1 = voluntary adopters) } \\
\hline Predictors & B & Sig. & $\operatorname{Exp}(B)$ \\
\hline The investment of a system is affordable & $3.438^{*}$ & .000 & 31.118 \\
\hline Solar energy is the best available technology to be self-sufficient & $-2.477^{* *}$ & .039 & .084 \\
\hline $\begin{array}{l}\text { Increasing prices of oil and gas will support the use of solar } \\
\text { energy }\end{array}$ & -1.353 & .299 & .258 \\
\hline Solar energy is considered as the most sustainable energy source & .863 & .418 & 2.369 \\
\hline Solar energy will become cheaper than oil and gas & .058 & .957 & 1.060 \\
\hline The environmental benefits of solar energy are positive & 19.630 & .998 & $3.351 E 8$ \\
\hline
\end{tabular}

* Significant at the 0.01 level; ** Significant at the 0.05 level; *** Significant at the 0.1 level 
In this research we used binominal logistic regression analysis because we want to be able to predict the presence or absence of an item or characteristic based on values of a set of predictor variables. This analysis is similar to a linear regression model but is suited to models where the dependent variable is dichotomous, as is the case in this research. In this research the binominal logistic regression analysis was conducted by using the relevant relative advantage concepts as the predictors of adoption or rejection the technology. In this analysis respondents are coded 1 for voluntary adopters and 0 for rejecters, and predictors coded 1 for agree with the statement and 0 for not agree with the statement. The coefficient is given in the column labeled " $\mathrm{B}$ " and the odds ratio is given in the right-most column labeled " $\operatorname{Exp}(\mathrm{B})$ ".

The results show that the first two items are statistically significantly $(P<0.05)$, the effect on adoption of the other concepts is not significant. The results suggest that the investment of a system is affordable is the best predictor for PV adoption (positive significant value of $B ; P<0.01$ ). The positive value of $B$ indicates that for the statement that the investment of a system is affordable the target group (voluntary adopters) tends to have more of those coded ' 1 ' (agree with the statement) than of the code ' 0 ' (not agree with the statement), after controlling for the other predictors. Thus, for voluntary adopters the system is affordable but the rejecters see the investment they have to do as an issue for not adopting a system which corresponds with the results of the descriptive analysis. The descriptive analysis tells us that the price of a solar system is indicated as the most important issue perceived by the respondents ${ }^{76}$ (66\%). However, the affordability of the system is considered as low by the non-adopters (6.5\%) and high by the adopter (60\%). The financial advantage adopters have with having PV was also one of the main reasons for adopting which corresponds with our earlier findings (see thresholds and benefits).

The predictors increasing prices of oil and gas will support the use of solar energy and solar energy will become cheaper than oil and gas ${ }^{77}$ are not statistically significant predictors for past adoption. In the table we see that solar energy is the best available technology to be self-sufficient has a statistically significant effect on the prediction of the adoption process (negative significant value of $B ; P<0.05$ ). The negative $B$ indicates that the voluntary adopters tend to have more of those coded ' 0 ' than ' 1 ' compared to the rejecters. Thus more rejecters than voluntary adopters agreed with this statement which shows that it is a predictor that influences whether a respondent reject a system. A possible explanation for this remarkable finding is that adopters are also more aware of

\footnotetext{
${ }^{76}$ Since the questionnaire did not ask people about the relative importance of the several aspects of this price (purchase, operating costs, maintenance costs, and insurance rates) it is impossible to determine which are perceived as most important.

${ }^{77}$ This aspect is added as a reason for delaying the solar investment.
} 
other green technologies, some of which may be preferred over PV. However, this cannot be confirmed. The self-sufficiency is an important reason for owning a PV system; the descriptive analysis shows that $83.1 \%$ of all the respondents agreed with this statement.

The environmental benefits of solar energy do not come out as a predictor for adoption of a system. From this we can conclude that financial aspects play a more important role than the environmental benefits. Other items which relate to the concept of relative advantage are improvements on the system are necessary and the system is profitable. These items are not asked to all four groups (see method) and therefore it was not possible to include these in this analysis, nevertheless we can still describe these items. $31.8 \%$ of the respondents reported that improvements of the system are necessary before they consider adoption, which indicated that it is not the best predictor for adoption. A good predictor for adoption, however not statistically proven, is the profitability of the system, $73.1 \%$ of the adopters indicated this as important item, which had a big relative advantage during the adoption process.

\section{Complexity}

In the previous part we investigated factors that had an influence on the voluntary adoption of a PV system. The results suggest that the financial aspect have an important influence for adopting or not adopting a system. However, we are also interested in factors related to the complexity of a PV system that have an effect on the respondents that are labeled as potential adopters of PV compared to the rejecters (again a binary variable). Complexity is the perceived degree to which an innovation appears difficult to understand and use, and is a subjective perception. Complexity involves both usability (easy or difficult to use) and comprehension (easy or difficult to understand), but the two can be viewed as separate in mind of potential adopters. For instance, one may perceive a technology as simple to understand (online banking) but difficult or inconvenient to use (no internet access), which is why we should take both aspects to provide a full depiction of complexity.

Solar energy, or a PV system, is a complex and abstract concept for which is assumed that people might not recognize what it exactly is and how it can precisely contribute to the reduction of $\mathrm{CO}_{2}$. We found out that it is difficult to test the generic knowledge of PV as there is a discrepancy between what people say they know and what they actually know. To respond to this, we use some obvious factors related to the complexity of the system to identify their influence: (1) technical knowledge is not a barrier, (2) the subsidy procedure is clear, (3) the application of a system is easy, (4) enough information is available on solar energy and the possibilities, (5) importance of environmental benefits (see Table 26). Respondents are coded ' 0 ' for rejecters and ' 1 ' for voluntary adopters; 
predictors coded ' 0 ' for not agree with the statement and ' 1 ' for agree with the statement.

Table 26. The influence of complexity as a predictor for potential adoption of PV.

\begin{tabular}{llll}
\hline Complexity - The perceived difficulty to understand and use the innovation & & & \\
\hline Logistic regression analysis ( $0=$ rejecters; $1=$ potential adopters) & B & Sig. & Exp(B) \\
Predictors & $-.802^{*}$ & .000 & .449 \\
\hline Enough information is available on solar energy and the possibilities & $1.725^{* *}$ & .002 & 5.615 \\
Importance of environmental benefits & $.431^{* * *}$ & .099 & 1.539 \\
The application of a system is easy & .251 & .352 & 1.286 \\
The subsidy procedure is clear & .190 & .433 & 1.209 \\
Technical knowledge is not a barrier &
\end{tabular}

* Significant at the 0.01 level; $\quad * *$ Significant at the 0.05 level; $* * *$ Significant at the 0.1 level

The results show that the relationship between the complexity items and adoption can be analysed; the chi-square test is not statistically significant (.661). In the logistic regression analysis, the availability of information had the largest significantly $(P<0.001)$ negative influence on the adoption intention. The negative $\mathrm{B}$ for the statement enough information is available on solar energy and the possibilities indicates that more potential adopters answered that there is not enough information available. Thus, this statement is not a predictor for whether a respondent will adopt a system. Rather it is a predictor which shows that one of the reasons why potential adopters have not adopted a system at the moment is that they lack knowledge about PV. These findings suggest that public information about the possibilities and the procedures may be helpful to those interested in adopting PV. However, there is no evidence that such information alone would motivate anyone to buy a system. Similar findings are reported by Kaplan (1999) and Jager (2006).

Two positive significant predictors for the willingness to adopt are the importance of environmental benefits and the application of a system is easy. The latter is in contract to the negative predictor of the availability of information and the possibilities of it. However, $47.8 \%$ of the non-adopters reported technical knowledge as a barrier which indicates that the provision of technical knowledge would be necessary. But, such information might fall on deaf ears unless its recipients have already been motivated to adopt it (potential adopters), which confirmed this result (potential adopters (1) agreed more with the statement (1) than rejecters).

While information alone will not change the decision, clear and understandable product information could help raise consumer awareness of environmentally friendly products, in our case a PV system. This could, in turn, increase the purchase of PV because the product is more familiar, the product benefits are more transparent, and the behavior could potentially be more convenient for the consumer. This is in line with the second 
positive statistically significant item $(P<0.05)$ as the environmental benefits have a positive influence for potential adopters with respect to rejecters (potential adopters (1) agreed more with the statement (1)). Thus, the importance of environmental benefits of the system is a good predictor in the adoption process.

\section{Social influence}

The social influence is the degree to which an individual feels pressure from others to adopt an innovation. Such influence may be important or not, depending on whether people are independent decision makers or not. We designed some proxies for social influence and independence of decision-making, which are (1) whether they take big decisions dependent of others, (2) try to be an example for others (3) put themselves in service of others, (4) feel pressure from friends and family to purchase solar panels (see Table 27). We analysed whether those factors differ between potential adopters of PV and rejecters. It is also interesting to analyse whether the actual adopters were influenced by their social environment or the social nature of a person. In our analysis social influence does not come out as a significant factor. None of the variables used has a significant influence on adoption.

Table 27. Logistic regression analysis using relevant factors for social influence, an analysis between potential adopters and rejecters.

Social Influence - The degree to which an individual perceives that important others believes he or she should use the new system

\begin{tabular}{lccc}
\hline $\begin{array}{l}\text { Logistic regression analysis ( } 0=\text { rejecters; } 1=\text { potential adopters) } \\
\text { Predictors }\end{array}$ & B & Sig. & Exp(B) \\
\hline I feel pressure from social environment to purchase solar & .178 & .724 & 1.195 \\
panels & & .157 & .855 \\
I take big decisions dependent of others & -.098 & .894 & 1.026 \\
I like to pose myself in service of others & .178 & .724 & 1.195 \\
\hline I try to be an example for others
\end{tabular}

* Significant at the 0.01 level; ** Significant at the 0.05 level; *** Significant at the 0.1 level

For this analysis we coded the respondents with ' 0 ' for rejecters and ' 1 ' for potential adopters, and predictors coded ' 0 ' for not agree with the statement and ' 1 ' for agree with the statement. The effect on adoption of all the concepts is not significant, nevertheless, this is also an interesting result. This result indicates that none of the predictors can influence the adoption process, thus rejecters and potential adopters did not answer differently on the different statements.

The descriptive analysis shows that only $2.6 \%$ of the potential adopters and $2.5 \%$ of the rejecters agreed with this statement. However, it is likely that the individual will adopt a particular attitude when a large portion of an individual's referent social group holds it as well. Additionally, it is also expected that individuals change their opinion under the influence of another who is perceived to be an expert in the matter at hand. Since the 
questionnaire did not contain a question about the relative importance of these aspects it is impossible to determine which are perceived as more important.

\section{Knowledge of grants and costs}

To study the influence of knowledge of grants and costs we queried voluntary adopters and rejecters to indicate their agreement of different factors related to their familiarity and knowledge of grants and costs of adoption. Our model is not significant (.208), suggesting that knowledge variables are not strong predictors for adoption. Our proxies for this analysis are the expectation that - the subsidy procedure is clear (1), the view that people are familiar with the costs of solar panels (2), and the view that people are aware of grants. We do find some evidence that knowledge matters.

Table 28. Logistic regression analysis using relevant factors for knowledge of grants and costs. an analysis between potential adopters and rejecters.

Knowledge of grants and costs - This refers to knowledge of grants and costs that promote environmental protection; positive incentives designed to control activities that may be harmful to the environment.

Logistic regression analysis ( $0=$ rejecters; $1=$ potential adopters)

\begin{tabular}{llll} 
Predictors & B & Sig. & Exp(B) \\
\hline The subsidy procedure is clear & $.520^{*}$ & .000 & 1.682 \\
Familiar with the costs of solar panels & $.351^{* *}$ & .019 & 1.420 \\
Aware of grants & $.253^{* * *}$ & .094 & 1.288 \\
\hline
\end{tabular}

* Significant at the 0.01 level; ** Significant at the 0.05 level; $* * *$ Significant at the 0.1 level

The results show that all the items related to knowledge of grants and costs have a positive influence on the adoption process (positive significant value of $B ; P<0.1$ ). More in detail, the positive values of $\mathrm{B}$ indicates that for the different statements the target group (voluntary adopters) tends to have more of those coded ' 1 ' (agree with the statement) than ' 0 ' (not agree with the statement). To say it in words, for rejecters, the subsidy procedure is less clear, they are less familiar with the costs of solar panels and less aware of grants. Of these variables, the best predictor for potential adoption of a PV system is that the subsidy procedure is clear, the second predictor is that they are familiar with the cost and also often are aware of grants, third predictor. Provision of public information about the possibilities and the procedures may be helpful to those interested in. however there is no evidence that such information alone would motivate anyone to buy a system.

Looking at the adopters, it was found that six respondents have used a subsidy program and two a stimulation program. For all these respondents (8) the program had a decisive role. Eight out of the 18 have used a program which corresponds with $44.4 \%$. It was also found that ten respondents installed the system themselves. 


\subsection{Conclusion and discussion}

In this paper we studied factors behind the adoption and non-adoption of PV in the Netherlands. The main purpose of this paper was to gain insight in and to understand the adoption of PV in the Netherlands from a user perspective. In examining the adoption of PV, we examined the explanatory power of some the key concepts introduced by Venkatesh, the perceived components introduced by Rogers, some concepts introduced by Davis and some sub categories of the work of Kemp and Schot. In our analysis, the influence of the following four factors was studied: the perceived relative advantage and complexity of the innovation, social influence, and knowledge of grants and costs. Different measures were used to investigate the relative importance of those factors and specific elements thereof.

Descriptive analyses are conducted to analyse the perception of a representative sample of the Dutch population (e.g. motives and thresholds behind the adoption process) and logistic regression analyses are used to identify positive predictors for adoption. A segmentation model, based on the adoption or rejection of PV, is used for grouping the respondents. The main added value of the segmentation model is that non-adopters are not seen as a homogeneous group but as two groups: one group of potential adopters and one group of rejecters. Over time it is possible that rejecters become potential adopters and even proceed to adopters. In our view, we offer a novel contribution to the literature through the use of a segmentation model which adds insights in adoption research.

In our analysis, we studied the motivations for adoption for the subgroup of adopters and compared the relevance of different factors for non-adoption for the subgroups of potential adopters and rejecters. The analysis is based on attribute perceptions instead of on objective data. What we find is that that for adopters the costs of adoption are considered affordable, whereas for non-adopters they are viewed as being too high. The differences have to do with adopters valuing the benefits of this technology more than non-adopters. Whether they adopt or not adopt PV panels is just not a matter of costs only, although they certainly are an important element. Unless electricity prices rise significantly and the costs of PV systems decrease substantially, we expect the diffusion of PV systems to be slow.

Furthermore, we find that one of the reasons why potential adopters have not adopted a system so far is that they lack knowledge about PV. The importance of this was revealed through the statistical analysis, where we found that knowledge about PV is a predictor for adoption. (The influence of this variable was revealed through the statistical analysis. The lack of knowledge was not a self-stated reason for non-adoption.) This suggests that better information about solar energy will stimulate adoption. Not only information of the costs and quality aspects is important, also information on social and 
environmental matters. The importance of the latter and the knowledge of grants and costs were found to be positive predictors for the willingness to adopt. This suggests that two useful strategies to stimulate the diffusion of PV are: to reduce the investment costs and increase the knowledge about it. The relative effectiveness of both strategies cannot be determined from our analysis.

Our empirical results show similarities and differences from those found in other empirical literate on adoption of PV. We found that knowledgeability has a positive influence on future adoption which confirms the empirical findings of Labay and Kinnear (1981) on the role of knowledge. This suggests that public information about the possibilities and the procedures may be helpful to those interested in adopting PV (potential adopters). Similar findings are reported by Kaplan (1999) and Jager (2006).

The innovativeness of a system, the visual aspect and the ease to install a system are less important motives for people to adopt a system. These results are not in line with the research of Jager (2006) and Palm and Tengvard (2011), who rated the contribution to a better natural environment as the most important motive for adoption. Palm and Tengvard (2011) also indicated the symbolic meaning as an important aspect which is also not in line with our findings. In the study of Jager [19], savings on the electricity bill was not included in the list of motivating factors which is a reason for why it was missed. In the study of Palm and Tengvard (consisting of 20 interviews in Sweden) savings on the electricity bill did not come out as an important issue but perhaps this was not asked. The study does bring out that the high costs of investments act as a barrier, which shows that economic aspects do matter. The economics of PV are a complex issue because it can be viewed in different ways: in terms of the payback period (which has to low enough) or in terms of costs savings on the energy bill. It is an issue for deeper analysis.

We also want to point to weaknesses in our study. A first weakness is that we did not incorporate the influence of opportunity costs and competition with other products in the analysis. A second weakness is that we did not do a deeper analysis of the social environment as a facilitating and constraining factor. Thirdly, the exact influence of effort expectancy behind the adoption and non-adoption of PV could not be determined in this research. Fourthly, we were not able to determine the influence of anxiety because it was not included in our questionnaire.

Perhaps the most salient finding is that for some adopters the cost of adoption are acceptable, and for others not. This shows that adoption depends on attribute perceptions. Perception of attributes and the attributes themselves are interrelated. An interesting question is whether government can have a greater effect on adoption decisions by reducing the costs of adoption or by changing the perceptions of existing costs, giving budget constraints and the ability of government to alter cost perception. 


\section{Chapter 9: \\ The role of users in socio-technical transitions - Local energy initiative PV}





\subsection{Introduction}

In this chapter a local energy initiative (LEI) ${ }^{78}$ is studied to analyse how individuals as real people interact with each other to learn about PV and what decisions they reach in terms of adoption and non-adoption. LEls are part of a trend away from the present conventional top-down and centralized structures of energy provision towards innovative bottom-up and decentralized managed methods of energy provision. Agentschap NL (2011) describes it as an independent business-like operating entity that has the objective to execute local generation and/or delivery of sustainable energy in the form of heat and electricity and to realize energy savings. This description is in line with the definition of the Ministry of Economic Affairs (2013), who defines a LEI as 'an entity that generates and/or uses ${ }^{79}$ local energy, whereby energy can consist of sustainable heat and/or sustainable electricity'. The concept of local energy is then again defined, according to the vision of Minsitry of Economic Affairs, as 'energy generation whereby the produced energy is used in proximity of the place where the energy is generated' (Min EZ 2013 p. 2-3). Within this context, it implies that the generation and/or delivery of energy and/or energy saving takes place within a geographically area. Often it is a partnership of citizens or local parties and a municipality or housing association. Many of the current initiatives are driven by the needs for social benefits, such as contributing to more sustainable energy or controlling energy costs for residents (Agentschap NL 2011 p.4). Thus, the general idea behind the LEls is that it is a (self-supporting) participatory energy generation project in which energy is produced in the vicinity of the participants. This means that a participant is both the producer and the consumer of the electricity and that the electricity is produced in the vicinity of its users. During the last years, the emergence of these initiatives in the Netherlands has shown a substantial growth. In 2011, there were known approximately 50 existing and beginning initiatives, mid 2012 there were 300 and at the end of 2012 about 1500 of them (Oostra and Jablonska 2013). Due to their recent emergence little is known about the factors that stimulate or hamper the appearance and development of this phenomenon. Therefore the purpose of this chapter is to understand this new phenomenon. We would like to further narrow down the unit of analysis to LEIs using solar energy (LEI-PV) that both produce and consume (prosume ${ }^{80}$ ) local energy in the form of electricity. The restriction to PV can be motivated by the argument

\footnotetext{
${ }^{78}$ This phenomenon is also known as Energy Service Companies (ESCOs) or Local Renewable Utilities (LRU). Currently there is not a common term used for this phenomenon but we prefer initiatives above companies or utilities because it also covers projects with a certain time range and/or goal (e.g. 20\% renewables before 2020).

${ }^{79}$ For the purpose of this research, the term delivery that was present in the definition of Agentschap NL is replaced by the term use. The reason for this is that under current Dutch legislation it is impossible for a LEI to deliver its own energy to the public (low-voltage) grid without involvement of an energy supply company (Elektriciteitswet 1998, Art. 95a, lid2, sub a and c). Therefore, the term use captures more adequately the main characteristic of a LSEI which is that the producers are at the same time the users of local energy.

${ }^{80}$ Prosume is a portmanteau formed by contracting produce with the word consume.
} 
that LEI-PV are most numerous and are growing at a particularly quick rate (Polder-PV 2012). Consequently, LEls that have already achieved this ambition (both prosume and consume local energy in the form of electricity) can be considered as frontrunners within the field. These frontrunners are especially relevant for the identification of drivers and barriers as they might indicate future trends within the field of LEI as well. The governmental demand provides room for these initiatives to diffuse and develop themselves further is particularly strong. This demand directed at local initiatives using PV is amongst others visible in the motion of Dutch politician van der Werf on December 5, 2011. Van der Werf requests the government to examine how (collectives) domestic consumers, who want to produce decentralized renewable energy for their own use, can be empowered by developing low-threshold models and where necessary adapt laws and regulations within responsible financial frameworks for the state (Overheid.nl 2011). But also the letter from e-Decentraal directed to the political leaders responsible for the formation of the government in October 2012 shows the demand for these initiatives. In this letter, e-Decentraal states that a number of legal barriers have to be solved in order to make decentralization of renewable electricity generation methods possible. PV is mentioned as one of the options besides wind energy and hydropower (e-Decentraal 2012). This in turn might have led these political leaders to specifically mention solar initiatives - next to generally referring to local energy generation - when proposing a diminished fiscal tariff for local energy as one of the key measures that the government intends to implement in its government term (Regeerakkoord 2012 p.9).

In this chapter the focus is on the people in a neighbourhood involved in making a decision about buying PV, the interactions between the people and learning processes. The neighbourhood Biesland in the city of Maastricht is used as case study. Data is collected via a questionnaire and follow-up interviews. The questionnaire took place in June 2012 and follow-up interviews were conducted from October 2013 to January 2014 with people in the neighbourhood.

The structure of this chapter is as follow. Section 2 offers a description of LEI-PV ${ }^{81}$ including a part which describes the structure of a LEI-PV in terms of actors, networks and institutions. Section 3 describes the case Biesland Solar and section 4 states the conclusions and offers a discussion.

\subsection{Local Energy Initiative - PV}

The literature on LEls can be distinguished in three strands of research: (1) the role of public perceptions and community ownership in local sustainable energy initiatives; (2) the future prospects of local energy in order to conclude with policy recommendations; (3) the variety of factors that account for differences between countries regarding the

\footnotetext{
${ }^{81}$ Note, it is not our purpose to be exhaustive, but rather to broaden insight in the applicability of an initiative.
} 
role of local sustainable energy. In these strands, decentralisation of energy provision through LEls appears on multiple levels, ranging from individual households to regional cooperative arranged organisations, and can involve a diverse composition of actors with different motives, responsibilities and forms of ownership. Moreover, renewable energy within an initiatives/organization can be generated through multiple technologies, e.g. solar energy or wind energy. Because of these reasons, there exist many different ways in which these technical and social aspects can interact with each other. From the complete spectrum of possible interactions, Walker and Cass (2007) outlined five modes in which renewable energy has been implemented in the UK and how these involve different configurations of technology and social organisation. They specifically use the term mode in preference to the terms regime and niche that are commonly used in the literature on socio-technical systems since mode allows for greater simultaneous heterogeneity and avoids some of the problematic assumptions of the deliberate nested hierarchical transition management framework (Walker and Cass 2007). The five modes are public utility, private supplier, community, household and business. In line with the above mentioned description of LEls, the community and household mode discussed by Walker and Cass (2007) are interesting in this research as the focal point is on local arrangements founded by civilians or inhabitants, which enables community members to own and utilize renewable energy technologies.

Based on the description of a LEI, a plethora of different initiatives can be distinguished that vary in locality on both process and outcome dimensions. More specifically, these initiatives can roughly be split up into two main categories namely the LEls that form technology specific local sustainable initiatives and local sustainable energy companies (Schwencke 2012). Although this is not a clear cut categorisation, since technological specific local initiatives can also be local sustainable energy companies and local sustainable energy companies can also finance/participate in technological specific LEls, it is nevertheless useful to perceive them as a distinct category because they each have their own internal developmental dynamic (Schwencke 2012).

For the first category, technology specific local sustainable initiatives, roughly four different sources of energy can be distinguished, namely wind energy, solar energy, biomass and geothermal energy. A variety of technologies can be used in order to generate energy in the form of electricity, gas or heat. The second category, the local sustainable energy companies, often makes use of different sources of energy. They can also be involved in the trading of energy ${ }^{82}$. Lots of these companies were founded as a direct response to dissatisfaction with the market power of those large suppliers, therefore, these initiatives should not be seen as local front offices of national energy suppliers

\footnotetext{
${ }^{82}$ They purchase energy from (other) sustainable energy producers and they sell and deliver this energy to their own customers.
} 
(Schwencke, 2012, p. 22). Texel Energie and Zutphense Energietransitie are two examples of this latter category.

Within the PV technology, three different types of initiatives can be distinguished (See Table 29). Between these three types of initiatives, there is a considerable overlap between the technology specific local sustainable initiatives and local sustainable energy companies.

Table 29 Types of initiatives.

\begin{aligned} \hline Type of initiative & Description (Schwencke 2012, Wijnbergen 2013) \\ \hline District initiative & Production and/or use of sustainable electricity typically take \\ & place within a city district, neighbourhood or other socially \\ & and geographically delineated area. Social cohesion plays an \\ & important role in these initiatives, consequently, cooperation \\ & on energy sometimes spills over to other areas such as \\ & communal gardens and car sharing. Initiatives that fall within \\ & this category can be initiated by homeowners associations \end{aligned}

Collective procurement of the technology
Energy suppliers offer PV panels packages with attractive discounts. Energy suppliers see these packages as an opportunity to both attract and retain customers. Usually, there is first a subscription round and when there are enough subscriptions, the initiatives orders the panels. Therefor the price is not fixed before the subscription.

Separation between ownership of Initiatives whereby PV panels are owned by the participants of the initiative and are being placed elsewhere e.g. roofs of technology and location of energ production farmers, government buildings or company buildings. In this type of initiatives, the ownership of the panels and the owngy ership of the location where the solar energy is generated are strictly separated.

It is difficult to distinguish these initiatives from local sustainable energy companies, especially when they also formulate the objective to also deliver sustainable energy to their members. The practice of salderen ${ }^{84}$ plays a role by these initiatives.
ENERGIE van

boerENbuur

(farmers and neighbours invested some of their savings to collectively

purchase a PV installation, placed on the roof of a farmer)

\footnotetext{
${ }^{83}$ A homeowners association is an organisation made up of neighbours concerned with managing the common areas of a condominium complex.

${ }^{84}$ Salderen can be described as a current practice in the Netherlands whereby the amount of electricity that is produced behind a retail connection is netted with the amount of electricity that is consumed. As a result no energy tax and VAT (value added tax) is levied on the amount of energy that is produced behind this retail connection. only on the electricity that is fed into the grid AgentschapNL (2012). Zonnestroom en de Nederlandse wetgeving. Utrecht, Agentschap NL - NL Energie en Klimaat..
} 
The structure of the LEI-PV

In the innovation diffusion theory a technological innovation is often examined in terms of three structural components, namely actors, networks and institutions (Bergek, Hekkert et al. 2008 p.81). The actors include firms within the whole value chain (Porter 1985), as well as universities, industry organisations, intermediary organisations, NGOs and government bodies. The networks can be both 'learning networks', which can link suppliers with users, related firms, competitors or researchers, and/or 'political' networks (or advocacy coalitions). The third component, institutions, is at the heart of the process whereby new technologies gain ground (Bergek, Hekkert et al. 2008).

A LEI-PV is not a technological innovation because it is not a new technology, although, it can be seen as a social innovation for the PV technology that can made the applicability cheaper. However, this does not make the LEI-PV an innovation, the fact that LEI-PV applies PV in a new product makes it an innovation. The new product is electricity from your own PV panels that, in most cases, are installed and maintained for you against a competitive price, no matter how long you choose to use these panels. In this way, the customer/participant is provided with the means to produce and use their own local energy and to do so according to his or her own specifications. When the PV panels are producing more electricity than is used, the excess of electricity is fed into the grid. This is another product than is offered by traditional energy companies like Essent or Eneco, they sold electricity (conventional energy or energy from renewable energy sources) rather than the means to produce and use it. Thus, a LEI-PV can be seen as an innovation which makes the structural component of a technological innovation system (see section 2.3.3 technological innovation system approach as analytical framework) also feasible to describe these initiatives in terms of actors (e.g. firms and other organizations), networks and institutions (Jacobsson and Johnson 2000, Carlsson, Jacobsson et al. 2002).

\section{Actors}

The actor constellation within a LEI is slightly different from other technological innovations as the traditional boundaries between suppliers (producers) and users (consumers) are blurred in a LEI. The reason for this is that the members of a LEI are simultaneously involved in the production and consumption of energy (Wijnbergen 2013). The term prosumer, originated from Alvin Toffler who first used the term in his 1980 book The Third Wave, is often used to describe this phenomenon. Toffler defined the prosumer as someone who blurs the distinction between a consumer and a producer (Toffler 1980) ${ }^{85}$. However, in this research the term consumer-citizens is used instead of the notion of prosumers. These consumer-citizens are individuals who makes their choices based on social, economic and ecological considerations and ideally form the largest group. It are the group of actors who have to join the initiative and can make a success story out of it.

\footnotetext{
${ }^{85}$ It is used to describe consumers who were predicted to each become active to help personally improve or design the goods of the market place, transforming it and their roles as consumers.
} 
The most important actors within a LEI are the initiators, but there are also the supply side firms such as the energy companies (e.g. Nuon, Trianel, Green Choice, Eneco) and the suppliers of the PV panels from both the Netherlands and abroad (Germany and China).

There is a variety of intermediaries active in this field such as Hier Opgewekt, eDecentraal and ODE. Banks are also important actors as cooperation often requires external capital to start up. Government organisations such as the Ministry of Economic Affairs, Agentschap NL, regional governments and municipalities are also involved in these initiatives. The demand side is composed of the members of the LEl including their social connections.

\section{Networks}

The learning network and political network, as decribed before, are quite difficult to distinguish; they develop simultaneously. These interchangeable networks are important for LEIs because they link the different actors, but also influence the expectations of the future, share a set of beliefs and seek to influence the political agenda. These are important processes because the initiatives need to gain ground and engage in the wider political debate in order to be successfully diffused and implemented. Since the end of 2011, policy networks or advocacy coalitions that lobby the government were formalised through the organisation e-Decentraal.

\section{Institutions}

Institutions consist of three types, namely regualative institutions, normative institutions and cognitive institutions.

The main regulative institutions that are of importance for the future success of LEI-PV in the Netherlands are policy goals and programs and can roughly divided into six different elements (Wijnbergen 2013): (1) overarching target on the share of sustainable energy within the Netherlands; (2) subsidy programme - SDE+; (3) regulatory framework (set within the Elektriciteitswet 1998) (AgentschapNL 2012); (4) Green Deals - a agreement between the government and civil society so that civil society can set up projects that contribute to more sustainable energy (Rijksoverheid 2012); (5) national innovation policy - R\&D budgets for sustainable energy are being awarded (Topsector Energie 2012).

Also socially shared expectations of appropriate behavior and social exchange processes played a role in LEI-PV (normative institutions). And finally, to a lesser extent, cognitive institutional support, e.g. creating shared identities. 


\subsection{Biesland Solar}

\section{A reconstruction of the initiative and research process}

The case Biesland Solar is a typical bottom-up project, initiated by a group of local citizens from a diversity of backgrounds (i.e. accountant, entrepreneur and researchers of the university - including myself). The main idea was to involve the expertise that existed within the own community', without spending funds on lawyers, process managers and consultants. Hence, the formation process of Biesland Solar was deliberately built on personal expertise. The aim of Biesland Solar was twofold: (1) to use renewable electricity from the sun generated within the neighbourhood entirely locally by linking it to energy demand from homes and businesses; (2) to assist the social aspects involved in the process of moving toward sustainability (my contribution). The latter centered around the following question: how do you get the people in the neighborhood to the point where they want to switch to renewable energy?

Biesland Solar was formally launched with a press conference on November $11^{\text {th }} 2011$, National Sustainability Day. Thereafter the initiators (including myself) and other people interested in the project met each other on a weekly basis, all driven by their own motivations and reasons. During these meetings, opportunities and threats to the initiative were discussed and occasionally municipal practitioners (economy and sustainability) and policy makers were invited to join the discussions. The outcome of these meetings was that the Biesland Solar initiators were further strengthened in their belief that local efforts can help to realise the large-scale implementation of PV, which was also already proven by more than hunderd local initiatives within the Netherlands. Hence, they decided to continue the start-up of their own LEI.

Prior to developing the business plan of the Biesland Solar Cooperation, the following steps were taken: (1) recruitment of people who were interested and willing to contribute to the initiative; (2) the formulation of ambitions, goals, and priorities as well as detailing how to cooperate (including assigning the different tasks and roles); and (3) setting into place the different building blocks (technical, legal, financial and organisational) of the initiative.

The outcomes of this three-step approach were included in the formulation of the main aims of Biesland Solar, namely: (1) o offer all the inhabitants of the neighbourhood the opportunity to buy PV panels packages with attractive discounts through collective purchase; (2) the installation and maintenance will be provided and regulated through the cooperation; and (3) the cooperation provides information to the inhabitants and thus encourages them to use renewable energy, in particular solar energy, and to match their energy demand to the supply. 
A next step of the cooperation was to place an advertorial in a local newspaper in which they promoted Biesland Solar, calling on other consumer-citizens to join this initiative. Also an information meeting was organized in the neighbourhood to inform the inhabitants about the ins and outs of solar energy. A wide range of aspects were covered to account for the fact that different people will have different interests in PV. Not only information concerning costs and quality aspects was presented, also information on social and environmental matters.

For me, this information meeting offered an excellent opportunity to introduce and explain the current study to the participants. First I introduced myself as a researcher at the University of Maastricht, who is investigating the reasons for adoption and nonadoption of PV in the Netherlands. Accordingly, I explained to the meeting's participants that Biesland Solar provided an interesting case study, as Biesland represents a well-todo neighbourhood in the city of Maastricht. It is fair to assume that most inhabitants are able to finance a PV system, based on income and education. Additionally, I emphasised that this research addressed the need to study how individuals as real people interact with each other to learn about PV and what decisions they make in terms of adoption and non-adoption. After explaining that a questionnaire is a well-accepted research tool to collect individual-specific information, such as attitudes or knowledge, I asked them to fill out the questionnaire, which contained both open and closed question.

The questionnaire first addressed a number of general solar energy topics in order to collect data for testing differences in tacit knowledge and preferences between individual respondents. For several multiple-choice questions there was the option to leave the answer undecided. The questionnaire continued with questions that specifically aimed at investigating the usefulness of the meeting. All questions were kept as simple as possible to ensure that the research population would understand the questions. The final part of the questionnaire consisted of some demographic questions (e.g. age, gender, income, education level).

The questionnaire was completed by 18 people, which corresponds to 18 households in the neighbourhood Biesland interested in the adoption of a PV system. All the respondents were homeowners and all indicated to be satisfied with their living situation. Additionally, 17 out of the 18 respondents indicated that they were considering the purchase of a PV system. This outcome shows the interest in adopting the technology. The questionnaire results will be further discussed in the next section.

In the weeks after the information meeting, several participants requested for a calculation to compute the size, the actual costs and benefits of installing a solar energy system. The calculations were provided by one of the initiative takers of Biesland Solar. All inhabitants of the neighbourhood were offered the opportunity to purchase a PV panel 
package with an attractive discount. Some people made use of this opportunity, while others choose not to.

After the first information meeting, the Biesland Solar cooperation organized several meetings for cooperation members only in the period after the information meeting, however, the meetings proved to be not very constructive. One of the biggest problems was that people joined the meeting unprepared, not knowing what they wanted to get out of the meeting. A stated purpose or agenda was missing which resulted into aimless social gatherings rather than productive working sessions. On top of this, one of the board members who is naturally long-winded, talked a lot and monopolized the meeting time which turned off other meeting participants. These unmanaged meeting problems resulted in wasted time and frustration. Some even indicated to dread attending future meetings.

In the end, no follow-up was given to the meetings, the board had a wait-and-see attitude. The initial idea was to organise a follow-up workshop so that making progress and learning could continue, however, this workshop has not taken place so far.

One and a half years after the information meeting, I conducted follow-up interviews, among the meeting participants and other citizens in the neighbourhood Biesland, with 3 adopters and 8 non-adopters among the meeting participants and other citizens in the nieghbourhood Biesland. The main aim of these interviews was to corroborate and provide depth to the questionnaire results, and to assess the attitude and actual behaviour of the households. The interviews were semi-structured and in the form of a discussion. Since each discussion progressed slightly different, statistical analysis of the results was not possible. As I did not get all interviewee's permission, conversations were not recorded for later reviewing and direct quoting. Instead, notes were taken during the interviews. The quotes, based on the notes, presented in this chapter have been anonymized. These informal interviews were used to clarify and refine issues as they emerged. However, it is to be kept in mind that these are reported behaviours - the rationalisation people developed with regard to the decision - which may differ from actual ones, nevertheless, interesting information can be attained.

The next section will elaborate on the data obtained from the questionnaire and the interviews (see Appendix D).

Results

Based on the outcomes of the questionnaire and subsequent interviews, this section provides an analysis of how individuals as real people in a neighbourhood interact with each other to learn about PV and what decisions they make in terms of adoption and non-adoption. Both, the presentation and analysis of the research results are structured according to the identified most relevant factors influencing PV purchasing in particular. The questionnaire offers useful insight into these relevant factors by asking questions 
such as 'what are the reasons for not adopting a PV system?' and 'under which circumstances would you adopt a PV system?'. In Table 30 the survey results are given.

Table 30 What are the reasons for not adopting a PV system and under which circumstances would you adopt a PV system. ranked from important to unimportant.

\begin{tabular}{|c|c|c|c|}
\hline Reasons for not adopting a system & $\begin{array}{l}\text { Number of } \\
\text { respondents }\end{array}$ & $\begin{array}{l}\text { Under which circumstances would } \\
\text { you adopt a system }\end{array}$ & $\begin{array}{l}\text { Number of } \\
\text { respondents }\end{array}$ \\
\hline $\begin{array}{l}\text { Lack of information / will gather } \\
\text { more information }\end{array}$ & 10 & If the payback is 5 years max & 7 \\
\hline Investment is too high & 9 & $\begin{array}{l}\text { If there is an attractive subsidy } \\
\text { program }\end{array}$ & 6 \\
\hline Energy yield is too low & 3 & $\begin{array}{l}\text { If the investment drops significantly. } \\
+/-25 \%\end{array}$ & 5 \\
\hline Fear of gaining promised efficiency & 2 & If the payback is 7.5 years max & 4 \\
\hline Visual representation & 2 & If the quality of the system improve & 3 \\
\hline Fear of subsidy adjustments & 2 & $\begin{array}{l}\text { If the investment drops significantly. } \\
+/-50 \%\end{array}$ & 2 \\
\hline Too innovative & 1 & If the payback is 2.5 years max & 1 \\
\hline I am too old & 1 & If the system is nicely integrated & 1 \\
\hline No reason at all & 1 & If the yield is good & 1 \\
\hline
\end{tabular}

The results show that a lack of information and high investment costs were the most often stated reasons for non-adoption. Through the questionnaire I also acquired information concerning the circumstances in which people would adopt a system. A payback period of maximum 5 years was most often mentioned, followed by attractive subsidies and lower investment costs (financial circumstances).

Thus two relevant factors in order to better understand the reasons for adoption and non-adoption a PV system are the provision of information and the financial concerns. However, I also learned that the attitude of people - their beliefs and values regarding $\mathrm{PV}$ - is a relevant factor too.

The provision of information

In the survey, respondents were asked whether more information about the ins and outs of $\mathrm{PV}$ is necessary and had the opportunity to use the interviews to let people elaborate and explain what they actually want to know and how their information gathering process look like. The descriptive survey results provide insights into reported frequency of the information sources consulted (see Figure 28). 


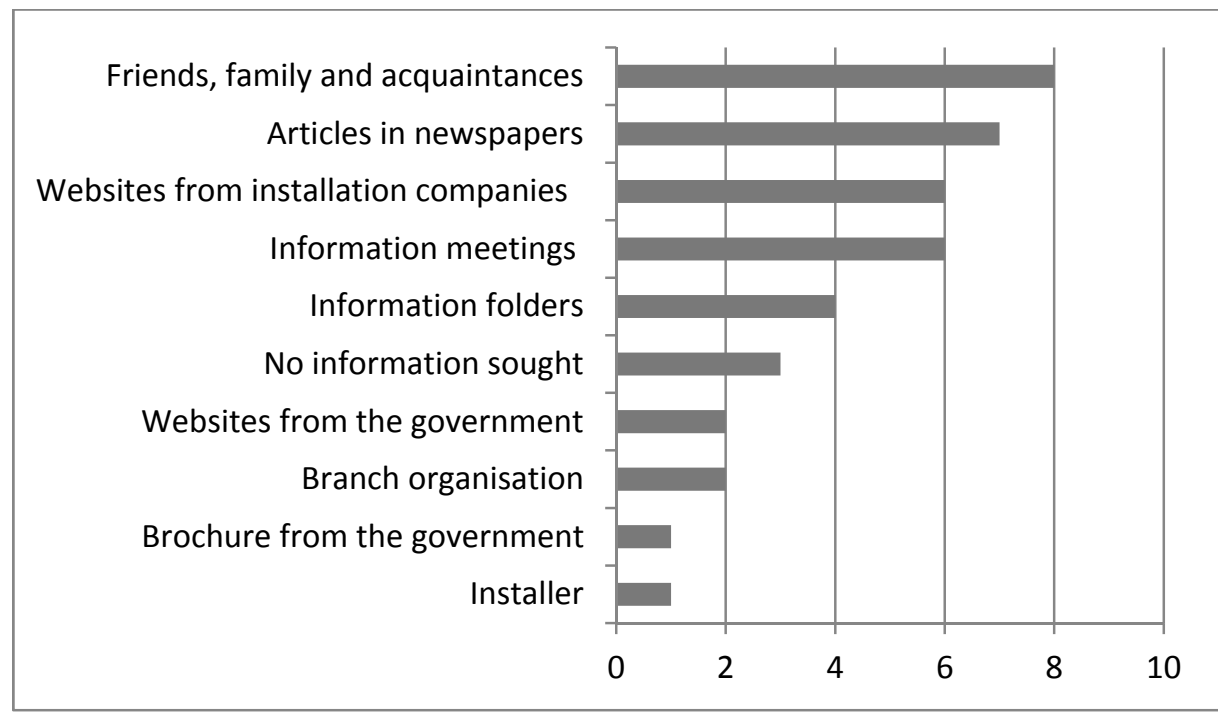

Figure 28. Different types of information sources consulted by the respondents.

Hence, these qualitative results indicate that it is might be rather common for people to contact several information sources for more information about PV, the different possibilities available and the best buy. When I invited the interviewees to reflect on this 'learning and information seeking process' and how the information is actively sought out, not everyone could explain me the steps taken in their adoption process. Some people bought the system at the PV installer recommended by Biesland Solar because this adoption process was in their view easier, while others wanted to consider other installers as well. As an argument for the latter, they indicated that they did not believe that the recommended installer, who was also a member of the Biesland Solar board, was also the best option. Important to note is the fact that early every potential adopter I spoke to was looking for information to identify the 'best deal' and by that, they usually meant the cheapest. However, there are many factors involved in a PV installation which mean that the cheapest deal is very often not the best.

One interviewee explicitly reflected on the recommended PV installer:

It is important that the facilitator of an information meeting is an expert in the field and not a business person who want to sell his products.

Another interviewee explicitly reflected on the provision of information by Biesland Solar, indicating that the lack of understandable information on a PV system was a big hurdle in the adoption for them personally. She further explained that the necessary information can be found in manufacturers' literature and that the remainder information can usually be obtained from a manufacturer's representative or distributor. This 
is relevant since the information considered as simple or general by Biesland Solar may still be not clear enough and too complex to grasp for some inhabitants. In this context proper information meetings are important. The importance of this issue is confirmed by some small talks after the information meeting. Some people noted that the brochure has aroused interest and that the initiative did became a topic to talk about. For example, they exchanged thoughts about the upcoming meeting, financial arguments regarding PV and how they actually think about the adoption of a system.

In line with this observation, the importance of information exchange through these small 'PV' talks within the neighbourhood (friends. family. and neighbours) is also confirmed by the quantitative results (see in Figure 28. friends. family and acquatiaion are the most consulted information source). The answers revealed that most of the respondents already spoke with friends, family and neighbours about adoption of PV; more than $45 \%$ have people around them who already adopted a system (almost $30 \%$ have neighbours with a system). Hence, the question arises to what extent their interests and attitudes towards PV are influenced by the behaviour and opinions of people in their immediate environment. Only one respondent indicated to feel peer pressure. In the interviews I asked people to describe this social issue, however, no interviewee explicitly reflected on this. Maybe some respondents felt a sense of reassurance thourgh people in their immediate environment, however this is not openly stated.

These outcomes were not unexpected because the influence of others often happens imperceptible and people see themselves often as autonomous decision makers.

\section{Financial concerns}

The high investment costs ${ }^{86}$ of a PV system represent another important factor for the people in Biesland in their decision about (non) adopting a PV system (see Table 30). Indeed, PV systems are quite expensive and therefore one would expect PV households to have higher incomes than the general public. Half of the respondents who provided information about their income earned more than 3000 euro gross per month, which is above average. This was also a main reason why Biesland offered such an interesting case study; the demographic characteristics of the inhabitants revealed high levels of education, income and home-ownership and a bias towards middle-aged and older individuals.

In the survey, respondents were first asked to answer some know-how question, e.g. if they are familiar with the costs, grants, affordability, life time, etc. Thereafter, they were asked which aspects play a significant role in shaping their behaviour in terms of adopting or non-adopting a PV system. The questionnaire also asked about the perceived

\footnotetext{
${ }^{86}$ The questionnaire did not ask people about the relative importance of the several aspects of the costs (purchase, operating costs, maintenance costs, and insurance rates), thus it is impossible to determine which are perceived as most important.
} 
importance of different PV system characteristics, such as price, efficiency and lifetime. The interview results allow for a more in-depth analysis, elaborating on the reasons why the actual adoption has taken place or has not yet occurred.

According to the qualitative questionnaire results, people are familiar with the costs of a system; they are willing to invest in the technology; and they can afford (enough financial resources) a system. Almost $90 \%$ stated that they currently are considering the purchase of PV panels. However, during the period between the information meeting (questionnaire) and the interviews, only four people actually adopted a system. In this light, I wanted to know why the actual purchase has not taken place. Interviewees struggled to explain their motivation, behaviour and considerations. Some respondents indicated to consider themselves as too old for the purchase of a system. The length of time it takes to recover the cost of solar panels (payback) may have led them to the decision not to invest as the pay-off may seem too far in the future (see also Table 30 right column). Others mentioned that their partner made this kind of decisions, most of them being housewives. Remarkable, no interviewee explicitly reflects on the costs of a system. Also by asking whether it is a financial consideration they gave me no insight in this issue and stayed rather vague in answering this question.

In line with my expectations, adopters of a system struggled much less to explain their considerations. They were able to give some clear and obvious reasons. One interviewee pointed out that she and her partner made the investment, because it changes their pension income in a positive way ${ }^{87}$. This is a financial benefit which favour when pension incomes are rising faster than inflation. Another financial benefit of owning PV that was mentioned in several interviews concerned the savings incurred by importing less electricity from the grid, as indicated by the following interview quotations:

The system price is a 'fixed price' while the electricity price (from the grid) would inevitable rise the coming years due to the increasing scarcity of fossil fuels.

Over the life of a PV system, I will be able to power my home with electricity cheaper than I would pay for from the main grid.

Environmental concerns were not included in the questionnaire, however, during the interviews I asked the respondents whether they made a certain decision because it reduces their negative impact on the environment. One of the interviewees indicated that a good level of understanding about the climate change problem and the link to

\footnotetext{
${ }^{87}$ This financial argument can be explained as follows: retired people tend to particularly benefit from the bill reduction compared to other groups as they use more appliances during the day when solar panels are working best, which is especially in favour when pensions are not rising as fast as inflation.
} 
energy consumption confirmed his decision to adopt a system. He formulated this as follows:

The environmental problem was for me an obvious and straightforward motivation for the purchase of $P V$.

However, the majority of the non-adopters indicated to be less convinced about this 'green thinking' and therefore the purchase was not seen as an urgent matter for environmental reasons. Rather they mentioned that self-sufficiency and protection from rising energy prices were more important issues in their decision making process.

Finally some words about grants, which directly relates to the investments costs of a system. The qualitative questionnaire answers revealed that most of the respondents were aware of subsidy programs; the possibilities for grant application; the lifetime; and the pay-back period. They also indicated the importance of grants. During the period between the questionnaire and the interviews, a grant became available by the province and the state. However, the majority of the respondents of the questionnaire did not adopt a system in the meantime, which indirectly indicates that grants on their own cannot fully address the financial issue. Hence, the remaining question is whether PV grants are really that important for the people in Biesland. Given that they have the financial resources for a system and at the same time are willing adopt it, why did it not happen? Are there other reasons which are not mentioned or in their view not important enough? It is hard to interpret whether this outcome is predominantly the result of attitude. Do they perhaps consider the systems too expensive or do they prefer other financial spendings, e.g. holiday versus PV? What I learned from this is that the difference between the outcomes of the questionnaire and the interviews related to financial issues revealed that the initially reported willingness and financial ability to adopt a PV system and the actual behaviour can be very different, still leaving important questions about the cause of this finding to be further investigated.

\section{Personal attitude}

The personal attitude is analysed as a third important factor in this research. In this study, personal attitude refers to the way a person expresses or applies their beliefs and values which in turn is expressed through their behaviour. In case of PV systems, the adoption or non-adoption reflects the attitude with respect to PV and this attitude vary greatly among individuals. In order to cover this aspect, I investigated the beliefs and values people have. In the questionnaire, respondents were invited to rate the following PV system characteristics: (1) price; (2) efficiency - amount of energy integration; (3) lifetime of the system; (4) integration; and (5) attractiveness / visual representation. During the interviews, participants were invited to reflect on their beliefs and values, e.g. 
what is of worth and what is considered as important in guiding their attitude/behaviour.

The questionnaire results reveal that the PV system characteristics (attributes) 'cost' and 'efficiency' ${ }^{\prime 88}$ are considered the most important issues for adoption (see Table 31). I assume that the reason for people focusing mainly on the costs is that no much information exists on the other matters. Unfortunately, I cannot illustrate this argument with a quote from one of the citizens in the neighbourhood.

Table 31. Attributes of a PV system (percentages).

\begin{tabular}{lcc}
\hline Attributes & Important & Less important \\
\hline Efficiency - amount of energy & 100 & 0 \\
Integration & 55.6 & 44.4 \\
Lifetime of the system & 93.3 & 6.7 \\
Price & 100 & 0 \\
Visual representation & 28.5 & 71.5 \\
\hline
\end{tabular}

A vast majority of the questionnaire respondents considered the attractiveness of a set of panels less important than the other mentioned characteristics. This is in contrast with the results of the interviews and is illustrated by the following statements:

I do not want that my roof turns into an ugly one.

PV panels are not the most glamorous technology.

Usually PV panels are tucked away on a roof, and when you can see them, they are ugly.

Cleaning PV panels (maintenance) is a cause of worry for many consumer-citizens with age in the neighbourhood Biesland, although the information meeting's facilitator explained that PV panels does not have any moving parts or problems with fatigue and that PV panels are cleaned by rain thus maintenance of a PV system is more or less zero. Regular visits to the roof would not be necessary and by joining the LEI it could be managed though the cooperation. Thus age should not be perceived as a barrier for having a PV system; in fact they can be considered more suitable for the elder generation (see footnote 81 and discussion above). Despite this explanation, however, during the interviews this issue is mentioned several times as an important motivation to decide to not adopt a system. Thus, some people have the internal feeling that their thoughts are true

\footnotetext{
${ }^{88}$ The PV technology keeps on developing and its main component, the PV cells, are expected to become more efficient in converting solar energy into electricity (IEA 2010). The performance ratio, the fraction of the output of the solar cells that is fed to the grid, is also expected to grow in the future (Jahn and Nasse 2004).
} 
even though that belief is not based on (the provided information and) proof. The same applied to the environmental issues (e.g. less $\mathrm{CO}_{2}$ ) and the perceived unsuitable weather in the Netherlands. The latter issue was extensively explained during the information meeting: the systems even work on gloomy days which make them also a viable option for the Netherlands.

The value of importance attached to owning a PV system, varies between individuals and is elaborated in the interviews through the people who adopted a system. The possibility that PV was purchased as a status symbol or serve as a symbol to communicate a certain identity or value orientation was not openly stated, so perhaps it was not true. Some interviewees indicated that they were raised in an environmentally-responsible environment and saw this as a strong element of their decision to purchase a system. Selfsufficiency and protection from future energy prices were important issues of owning a system, however, PV did not provide the level of independence that one of the interviewees expected.

The added value to the house is also explained during the information meeting. Most interviewees agreed and some added: 'especially in times of crisis'. Despite the fact that they were aware of this argument, the majority of the interviewees did not considered this value as important enough. Interestingly, the results also show that at least some of the adopters want to grow old in their home, the added value by selling their house was not decisive. Here, I learned that values are often reflected in the way we live our lives (e.g. I value self-sufficiency, or I value to live as long as possible at this place).

Finally, I invited people to reflect on changes they have experienced since the adoption of a system, however, the interview results do not provide a solid basis for judging whether their life significantly changed since the initial information meeting. It is important to keep in mind that the adoption of a PV system is a one-time decision and not related to behaviours or practice people engage in for example food and transport. The only thing people mentioned is that they were conscious of their own electricity. This in turn could lead to more careful use of electricity, for example by turning the lights more frequently, however, this behaviour change is not explicitly proven.

\section{Evaluation of the initiative}

One urgent question left is whether a LEI, like Biesland Solar, can actually stimulate the diffusion of PV systems. To gain more insight in this question, the questionnaire included questions asking respondents about their impression of the Biesland Solar initiative and in particular their impression of the information meeting. The respondents were positive about both and the majority were more positive about the installation and the use of PV after the information meeting than before. Self-sufficiency and protection from rising energy prices were important issues of owning a system, however, PV did not provide the level of independence that one of the interviewees expected. 
Furthermore, I further investigated whether adopters were still positive about their system. Most of them were, only one interviewee pointed out that estimates made by the PV installer suggested that the panels start to earn profit after 5 years given the size of the initial investment, which in his opinion was not true. One year after the installation, he concluded that the amount of energy produced and exported is less than the estimations made before. His investment will probably be paid off in the next 10-15 years. On the question whether he would made the same decision again he answered:

Yes, but I would choose another PV installer as I had a short circuit after half a year. A few months after installing the system I figured out that the return was marginal, after some calls I found out that I had to sign in as an energy supplier and had to install a smart meter.

Despite this bad experience, this interviewee is still positive regarding PV systems in general. He also told me that his son-in-law decided to adopt a system, but that he is doing business with another supplier. Thus, it is important to pay enough attention to problems people have with the system and ensure that the technology is functioning well, otherwise there is a risk that participants of a LEI step out and develop a negative attitude.

Finally, the questionnaire asked about the importance of different services or aspects of the LEI. The respondents indicated that a lower electricity bill is most important, followed by the collective procurement and the independency of large monopolistic energy companies. Remarkable, mutual learning among participants and the fact that the cooperation takes care for the installation and maintenance is indicated as less important. Finally, I asked about the willingness to adopt a system, this was increased by almost $75 \%$ of the respondents. These results confirm the usefulness of such meetings, as they can play a relevant role in the adoption process of people.

\subsection{Conclusion and discussion}

In this chapter, I investigated how individuals as real people interact with each other about PV, what decisions they reach in terms of adoption and non-adoption for the case of Biesland Solar, a technology specific local initiative. Bielsand Solar is a district initiative in the city of Maastricht that focused on the collective procurement of the technology. Biesland Solar was initiated by some local citizens and promoted PV via a brochure and website. They organised an information meeting with a direct link to a recommended PV installer, which made the adoption process easier.

These empirical results confirm the usefulness of information meetings, it shows that these meetings can play a relevant role in the adoption process of people. However, only 
a few respondents actually purchased a system which shows that even with knowledge of PV technology, high environmental concern, and the assistance of the government grants, additional triggers appear to be still needed for more people to adopt PV. This observation provides interesting avenues for further research.

Regarding the demographic characteristics of the inhabitants, they revealed high levels of education, income and home-ownership and a bias towards middle-aged and older individuals. Related to this last characteristic, age is several times mentioned as a consideration to decide not to adopt a system. On the other hand, a trigger for the adoption of PV systems could be that a PV system offers a 'fixed price' while the electricity price would inevitable rise the coming years due to the increasing scarcity of fossil fuels. The latter is age independent. In line with this, another reason mentioned for the adoption is the positive change in the pension. Self-sufficiency and the environmental advantage are other motivations. Important reasons mentioned why participants decided not to adopt a PV system are the length of time it takes to recover the costs, the visual representation of the system (ugly), concerns about maintenance of the system, and understandable information.

Based on the literature, the questionnaire outcomes and the follow-up interviews, I inferred five conclusions through which LEls based upon active consumer-citizens (where the case of Biesland is one example of), can contribute to the diffusion of PV in the Netherlands.

First, LEls can facilitate the collective procurement of PV in order to gain economies of scale. The systems will become competitive and therefore it should be possible to exist without government subsidies in the near future. In this way a substantial and constant demand for PV systems will be created which will probably stimulate the diffusion of PV in the Netherlands.

Second, the case Biesland Solar however demonstrated that it is better to avoid any (perceived) conflict of interest by excluding people with a financial interest in the initiative from the cooperation's board. Thus the collective procurement is best done by an independent PV installer.

Third, LEls make PV systems legitimate by spreading a positive image of PV systems through referencing (e.g. interaction between individuals). However, I do not have empirical evidence to confirm that conversations with adopters about PV convinced potential adopters to adopt PV.

Fourth, LEls provide potential adopters with the ins and outs regarding PV and by reducing perceived complexities. Fifth, during the information meeting of Biesland Solar, one of the initiators started a plea about the necessity to buy a system from one of the initiators. Subsequently, the attention of the attendees directly disappeared. Hence, the Bieland Solar case demonstrates that the citizen's questions asked during such information meetings could best be answered by independent expert advisors. Thus, hiring experts for providing independent information could have a larger and longer-lasting effect on 
the diffusion/adoptation of PV than, for example, spending the money directly on subsidies.

Methodologically my research is based on original data collection through a questionnaire performed direct after the information meeting and on interviews one and a half year later. A shortcoming of this data collection is that it is reported behaviour - the rationalisation people developed with regard to the decision - they took which may differ from actual ones, nevertheless, interesting information is obtained. The results are structured according to three relevant factors influencing the purchasing of PV: (1) provision of information; (2) financial concern; and (3) the personal attitude people have.

The empirical results show several similarities from those found in other empirical studies on adoption of PV. First, the high percentage of willingness to invest in the technology is also indicated by a recent study of the University of Groningen. Stokman and Wolfs (2011) investigated the willingness to take part in initiatives for local production of renewable energy in three municipalities in the north of the Netherlands (Veendam, Stadskanaal and Oldambt). Local residents were asked whether they would participate in cooperative initiatives. Outcomes revealed that $35 \%$ of the respondents would immediately participate and another $27 \%$ would participate if a good number of other people had joined the initiative (social cohesion); $65 \%$ of the respondents would definitely put a PV system on their roof (Stokman and Wolf 2011). In the case Biesland Solar, more than $90 \%$ of the respondents who attended the meeting is willing to invest in the technology. Second, the results have indicated the importance of small 'PV' talks within the neighbourhood - conversations between friends, family and neighbours. This result is in line with earlier findings from Stern (1992). In his research he also indicates the strong influence of information from non-expert friends on household energy decisions.

Third, the potential adopters actively searched for more information, i.e. through contacting several installers for information and the best buy. In earlier research, consumers already indicated that installers could play a role in encouraging further behaviour change (Keirstead 2007).

Finally, I want to say that how the decision-making process at household level over time looks like does not become fully clear in this research. It may seem obvious that early adopters generally make independent decisions and are guided by their needs whereas late adopters are more influenced by their social network. However, this phenomenon should be further investigated. 



\section{Intermezzo 2}

In the previous chapters (Chapter 7, Chapter 8, and Chapter 9), the empirical outcomes of the user perspective have been reported (step two of the research approach: adoption of innovative technologies). It focused on the user as a consumer-citizen since they eventually are the ones who are the users or non-users of the technology. The user perspective is able to articulate the demand which is an important force to guide and shape innovations.

In order to understand the adoption process from a user perspective, a segmentation model is introduced which can be used to determine empirically groups of PV technology adopters. In Chapter 7, the results of an analysis, based on a survey of 817 households, into the adoption and non-adoption of PV in Dutch households was presented. Households were aggregated into four groups based on whether the adoption was voluntary or involuntary (when people bought a house with solar panels) and whether or not the household could be considered a potential adopter or rejecter. For these four groups, the characteristics of adopters and non-adopters of PV were studied and compared. Different groups of characteristics were taken into account (demographical; geographic; physiographical; behavioural), however, the link between the characteristics and the actual adoption behaviour was found not to be strong enough. According to Rogers (2003), potential users of society first look at the characteristics of the technology to decide whether to use it. From this example it became clear that the influence of different factors (determinants) identified in the diffusion and adoption literature was relevant to study in order to better understand the motivations to (not) purchase a system (see Chapter 8). It has been found that the slow diffusion of PV is not driven by single factors such as price or technology change, but instead typically involves coevolution between multiple developments. It is related to consumer preferences, product offerings and slow introduction of policies to promote the use of renewables. This outcome clearly showed that it is impossible to speak of 'the users', but that the distinction between several types of users is necessary (which is done in Chapter 7). To a certain extent it is possible to move to another type of user. Potential adopters, for example, can become adopters of the technology and rejecters of the technology can also become potential adopters which in turn can become adopters of the technology. As an implication, this 'process' can be accelerated through the use local energy initiatives. In Chapter 9, a local energy Initiative - Biesland Solar - is studied to investigate how individuals interact with each other about PV, what decisions they reach in terms of adoption and non-adoption. I observed that information meetings within a neighbourhood can play a relevant role in the adoption process of people. Only a few respondents actually purchased a system which shows that even with knowledge of PV technology, high 
environmental concern, and the assistance of the government grants, additional triggers are still needed for more people to adopt PV. My empirical results have identified three relevant factors influencing the purchasing of PV: (1) provision of information; (2) financial concern; and (3) the personal attitude people have.

From the foregoing, it has become clear that user involvement is a prerequisite for succesful innovation systems. In the next part, the results of the user perspective are combined with the results of the technological innovation system approach. Different lessons learned in terms of possible inducement mechanisms to accelerate the adoption and the diffusion of PV in the Netherlands are addressed. 
Part 4:

Synthesis 

Chapter 10:

An integrated evaluation of the diffusion of PV in the Netherlands 



\subsection{Introduction}

In this PhD study I have shown that the (slow) diffusion of PV in the Netherlands is a story of supply and demand. At the supply side, manufacturers produce established and new products. At the demand side I find heterogeneous people of different income and lifestyles, equipped with preference, beliefs and ways of thinking, who may be grouped into consumer segments (see Figure 22). Demand for innovation interacts and coevolves with supply. However, the interaction of supply and demand is different in each sector and has its own unique aspects. In the case of PV in the Netherlands, the complex technology of solar cells (low efficiency) can act as a barrier for the transition path. However, more barriers are conceivable. For example, PV is not able to compete with conventional fossil fuels which can indicate a too high economic payback period. Barriers are very heterogeneous in nature and are observed for all actors in the market. They are experienced differently among technology suppliers and technology adopters, but also vary between technologies. As a consequence, many different ways to interpret and classify barriers emerged.

Weber (1997) offers a typology of barrier regarding efficient use of energy. He suggests a typology of four groups of barriers: (1) institutional barriers (barriers caused by political institutions, i.e. state government and local authorities $)^{89}$; (2) market barriers or market failure. (e.g. monopolies, lack of information or subsidies; subjects obstructed are mainly individuals and firms); (3) organizational barriers (obstacles in organizations may result from asymmetry of information, a trade-off with non-energy-specific goals or missing responsibility with regard to energy consumption; and (4) behavioural barrier (focus on individuals with their values and attitudes towards energy conservation, e.g. lack of attention towards energy consumption, lack of perceived control). The IPCC (2001) proposes to distinguish four broad groups of barriers, namely, lack of information, limited availability of capital, lack of skilled personnel and a bundle of other barriers. These broad groups are further differentiated by Sorrell et al. (2004) and Schleich (2009) who classify barriers into six groups. They differentiate imperfect information, hidden costs, risk and uncertainty, split incentives, access to capital and bounded rationality. Other studies simply distinguish two main groups of barriers. Sardianou (2008) distinguishes barriers with respect to energy efficiency investments in (1) financial and market barriers and (2) organizational and human factors barriers. In the study of Thollander and Ottosson (2008), barriers to energy efficiency are categorized into market related barriers as well as organizational and behavioural related barriers. There are more studies that distinguish barriers, however, it is not the aim of this chapter to give a comprehensive theory and overview of barrier models, rather to provide an insight to the technical and social aspects of energy issues and how they are intertwined and dynamic over time. As all theoretical frameworks of complex real-world phenomena

\footnotetext{
${ }^{89}$ Weber notes that institutions can hardly be changed by individuals and develop slowly.
} 
involving people and organizations, the theory should rather be seen as an analytical tool. This should be kept in mind when analysing the empirical findings outlined in the result sections where many of the barriers expressed by the respondents fit into more than one theoretical barrier.

In this integrated chapter I will address the barriers ${ }^{90}$ in the transition process for the introduction of PV in the Netherlands and what can be done to accelerate this process (lessons learned). Different perspectives can be used to point out the barriers which hamper the implementation of PV in the Netherlands. In this PhD research the functions of technological innovation systems (TIS) approach is used in combination with a questionnaire. The functions of a TIS approach hold that a set of seven functions that need to be fulfilled in order for a technological innovation systems (TIS) to function properly. This approach offers a dynamical component by focusing on the events that compose the system. The questionnaire aimed to find out which aspects (non) adopters of PV find important during the adoption process of PV.

The structure of this chapter is as follows. Section 2 describes the interaction of supply and demand, which is illustrated for the case of PV in the Netherlands in section 3. Finally this report ends by a conclusion and discussion.

\subsection{The interaction of supply and demand}

Supply interacts and co-evolves with demand for innovation. As Saviotti (2005) argued, demand is created gradually as an innovation diffuses and as various forms of learning take place, both on the consumer and on the producer side. In particular the active involvement of consumer-citizens in innovation processes and the realisation of interactive innovation and learning processes can increase the chance that the demands made of an innovation are known in an early stage and that changes can be made if necessary. In this research, a three step approach is introduced to analyse this interaction between supply and demand (see also Chapter 3.1). The technological innovation system (step 1) highlights the knowledge and the development of new technologies on both supportive and commercial level. This approach also incorporates the governmental aspects since the diffusion of new technologies strongly depends on policies. The user perspective (step 2) is able to provide demand articulation to other components of the system, which is an important force to guide and shape innovations. The different approaches signal different requirements or conditions necessary for socio-technical transitions to occur.

\footnotetext{
${ }^{90}$ The barriers are partly validated and partly based on the information gathered during the interviews with the various experts in the field and the questionnaire among the Dutch population.
} 
As Geels and Schot (2007, P.400) states, "the MLP argues that transitions come about through interactions between processes at three levels: (a) technological niche innovations build-up internal momentum, through learning processes, price/performance improvements, and support from powerful groups, (b) changes at the landscape level create pressure on the regime and (c) destabilization of the regime creates windows of opportunity for niche innovations". Thus, on the one hand the components of a system and on the other and multiple levels are of importance to facilitate technological innovations and socio-technical transitions. Table 32 gives an overview of possible changes at multiple levels corresponding with the components of a system.

Table 32. Changes to facilitate technological innovations and socio-technical transitions.

\begin{tabular}{|c|c|c|}
\hline & $\begin{array}{l}\text { Technology innovation system } \\
\text { (supply. knowledge. governmental. political) }\end{array}$ & $\begin{array}{l}\text { User perspective } \\
\text { (demand. including consumers) }\end{array}$ \\
\hline $\begin{array}{l}\text { Socio-technical } \\
\text { landscape }\end{array}$ & $\begin{array}{l}\text { Changing exogenous environment } \\
\text { (globalization. individualization. } \\
\text { macroeconomic factors and physical } \\
\text { environment infrastructure) } \\
\text { Changing modes of governance }\end{array}$ & $\begin{array}{l}\text { Changing lifestyles (new ways of using for } \\
\text { example solar energy and producing } \\
\text { electricity) }\end{array}$ \\
\hline $\begin{array}{l}\text { Socio-technical } \\
\text { regime }\end{array}$ & $\begin{array}{l}\text { Changing intermediaries and networks } \\
\text { Changing persons concerned and creating } \\
\text { visions }\end{array}$ & $\begin{array}{l}\text { Changing focus intermediaries (especially } \\
\text { legitimacy and acceptance of new } \\
\text { technologies) }\end{array}$ \\
\hline $\begin{array}{l}\text { Technological } \\
\text { niche }\end{array}$ & $\begin{array}{l}\text { Changing focus in research and development } \\
\text { Changing regulations and standards }\end{array}$ & Changing user behaviour and routines \\
\hline
\end{tabular}

Established regimes ${ }^{91}$ have enormous impact on the successful diffusion of technological innovations since it is characterized by stability and lock-in. Regime actors usually resist radical change at the regime level, and dedicate activities towards incremental improvement along existing trajectories. However, the breakthrough of radical change at regime level is possible with good timing and good nature of the interaction. In more detail, whether or not niche-innovations are relatively well prepared when the landscape pressure occurs and whether niche-innovations have a competitive relationship with the dominant regime(s) or a symbiotic relationship. These mechanisms may suggest that products from an established regime will always have a relative advantage in comparison to products from new regime-disruptive niches, due to scale and learning benefits, and will therefore hardly be overthrown in the absence of mandated (i.e. regulated) changes (Kemp and Dijk 2013). In this respect various studies refer to path dependent character of technological change (e.g. David 1985, Arthur 1989).

As an implication, the developments of the new technology can trigger the break through by taking advantage of the window of opportunity. However, the same devel-

\footnotetext{
${ }^{91}$ Regimes are the main focus and transitions are viewed as fundamental change in regimes, influenced by higher and lower levels. The use of the regime concept in empirical studies would be very helpful in discovering promoting and limiting factors (barriers) outside of the development of the technology itself.
} 
opments can also block or hamper the further diffusion towards a more sustainable system. Different barriers are conceivable which have to be overcome for a successful socio-technical transition. An example of a barrier in the Dutch energy transition is the inconsistent and complicated policy of the Dutch government, in which no long-term strategy is provided and no security ensured. Another example of a barrier can be found by knowledge institutions. The role of institutions in the sense of R\&D laboratories, patent systems, and technical standards is meant to stimulate technological innovation. However, the same institutions can also become barriers that hamper the development and diffusion of a new technological innovation, when they become established and lead a life of their own, they may become unsuitable to stimulate a new technical innovation. Barriers can trigger again the expansion of the niches through further improvement, increasing reliability, and cumulated experiences and learning about functionalities and potential applications. After some level of improvement of the technological innovation, and after learning more about its potential, it may find its way in specific market applications, often typical segments that exploit new functional characteristics of the technology which possible fit within certain lifestyles.

\subsection{The interaction effect for the case of PV in the Netherlands}

In the previous chapters a description of the transition path for PV was given, based on the TIS approach augmented with information in documents and from questionnaires. I have seen that from the technology innovation system approach guidance of the search (F4), resources mobilization (F6) and creation of legitimacy (F7) scored weak. Due to the lack of a clear vision for PV from the government, that there are not enough (financial) resources and an insufficient lobby power to overcome resistance. Market formation (F5) scored very weak due to the lack of the Dutch market for PV at the moment. Furthermore, all the System Functions with the exception of System Function 1 (entrepreneurial activities) hamper the further development of the PV Innovation System (see Chapter 4). From the perspective of the user, based on attribute perceptions instead of on objective indicators, I have seen that the cost of a PV system is an important element behind the adoption and non-adoption of PV in the Netherlands. Information of the costs, quality aspects, social and environmental matters is also indicated as important (see Chapter 8). 


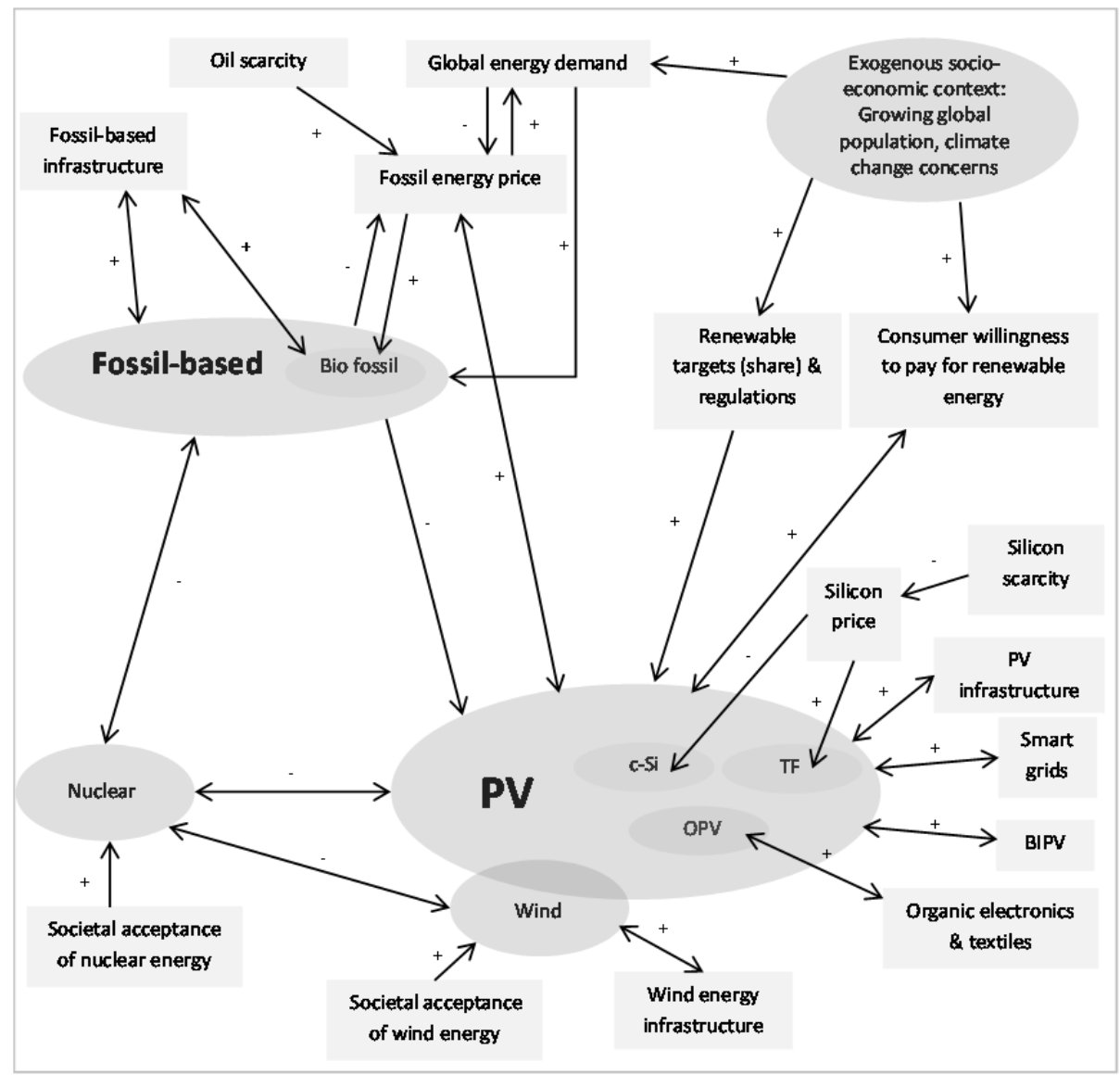

Figure 29. Factors promoting and detracting the adoption of different energy technologies (Based on Kemp 2012).

The case of PV clearly shows that for both perspectives, the TIS approach and the user perspective, various forms of learning take place. These forms of learning are interrelated, in the sense that at the very beginning suppliers of the technology have to inform consumers about the innovation, but then suppliers themselves gradually learn how to evaluate demand as an innovation diffuses. Learning in this case entails the availability of new skills and knowledge, new social connotations, changing future expectations, new supply-demand relationships, and changes in the regulatory framework. Consumers, with their different ways of interpreting, using and talking about PV technologies, further contribute to their social shaping. This is part of what some call the domestication process of product into daily life (Lie and Sørensen 1996). Thus, the case of PV shows that both the technology and the relevant social context is a complex co-evolution process with evolutionary traits of variation, selection and retention. Figure 29 sketches how different developments in policy, supply, infrastructure and demand may affect the 
innovation path. The plus (+) and minus (-) sign that accompany the arrows in the figure indicate influences that promote $(+)$ or detracting $(-)$ the developments of different PV technologies. However, it does not include every possible effect, but focus on what the authors considers to be most important relations.

The figure clearly illustrates the competitive and synergetic effects. In case of competitive effects, the diffusion of one technology goes at the expense of another technology. Compared to fossil-based technologies (quantity - level of use - and quality), the more sustainable technologies including PV are expected to benefit from the following developments: fossil energy price, policies to promote the use of renewable energy, renewable energy targets, new business propositions such as BIPV and smart grids, and the consumer willingness to pay for renewable energy (cultural acceptance). Climate change concerns (exogenous socio-economic context) can be expected to stimulate the consumer willingness to pay more for renewable energy which feed on PV adoption. There are also balancing developments: the availability of cleaner fossil fuels, e.g. bio fossil fuels (complementary innovation system) will slow down the diffusion of renewable energy technologies.

It is common to consider the slow diffusion of PV from the viewpoint of concrete barriers. Two examples of a barrier are the lack of consistent policies and insufficient demand (Dutch market). However, the previous chapters as well as Figure 29 show that the slow diffusion of $\mathrm{PV}$ is not driven by single factors such as price or technology change, but typically involves co-evolution between multiple developments. It has to do with consumer preferences, product offerings and slow introduction of policies to promote the use of renewables. Instead of the notion of barriers, it is better to think in terms of a 'web of constraints' acting as a blocking mechanism. Likewise, instead of a single driver I should think in terms of multiple drivers creating a positive inducement mechanism when they support each other. Positive stimuli interact with negative ones.

The 'web of constraints' currently acting as a blocking mechanism for PV in the Netherlands consists of five relevant barriers, which, at the same time, are potential sources for escaping the lock-in:

- Policies and targets that included the use of more renewable energy technologies as source of reduction of greenhouse gas emissions

- $\quad$ Better quality of the integrated PV systems and PV system guarantees can be expected to encourage PV technology adoption

- User involvement can arouse consumer curiosity and broaden consumer choice

- The collaboration between the local, national and international level can support the breakthrough of PV

- $\quad$ PV can become an attractor in the building market 
Policies and targets that included the use of more renewable energy technologies as source of reduction of greenhouse gas emissions

A general political uncertainty overshadows the PV Innovation system at the moment since the government formulates no common and consistent regulations. The impulses and efforts to establish PV as a solution for e.g. the climate change problem, development and application of PV is still delayed due to inconsistent policies and regulations. The reason for these inconsistencies resulted from technological disappointments ${ }^{92}$ and wrong judgments of innovation timeframes which often led to attention shifts towards alternative trajectories. It is not clear which direction the government will take with respect to financial support, such as the energy tax, since such regulations are still very important for the development of PV to become a self-sustained technology. An example of financial and political uncertainty is the (delayed) introduction, cancellation and re-introduction of the SDE regulation within a short time period. Beside the unpredictable regulation for the consumers, there are also insufficient financial resources for investments. The provided financial resources, such as the EOS programme, are used for research and technology development in the field. The research and technology development reaches a very good position within the Netherlands as well as worldwide. But venture capital is a problem for small and medium enterprises, since the risks are too high when new technologies, such as PV, are invented. The risk for opening a factory is lower which resulted in sufficiently available capital for manufacturers. Thus the 'valley of death' (space between research and production) is the main bottleneck.

I have seen that Germany has been the case of good practice in maintaining a feed-in system (EEG) over a long period of time that has been altered over the years (in 2000, 2004,2008 ) in agreement with the renewable energy sector which resulted in a largescale implementation of renewable energy technologies (see Chapter 5). Actually the favourable regulations in Germany attracted many companies to move to Germany (e.g. Shell Solar to Gelsenkirchen; Solland Solar in Heerlen-Aachen) or to focus the export of their products such as PV panels to the German market amongst others Japan and the Netherlands (see Chapter 6).

The unpredictable regulatory support for consumers and insufficient financial resources for investments can be traced back to the lack of a clear goal for specific PV by the government. Although, a general goal is formulated for the stimulation of sustainable energy: an annual energy saving of $2 \%$, an increase in the share of sustainable energy to $20 \%$ by 2020 and a 30\% reduction in greenhouse gas emissions by 2020 relative to 1990 . But a specific vision for PV is lacking which in turn blocks the further development. A goal specific for PV is formulated by the PV sector itself (Holland Solar), but the government does not adopt this goal. The Dutch government mentioned that they want to experi-

\footnotetext{
${ }^{92}$ The main mentality that reigns among policy makers is that technological developments are expected to be a short term process and that investments in R\&D are expected to lead quickly to market ready technologies.
} 
ment with PV in the building sector. But this is not enough to overcome this barrier. A clear formulated goal specific for PV is needed, such as an obliged increase in the share of PV to $10 \%$ by 2016 relative to 2013 specific for housing. Furthermore, a long term period of trial and error is needed to create a well-functioning, reliable and profitable technology which in turn gather more support and enthusiasm from entrepreneurs and investors and finally also from the necessary policy makers. Thus a balance between short and long term vision is necessary to gain social involvement and confidence by many individuals and other involved actors caused through the reliable behaviour of the government.

Better quality of the integrated PV systems and PV system guarantees can be expected to encourage PV technology adoption

A second mechanism starts with the mutual competition of entrepreneurs in the early phase of development. They should form coalitions and alliances in order to be more influential with respect to obtaining resources and creating a niche market for PV. This will increase the chances of success, i.e. the quality improvement of systems and the guarantee of it.

Standardization of PV systems (uniformity of operating procedures for PV systems) is essential for quality, lifetime and responsible integrating in the building sector. This in combination with system guarantee is important for the PV sector. The SDE subsidy is for example valid for a period of 15 years while the guarantee of PV systems does only last for two years. This means, when the system failed after three years you need to pay the full tariff for reparation of the system. Certification of the PV system and the installation of it offers an option. Such a certificate stands for quality, professional skill, assurance and guarantee. When the PV system has such a certificate, the system is reliable and guarantees a good quality towards the end users. The certificate for the system installers means that an education program is preceded of 'how to install PV on the roof' with all the possible bottlenecks, systems and roof types. In this way the customer knows by purchasing a system whether the system is reliable or not. The installer has to realize a correct installation of the PV system with respect to fitting as well as configuration. And the supplier has to deliver qualitative good components of the system as well as that these are connected on a correct manner (professional skill). Furthermore the supplier of the PV system has to mention the lifespan of their system and of the different components where the system consist of.

At the same time, knowledge of how PV is applied in the Dutch market is insufficient. Monitoring and evaluation of the existing PV panels and the combination between the system and the grid is lacking. There is not a mass market, but the monitoring and evaluation is important since it is not clear what happened if every house delivers its own generated electricity back to the grid. 
User involvement can arouse consumer curiosity and broaden consumer choice Social involvement relates to amongst others the consumer awareness of climate change and the need for renewable energy sources (socio-economic context). The consumer-citizen awareness is important since this is the first step towards a successful implementation of PV. When the end user is aware of the advantages, they are probably more willing to purchase a PV system. However, at the moment the demand for PV is insufficient. The analysis shows (see Chapter 8) that one of the reasons why people are not adopting PV at the moment is the high investments costs for a system ${ }^{93}$. The investment costs depend on the production conditions for solar cells. The price of solar cells strongly depends on the microelectronics sector due to competition over silicon wafers. Silicon wafers are produced for the microelectronics sector, but the surplus of wafers is sold to solar cell manufacturers. High growth rates in the microelectronics sector lead to silicon shortages and higher prices of solar cells. In Figure 29 I see that the effect of the higher price is twofold, it has a negative effect on the price of c-Si solar cells and at the same time a positive effect on the thin film (TF) solar cell price (through the use of less silicon the price of the PV system will decrease). Thus, the price of silicon creates coevolution between multiple PV developments. However, the development of the technology will hamper when the demand is not increasing since the confidence in the technology will be lost.

I also have seen that another reason for not adopting PV is related to the knowledge distribution. PV systems are available in small amounts and are up for sale on the World Wide Web and in some do-it-yourself stores. Besides these places, there is almost nowhere information concerning the sale of such system and there is almost no advertisement for the systems at all. For citizens it is unclear where, when and how the system can be placed onto the roof since the information is still lacking. An intervention for this barrier is to strengthen the knowledge distribution at moments that take place naturally. The possibility to apply PV must be available by mortgages providers, municipalities and $d-i-y$ stores. On such a way PV can become a 'legal' option for the citizen and it can arouse consumer curiosity for adopting a system and the threshold to switch to PV will become smaller and smaller. Thus the task is to create consumer awareness of the necessity of PV in such a way that an environment will be created where sustainable energy in acceptance is equal as the conventional grey energy.

The strong cooperation for research projects between knowledge institutions and entrepreneurs, both national and international, increased through the years. However, the social involvement, in particular the essential cooperation with the end users, is weak at the moment. This cooperation is of importance since differences in motivation can influence and maybe overcome some of the main bottlenecks. Involvement of the end users in research project can for example influence the visual representation of the systems and roof integration possibilities which in turn can widen the consumer choice.

\footnotetext{
${ }^{93}$ Despite the fact that the costs of solar panels have fallen due to cheap Chinese product offering.
} 
The collaboration between the local, national and international level can support the breakthrough of PV

For the case of PV in Germany, Japan and the Netherlands, the technology is still in development, which makes government support and knowledge exchange with local, national and international actors important. In all three countries R\&D, production and implementation of PV technology take place and there are explicit national goals and policies. Regarding the technology, I have observed that the transition paths are to a large extent dependent on international developments in technology and on the choices of foreign PV companies. Especially in recent years, international competition between PV companies is increasing, and new export markets are opening up. This implies that selection processes are partly out of reach of Dutch PV actors. International exchange of knowledge and experience in the form of international project collaboration and participation in international conferences can deal with such dependencies on developments abroad.

For the Dutch case I have seen that if the national government gives insufficient support or even resistance, the actors in the field may find it more effective to draw support from local governments and energy companies. Local energy initiatives (LEIs) are a good example of this (see Chapter 9). LEls are part of a trend away from the present conventional top-down and centralized structures of energy provision towards innovative bottom-up and decentralized managed methods of energy provision. These local initiatives can have a positive effect on the diffusion of PV in the Netherlands and can even foster the transition from a fossil-based system to a more sustainable energy based system. In this way, PV is influenced by actions of more than one government department and these departments are often not joined-up in their policy goals and implementation. This extends to coordination of local and national government policy as well, with some boroughs and councils (local level) actively promoting PV while parts of the national government are backing away from similar measures.

PV can become an attractor in the building market

Almost every citizen of the Netherlands is engaged in renovation their houses and building new houses. For these people the possibility to use PV on their roof must become part of the construction activity. Although the esthetical representation is not indicated as most important attribute for PV system, the integration is still amendable for further esthetical improvements.

The panels do often not fully fit within the surrounding and are not attractive, which leads to discouragement of other consumers to install PV on their own roof. However, the PV technology improved over the years and product designs are becoming less obtrusive. Besides the traditional PV roof panels, PV roof tiles or shingles ${ }^{94}$ is another viable

\footnotetext{
${ }^{94}$ Many different forms of PV roof tiles are available on the market, the most common solutions are tiles with amorphous solar cells. Roof tiles with mono- or polycrystalline solar cells can also be used together with the
} 
option. They made it possible that a roof still look like a roof even as it pulls in the wattage. PV roof tiles differ from traditional PV roof panels in effectiveness and costs as well as in appearance. Although PV roof tiles and shingles are probably the most interesting possibility how to integrate PV into the building's roof, the advent of real products in the market has been hindered and delayed by i.a. the poor cooperation between roof companies and manufacturers of roof tiles, the lack of interest and cooperation with architects and the technical performance ${ }^{95}$.

To accelerate the market acceptance of the above mentioned products, the aesthetic posibilities of PV for building integration should be better exploited in combination with high technical quality. A rapid increase of market share is a prerequisite for low-cost production, which is only possible with high production volumes. This again emphasizes the usefulness of involving users in possible development paths. Companies and manufacturers that maintain insufficient contact with their end-users run the (unnecessary) risk of launching products on the market that fall short of the expectations of the public and therefore fail. User involvement and participation goes further than marketing by active involvement, or in other world mobilising creative potential. Actually, it should enhance the quality of the innovation process and thereby considerably improve the competitive position of PV industry. Thus, a better cooperation between the different parts in the value chain is necessary in order to make PV an attractor in the building market. Guidelines with regard to the visual impression of PV on the roofs in cooperation with architects and fitters and/or more attractive PV systems can overcome this issue.

\section{Complex and dynamic Dutch PV innovation system}

The five identified mechanisms are elementary, distinct and linear processes. As I have seen in the Chapter 2 and in Table 32, changes to facilitate technological innovations and socio-technical transitions are complex, interdependent and non-linear. A relevant question that arises is how these simple mechanisms can serve the purpose of this PhD research, analysing the complex and dynamic PV innovation system in the Netherlands. Especially the collaboration and existence of multiple actors in the system increase the complexity. Here I have to point out that the identified mechanisms do not stand and operate on their own, they are connected and interlinked to each other. One mechanism can be the trigger for another one and creates in this way a non-linear structure that is capable to generate the complex dynamics. In that respect, the mechanisms should be considered as 'building blocks' of internal dynamics of the Dutch PV innovation system.

\footnotetext{
classical roof tiles of the same producer. In this case higher temperature and lower yield in case of limited air flow behind solar roof tiles must be considered during design phase. Roof shingles are produced with crystalline or with thin-film solar cells, thin film solar cells on glass or metal substrate are other possibilities.

${ }^{95}$ The panels are electrically connected one by one; the curved shape of the Dutch tile provides shade (lower efficiency).
} 


\subsection{Conclusion and discussion}

In this chapter I studied the barriers in the transition process for the introduction of PV in the Netherlands. I have shown that technological and social changes interact and mutually influence each other and that various forms of learning take place. I find that the development of the PV technology depends on evolution of energy prices, changes in global energy demand, changes in infrastructure, targets and regulations, and changes in the energy sector. Attention is also given to interaction of technological alternatives, specifically the competitive and synergetic effects.

The functions of TIS approach is used in combination with a questionnaire to point out the barriers. Instead of the notion of single barriers I think in terms of a 'web of constraints' acting as a blocking mechanism. Instead of a single driver I think in terms of multiple drivers creating a positive inducement mechanism when they support each other. Positive stimuli interact with negative ones. Based on the different analyses which are done in this research, I formulated five interrelated inducement mechanisms for the case of PV in the Netherlands: (1) policies and targets that included the use of more renewable energy technologies as source of reduction of greenhouse gas emissions; (2) better quality of the integrated PV systems and PV system guarantees can be expected to encourage PV technology adoption; (3) user involvement can arouse consumer curiosity and broaden consumer choice; (4) the collaboration between the local, national and international level can support the breakthrough of PV; and (5) PV can become an attractor in the building market. However, these 'elementary' mechanisms are not complex themselves but can be used to reconstruct the complex and dynamic network of the Dutch PV innovation system.

Further work could be undertaken in understanding these interrelated inducement mechanisms. It is useful to understand more fully why certain barriers are a barrier for some and not for others (getting more into the heterogeneity of the population of potential adopters). But also what attempts have been made to eliminate these barriers and with what success. This can give us insights into the hardness of constraints and the identification of interventions that make a difference. Should enough data be available, it would be useful to further empirically investigate how the barriers are affected by the evolution of various developments upstream and downstream and in neighbouring fields. Kemp and Dijk (2013) give already attention to these questions in an analysis of barriers regarding electric mobility. 
Chapter 11:

Conclusion 

The need to better understand the users or the consumers of an emerging technology has been the driving force of this PhD research. Users are an integral part of transition processes and have to buy and use a technology to turn it into a success story. Therefore it is important to inquire into how users are conceptualised and can or should be involved in innovation processes and how learning among users can be facilitated. The requirements different users have often vary and are unknown to the provider of the technology, at least initially. Thus, the learning processes among and between the developers and suppliers of a technology and the users of the technology have been studied in this thesis. In Chapter 1 the following central research question was formulated:

How does supply interact with demand in the case of PV in the Netherlands and what does this imply for socio-technical transition research?

In this research, the specific technology that has been analysed is photovoltaic (PV) solar energy technology. PV is one of the more promising sustainable energy technologies. The technological and economic potential is already proven but the implementation of this technology is slower and more difficult than expected. I mainly focussed on the Netherlands, because there is a long history of policy efforts in the Netherlands to stimulate PV, but results in terms of diffusion of PV panels in the Netherlands are disappointingly low, which clearly represents a case of slow diffusion.

To address the central research question, the following more specific research questions were formulated:

1. How is user behaviour conceptualised in socio-technical transition research? How are user choices studied empirically?

2. How can I explain the slow diffusion of PV in The Netherlands and what does this imply for policy support and socio-technical management?

3. How can I understand adoption and non-adoption of PV from a user perspective?

4. What can be learned from combining the user perspective with the technological innovation system approach and multilevel perspective in terms of possible inducement mechanisms to accelerate the adoption and the diffusion of PV?

In answering the research questions, a mixture of theoretical and empirical material was used. The theoretical part of the thesis describes the potential of niche-based approaches to contribute to wider changes in socio-technical regimes. Social theories that can help to accelerate the transition to a more sustainable energy system are discussed from a systemic and a user perspective. The empirical part of the PhD research comprised a study of the history and dynamics of PV. Data were derived from (1) a literature review; (2) an event analysis; (3) interviews; and (4) questionnaires. 


\subsection{Answer to research question one}

How is user behaviour conceptualised in socio-technical transition research? How are user choices studied empirically?

The first question aimed to get insights into the possibilities and limitations of various research approaches in the transition literature to study the diffusion and adoption of emergent sustainable energy technologies. To answer this question the state-of-the-art in socio-technical transition research was studied with special attention to the way in which user behaviour and choices are conceptualised and studied. The literature review in Chapter 2 already portrayed four perspectives to describe socio-technical transitions. Two perspectives begin with the technology in question to describe, understand and analyse the changes associated with transitions and system innovations.

The multi-level perspective (MLP) on technological transitions. The MLP argues that transitions come about through interactions between processes at three levels: the macro-level of the landscape, the meso-level of socio-technical regimes and the microlevel of the niche. This framework describes how new technologies emerge within more or less protected niches and how they become more widely-used/operational from configurations that shape and reshape regimes (e.g. Geels, Kemp, Rotmans).

The technological innovation system approach (TIS). The idea behind the TIS is that technologies develop within the context of a system which consists of actors (e.g. firms and other organizations), institutions, networks, and the interrelations between them. It takes a very dynamic approach by not only focusing on the structure of the system, but also on the key processes that take place within the system. These processes contribute to the build-up of a technological innovation system and to the successful development and diffusion of the emerging technology (e.g. Hekkert, Negro, Bergek).

The two other prominent perspectives take a user perspective as starting point. Here I emphasized the work of Shove and Spaargaren. Both researchers have studied the specific conditions for consumption in socio-technical systems like energy, water and waste systems.Although Shove and Spaargaren offer similar criticisms of transition theory, their approaches are not equal.

- $\quad$ By using the concepts of cleanliness, comfort and convenience, Shove stresses the importance of how social practices change over time, how new practices become normal and what the consequences on sustainability are.

- Spaargaren uses this theoretical approach by Shove and puts social practices into a conceptual model, which has a strong emphasis on the sustainability of existing lifestyles and on the ecological modernization of society.

Based on the literature review, it can be concluded that all reviewed perspectives fall short when trying to understand socio-technical transitions and the associated complexity of transition processes. For the first two perspectives, the answer to problems concerning sustainability lies largely in systems and structures. Cultural and social aspects 
are in general neglected in their theories, while changes in technological systems also imply changes in routines for the actors involved. The role of users as important actors is increasingly accepted; however, their role is insufficiently theorized and empirically studied. In the aforementioned two perspectives, practices are the unit of analysis and not technologies. The critique on transitions literature consists of not taking into account the actual situation in which consumers of new technologies find themselves. However, the criticism is also oriented towards the negligence of the role of the citizen as consumer; furthermore the view of the citizen as an active actor in transition processes that goes beyond the passive carrier of routines and behaviour is also neglected in the social practice literature.

Thus, studies of socio-technical transitions as they have hitherto developed focus mainly on the systems level. One of the consequences of this is the underrepresented role of and attention on users/consumer-citizens. There are some studies that focus on the active role of consumers (including consumer choices), however, these studies are done at a rather general level through the identification of consumer groups and lack detailed knowledge of the characteristics of the different consumer groups. I related to this shortcoming by providing a deeper study of the characteristics of first adopters and rejecters and a segmentation of present rejecters into potential adopters and rejecters. This thesis offers a novel contribution to the literature on user acceptance and determinants of technology adoption, the details of which are discussed in the next sections.

\subsection{Answer to research question two}

Which factors account for the slow diffusion of PV in the Netherlands and what does this imply for policy support and socio-technical management?

In Chapter 4, Chapter 5 and Chapter 6 the empirical outcomes of the technology innovation system perspective are described. The three PV cases studied, the Netherlands, Germany and Japan, shed an ambivalent light on the build-up of the Dutch PV TIS. On the one hand I have seen a continuously increasing knowledge base and a rise in entrepreneurial activities related to PV production. These are important indicators for a wellfunctioning innovation system. On the other hand, I have observed a strongly fluctuating market formation function. Periods where market formation stopped resulted in 'motors of decline' that led to a deterioration of the TIS. From previous studies (Negro, Hekkert et al. 2007, Negro and Hekkert 2008, Negro, Hekkert et al. 2008, Negro, Suurs et al. 2008, Suurs 2009) I observed that strongly fluctuating guidance of the search and lack of market formation proved to be very damaging for innovation system build-up. Surprisingly, two very important functions, knowledge development and entrepreneurial activities, were not very much affected by the periods of poor market formation. Chapter 5 shows that the German market was a good enough substitute for the home market to 
keep the sector going also in times when Dutch policy was not in favour of creating a market for solar energy.

Earlier, Hekkert et al. (2007) claimed that a TIS crosses national boundaries, especially for system functions such as knowledge development and knowledge diffusion. However, much of the guidance and many favourable institutions were claimed to be often local, which was an argument for delineating the TIS under study to the level of a nation. From this example it became clear that also for the market breakthrough of technologies the international dimension is very important.

Chapter 6 included international factors in the framework for analysis, such as import share, export activities, foreign direct investment and international knowledge exchange. Japan is found to have a well-functioning PV TIS with a strong industry and a large market for PV, whereas the Dutch have a considerably less established TIS. Based on the differences between and within cases a number of lessons for the Dutch PV TIS were formulated: (1) system functions such as guidance of the search (F4) and advocacy coalitions (F7) need to be strengthened in order to reinforce each other in a positive way; (2) consistent goals need to be formulated, maintained, and translated into longterm policies and stimulation measures in order to allow a gradual build-up of networks and skills/expertise; (3) legitimacy needs to be built-up and maintained within the institutional setting; (4) the TIS needs to be strengthened in order to grow in terms of capital and capabilities for the SMEs.

For stimulating demand, it is important to know what prevents people interested in PV from adoption (research question 3).

\subsection{Answer to research question three}

Which factors account for the adoption and non-adoption of PV in the Netherlands?

In order to understand the adoption process from a user perspective, I introduced a segmentation model which can be used to empirically determine groups of PV technology adopters in Chapter 7. The groups were determined based on the knowledge obtained from the comparison of the different segmentation models used in the construction market in the Netherlands. The model consists of four segments which were determined by two axes: the view that citizens have on the technology (positive versus neutral or negative) and the decision making process of major technological innovations. The four segments are voluntary adopters, involuntary adopters, potential adopters and rejecters. In our analysis, four groups of characteristics were taken into account: demographical characteristics, geographic characteristics, physiographical characteristics (opinions, attitude), and behavioural characteristics. In this way, our segmentation model differs from other segmentation models as it is not product or service-specific.

Our analysis helped to establish determining factors for the adoption of PV by households. Particularly, characteristics concerning the cost and benefits of adoption were 
reported as important. Socio-economic variables (age, education) played a less important role. In this research, the price of a system was indicated as the most important issue perceived by the different groups. The efficiency of a PV system and the energy yield were other important determining factors. However, the explanatory link between the different characteristics studied and the actual adoption behaviour was found not to be strong enough. Therefore, I found it beneficial to study the behavioural characteristics in more detail to better understand (non-)adopters' motivations to (not) purchase a system (Chapter 8).

In chapter 8 , the influence of factors which are identified in the diffusion and adoption literature as relevant was studied: the perceived relative advantage of the technology, the complexity of the innovation - effort expectancy, the social influence, and knowledge of grants and costs were taken into account to help gauge people's perception of PV which shapes the adoption process. For each of the factors, different proxies were used in an attempt to study individual components. Some important implications for the adoption and non-adoption of PV in the Netherlands from a user perspective: (1) the relative advantage, more particularly the financial advantage, adopters have with owning PV is one of the main reasons for adoption; (2) the exact influence of effort expectancy is not determined in this research, however, it has an important role. External parties can play an important role in assisting people with their PV adoption process through advising and education, i.e. explaining the benefits and promoting the potential of PV; (3) the attitude towards using PV and self-efficacy is less important than social influence and effort expectancy; (4) the influence of anxiety cannot be confirmed because I gathered no information about this concept; (5) adoption depends on attribute perceptions since for some adopters the costs of a PV system are acceptable while for others they are not.

In this research, non-adopters are not seen as a homogeneous group but as two groups: one group of potential adopters and one group of rejecters. Over time it is possible that rejecters become potential adopters and even proceed to adopters. Chapter 9 shows that this process can be accelerated through the use of local energy initiatives (LEIs), as was experienced through a questionnaire and interviews amongst local residents in the Biesland neighbourhood in the city of Maastricht and confirmed by a study of the University of Groningen (Stokman and Wolf 2011). Five conclusions were formulated through which LEls can contribute to the diffusion of PV in The Netherlands: (1) LEIs can facilitate the collective procurement of PV in order to gain economies of scale; (2) the collective procurement is best done by an independent PV installer; (3) LEls make PV systems legitimate by spreading a positive image of PV systems through referencing; (4) LEls provide potential adopters with the ins and outs regarding solar energy to reduce perceived complexities; (5) questions during an information meeting could best be answered by independent expert advisors. Hiring experts could have a greater and longer lasting effect on the diffusion of PV than spending the money directly on subsidies. 


\subsection{Answer to research question four}

What can be learned from combining the user perspective with the technological innovation system approach and the multilevel perspective on socio-technical transitions in terms of possible inducement mechanisms to accelerate the adoption and the diffusion of $P V$ ?

It is common to consider the slow diffusion of PV from the viewpoint of concrete barriers. However, this research showed that the slow diffusion of PV is not driven by single factors such as price or technology change, but typically involves co-evolution between multiple developments. It is related to consumer preferences, product offerings and slow introduction of policies to promote the use of renewables; therefore, the term 'web of constraints' was used instead of the notion of single barriers. Likewise, instead of considering single drivers, the drivers should be considered as a whole creating a positive inducement mechanism when they support each other. Positive stimuli interact with negative ones.

From this research, I have learned that there are five interrelated inducement mechanisms for the case of PV in The Netherlands. (1) Policies and targets that included the use of more renewable energy technologies as a source of reduction of greenhouse gas emissions; (2) better quality of the integrated PV systems and PV system guarantees can be expected to encourage PV technology adoption; (3) user involvement can arouse consumer curiosity and broaden consumer choice; (4) the collaboration between the local, national and international level can support the breakthrough of PV; and (5) PV can become an icon in the construction market. However, these mechanisms do not stand and operate on their own; they are connected and interlinked to each other. One mechanism can be the trigger for another one and creates in this way a non-linear structure that is capable of generating complex dynamics. In that respect, the mechanisms should be considered as 'building blocks' of internal dynamics of the Dutch PV innovation system.

\subsection{Answer to the main research question}

How does supply interact with demand for the case of PV in the Netherlands and what have been learnt towards socio-technical transition research?

From this PhD research it became clear that supply interacts and co-evolves with demand for innovation. As Saviotti (2005) argued, demand is created gradually as an innovation diffuses and as various forms of learning take place, both on the consumer and on the producer side. However, analyses of socio-technical transitions as they have hitherto developed, focus mainly on the system level and as a consequence too little attention has been paid to the individual actors. One of the consequences of this has been the underrepresented role of and attention on users as consumer-citizens who consciously 
choose to adopt a technology or reject a technology. To address this knowledge gap, a three-step approach was introduced in which technology and society, or supply and demand, co-construct each other. The approach was built upon the idea that technological innovations can be studied as a system in which different phases are differentiated that shape new technologies and technological landscapes. In this approach, three steps are distinguished: (1) development and diffusion of innovative technologies; (2) adoption of innovative technologies; (3) learning processes. The combination of these steps (different research fields) helped to understand how the system context influences users on the one hand and how users shape the system on the other. The preceding chapters have shown that each of these steps addresses different aspects of the dynamics of the PV system in the Netherlands and that by following this technological innovation over time (over the past forty years), the different aspects will be more or less salient.

The technology innovation system approach (step 1) showed that guidance of the search, resource mobilisation, and creation of legitimacy in the Netherlands is weak. Due to the lack of an ambitious view for PV from the government, there are not enough (financial) resources and an insufficient lobbying power to overcome resistance. Furthermore, the market formation strongly fluctuates over the years due to the lack of the Dutch market for PV at the moment. Interestingly, knowledge development and entrepreneurial activities were not very much affected by the periods of poor market formation due to the focus on the international market. The influence of users (step 2) was studied along with the influence of a number of determinants. It was found that the slow diffusion of $\mathrm{PV}$ is not driven by single factors such as price or technology change, but typically involves co-evolution between multiple developments. It is related to consumer preferences, product offerings and slow introduction of policies to promote the use of renewables.

The case of PV clearly showed that at the side of the technology innovation system approach and at the side of the user perspective, various forms of learning take place (step 3). These forms of learning are interrelated, in the sense that at the very beginning suppliers of the technology have to inform consumers about the innovation, but then suppliers themselves gradually learn how to evaluate demand as an innovation diffuses. Learning in this case entails the availability of new skills and knowledge, new social connotations, changing future expectations, new supply-demand relationships, and changes in the regulatory framework. This element has not been deeply studied in this PhD for PV but is addressed in the innovation literature. In this PhD the focus is on the adoption decisions and how different consumers influence each other, directly and indirectly via feedback loops.

The second part of the main research question relates to the issue of what has been learned for socio-technical transition research; in other words, whether the approach used could help to explain the dynamics of socio-technical systems in transition. The 
research approach helped to identify and compare the crucial activities during the development and implementation of more sustainable energy technologies. It also created insight into the dynamics and possible mechanisms of technological and social change. By doing so, the research approach offered policy makers and other actors involved in innovation and transition processes useful insights that may guide and support their actions. Insights can be obtained about useful government policies fitting in with the needs of the consumers and how suppliers of this technology can optimize their product based on identified consumer preferences and frames. Methodologically, the thesis shows ways to study adoption decisions within a broader innovation systems framework. 


\section{References}

Aan den Brugh, M. (2009). Hoe een 'groene' wet in Duistland tot een onverwachts groot succes leidt bij duurzame energie. NRC Handelsblad - 18, 19 juli 2009

Abell, D. F. and J. S. Hammond (1979). Strategic market planning, problems and anallytical approaches, Prentice-Hall.

Aberle, A. G. (2006). "Progress with polycrystalline silicon thin-film solar cells on glass at UNSW." Journal of Crystal Growth 386-390.

Agentschap NL (2011). Wetten \& regels voor Lokale duurzame energiebedrijven. Utrecht, Agentschap NL.

AgentschapNL (2009). Innovatie Programma Zonnestroom Innovatieagenda Energie - offerte, AgentschapNL/SenterNovem.

AgentschapNL. (2010). "Stimulering Duurzame Energieproductie (SDE)." Retrieved December 10, 2010, from http://regelingen.agentschapnl.nl/content/stimulering-duurzame-energieproductie-sde.

AgentschapNL (2012). Zonnestroom en de Nederlandse wetgeving. Utrecht, Agentschap NL - NL Energie en Klimaat.

Alkemade, F., C. Kleinschmidt and M. P. Hekkert (2007). "Analysing emerging Innovation Systems: A Functions Approach to foresight." International Journal of Foresight and Innovation Policy 3(2): 139-168.

Andriessen, J. E. (1993). Vervolgnota Energiebesparing: Brief van de Minister van Economische Zaken.

ANRE (2006). New National Energy Strategy. 31th May 2006.

Arakawa, H. (2008). personal communication with Hironori Arakawa, Tokyo University of Science, 4 April 2008, Kyoto, Japan.

Arthur, W. B. (1989). "Competing Technologies, Increasing Returns, and Lock-In by Historical Events." The Economic Journal 99(394): 116-131.

Axsen J, TyreeHageman J and Lentz A (2012). "Lifestyle practices and pro-environmental technology." Ecological Economics(82): 64-74.

Bakker S, de Coninck H and Groenenberg H (2010). "Progress on including CCS projects in the CDM: Insights on increased awareness, market potential and baseline methodologies." International Journal of Greenhouse Gas Control 4: 321-326.

Beal, G. M. and J. M. Bohlen (1957). The diffusion process. Special Report No. 18. Ames, lowa, Cooperative Extension Service, lowa State University of Science and Technology . . (reprinted 1-67, 10-71, 5-75, and 1181).

Beal, G. M., E. M. Rogers and J. M. Bohlen (1957). "Validity of the concept of stages in the adoption process." Rural Sociology 22(2): 166-168.

Beane T P and Ennis D M (1987). "Market Segmentation: A Review." European Journal of Marketing 21(5): 2042.

Berchem, A. (2006). Das Unterschatzte gesetz. Zeit online, ZeitOnline.

Berenschot (2011). Zon op Nederland - Roadmap 2011 - 2015.

Bergek, A., . (2002). Shaping and Exploiting Technological Opportunities: The case of Renewable Energy Technology in Sweden. Goteborg, Chalmers University of Technology - Department of Industrial Dynamics.

Bergek, A., M. Hekkert and S. Jacobsson (2008). Functions in innovation systems: A framework for analysing energy system dynamics and identifying goals for system-building activities by entrepreneurs and policy makers. Innovation for a Low Carbon Economy: Economic, Institutional and Management Approaches. T. J. Foxon, J. Koehler and C. Oughton. Cheltenham, Edward Elgar.

Bergek, A., M. Hekkert and S. Jacobsson (2008). Functions in innovation systems: a framework for analysing energy system dynamics and identifying system building activities by entrepreneurs and policy makers. Innovations in Low-Carbon Economy. T. K. Foxon, J.; Oughton, C, Edward Elgar: 79-111.

Bergek, A., S. Jacobsson, B. Carlsson, S. Lindmark and A. Rickne (2008). "Analyzing the functional dynamics of technological innovation systems: A scheme of analysis." Research Policy 37(3): 407-429.

Bergek, A., S. Jacobsson, B. Carlsson, S. Lindmarki and A. Rickne (2005). Analysing the dynamics and functionality of sectoral innovation systems - a manual. DRUID Tenth Anniversary Summer Conference, Copenhagen, Denmark. 
Berkhout, F., A. Smith and A. Stirling (2004). Socio-technical regimes and transition contexts. In: System Innovation and the Transition to Sustainability. Theory, Evidence and Policy. B. Elzen, F. Geels and K. Green. Cheltenham UK and Northampton MA, Edward Elgar: 48-75.

Bijker, W. E. (1995). Of Bicycles, Bakelites and Bulbs: Toward a Theory of Sociotechnical Change. Cambridge, The MIT Press.

Bijker, W. E., T. P. Hughes and P. T (1987). The Social Construction of Technological Systems. New Directions in the Sociology and History of Technology. Cambridge, Massachusetts, MIT Press.

Binz, C., B. Truffer, L. Li, Y. Shi and Y. Lu (2012). "Conceptualizing leapfrogging with spatially coupled innovation systems: The case of onsite wastewater treatment in China." Technological Forecasting and Social Change 79: 155-171.

Blok, K. (1985). Overheid drukt duurzamew energie niet door. DE. 3: 4-5.

BMU (2000). Act on Granting Priority to Renewable Energy Sources (Renewable Energy Sources Act) The Federal Ministry for the Environment, Nature Conservation and Nuclear Safety.

BMU (2004). "Konsolidierte Fassung der Begründung zu dem Gesetz für den Vorrang Erneuerbarer Energien (Erneuerbare-Energien-Gesetz - EEG) vom 21. Juli 2004." BGBI. 2004 I S. 1918.

BMU (2008). Act Revising the Legislation on Renewable Energy Sources in the Electricity Sector and Amending Related Provisions - Renewable Energy Sources Act - EEG 2009 The Federal Ministry for the Environment, Nature Conservation and Nuclear Safety.

BMWA (2005). Innovation and New Energy Technologies - The 5th Energy Research Programme of the Federal Government, Federal Ministry of Economics and Labour

Bode (2005). Vijf vragen aan Gosse Boxhoorn. April: 16-17.

Bokhoven, T. P. (1987). Bouwwereld kan niet om zonne-energie heen. DE. 1: 46.

Bolinger, M. and R. Wiser (2002). Support for PV in Japan and Germany. Case Studies of State Support for Renewable Energy, Berkeley Lab and the Clean Energy Group.

Boon, W. P. C. (2008). Demanding Dynamics, Demand articulation of intermediary organisations in emerging pharmaceutical innovations, Utrecht University

Bradford, M. and J. Florin (2003). "Examining the role of innovation diffusion factors on the implementation success of enterprise resource planning systems." International Journal of Accounting Information Systems 4(3): 205-225.

Breschi, S. and F. Malerba (1997). Sectoral Innovation Systems: Technological Regimes, Schumpeterian Dynamics, and Spatial Boundaries. In: Systems of Innovation - Technologies, Institutions and Organizations. C. Edquist. London, Pinter Publisher LTD: 130-156.

Breyer, C. and A. Gerlach (2012). "Global overview on grid parity." Progress in Photovoltaics: Research and Applications.

Bubenzer, A. and J. Luther (2003). Photovoltaics Guide Book for Decision Makers. Berlin Heidelberg, SpringerVerlag

Bundy, C. (2008). "The Netherlands Announces Pledges on Renewable Energy at the Washington International Renewable Energy Conference." Retrieved May 10, 2008, from http://www.netherlandsembassy.org/article.asp?articleref=AR00002427EN.

Byrne J, Zhou A, Shen B and Hughes K (2007). "Evaluating the potential of small-scale renewable energy options to meet rural livelihoods needs: A GIS- and lifecycle cost-based assessment of Western China's options." Energy Policy 35: 4391-4401.

Carbo M C, Smit R, van der Drift B and Jansen D (2011). "Bio energy with CCS (BECCS): Large potential for BioSNG at low CO2 avoidance cost." Energy Procedia 4: 2950-2954.

Carlsson, B. (1997). "On and off the beaten path: the evolution of four technological systems in Sweden." International Journal of Industrial Organisation 15(6): 775-799.

Carlsson, B., S. Jacobsson and A. Bergek (2005). Dynamics of innovation systems-policy-making in a complex and non-deterministic world. DRUID Summer Conference 2004: Industrial Dynamics, Innovation and Development, Copenhagen.

Carlsson, B., S. Jacobsson, M. Holmén and A. Rickne (2002). "Innovation Systems: Analytical and Methodological Issues." Research Policy 31(2): 233-245.

Carlsson, B. and R. Stankiewicz (1991). "On the nature, function and composition of technological systems." Journal of Evolutionary Economics 1: 93-118.

Cesta, J. R. and P. G. Decker (1978). "Speeding solar energy commercialization: A Delphi research of marketplace factors." Journal of Business Research 6(4): 311-328.

Chesbrough, H. W. (2003). Open Innovation: The New Imperative for Creating and Profiting from Technology. Boston, Harvard Business School Press. 
Coalitieakkoord (2007). "Coalitieakkoord tussen de Tweede Kamerfracties van CDA, PvdA en ChristenUnie."

Coenen, L. and F. J. Diaz Lopez (2010). "Comparing systems approaches to innovation and technological change for sustainable and competitive economies: an explorative study into conceptual commonalities, differences and complementarities "Journal of Cleaner Production 18: 1149-1160.

Coopers, R. G. (1993). Winning at New Products: Accelerating the Process from Idea to Launch Cambridge, MA Perseus Books

Cowan, R. S. (1987). The Consumption Function: A Proposal for Research Strategies in the Sociology of Technology. In: The Socail Construction of Technological Systems. W. E. Bijker, T. P. Hughes and T. J. Pinch. Cambridge, Massachusetts / London, England, The MIT Press: 261-280.

Crum, M. R., G. Premkumar and K. Ramamurthy (1996). "An assessment of motor carrier adoption, use, and satisfaction with EDI." Transportation Journal 35(4): 44-57.

David, P. (1985). " Clio and the Economics of Qwerty." American Economic Review 75(2): 32-337.

Davis, F. D. (1989). "Perceived usefulness, perceived ease of use, and user acceptance of information technology." MIS Quarterly 13(3): 319-340.

de Castro C, Mediavilla M, Miguel L J and Frechoso F (2011). "Global wind power potential: Physical and technological limits." Energy Policy 39: 6677-6682.

de Haan, J. (2007). Pillars of change: a theoretical framework for transition models. ESEE 2007 Conference, Integrating Natural and Social Sciences for Sustainability, Leipzig, Germany.

de Vries B, van Vuuren D P and Hoogwijk M M (2007). "Renewable energy sources: Their global potential for the first-half of the 21st century at a global level: An integrated approach." Energy Policy 35: 2590-2610.

Desertec.org. (2013). "Desertec Foundation." Retrieved January 16, 2013, from http://www.desertec.org/.

Dewald, U. and B. Truffer (2010). "Market Formation in Technological Innovation System - Diffusion of Photovoltaic Applicaton in Germany." Industry and Innovation.

Dolata, U. (2008). The Transformative Capacity of New Technologies. How Innovations Affect Sectoral Change: Conceptual Considerations. MPIfG Discussion Paper, Max-Planck-Institut für Gesellschaftsforschung, Köln Max Planck Institute for the Study of Societies, Cologne.

Doloreux, D. and S. Parto (2004). Regional Innovation Systems: A Critical Review. Québec, Canada \& Merit, Maastricht.

Doornbos, L. (2004). Vraaggestuurd werken en segmentatie. Veranderd ondernemen in de non-profisector. Maarssen, Elsevier Gezondheidszorg.

Duurzame Energie (1987). Zonneceltechnologie krijgt veel aandacht. Number 2 - April: 24-26.

Duurzame Energie (1991). Steunregeling beknelt zonne-energie. Number 1 - February: 14.

Duurzame Energie (1994). Rendement 16 procent. Number 4 - August: 9.

Duurzame Energie (1995a). Het nieuwe NOZ-PV: marktgerichter. Number 2-May.

Duurzame Energie (1997). PV-convenant 1997-2000. Number 3 - June: 26-27.

Duurzame Energie (1997b). Shell wil PV fabriek van 20 MW. Number 2 - April: 21.

Duurzame Energie (1997c). Vijf MW zon-PV in 'Stad van de zon'. Number 2 - April: 8.

Duurzame Energie (2000). Vijf hectare zonnepanelen. Number 3 - June: 18-19.

Duurzame Energie (2000a). Duizenden particulieren schaffen solaris zonnepaneel aan. Number 1 - February: 12.

Duurzame Energie (2001a). Stijging aantal groene-energieklanten. Number 5 - October: 44-45.

Duurzame Energie (2001c). Forse kortingen voor Groningers. Number 6 - December: 24.

Duurzame Energie (2002a). Grootste aaneengelsoten zonnedak ter wereld op Floriade. Number 2 - March: 17.

Duurzame Energie (2002b). EPR biedt kansen voor zonnepanelen. Number 1- February: 23-24.

Duurzame Energie (2002c). Shell Solar sluit fabriek. Number 6 - December: 28.

Duurzame Energie (2003). Love me Tender. Number 3 - May: 32.

Duurzame Energie (2003a). Duurzame-energiebranche zorgelijk over kortwieken EPR. Number 5 - Oktober: 6-7.

Duurzame Energie (2003b). PV-wereld mist visie op langer termijn bij de overheid. Number 3 - May. 27.

Duurzame Energie (2004). Mijlpaal Vereniging Zonnestroom. Number 1 - January: 16.

Duurzame Energie (2004a). Europees platform stroomlijnt PV-onderzoek. Number 1 - January: 29.

Duurzame Energie (2004b). Campagne 'Meer dak onder de zon'resulteert in $3 \mathrm{MW}$ aan zonnepanelen. Number 3- June: 28-29.

e-Decentraal. (2012). "Brief e-decentraal aan Tweede Kamer - Voorstel aanpassing salderingsmogelijkheden." Retrieved October 10, 2012, from http://www.hieropgewekt.nl/sites/default/files/documents/20121010Brief-aan-2de-kamer-decentraal-duurzaam-brede\%20alliantie.pdf.

Ecofys (2012). National Survey Report of PV Power Applications in The Netherlands 2011, Ecofys Netherlands BV. 
Edquist, C. (1997). Systems of Innovation; Technologies, Institutions and Organisations. London, Printer Publisher LTD.

Edquist, C. (2001). The Systems of Innovation Approach and Innovation Policy: An account of the state of the art. DRUID, Aalborg.

Edquist, C. (2004). "Reflections on the systems of innovation approach." Science and Public Policy 31(6): 485489.

Edquist, C. (2004). Systems of Innovation: Perspectives and Challenges. In: The Oxford Handbook of Innovation. J. Fagerberg, D. C. Mowery and R. R. Nelson. Oxford, Oxford University Press: 181-208.

Edquist, C. and B. Johnson (1997). Institutions and Organizations in Systems of Innovation. Systems of Innovation - Technologies, Institutions and Organizations. C. Edquist. London, Pinter Publisher. 41-63.

Edquist, C. and B. Johnson (1997). Institutions and Organizations in Systems of Innovation. In: Systems of Innovation - Technologies, Institutions and Organizations. C. Edquist. London, Pinter Publisher LTD: 41-63.

Eisenhardt, K. M. and M. E. Graebner (2007). "Theory Building From Cases: Opportunities and Challenges." Academy of Management Journal 50(1): 25-32.

Eliasson, G. and Å. Eliasson (1997). "The Biotechnological Competence Bloc." Revue d'Economie Industrielle 78(4).

Energie \& Milieu (1994). Regeerakkoord: fors bezuinigen op energiesubsidies - Nederlandse terugleververgoeding voor electriciteit is laag Number 9: 5.

Energie+ (2006). Belonen of verplichten. Number 6: 12

Energie+ (2007). Leercurve in subsidie is onmisbare stimulans. Number 1 - January: 20-23.

EnergieNed (2000). MAP Eindrapportage 1990-2000, EnergieNed.

EnergieVerslag (1997). Fotovoltaische energie: toelomst voor de zon in nederland?, Energieonderzoek Centrum Nederland.

espacenet.com. Retrieved December 6, 2010, from http://www.espacenet.com/index.en.htm.

eupvplatform.org. Retrieved July 8, 2010, from http://www.eupvplatform.org/.

Eveleens, C., S. de Boer and M. Hekkert (2011). Zon-PV. Een analyse van het Nederlandse innovatiesysteem rond zonnestroom, Agentschap NL \& Universiteit Utrecht.

Faiers, A. and C. Neame (2006). "Consumer attitudes towards domestic solar power systems." Energy Policy 34(14): 1797-1806.

Feather N T (1975). Values in Education and Society. New York, Free Press.

Fischedick M, Schaeffer R, Adedoyin A, Akai M, Bruckner T, Clarke L, Krey V, Savolainen I, Teske S, Ürge-Vorsatz D and Wright R (2011). Mitigation Potential and Costs. IPCC Special Report on Renewable Energy Sources and Climate Change Mitigation. Edenhofer $O$, Pichs-Madruga R, Sokona $Y$ et al. Cambridge, United Kingdom and New York, NY, USA, Cambridge University Press.

Fishbein, M. and I. Ajzen (1975). Belief, attitude, intention, and behavior: An introduction to theory and research. Reading, MA, Addison-Wesley.

Freeman, C. (1987). Technology policy and economic performance - Lessons from Japan, Pinter Pub Ltd

Freeman, C. and F. Louca (2001). As Time Goes By: From the Industrial Revolutions to the Information Revolution. New York, Oxford University Press Inc.

Freeman, C. and B. A. Lundvall (1988). Small countries facing the technology revolution. London, Printer Publisher LTD.

Fthenakis, V. M., H. C. Kim and E. Alsema (2008). "Emissions from Photovoltaic Life Cycles." Environmental Science \& Technology 42(6): 2168-2174.

Galli, R. and M. Teubal (1997). Paradigmatic shifts in national innovation systems. In: Edquist, C. (Ed), Systems of Innovation: Technologies, Institutions and Organizations. London, Pinter Publishers: 342-370.

Gankema, H. G. J. and M. Wedel (1992). Marktsegmentatieonderzoek in theorie en praktijk. Recente Ontwikkelingen in het Marktonderzoek. Haarlem, De Vrieseborch. Jaarboek 1992-'93: 207-222.

Geels, F. and J. Schot (2007). "Typology of sociotechnical transition pathways." Research Policy 36: 399-417.

Geels, F. W. (2002). "Technological transitions as evolutionary reconfiguration processes: a multi-level perspective and a case-study." Research Policy 31(8-9): 1257-1274.

Geels, F. W. (2004). "From sectoral systems of innovation to socio-technical systems - Insights about dynamics and change from sociology and institutional theory." Research Policy 33(6-7): 897-920.

Geels, F. W. (2004). Understanding system innovations: a critical literature review and a conceptual synthesis In: System Innovation and the Transition to Sustainability. Theory, Evidence and Policy, . B. Elzen, Geels, F., Green, K. Cheltenham UK and Northampton MA, Edward Elgar: 19-47.

Geels, F. W. (2005). Technological Transition and System Innovations. A Co-Evolutionary and Socio-

Technical Analysis, . Cheltenham UK and Northampton MA, Edward Elgar Publishing. 
Geels, F. W. (2006). "Co-evolutionary and multi-level dynamics in transitions: the transformation of aviation systems and the shift from propeller to turbojet (1930-1970) "Technovation 26(9): 999-1016.

Geels, F. W., B. Elzen and K. Green (2004). General introduction: system innovation and transitions to sustainability. In: System Innovation and the Transition to Sustainability, Theory, Evidence and Policy,. B. Elzen, F. Geels and K. Green. Cheltenham UK and Northampton MA, Edward Elgar: 1-18.

Geels, F. W. and R. Raven (2006). "Non-linearity and expectations in niche-development trajectories: ups and downs in Dutch biogas development (1973-2003)." Technology Analysis\&Strategic Management 18(3-4): 375-392.

Geels, F. W. and J. Schot (2007). "Typology of sociotechnical transition pathways." Research Policy 36(3): 399417.

Geest, T., J. Jansen, E. Mogulkoç, P. Vries and S. Vries (2008). Segmentation and E- Government; a literature review, Universiteit Twente \& Telematica Instituut.

Genus, A. and A. M. Coles (2008). "Rethinking the multi-level perspective of technological transitions." Research Policy 37(9): 1436-1445.

Giddens, A. (1984). The Constitution of Society: Outline of the Theory of Structuration. Berkeley, University of California Press.

Giddens, A. (1991). Modernity and Self-Identity. Self and Society in the Late Modern Age. Cambridge, Polity Press.

Gostelie, E., J. Maas, R. Mohr and J. Koch (2010). Groen licht voor groene stroom. Amsterdam, Boston Consulting Group.

Haas, R. (2002). Market Development Strategied for PV Systems in the Built Environment, : An evaluation of Incentives, Support Programmes and Marketing Activities. Australia, Institute of Power systems and Energy Economics.

Hasan, R. (2009). "The Solar Silicon Shortage and Its Impact on Solar Power Stocks."

Hawkins D, Mothersbaugh D and Best R (2007). Consumer Behavior: Building Marketing Strategy.

Head, J. (2004). Japan sounds alarm on birth rate. BBC News 5-02-2009.

Heitgerd J L and Lee C V (2003). "A new look at neighborhoods near National Priorities List sites." Social Science \& Medicine 57(6): 1117-1126

Hekkert, M. P. and S. O. Negro (2008). "Functions of innovation systems as a framework to understand sustainable technological change: Empirical evidence for earlier claims." Technological Forecasting and Social Change In Press.

Hekkert, M. P. and S. O. Negro (2009). "Functions of innovation systems as a framework to understand sustainable technological change: Empirical evidence for earlier claims." Technological Forecasting and Social Change 76 584-594.

Hekkert, M. P., R. A. A. Suurs, S. O. Negro, S. Kuhlmann and R. E. H. M. Smits (2007). "Functions of innovation systems: A new approach for analysing technological change." Technological Forecasting and Social Change 74(4): 413-432.

Hessing, E. and A. M. H. Reuling (2003). Waarden in Nederland: Segmentatie van doelgroepen. MarktOnderzoekAssociaties Jaarboek 2003: 163- 175.

Hofman Y, de Jager D, Molenbroek E, Schilig F and Voogt M (2002). The potential of solar electricity to reduce CO2 emissions. Utrecht, Ecofys: 106.

HollandSolar (2007). Transition path thermal solar energy - The roadmap of Holland Solar. Utrecht, HollandSolar.

Holtz, G., M. Brugnach and C. Pahl-Wostl (2007). "Specifying "regime" - A framework for defining and describing regimes in transition research." Technological Forecasting \& Social Change 75: 623-643.

Hoogma, R., M. Weber and B. Elzen (2005). Integrated Long-Term Strategies to Induce Regime Shifts towards Sustainability: The Approach of Strategic Niche Management In: Towards Environmental Innovation Systems. M. Weber and J. Hemmelskamp, Springer Berlin Heidelberg: 209-236.

Hoogwijk M (2004). On the global and regional potential of renewable energy sources, Utrecht University, Department of Science, Technology and Society 256.

Hoogwijk M and W. Graus (2008). Global potential of renewable energy sources: A literature assessment Ecofys.

IEA-PVPS (2004). "Annual report 2003 - Implementing Agreement on Photovoltaic Power Systems."

IEA-PVPS (2005). Annual report 2004 - Implementing Agreement on Photovoltaic Power Systems.

IEA-PVPS (2007). Trends in Photovoltaic Applications - Survey report of selected IEA countries between 1992 and 2006. Report IEA-PVPS T1-16:2007.

IEA-PVPS (2008). "Annual report 2007 - Implementing Agreement on Photovoltaic Power Systems." 
IEA-PVPS (2009). "Annual report 2008 - Implementing Agreement on Photovoltaic Power Systems."

IEA-PVPS (2010a). Trends in Photovoltaic Applications - Survey report of selected IEA countries between 1992 and 2009. Report IEA-PVPS T1-19:2010.

IEA-PVPS (2010b). "Annual report 2009 - Implementing Agreement on Photovoltaic Power Systems."

IEA-PVPS (2013). National Survey Report of PV Power Applications in the Netherlands 2012

IEA-PVPS (2014). "Annual report 2013 - Implementing Agreement on Photovoltaic Power Systems.".

Ikki, O. and K. Matsubara (2007). National survey report of PV Power Applications in Japan 2006, International Energy Agency.

IPCC (2001). Climate Change 2001: Mitigation. Contribution of Working Group III to the Third Assessment Report of the Intergovernmental Panel on Climate Change. Cambridge and New York, Cambridge University Press.

IPCC (2013). Climate Change 2013: The Physical Science Basis. Intergovermental Panel on Climate Change, Working Group I Contribution to the IPCC. Fifth Assessment Report. United Kingdom and New York, NY, USA, Cambridge University Press, Cambridge.

IPCC (2014). Climate Change 2014: Mitigation of Climate Change, IPCC Working Group III Contribution to AR5

Jacobson M Z and Archer C L (2012). "Saturation wind power potential and its implications for wind energy." Proceedings of the National Academy of Sciences 109: 15679-15684.

Jacobson, M. Z. and M. A. Delucchi (2009). A path to sustainable energy by 2030, Scientific American

Jacobsson, S. (2008). "The emergence and troubled growth of a 'biopower'innovation system in Sweden." Energy Policy 36(4): 1491-1508.

Jacobsson, S. and A. Bergek (2004). "Transforming the energy sector: the evolution of technological systems in renewable energy technology." Industrial and Corporate Change 13(5): 815-849.

Jacobsson, S. and A. Johnson (2000). "The diffusion of renewable energy technology: an analytical framework and key issues for research." Energy Policy 28(9): 625-640.

Jacobsson, S., B. A. Sanden and L. Bangens (2004). "Transforming the energy system-The evolution of the German technological system for solar cells." Technology Analysis \& Strategic Management 16(1): 3-30.

Jäger-Waldau, A. (2007). PV Status Report 2007 - Research, Solar Cell Production and Market Implementation of Photovoltaics, European Communities, Luxembourgh: Office for Official Publications of the European Communities.

Jager, W. (2006). "Stimulating the diffusion of photovoltaic systems: A behavioural perspective." Energy Policy 34: 1935 - 1943.

Johansson T B, McCormick K, Neij L and Turkenburg W (2004). The Potentials of Renewable Energy - Thematic Background Paper. International Conference for Renewable Energies. Bonn.

John, G. (2009). Global Solar Photovoltaic Market Analysis and Forecasts to 2020.

Johnson, A. (1998). Functions in Innovation System Approaches. Sweden, Chalmers University of Technology.

Johnson, A. (2001). Functions in innovation system approaches. In: Electronic Paper at the Proceedings of the Nelson and Winter Conference, Aalborg.

JPEA (2006). Vision of the Future of the Photovoltaic Industry in Japan 2006 - Aiming to be the World's Leading PV Nation.

JPEA (2008). personal communication with Takayuki Nakajima, Tetsuzo Kobayashi, Junichi Honda, Masahiro Sakurai, 16 April 2008. Tokyo, Japan.

JPEA. (2012). "Japan Photovoltaic Energy Association (JPEA)." Retrieved November 13, 2012, from http://www.jpea.gr.jp/08eng.html.

Kahle L R, Beatty S E and Homer P (1986). "Alternative Measurement Approaches to Consumer Values: The List of Values (LOV) and Values and Life Style (VALS)." Journal of Consumer Research 13(3): 405-409.

Kaizuka, I. (2008). Current Status and Prospects of Photovoltaics in Japan: Towards sustainable PV market. 4th Workshop on the Future Direction of Photovoltaics.

Kamp, L. (2002). Learning in wind turbine development: a comparison between the Netherlands and Denmark, Utrecht University.

Kamp, L. M. (2008). Analyzing the introduction of renewable energy technologies in The Netherlands with the FIS approach - possibilities, limitations and additions. Conference Proceedings Dynamics of Institutions and Markets in Europe (DIME). Bordeaux.

Kamp, L. M. (2008). "Sociotechnical analysis of the introduction of wind power in The Netherlands and Denmark." International Journal of Environmental Technology and Management 9(2/3): 276-293.

Kamp, L. M., R. E. H. M. Smits and C. D. Andriesse (2004). "Notions of learning applied to wind turbine development in The Netherlands and Denmark." Energy Policy 32(14): 1625-1637. 
Kaplan, A. W. (1999). "From passive to active about solar electricity: innovation decision process and photovoltaic interest generation." Technovation 19(8): 467-481.

Keirstead, J. (2007). "Behavioural responses to photovoltaic systems in the UK domestic sector." Energy Policy 35: $4128-4141$

KEMA (2010). National Survey Report of PV Power Applications in The Netherlands 2009, International Energy Agency Co-operative Programme on Photovoltaic Power Systems.

Kemp, R. (2012). Dynamics of emerging technologies and barriers to disruptive innovation. Presentation at ORGANEXT seminar ICIS - UNU-Merit Emerging technologies in a regional context. March 1, 2012

Kemp, R. and M. Dijk (2013). An analytical framework for understanding resource inefficiency. Polfree Report. Maastricht, ICIS.

Kemp, R. and D. Loorbach (2006). Transition management: a reflexive governance approach. In: Reflexive Governance for Sustainable Development. J.-P. Voss, D. Bauknecht and R. Kemp. Cheltenham UK and Northampton MA, Edward Elgar: 103-130.

Kemp, R. and S. Pontoglio (2008). The innovation effects of environmental policy instruments - a typical case of the blind men and the elephant. Paper for DIME WP 2.5 Workshop on Empirical Analyses of Environmental Innovations, Fraunhofer Institute for Systems and Innovation Research (ISI), Karlsruhe, January, 17th-18th, 2008.

Kemp, R., A. Rip and J. Schot (2001). Constructing Transition Paths through the Management of Niches. In: Path Dependence and Creation. R. Garud and P. Karnøe. Mahwah, New Jersey and London, Lawrence Erlbaum Associates: 269-299.

Kemp, R. and J. Rotmans (2004). Managing the Transition to Sustainable Mobility. In: System Innovation and the Transition to Sustainability: Theory, Evidence and Policy B. Elzen, F. Geels and K. Green. Cheltenham, Edgar Elgar: 137-167.

Kemp, R., J. Schot and R. Hoogma (1998). "Regime shifts to sustainability through processes of niche formation: The approach of strategic niche management." Technology Analysis \& Strategic Management 10(2): 175195.

Kemp, R. P. M. and J. W. Schot (1996). "De toekomst voorspeld voor de toepassing van milieugerichte technieken." Tijdschrift voor Milieukunde

KNAW (2007). Duurzaamheid duurt het langst - Onderzoeksuitdagingen voor een duurzame energievoorziening. Amsterdam, Koninklijke Nederlandse Akademie van Wetenschappen.

Kurokawa, K. (2008). personal communication with Professor Kusoke Kurokawa, Tokyo Institute of Agriculture and Technology, 7 April 2008. Tokyo, Japan.

Kushiya, K. (2008). personal communication with Professor Katsumi Kushiya, Showa Shell Sekiyu K.K., 7 May 2008. Atsugi, Japan.

Labay, D. G. and T. C. Kinnear (1981). " Exploring the consumer decision process in the adoption of solar energy systems." Journal of Consumer Research 8(3): 271-278.

Larosse, J. (2004). "Towards a 'Third Generation' Innovation Policy in Flanders: Policy Profile of the Flemish Innovation System." IWT-Studies Brussels 49.

Lie, M. and K. H. Sørensen (1996). Making technology our own?: Domesticating technology into everyday life. Oslo, Stockholm, Scandinavian University Press.

Linder, J. C., S. Jarvanpaa and T. H. Davenport (2003). "Towards an Innovation Sourcing Strategy." MIT Sloan Management Review 44(4): 43-49.

Liu, X. and S. White (2001). "Comparing innovation systems: a framework and application to China's transitional context." Research Policy 30: 1091-1114.

Loorbach, D. (2007). Transition Management, new mode of governance for sustainable development, Erasmus Universiteit

Lundvall, B. A. (1992). National systems of innovation - towards a theory of innovation and interactive learning. London, Pinter Publishers LTD.

Lysen, E. (2006). Fifty years of solar PV in the Netherlands Utrecht Centre for Energy research.

Markard, J. and B. Truffer (2008). "Technological Innovation Systems and the Multi-Level Perspective: Towards an Integrated Framework." Research Policy 37(4): 596-615.

Marketbuzz. (2008). "2007 World PV Industry report highlights." http://www.solarbuzz.com/Marketbuzz2008intro.htm

Maslow A H (1954). Motivation and Personality. New York, Harper.

McKelvey, M. (1997). Using Evolutionary Theory to Define Systems of Innovation. In: Systems of Innovation Technologies, Institutions and Organizations. C. Edquist. London Printer Publisher LTD: 200-222. 
Meijer, I. S. M. (2008). Uncertainty and entrepreneurial action: The role of uncertainty in the development of emerging energy technologies, University Utrecht.

Mendonca, M. (2007). Feed-In Tariffs - Accelerating the Deployment of Renewable Energy London, EarthScan

Metcalfe, J. S. (1995). "Technology systems and technology policy in an evolutionary framework." Cambridge Journal of Economics 19: 25-46.

Mickwitz, M., H. Hyvättinen and P. Kivimaa (2008). "The role of policy instruments in the innovation and diffusion of environmentally friendlier technologies: popular claims versus case study experiences." Journal of Cleaner Production 16(S1): S162-S170.

Min EZ (1995). Derde Energie Nota. Den Haag, Ministerie van Economische Zaken

Min Ez (2008). Energie Innovatie Agenda. The Hague.

Min EZ (2013). Visie Lokale Energie (internal document). Ministerie van Economische Zaken.

Mints, P. (2007). "Germany - model success?: Germany has achieved much in terms of encouraging RE takeup, but what does the future hold?" Refocus 8(3): 48- 50

Montfoort, J. A. and J. P. M. Ros (2008). Zonne-energie in woningen - Evaluatie van transities op basis van systeemopties. Bilthoven, Milieu- en Natuur Planbureau: Rapport 500083009.

Moriarty P and Honnery D (2012). "What is the global potential for renewable energy?" Renewable and Sustainable Energy Reviews 16: 244-252.

Motivaction. (2010). "Mentality ${ }^{\mathrm{TM}}$-model." Retrieved February 7, 2010.

Movellan, J. (2012). Japanese PV Module Makers Regroup for Overseas Push but Also to Protect Home Turf, Solarbuzz.

Nagashima, T. (2011). Invest Japan Report New Trends for Direct Investment in Japan, JETRO SENSOR.

Natuur \& Milieu (1990). Uitbreiding subsidie zonne-energie. Nummer 11 - November: 17.

Negro, S. O. (2007). Dynamics of Technological Innovation Systems - The Case of Biomass Energy, Utrecht University.

Negro, S. O., F. Alkemade and M. Hekkert (2012). "Why does renewable energy diffuse so slowly? A review of innovation system problems." Renewable and Sustainable Energy Reviews 16(3836-3846).

Negro, S. O. and M. P. Hekkert (2008). "Explaining the success of emerging technologies by innovation system functioning: the case of biomass digestion in Germany." Technology Analysis and Strategic Management 20(4): 456-482.

Negro, S. O. and M. P. Hekkert (2008). "Explaining the success of emerging technologies by innovation system functioning: the case of biomass digestion in Germany." Technology Analysis and Strategic Management 20(4): 456-482.

Negro, S. O., M. P. Hekkert and R. E. Smits (2007). "Explaining the failure of the Dutch innovation system for biomass digestion--A functional analysis." Energy Policy 35: 925-938.

Negro, S. O., M. P. Hekkert and R. E. Smits (2007). "Explaining the failure of the Dutch innovation system for biomass digestion -- A functional analysis." Energy Policy 35(2): 925-938.

Negro, S. O., M. P. Hekkert and R. E. H. M. Smits (2008). "Stimulating renewable energy technologies by innovation policy." Science and Public Policy 35(6).

Negro, S. O., W. Sinke, J. Swens, B. Janson, F. Witte, S. Wan, J. Cace, G. Boxhoorn and K. Van der Klein (2008). Analyse 13 Zon PV - Sessie fotovoltaische zonne-energie. Analyse Transitie Paden Economische Zaken. Utrecht, University

Negro, S. O., R. A. A. Suurs and M. P. Hekkert (2008). "The bumpy road of biomass gasification in the Netherlands: Explaining the rise and fall of an emerging innovation system." Technological Forecasting and Social Change 75(1): 57-77.

Negro, S. O., V. Vasseur, W. G. J. H. M. Van Sark and M. P. Hekkert (2012). "Solar eclipse: The rise and 'dusk' of the Dutch PV innovation system." Int. J. Technology, Policy and Management Science 12(2/3): 135-157.

Nelson, R. R. (1993). National innovation systems - A comparative analysis. New York, Oxford University Press.

Nelson, R. R. and S. G. Winter (1982). An Evolutionary Theory of Economic Change. Cambridge, MA, Belknap Press.

NetMBA. (2010). "Market Segmentation." Retrieved 26 October, 2012, from http://www.netmba.com/marketing/market/segmentation/

NWEA. (2008). "MEP/SDE Dossier." Retrieved February 18, 2009, from http://www.nwea.nl/dossier-sdemep.

Nygaard, S., S. Pogutz and A. Rickne (2008). Entrepreneurship and Innovation- Organizations, Institutions, Systems and Regions; Orchestrated and Bottum-Up Commercialisation Stratgeies for Emerging Technologies. DRUID 25th Celebration Conference 2008, Copenhagen, Denmark.

Nykvist, B. and L. Whitmarsh (2008). "A multi-level analysis of sustainable mobility transitions: Niche decelopment in the UK and Sweden." Technological Forecasting \& Social Change 75(9): 1373-1387. 
ODE. (2009). "Nederlands subsidiesysteem voor duurzame energie werkt niet." Retrieved February 18,, 2009, from http://www.duurzameenergie.org/nieuws/nederlands-subsidiesysteem-voor-duurzameenergiewerkt.html.

OECD (2005). Oslo manual guidelines for collecting and interpreting innovation data. Paris, Organisation for Economic Co-operation and Development : Statistical Office of the European Communities.

Olsson, P., C. Folke and T. Hahn (2004). "Social-ecological transformation for ecosystem management: the development of adaptive co-management of a wetland landscape in southern Sweden." Ecology and Society 9(4).

Olsson, P., L. H. Gunderson, S. R. Carpenter, P. Ryan, L. Lebel, C. Folke and C. S. Holling (2006). "Shooting the rapids: navigating transitions to adaptive governance of social-ecological systems." Ecology and Society 11(1).

Oostra, M. and B. Jablonska (2013). Understanding Local Energy Initiatives and Preconditions for Business Opportunities e-hub.

Ostlund, L. E. (1974). "Perceived Innovation Attributes as Predictors of Innovativeness." Journal of Consumer Research 1(2): 23-29.

Overheid.nl. (2011). " 33000 XIII: Vaststelling van de begrotingsstaten van het Ministerie van Economische Zaken, Landbouw en Innovatie (XIII) voor het jaar 2012." Nr. 69 Motie van de Leden van der Werf en Wiegman-van-Meppelen Scheppink. Retrieved January 8, 2013, from https://zoek.officielebekendmakingen.nl/kst-33000-XIII-69.html.

Ozag, D. and J. Jurkiewicz (2009). Information System Response Model : An Extension of the Tam Model Human Resources and their Development - Volume 2 M. J. Marquardt, UNESCO. 2.

Palm, J. and M. Tengvard (2011). "Motives for and barriers to household adoption of small-scale production of electricity: examples form Sweden." Sustainability: Science, Practice, \& Policy 7(1): 6 - 15

Paredis, E. (2009). Socio-technische systeeminnovaties en transities: van theoretische inzichten naar beleidsvertaling, Centrum voor Duurzame Ontwikkeling - Universiteit Gent

Parto, S., D. Loorbach, A. Lansink and R. Kemp (2007). Transitions and institutional change: the case of the Dutch waste subsystem. In: Industrial Innovation and Environmental Regulation. S. Parto and B. HerbertCopley. New York, USA, United Nations University Press.

Photon International (2004). Ambitious target. May: 20.

Photon International (2009). Japan METI Declares Commencement of application acceptance for residential solar generation installation subsidies for FY2008. January

PhotonInternational (2010). A comic masterpiece. Photon International. 4: 49-50.

Polder-PV. (2010). "SDE 2010." Retrieved May 21, 2010, from http://www.polderpv.nl/SDE_regeling13.htm.

Polder-PV. (2012). "Eindelijk nieuwe cijfers CBS grafieken." Retrieved November 23, 2012, from http://www.polderpv.nl/nieuws_PV94.htm.

Poole, M. S., A. H. Van de Ven, K. Dooley and M. E. Holmes (2000). Organizational Change and Innovation Processes, theories and methods for research. New York.

Porter, M. E. (1985). Competitive Advantage New York, The Free Press.

Porter, M. E. (1990). The Competitive Advantage of Nations. New York, Free Press.

PV-Nieuwsbrieven http://www.zonnestroomproducenten.nl/docs_pdfs/nieuwsbrievenarchief_pv.pdf.

(2002/2003)

PV ERA NET. (2009). "Germany - Organisations involved in PV ERA NET and PV RTD programming." Retrieved April 13, 2010, from http://www.pv-era.net/cms03/showlinx.asp?lang=e\&id=79\&menu=3.

Raven, R. (2005). Strategic Niche Management for Biomass. A comparative study on the experimental introduction of bioenergy technologies in the Netherlands and Denmark, Technische Universiteit Eindhoven.

Raven, R. P. J. M. and G. P. J. Verbong (2009). "Boundary crossing innovations: Case studies from the energy domain " Technology in Society 31(1): 85-93.

Regeerakkoord (2012). Bruggen slaan: Regeerakkoord VVD - PvdA, 29 oktober 2012.

Reiche, D. and M. Bechberger (2003). "Policy differences in the promotion of renewable energies in the EU member states " Energy Policy 42(7): 843-849.

Reinshagen, P. (1984). Zonne-energie trekt aan. DE: 9-10.

Reisman D, Glazer N and Denney R (1950). The Lonely Crowd. New Haven, CT, Yale University Press.

REN21 (2014). "Renewables 2014 Global Status Report ".

Reuters (2008). Japan to promote solar power for households: Nikkei. June 22, 2008.

Rickne, A. (2000). New Technology-Based Firms and Industrial Dynamics. Evidence from the Technological System of Biomaterials in Sweden, Ohio and Massachusetts, Chalmers University of Technology Goteborg. 
Rickne, A. (2001). Assessing the Functionality of an Innovation System. Goteborg, Chalmers University of Technology.

Rijksoverheid (2010). Regeerakkoord VVD-CDA - Vrijheid en verantwoordelijkheid

Rijksoverheid. (2012). "Green Deal." Retrieved March http://www.rijksoverheid.nl/onderwerpen/duurzame-economie/green-deal.

Rip, A. and R. Kemp (1998). Technological Change. In: Rayner, S., Malone, E.L. (Eds.), Human Choice and Climate Change. Battelle Press, Columbus, US. 2: 327-399.

Rogers, E. (1995). Diffusion of Innovations. New York, Free Press (Original work published 1964).

Rogers, E. M. (2003). Diffusion of innovations. New York, The Free Press.

Rogner H, Aguilera R F, Archer C L, Bertani R, Bhattacharya S C, Dusseault MB, Gagnon L and Yakushev V (2012). Chapter 7: Energy Resources and Potentials. Global Energy Assessment - Toward a Sustainable Future, Cambridge University Press, Cambridge UK and New York, NY, USA and the International Institute for Applied Systems Analysis, Laxenburg, Austri.

Rokeach, M. (1973). The Nature of Human Values. New York, Free Press.

Roos, J. and M. Blom (2001). Evaluatie NOZ-pv 1997-2000: Is de eeuw van de zon in 2000 begonnen? Delft.

Rosenberg, N. (1976). Factors affecting the diffusion of technology. Perspectives on Technology, Cambridge University Press, Cambridge.

Rosenberg, N. (1976). Perspectives on Technologie. Cambridge, Cambridge University Press.

Rotmans, J. and R. Kemp (2003). Managing Societal Transitions: Dilemmas and Uncertainties: The Dutch energy case study. OECD Workshop on the benefits of Climate Policy: Improving Information for Policy Makers.

Rotmans, J., R. Kemp and M. Van Asselt (2001). "More evolution than revolution: transition management in public policy." Foresight 3(1): 15 - 31.

Rotmans, J., R. Kemp, M. Van Asselt, F. Geels, G. Verbong and K. Molendijk (2000). "Transities \& Transitiemanagement. De casus van een emissiearme energievoorziening."

RTS Corporation (2008). PV Activities in Japan and Global PV Highlights - Summary in December. Tokyo, Japan, RTS Corporation. 14.

Sagar, A. D. and B. Van der Zwaan (2006). "Technological innovation in the energy sector: R\&D, deployment, and learning-by-doing." Energy Policy 34(17): 2601-2608.

Sam, A. (2010). "The Solar Future: India 2011 To Chart Roadmap For Indias Emergence As A Solar Superpower." Retrieved October 31, 2012, from http://www.articlesnatch.com/Article/The-Solar-Future--India-2011-ToChart-Roadmap-For-Indias-Emergence-As-A-Solar-Superpower/1978593\#.UJEpCsUTmmQ.

Sardianou, E. (2008). "Barriers to industrial energy efficiency investments in Greece." Journal of Cleaner Production 16(13): 1416-1423.

Saviotti, P. P. (2005). On the Co-evolution of Technologies and Institutions. Towards

Environmental Innovation Systems. W. Weber and J. Hemmelskamp. Berlin, Springer.

Schiffman L G and Kanuk L L (2010). Consumer Behavior - Global Edition. New Jersey, Prentice Hall

Schleich, J. (2009). "Barriers to energy efficiency: a comparisonacross the Germancommercial and services sector." Ecological Economics 68(7): 2150-2159.

Schoen, T. J. N. (2001). Building integrated pv installations in the Netherlands -examples and operational experiences. Utrecht Ecofys Energy and Environment.

Schot, J. W., G. P. A. Mom, R. Filarski and P. E. Staal (2002). Concurrentie en afstemming: water, rails, weg en lucht. In: Techniek in Nederland in de twintigste eeuw. Deel V. J. W. Schot, H. W. Lintsen, A. Rip and A. A. De la Bruheze. Zutphen, Walburg Pers: 19-43.

Schwann, G. M. P. (2005). Do Standards Enable or Constrain Innovation?. The Empirical Economics of Standards P. Temple. London, Department of Trade and Industry.

Schwencke, A. M. (2012). Energieke BottomUp in Lage Landen - De Energietransitie van Onderaf Over Vrolijke energieke burgers Zon- en windcoöperaties Nieuwe nuts Leiden, AS I-Search.

Segaar, P. J. (2010). Booming German PV market could cost ratepayers 70\% more in 2011. Solarplaza.

Senternovem. (2010). "Subsidie Zon-PV 2010 " Retrieved May 21, 2010, from https://www.senternovem.nl/sde/zonnepanelen/index.asp.

SenterNovem. (n.d./2010). "MEP: Milieukwaliteit van de Elektriciteitsproductie." Retrieved April 13, 2010, from http://www.senternovem.nl/mep/.

Seyfang, G. and A. Smith (2007). "Grassroots innovations for sustainable development: towards a new research and policy agenda." Environmental Politics 16584 - 603.

Shapori, S. and M. Wilk (1965). "An anlysis of variance test for normality (complete samples)." Biometrika 52: 591-611. 
Shove, E. (2003a). "Converging Conventions of Comfort, Cleanliness and Convenience." Journal of Consumer Policy 26: 395-418.

Shove, E. (2003b). Comfort, Cleanliness and Convenience: the Social Organization of Normality. Oxford, Berg.

Shove, E. (2003c). "Users, Technologies and Expectations of Comfort, Cleanliness and

Convenience." Innovation 16(2): 193-206.

Shove, E. (2004). Sustainability, system innovation and the laundry. In: System Innovation and the Transition to Sustainability. Theory, Evidence and Policy. B. Elzen, F. W. Geels and K. Green. Cheltenham, Edward Elgar.

Shove, E. and G. Walker (2007). "CAUTION! Transitions ahead: politics, practice, and sustainable transition management." Environment and Planning A 39: 763-770.

Sinke, W. (2002). Development and implementation of PV in the Netherlands. 29th IEEE PVSC, New Orleans.

Sinke, W. (2007). A Strategic Research Agenda for Photovoltaic Solar Energy Technology Research and development in support of realizing the Vision for Photovoltaic Technology, Prepared by Working Group 3.

Sinke, W. (2008). Personal communication with Wim Sinke, ECN, utrecht University, 20 May 2008 Pette, The Netherlands.

Smets, A. (2008). personal communication with Arno Smets, AIST, 18 April 2008. Tsukuba, Japan.

Smith, A. (2007). "Translating Sustainabilities between Green Niches and Socio-Technical Regimes." Technology Analysis \& Strategic Management 19(4): 427-450.

Smith, A., A. Stirling and F. Berkhout (2005). "The governance of sustainable socio-technical transitions." Research Policy 34 (10): 1491-1510.

Smits, R. and S. Kuhlmann (2004). "The rise of systemic instruments in innovation policy." The International Journal of Foresight and Innovation Policy 1(1/2): 4-32

Solarplaza. (2012). "Past Solarplaza events." Retrieved October 31, 2012, from http://www.solarplaza.com/events/pastsolarplazaevents/.

Sorrell, S., E. O'Malley, J. Schleich and S. Scott (2004). The economics of energy efficiency. Cheltenham, Elgar.

Spaargaren, G. (2003). "Sustainable Consumption: A Theoretical and Environmental Policy Perspective." Society \& Natural Resources 16(8): $687-701$.

Spaargaren, G. (2006). The ecological modernization of social practices at the consumption junction. ISA-RC-24 conference 'Sustainable Consumption and Society', Wisconsin, Madison.

Spaargaren, G., T. Beckers, S. Martens, B. Bargeman and T. van Es (2002). Gedragspraktijken in Transitie. De Gedragspraktijkenbenadering getoetst in twee gevallen: Duurzaam wonen en Duurzame toeristische mobiliteit. Tilburg - Wageningen, Globus - Wageningen University Environmental Sciences.

Spaargaren, G., S. Martens and T. Beckers (2006). Sustainable technologies and everyday life. In: User Behaviour and Technology Development: Shaping Sustainable Relations Between Consumers and Technologies. P. P. Verbeek and A. Slob, Springer. 107-118.

Spaargaren, G., H. Mommaas, S. van den Burg, L. Maas, E. Drissen, H. Dagevos, B. Bargeman, L. Putman, J. Nijhuis, D. Verbeek and E. Sargant (2007). Duurzamer Leefstijlen en Consumptiepatronen: een theoretisch perspectief voor de analyse van transitieprocessen binnen consumptiedomeinen, Onderzoeksrapport TMB-project, Environmental Policy Group Wageningen Universiteit - Milieu Natuur Planbureau TilburgUniversiteit Telos - Landbouw Economisch Instituut.

Spaargaren, G. and P. Oosterveer (2010). "Citizen-consumers as agents of change in globalizing modernity: the case of sustainable consumption." Sustainability: Science, Practice, \& Policy 2: 1887-1908.

Spaargaren, G. and B. van Vliet (2000). "Lifestyles, consumption and the environment; the ecological modernization of domestic consumption." Environmental politics 9(1): 50-76.

Staiß, F. (2007). Jahrbuch Erneuerbare Energien. Bieberstein, Radebeul.

Stern, P. C. (1992). "What psychology knows about energy conservation." American Psychological Association 47(10): 1224 - 1232

Stirling, A. (2011). "Pluralising progress: from integrative transitions to transformative diversity." Environmental Innovation and Societal Transitions $\quad$ (1): 82-88.

Stokman, F. N. and J. Wolf (2011). Bereid om mee te doen met initiatieven voor lokale productie van duurzame energie. Groningen, the Netherlands, University of Groningen.

Stone, D. (2001). "Learning Lessons, Policy Transfer and the International Diffusion of Policy Ideas." CSGR Working Paper 69(1).

Straub, E. T. (2009). "Understanding Technology Adoption: Theory and Future Directions for Informal Learning." Review of Educational Research 79(2): 625-649.

Stromen (2004a). Zonnecellen. June 25, 2004: 1.

Stromen (2004b). Zonnecelfabriek. December 17, 2004. 6: 4. 
Stryi-Hipp, G. (2004a). The Effects of the German Renewable Energy Sources Act (EEG) on Market, Technical and Industrial Development. 19th European Photovoltaic Solar Energy Conference, Paris.

Stryi-Hipp, G. (2004b). The 100.000 Roofs Programme, REACT-Altener.

Suurs, R. A. A. (2009). Motors of sustainable innovation - Towards a theory on the dynamics of technological innovation sytems.

Suurs, R. A. A. and M. P. Hekkert (2009b). "Cumulative causation in the formation of a technological innovation system: The case of biofuels in the Netherlands." Technological Forecasting and Social Change 76(8): 10031020.

Tanaka, R. (2007). Next-Generation Photovoltaics Development in Japan. British Embassy Tokyo, Science and Innovation Section.

Thollander, P. and M. Ottosson (2008). "An energy efficient Swedish pulp and paper industry: exploringbarriers to anddriving forces for cost-effective energy efficiency investments." Energy Efficiency 1(1): 21-34.

Toffler, A. (1980). The Third Wave USA, Bantam Books

Topsector Energie. (2012). "Energie." Retrieved March 6, 2013, from http://www.top-sectoren.nl/energie/.

TW (1997). Shell-cel scoort beter. 15 October: 1.

TW (1997a). Shell ziet het licht. 15 October: 3 .

Twidell J and Weir T (2006). Renewable energy resources. London; New York, Taylor \& Francis.

Underwood, K. (2009). "The Dark Side of Solar Panels." Retrieved December 18, 2012, from http://www.treehugger.com/corporate-responsibility/the-dark-side-of-solar-panels.html.

Unruh, G. C. (2000). "Understanding carbon lock-in." Energy Policy 28(12): 817-830.

Van de Van, A. H., D. G. Polley, R. Garud and S. Venkataraman (1999). The Innovation Journey. New York, Oxford, Oxford University Press.

Van de Ven, A. and R. Garud (1989). "A Framework for Understanding the Emergence of New Industries." Research on Technological Innovation, Management and Society 4: 195-225.

Van de Ven, A. H., D. G. Polley, R. Garud and S. Venkataraman (1999). The Innovation Journey. New York, Oxford, Oxford University Press.

Van den Akker, P. (2012). "Siemens stapt uit zonne-energie." Retrieved Oktober 12, 2012, from http://www.bnr.nl/programma/bnrduurzaam/109473-1210/siemens-stapt-uit-zonne-energie.

Van den Bergh, J. and R. Kemp (2006). Economics and Transitions: Lessons from Economic Sub-disciplines, Working Paper Series. Maastricht, UNU-MERIT.

Van der Brugge, R. (2009). Transition dynamics in socio-ecological systems. The case of duch water management, Erasmus Universiteit.

Van der Hoeven, D. (2009). Nieuw Licht - Inzicht in een duurzame energiehuishouding, Nederlandse Organisatie voor Wetenschappelijk Onderzoek in samenwerking met SenterNovem.

Van der Laak, W. W. M., R. P. J. M. Raven and G. P. Verbong (2007). "Strategic niche management for biofuels: Analysing past experiments for developing new biofuel policies "Energy Policy.

Van Lente, H., M. Hekkert, R. Smits and B. Van Waveren (2003). "Roles of Strategic Intermediaries in Transition Processes: The Case of Energy Innovation Systems." International Journal of Technology Management 7(3): 1-33.

Van Sark, W. G. J. H. M., G. W. Brandsen, M. Fleuster and M. P. Hekkert (2007). "Analysis of the silicon market: Will thin films profit?" Energy Policy 35(6): 3121-3125.

Vasseur, V. (2012). Consumer behaviour during the transition of PV in the Netherlands. Presented at Sociology Summer Conference, Lancaster.

Vasseur, V. and R. Kemp (2011). "The role of policy in the evolution of technological innovation system for photovoltaic power in Germany and the Netherlands." International Journal of Technology, Policy and Management (IJTPM) 11(3/4): 307-327.

Venkatesh, V. and F. D. Davis (2000). "A theoretical extension of the technology acceptance model: Four longitudinal field studies." Management Science 46(2): 186-204.

Venkatesh, V., M. Morris, G. B. Davis and F. D. Davis (2003). "User Acceptance of Information Technology: Toward a

Unified View." MIS Quarterly 27(3): 425-478.

Verbeek, D. H. P. and J. T. Mommaas (2008). "Transitions to sustainable tourism mobility: the Social Practices Approach." Journal of Sustainable Tourism 16(5): 49-60.

Verbong, G. and F. Geels (2007). "The ongoing energy transition: lessons from a socio-technical, multi-level analysis of the Dutch electricity system (1960-2004)." Energy Policy 35(2): 1025-1037

Verbong, G. P., J. A. van Selm, R. Knoppers and R. Raven (2001). Een kwestie van lange adem - De geschiednis van duurzame energie in Nederland. Boxtel., Eneas. 
Verbruggen A, Fischedick M, Moomaw W, Weir T, Nadaı" A, Nilsson L J, Nyboer J and Sathaye J (2010). "Renewable energy costs, potentials, barriers: Conceptual issues." Energy Policy 38 850-861.

Volkskrant (2003). Bezuinigingsplan wordt doodsteek zonne-energie. September 3, 2003.

Von Hippel, E. (2001). "Innovation by User Communities: Learning from Open-Source Software." MIT Sloan Management Review 42(82-87).

Walker, G. and N. Cass (2007). "Carbon reduction, 'the public' and renewable energy: engaging with sociotechnical configurations." Area 39(4): 458 - 469.

Watanabe, S. (2007). Trends in Japan's measures for photovoltaic power generation and new energy. 17th International Photovoltaic Science and Engineering Conference.

Weber, L. (1997). "Some reflections on barriers to the efficient use of energy." Energy Policy 25(10): 833-835.

Wedel M and Kamakura W A (2000). Market Segmentation: Conceptual and Methodological Foundations. . Dordrecht, Kluwer.

Wheelwright, S. C. and K. B. Clark (1993). Revolutionizing Product Development: Quantum Leaps in Speed, Efficiency and Quality. New York, Free Press.

WIFO (2009). Patent-based Technology Analysis Report - Alternative Energy, World Intellectual Property Organization

Wijnbergen, M. (2013). Technological Innovation System analysis: A study of the Development \& Diffusion of Local Sustainable Energy initiatives in the Netherlands

Williams, M., N. Rana, Y. Dwivedi and B. Lal (2011). Is UTAUT really used or just cited for the sake of it? A systematic review of citations of UTAUT's orginating article, ECIS 2011 Proceedings.

Wissing, L. (2009). National Survey Report of PV Power Applications in Germany 2008, Forschungszentrum Julich.

Yamada, H. and O. Ikki (2012). National Survey Report of PV Power Applications in Japan 2011. International Energy Agency.

Yamamoto, M. and O. Ikki (2010). National survey report of PV Power Applications in Japan 2009, International Energy Agency.

Yamamoto, M. and O. Ikki (2011). National survey report of PV Power Applications in Japan 2010, International Energy Agency.

Yin, R. K. (2003). Case study research - Design and methods. Thousand Oaks, SAGE publications.

Yoshikawa, S. (2008). personal communication with Susumu Yoshikawa, Kyoto University', 14 April 2008. Kyoto, Japan.

YourEnergy.net. Retrieved May 8, 2008, from http://www.yourenergy.nl/. 



\section{Appendix A:}

\section{Activity pattern of System Functions}

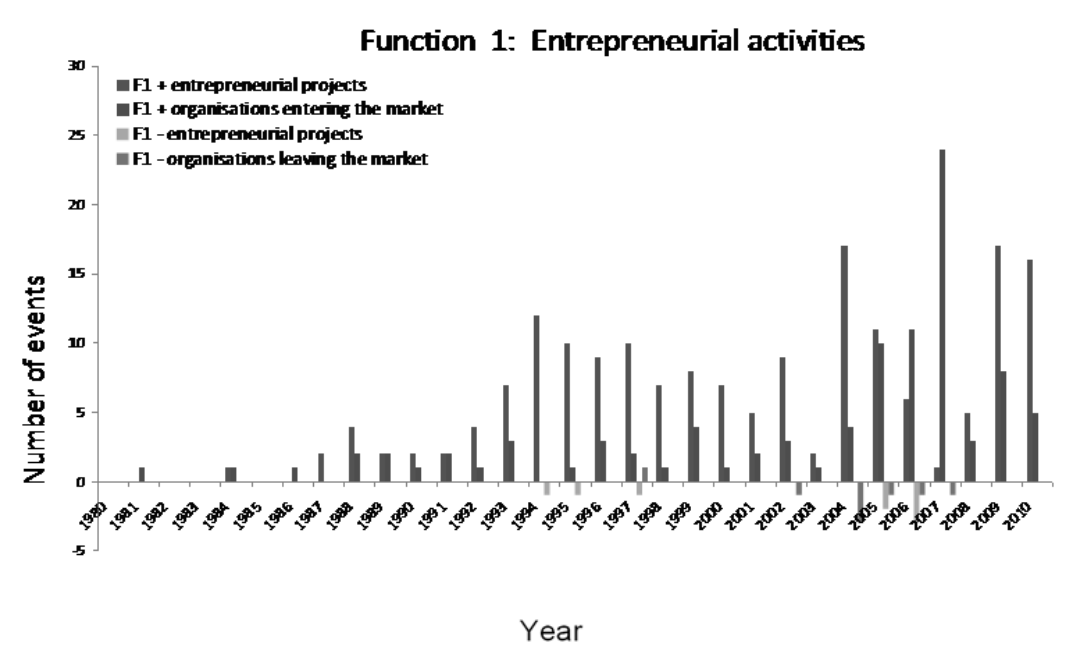

Figure 30. Activity pattern of Function 1: Entrepreneurial activities.

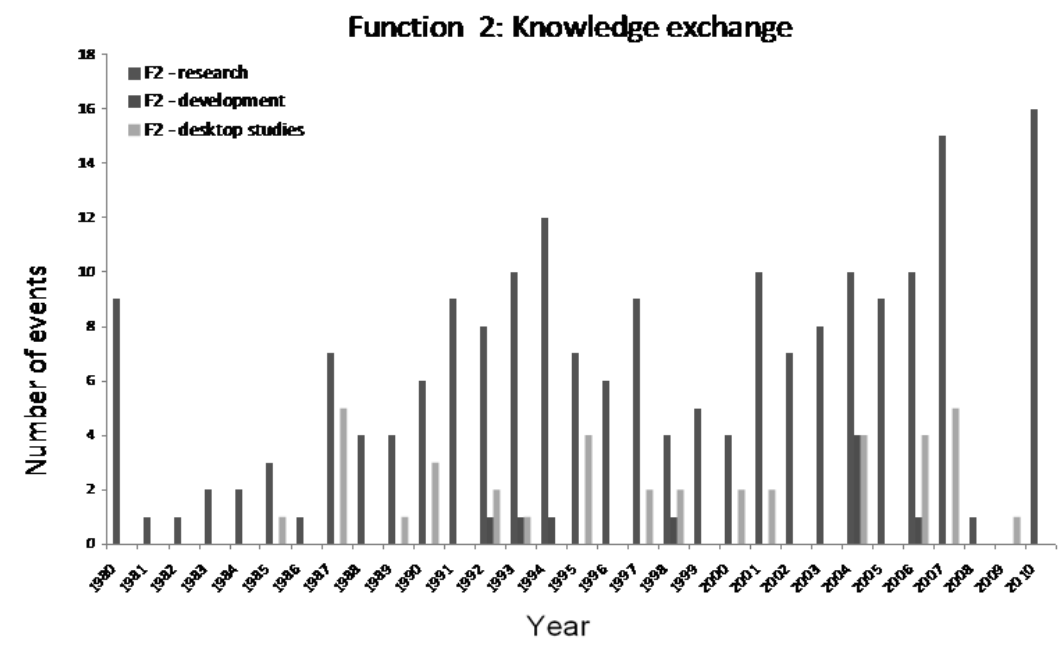

Figure 31. Activity pattern of Function 2: Knowledge exchange. 


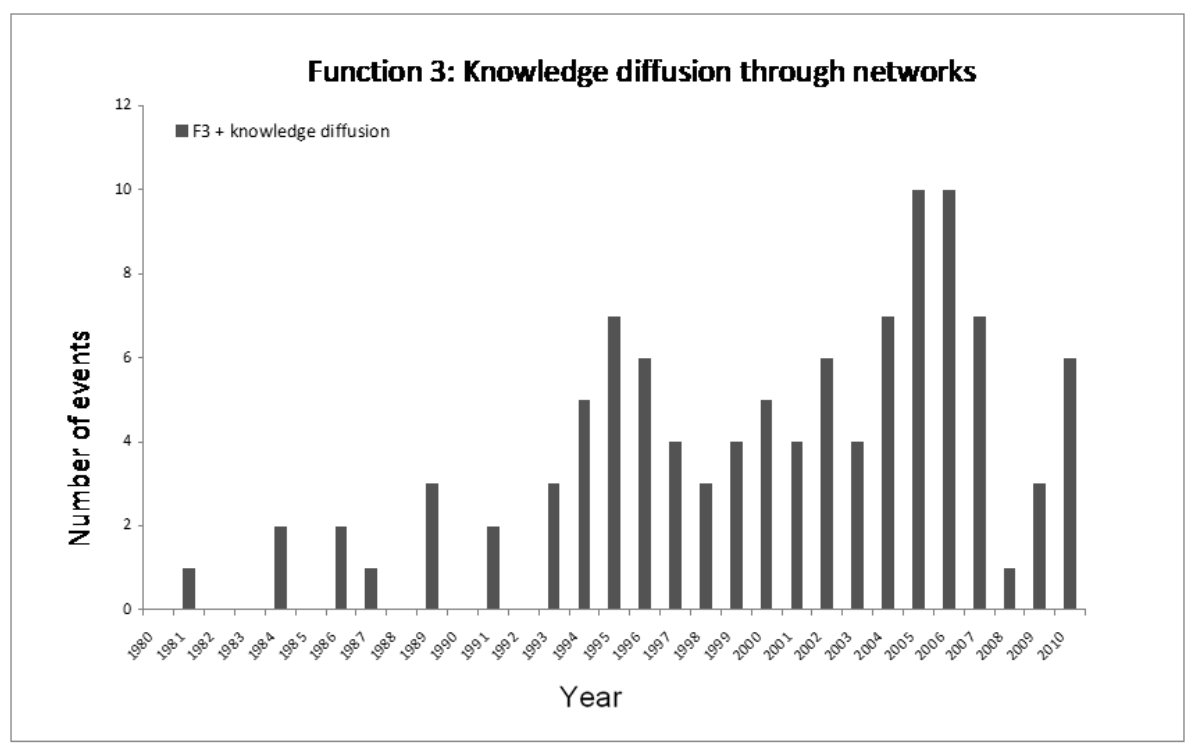

Figure 32. Activity pattern of Function 3: Knowledge diffusion through networks.

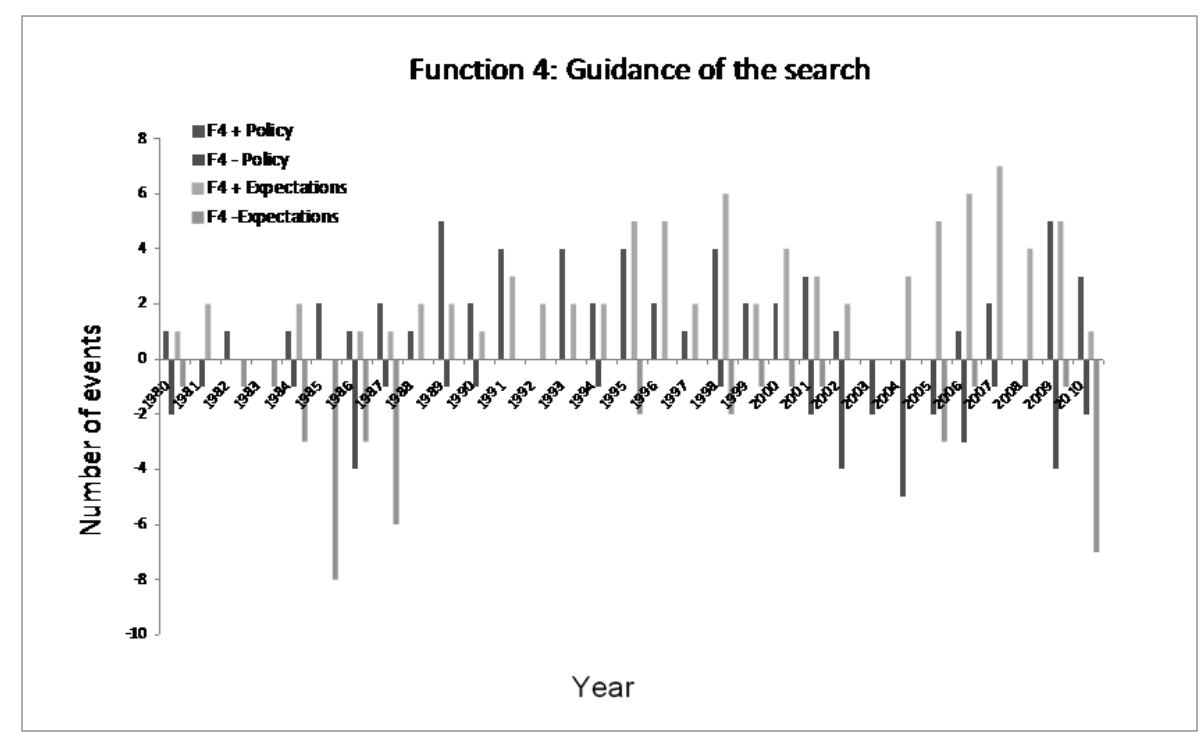

Figure 33. Activity pattern of Function 4: Guidance of the Search. 


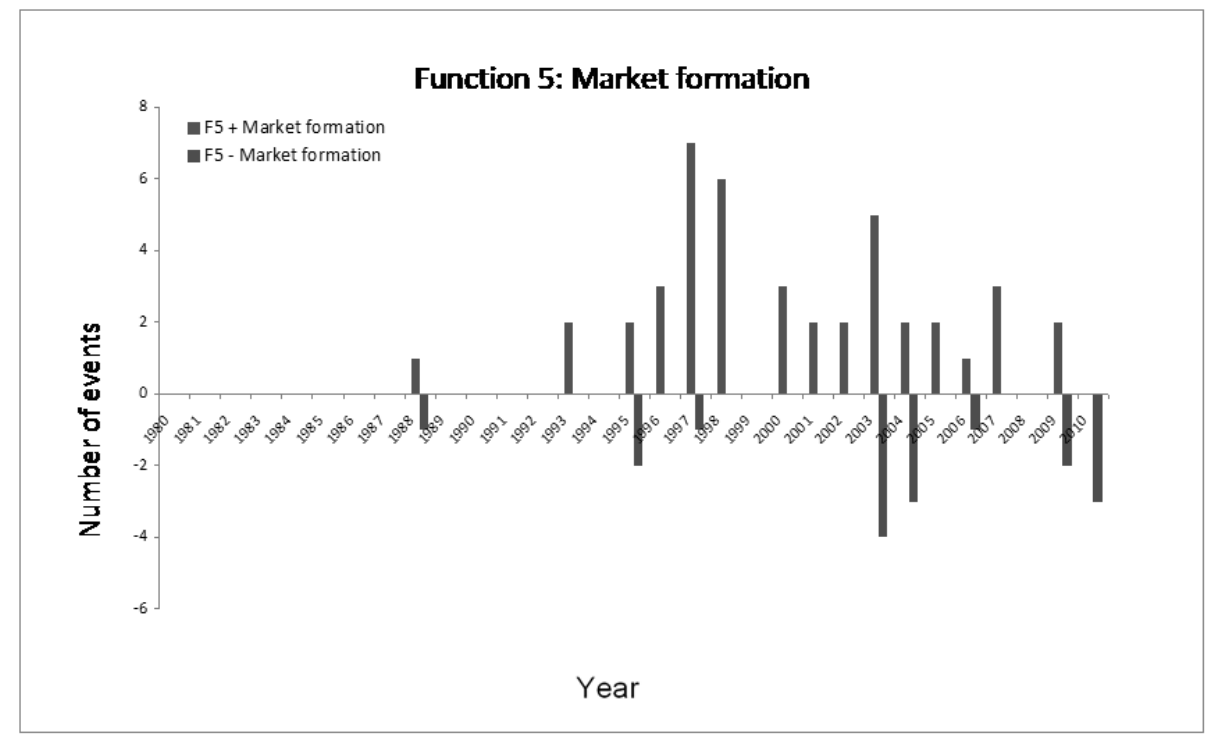

Figure 34. Activity pattern of Function 5: Market formation.

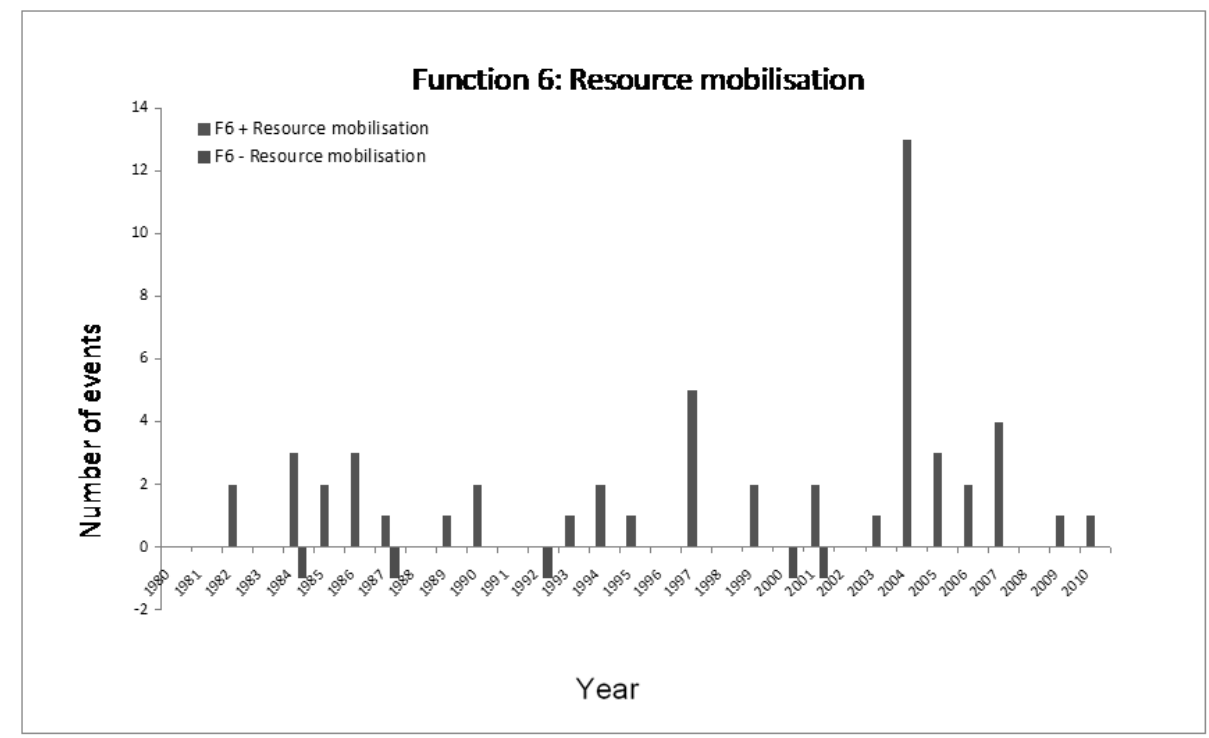

Figure 35. Activity pattern of Function 6: Resource mobilisation. 


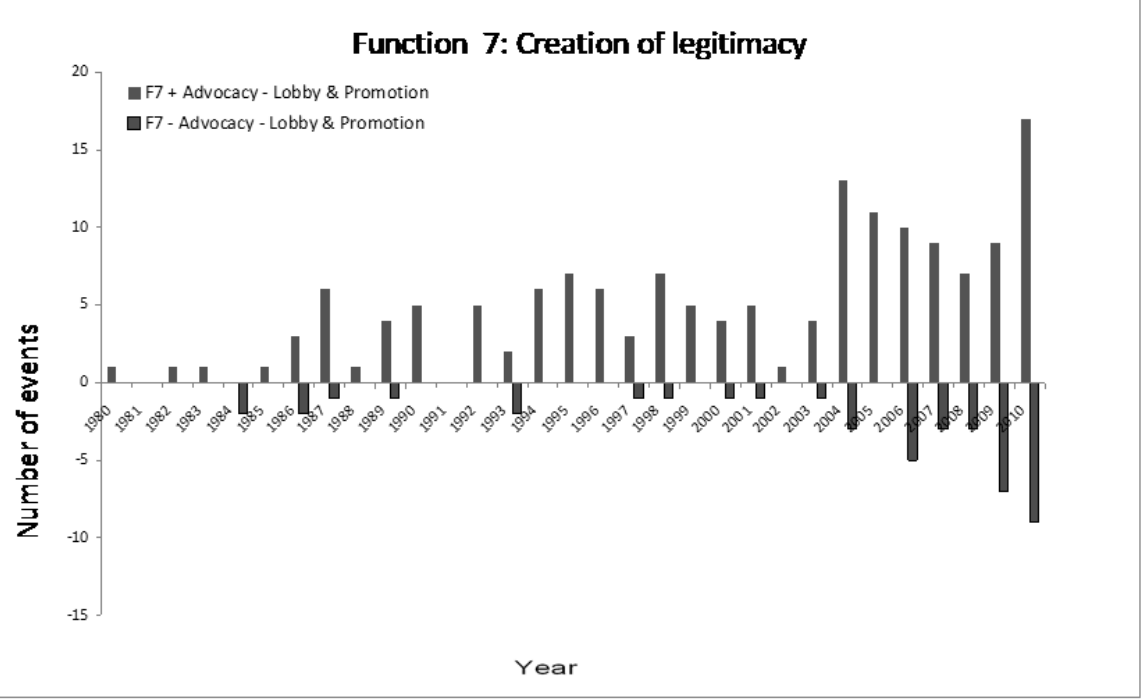

Figure 36. Activity pattern of Function 7: Creation of legitimacy. 


\title{
Appendix B:
}

\section{Overview classification of different segmentation models}

\author{
Valuebox-model of NFO trendbox \\ Order and decency Women in traditional families, average income, low to secondary education, orderly, \\ dutiful, polite emphasis on social rules, security, safety, cost-conscious and thrifty, \\ preference for familiar and stable environment.
}

Purposeful adventure Young single men, high income, high education, city dweller, preference for varied and comfortable life, perceptive and logical thinking, little orderly, positive future vision, ambitious.

Center Average Dutch people.

Uncomplicated Young men, secondary education, need for order and discipline, ambitious and career beneficiary oriented, positive future vision, longing for weekend.

Sober philosophy 50+ living alone, high education, seeking for freedom and peace, inner harmony, selfrespect and creativity, social interest, open-minded, environmentally conscious.

Spiritual

Altruists women 50+, two-person household, secondary education, family is important, equality, fairness and security, helpful and forgiving, traditional, carefully selected diet, frugal and cost conscious.

Mentaltiy model (Motivaction 2010) ${ }^{96}$

Traditional citizens

Comfort oriented

Modern citizens

New conservatives

Cosmopolitans
Traditional values, family is cornerstone and most important, harmony and rest, acceptance of authority and rules, disciplined, risk aversive, soberly, traditional division of roles.

Material wealth, freedom, entertainment, no responsibility, little ambition, longing for appreciation, impulsive, consumption minded, outward appearance very important.

Balancing between traditional values and change, family cornerstone, social status important, authority and rules, longing for appreciation, security, income and experience, technology minded, regularity, traditional division of roles, risk aversive, consumption and entertainment.

Traditional values, protecting social status, hierarchical, critical, interested in politics and history, work is more important than private life, culture and arts, soberly, risk aversive, etiquettes.

Success, self development, internationally oriented, interested in politics, tolerant, work is central motive, ambitious, materialistic, technology minded, impulsive and adventurous, status and etiquettes, arts and culture, focused on like- minded, consumption.

\footnotetext{
${ }^{96}$ Description of the different groups adopted from Offermans (2010).
} 
Upward mobiles Career, gaining social status, freedom from tradition and duties, change and modernization, international, longing for appreciation, work and achievement, income, materialistic, consumption and entertainment, technology minded, impulsive and adventurous, freedom, focused on like-minded.

Post materialists Self development, solidarity, attention for immaterial values, interested in social life and politics, reflexive, critical, solidarity, tolerant, international, balance between work and private, being societal useful, principle, not consumptive and not entertainment focused, sober, arts and culture.

Post modern hedonists Freedom, independency, carpe diem, new experiences, tolerant, equal changes, not interested in politics or society, work subordinate to private, impulsive, adventurous, without obligations, arts and popular culture, experience focused, friends more important than family.

Mosaic model

Free spirited

Young, single, living alone or sharing a house with friends, well educated, multicultural, involvement in the neighborhood is low, public transport, social, without obligations, aware of social development and new by watching the news, public transport.

The developed urbanQuite young, begin of career, well educated, urban nomad, social, no family life, dweller cultural, reading newspapers, interested in society.

Go-getter Young (<34), live alone, low educated, relatively low income, high-rise buildings, broad interested, arts and culture, no car, not often on holiday.

Dynamic families

Ambitious, self development, well educated, successful career, above average salary, live in the middle of the Netherlands, new housing estate, longing for appreciation, well-filled wallet is important, entertainment focused, sport/family car.

Modal citizens $\quad$ Family cornerstone, middle aged, executed jobs, below average to average salary, live often in the West of the Netherlands, terraced house, used family cars, watching action movies, regularly to cafeteria.

Successful families Family cornerstone, children of all ages, above average salary, secondary - well educated, free profession or management function, live in a neighborhood near a town, child friendly neighborhood, owner-occupied house, enjoying life.

Traditionalists

From conservative to liberal and from young to old but they have one thing in common: all work hard for a good life and family life, all kind of jobs, low - secondary educated, owner-occupied houses, semi-detached homes, comfortable, high social cohesion, above average on holidays with own caravan, support charity.

Rural family life $\quad$ Farmers and families of middle age, low-educated, above average salary, owneroccupied houses, detached house, more than one car often high price, modern equipment, no designer clothes.

Well-off people Well educated, career, well-paid professionals, far above average income, spacious villa, highest social class with status and etiquettes, luxury, shopping in exclusive stores, making long journeys.

Pension beneficiary Pensionable age, enjoy the little things in life, lower social class, low educated, apartment, cultural trips, volunteer work, buy traditional products.

WIN-model $^{97}$

Engaged

Harmony, stability, sociable person and prefer to do activities together with a group

\footnotetext{
${ }^{97}$ Description of the different groups adopted from Offermans (2010).
} 
Care takers

Conservatives

Hedonists

Luxury seekers/

Professionals

Broad minded

Balanced of other people, deliberate and well considered, when making decisions you think about the impact for the environment, more elderly people with a reasonably high level of education, interest in arts, nature and politics, not materialistic and not interested in new innovative technologies.

Focused on well being of others, social person receiving energy from helping fellow human beings, sober, generous for others, traditional values and traditions which provide rest and security, no need for change, self effacing, community people, like to do meritorious work for the (church) community, not very creative, prefer implementation over preceding development processes, both reading and television watching, regional newspapers, up to date for social and political situation, fairly cheap products who are reliable, social.

Focused on your own environment, security, family is most important, do not like to attract attention or seeing anybody else doing so, confirmation to rules and norms, bit impulsive, tidy people, preference for unconstrained entertainment like television, disappointed with society and politics, not really materialistic, but in favor of luxurious, modern stuff, confirmative.

Pleasure and enjoyment on physical and emotional level, more sportive than creative, challenge, risk, adventure and excitement, not a worrier, impulsive and showing things very easily (lazy), likes to go out in a group, not interested in social issues and politics, prefer watching television over reading, like to spend money on going out for diner, new and novel objects.

Ambitious, success, appreciation, comfort is highly valued, not somebody who keeps seated, seeking challenges and does not really matter about (behavioral) rules, not very religious, ego centered, not involved in other's businesses, judge quickly and talk straight from the shoulder, interest in society, both television watchers and newspaper readers (mainly telegraaf), possess lots of modern objects and willingness to show these to others, technological developments can not go fast enough, sensitive for trends, and you will be the first one possessing a novel object, achievement.

Ambitious, independent, educated, self development, working hard and a quick and creative thinker, free liver ("life enjoyer"), stimulating and challenging life, often double earners, high income, buying luxurious, tasteful, trendy objects and sensitive to technological novelties, giving money for good causes, critical but receptive for new things and point of views, watches a lot of actualities and background programs on television, up to date for social issues and politics, self destination.

Progressive and educated, lots of ideals who are mainly left wing, worried about social problems and trying to better the world, starting with yourself, environmental consciousness, keen on freedom, appreciate to make once own choices and to have a varied life with some risks, self development, make great demands on oneself and others, receptive for the world around, understanding, profundity, dislike prejudice, read a lot, politics and social issues come from the bottom of the heart, flexible, modern, engaged.

They are an average of all people. When it comes to interests, life style and so on, they are exactly in the middle or other people.

Censydiam-model of Sensovate

Vitality Achieving independence.

Enjoyment People try to maximize satisfaction of their physical and emotional needs.

Conviviality The need to open up socially, to really share emotions with others, to have a good 
time together.

Belonging The need to feel part of a group, to feel accepted and supported by their loves one

Security The need for comfort, tranquility, and relaxation.

Control Control is exercised, behavior is void of emotions and feelings.

Recognitions The need to be different, to stand out from the crowd, not drift with the current.

Power The need to achieve success and status in life.

BSR-model

Yellow - Harmony Commitment and harmony, group oriented, open minded, family.

Green - Protection Security and safety, group-oriented, less open, smaller world, less educated.

Blue - Control Ambition and control, performance, career, status, well-educated.

Red - Vitality Freedom, flexibility, independence, well-educated, active lifestyle, cultural development, travelling.

Experience profiles based on BSR-model

Living together Prefer quiet neighborhood, plenty space in and around home, focusing on family, a preference for traditional design.

Withdrawals Looking for safe and quiet neighborhood, advanced age, strongly focused on the district.

Dynamic individualist Luxurious and exclusive (large and green) living, carrier-/ego-oriented, sports, performance and career-oriented.

Anchored Commitment to peace and security.

Quiet luxury Preference for quiet and safe living environment, focusing on social quality of the neighborhood, living with like-minded.

Unattached urban nomad, idiosyncratic, non-conformist, well educated, not materialistic, active sports, interest in culture and politics, need for privacy and anonymity. 


\section{Appendix C: \\ Questionnaire and answer key - PV amongst Dutch population}

Consumenten enquete zonne-energie

Deze vragenlijst is onderdeel van het Organext project en beoogt uw standpunt op zonne-energie vast te leggen. De vragenlijst bestaat uit verschillende onderdelen: vragen over uw persoonlijke situatie, uw visie op duurzame ontwikkeling en uw visie op zonneenergie.

Het invullen van de vragenlijst duurt ongeveer 10 minuten. De antwoorden worden anoniem verwerkt.

Vraag 1. Persoonlijke vragen

A. Wat is de samenstelling van uw huishouden?

- Alleenstaand

- Tweepersoonshuishouden zonder kinderen

○ Eénoudergezin

○ Gezin

- Groepswonen (bijv. studentenwoning)

- Anders

B. Uit hoeveel personen bestaat uw huishouden?

- 1 persoon

- 2 personen

- 3 - 4 personen

- 5 of meer personen 


\section{Vraag 2. Persoonlijke voorkeuren}

A. Als $u$ moet kiezen bent $u$ het dan eens of oneens met onderstaande stellingen?

Eens; Oneens; N.v.t

- $\quad$ Ik wil mezelf graag nuttig voelen en dingen voor anderen doen

- $\quad$ Ik besteed mijn geld liever nu dan dat ik het spaar voor later

- $\quad$ Ik vind veel geld belangrijker dan veel vrije tijd

- $\quad$ Ik maak me zorgen om klimaatverandering

- $\quad$ Ik vind traditionele waarden en normen belangrijk

- $\quad$ In ons dagelijks leven hebben we regels nodig

- $\quad$ Ik vind mezelf gemakzuchtig

- Ik denk lang na over grote beslissingen

- Ik neem grote beslissingen onafhankelijk van anderen

- $\quad$ Ik stel mezelf steeds hoge doelen die ik probeer te bereiken

- $\quad$ Ik voel me verbonden met de natuur

- Ik tracht goed te doen

- $\quad$ Ik probeer een voorbeeld te zijn voor anderen

- Mijn werk is voor mij heel belangrijk

\section{Vraag 3. Werk}

Indien meerder antwoordmogelijkheden mogelijk zijn wilt $u$ dan bij het beantwoorden van de vraag uitgaan van het werk waar $u$ de meeste tijd aan besteedt, betaald of onbetaald.

A. Bent u op dit moment werkzaam?

o Ja. ik ben fulltime werkzaam

- Ja. ik ben parttime werkzaam ( $21 \mathrm{t} / \mathrm{m} 32$ uur per week)

- Ja. ik ben parttime werkzaam (12 t/m 20 uur per week)

- Nee. ik ben niet werkzaam of minder dan 12 uur

- Ik volg momenteel een studie Ik verricht momenteel vrijwilligerswerk

B. Wat is je netto inkomen per maand?

- Minder dan 900 euro per maand

- Tussen de 900 en 1250 euro per maand

- Tussen de 1250 en 1850 euro per maand

- Tussen de 1850 en 3000 euro per maand

- Tussen de 3000 en 5000 euro per maand

- Meer dan 5000 euro per maand

- Weet niet/ wil ik niet zeggen 
C. Uit welke inkomstenbron ontvangt $\mathrm{u}$ inkomen?
- Loon of salaris
- Winst uit eigen bedrijf
○ Uitkering (bijstand, WW)
- AOW, VUT of pensioen
- Een andere inkomstenbron (alimentatie, freelance)
o Geen inkomen

D. In welke bedrijfstak werkt u?

o N.v.t

- Landbouw en visserij

○ Delfstoffenwinning

- Industrie. reparatie. installatie

- Energie- en waterleidingbedrijven

- Bouw of bouwnijverheid

- Handel

- Vervoer en opslag (vervoer over land, water, lucht, opslag, post en koeriers)

- Horeca

- Informatie en communicatie

- Financiele instellingen

- Onroerend goed

- Zakelijke dienstverlening

- Openbaar bestuur

- Onderwijs

○ Gezondheids- en welzijnszorg

- Cultuur, sport en recreatie

o Overige dienstverlening

- Personeel in dienst van huishoudens

- Internationale gemeenschaporganen

- Anders

\section{Vraag 4. Wonen}

A. Waar woont u?
○ Stad
○ Dorp
- Platteland 
B. In welk type huis woont u?
○ Vrijstaand huis
○ Tussenwoning
- Twee-onder-een-kap
- Appartement / flat
- Boerderij
- Anders

C. Wie is de eigenaar van uw woning?
o Ikzelf
○ Woonstichting
- Particuliere huiseigenaar
○ Anders

D. In hoeverre Bent u tevreden met uw huidige woonsituatie?

$\begin{array}{lllll}1 & 2 & 3 & 4 & 5 \\ \text { Oneens } & & & \text { Eens }\end{array}$

\section{Vraag 5. Duurzame ontwikkeling}

A. $U$ kunt op verschillende manieren een bijdrage leveren aan duurzame ontwikkeling. Kunt $u$ aangeven of in uw huishouden onderstaande manieren gebruikt worden om een bijdrage te leveren?

Bijna altijd; Regelmatig; Af en toe; Nooit

- $\quad$ Ik recycle glas

- $\quad$ Ik recycle papier

- $\quad$ Ik recycle plastic

- Ik vermijd ongeadresseerd reclamedrukwerk en / of huis-aan-huis bladen

- $\quad$ Ik scheid mijn GFT afval

- $\quad$ Ik ga zuinig om met energie (bijv. lichten uit. spaarlampen)

- $\quad$ Ik ga zuinig om met water (bijv. spaarknop op wc's)

- $\quad$ Ik ga zuinig om met verwarming (bijv. regelbare / programmeerbare thermostaten)

- $\quad$ Ik koop energiezuinige apparatuur (A-label)

- $\quad$ Ik gebruik groene stroom

- $\quad$ Ik ga te voet of neem de fiets om kleine afstanden (tot $7 \mathrm{~km}$ ) af te leggen

- Ik vermijd het gebruik van de auto

- $\quad$ Ik kom in aanraking met duurzame energietechnologien tijdens mijn werk 
B. Wat is het beeld dat $u$ heeft van uw eigen levensstijl op het gebied van duurzaamheid?

- Ik ben voortdurend actief op zoek naar informatie over een duurzame levensstijl en nieuwe duurzame producten en probeer deze meteen uit, ik voel mij een voorloper op het gebied

- Ik ben bewust bezig met een zo duurzame mogelijke levensstijl en de keuzes voor duurzame producten

- Ik kies alleen voor een duurzame levensstijl en duurzame producten als ik niets (extra's) hoef te doen of laten

- Pas als anderen kiezen voor een duurzame levensstijl en duurzame producten, en het nut hiervan duidelijk voor mij is. doe ik dat ook

- Ik ben totaal niet bezig met een duurzame levensstijl of duurzame producten

C. Zou u duurzamer willen leven?

- Ja, als het geen extra moeite en geld kost

- Ja, zelfs als het meer geld kost

- Ja, zelfs als het meer moeite kost

○ Ja, zelfs als het meer geld en moeite kost

○ Nee

D. Kunt $u$ aangeven of u positief of negatief bent over de volgende energie opties? Positief; Negatief; Neutraal; Weet niet/ken ik niet

- Kolen

- Olie

- Gas

- Kernenergie

- Windenergie

- Zonne-energie

- Bio-energie

- Energie uit water / waterkracht

- Warmte uit de bodem /geothermische energie

\section{Vraag 6. Zonne-energie}

A. Bent $u$ in het bezit van zonnepanelen?

○ Ja, ik bezit genoeg zonnepanelen om mijn huishouden volledig van elektriciteit te voorzien

○ Ja, ik bezit zonnepanelen maar niet genoeg om mijn huishouden volledig van energie te voorzien

- Ja, ik bezit zonnepanelen maar deze zijn nog niet bevestigd of niet werkend 
- Nee, ik kies pas voor zonnepanelen als de meerderheid er voor kiest en/of voor mezelf het nut ervan duidelijk is

- Nee, ik ben ook niet van plan om zonnepanelen aan te schaffen

B. Kunt $u$ aangeven in hoeverre $u$ het eens of oneens bent met onderstaande stellingen? Eens; Oneens; Weet niet

- $\quad$ Ik vind de milieuvoordelen van zonnepanelen positief

- $\quad$ Er wordt voldoende informatie over zonne-energie verstrekt en de mogelijkheden ervan

- $\quad$ Ik denk dat zonne-energie in de toekomst goedkoper is dan olie en gas

- $\quad$ Ik denk dat een toenemende prijs van olie en gas het gebruik van zonne-energie kan bevorderen

- $\quad$ Ik denk dat zonne-energie de best beschikbare technologie is om zelfvoorzienend te zijn

- $\quad$ Ik beschouw zonne-energie als de meest duurzame energiebron

C. Vindt u dat de implementatie van zonne-energie gestimuleerd moet worden? (bijvoorbeeld door het vertrekken van subsidies)

- Ja (ga verder met vraag D)

○ $\quad$ Nee (ga verder met vraag F)

D. Wie zou volgens $u$ het voortouw moeten nemen om de implementatie van zonneenergie te stimuleren?

Maximaal 3 antwoorden mogelijk
○ Ikzelf
○ Gemeente
- Provinciale overheid
- Regering in Den Haag
- Europese Unie
- Bedrijfsleven
- Elektriciteits- en gasbedrijven
- Werkgevers- en werknemersorganisaties
- Wetenschap
○ Niemand
o Anders:

E. Op welke manier zouden zij volgens $u$ het voortouw moeten nemen bij de implementatie van zonne-energie? 
Maximaal 2 antwoorden mogelijk

○ Via wetgeving en handhaving

- Door mensen aan te spreken op hun verantwoordelijkheid

○ Door voorlichting

- Door belastingmaatregelen

- Door duidelijke doelen te stellen zodat we weten waar we aan toe zijn

- Door een duidelijke toekomstvisie te maken die laat zien wat bepaalde keuzes voor effect hebben

- Door innovaties te stimuleren

- Door belemmerde wetgeving te beperken

- Via contracten tussen burgers, overheden, bedrijfsleven

o Anders:

F. Kritiek op zonne-energie heeft vaak te maken met de prijs, de efficiëntie, de visuele representatie (uiterlijk van het systeem), de levensduur en de integreerbaarheid. Zet deze kenmerken op volgorde van belangrijkheid.

- Prijs

- Efficiëntie - hoeveelheid energie

- Visuele representatie

- Levensduur van het systeem

- Integreerbaarheid

G. Zonnecellen kunnen ook geïntegreerd worden in glazen ramen via speciale nanodeeltjes en depositietechnieken. De ramen leveren dan elektriciteit en blijven transparant. Wat is de eerste gedachte die bij u opkomt bij een dergelijke toepassing?
- Spreekt me wel aan
○ Vind ik een overbodige toepassing
- Is dat wel veilig?
o Ik heb hier geen gedachte over
o Anders:

Als u geen zonnepanelen bezit gaat u verder met vraag 7, als u wel zonnepanelen bezit gaat u verder met vraag 8 .

\section{Vraag 7. Enkel invullen als u geen zonnepanelen bezit}

A. Welke van de onderstaande overwegingen hebben een rol gespeeld om geen zonnepanelen aan te schaffen? 
Maximaal 3 antwoorden mogelijk

- Te hoge investeringskosten

- Te lage energieopbrengst

- Uiterlijk van het systeem - visuele representatie

○ Te innovatief (high-tech), te onbekend

○ Moeilijk monteerbaar

- Vrees voor het niet behalen van het beloofde rendement

- Vrees voor aanpassingen aan het subsidiebeleid

- Ik ben geen huiseigenaar

- Ik woon in een appartement / flat

- Ik heb plannen om te verhuizen

- Kennissen zijn ontevreden over hun installatie

- Geen enkele overweging, ik heb er uberhaupt nog niet over nagedacht en weet het ook niet

o Anders:

B. In welke situatie zou u overgaan tot de aanschaf van zonnepanelen?

Maximaal 2 antwoorden mogelijk

- Als de investering van zonnepanelen flink daalt

- Als de terugverdientijd maximaal 5 jaar is

- Als het systeem mooi geïntegreerd kan worden in mijn dak

- Als de kwaliteit van het systeem verbetert

- Als het systeem makkelijk zelf monteerbaar is

- Als er een aantrekkelijk subsidie programma komt

- In geen enkele situatie

o Anders:

C. Kunt $u$ aangeven of $u$ het eens of oneens bent met onderstaande stellingen?

Eens; Oneens; Geen mening

- Ik heb de aanschaf van zonnepanelen ooit overwogen

- Momenteel overweeg ik om zonnepanelen aan te schaffen

- $\quad$ Ik vind verbeteringen aan zonnepanelen een vereiste alvorens ik aanschaf overweeg

- Het regelen van een installatie is geen belemmering in de aanschaf

- Het invullen van subsidie aanvragen is geen belemmering in de aanschaf

- Technische kennis (wat betreft installatie, onderhoud, beheer etc.) is geen belemmering in de aanschaf 
- Ik ervaar druk van mijn sociale omgeving (familie, vrienden, buren, etc.) om zonnepanelen aan te schaffen

- $\quad$ Ik vind de investering in zonne-energie betaalbaar

- $\quad$ Ik ben bekend met de kosten van zonnepanelen

- $\quad$ Ik ben op de hoogte van subsidies op het gebruik van zonne-energie

- $\quad$ Ik heb behoefte aan informatie over de mogelijkheden van zonne-energie

- $\quad$ Ik vind het belangrijk dat de zonnepanelen mooi geïntegreerd zijn in mijn dak

\section{Vraag 8. Enkel voor eigenaren van zonnepanelen}

A. Heeft u de aanschaf van zonnepanelen zelf besloten ?

- Nee, de panelen zijn aangeschaft voordat ik in deze woning trad (ga verder met vraag B)

- Nee, een externe partij (bijvoorbeeld de woningbouw) heeft de panelen aangeschaft, ik woonde wel al in deze woning (ga verder met vraag $\mathrm{C}$ )

- Ja, dat heb ik (ga verder met vraag D)

o Anders:

B. Welke rol speelden de zonnepanelen toen u voor deze woning koos?

- Het speelde geen rol (ga verder met vraag $\mathrm{H}$ )

- Het speelde een positieve maar geen zwaarwegende rol (ga verder met vraag H)

- Het speelde een positieve doorslaggevende rol (ga verder met vraag $\mathrm{H}$ )

○ De zonnepanelen beschouwde ik als negatief (ga verder met vraag $\mathrm{H}$ )

C. Wat is uw houding ten opzichte van uw zonnepanelen?

- Positief (ga verder met vraag $\mathrm{H}$ )

- Negatief (ga verder met vraag $\mathrm{H}$ )

- Neutraal (ga verder met vraag $\mathrm{H}$ )

D. Wanneer heeft u zonnepanelen aangeschaft?

E. Wat was de directe aanleiding om zonnepanelen aan te schaffen? (Bijvoorbeeld, de aanschaf van een woning, een woningverbetering, positief verhaal van een bekende, verhaal in de media, ...) 
F. Welke van de onderstaande overwegingen hebben een rol gespeeld bij het aanschaffen van zonnepanelen?

Maximaal 3 antwoorden mogelijk

- Prijs / kosten van het systeem

- Besparing op de elektriciteitskosten

- Kwaliteit van het systeem

- Uiterlijk van het systeem - visuele representatie

o Zelfvoorzienend leven

- Innovatief systeem (high-tech)

- Makkelijk monteerbaar

- Belasting van het milieu is minder ten op zichte van conventionele energiebronnen zoals olie en gas

o Weet ik niet

o Anders:

G. Op welke manier heeft u de zonnepanelen gefinancierd?

- Spaargeld

- Erfenis

o Hypotheek

- Lening van de bank

o Anders:

- Vul ik liever niet in

H. Kunt u een antwoord geven op de volgende vragen?

Ja; Nee; Weet ik niet / n.v.t

- $\quad$ Heeft u gebruik gemaakt van een subsidieprogramma? (SDE, MEP, EPR, ...)

- Heeft u gebruik gemaakt van een stimuleringsprogramma? (Meer dak onder de zon, PV GO!, ZonZeker. ...)

- Was de subsidie voor u doorslaggevend?

- Heeft u de zonnepanelen zelf geïnstalleerd? 
I. Kunt $u$ aangeven of $u$ het eens of oneens bent met onderstaande stellingen?

Eens; Oneens; Weet niet / n.v.t.

- $\quad$ Ik vind de investering in zonne-energie betaalbaar

- $\quad$ Ik heb geen spijt van mijn beslissing om zonnepanelen te nemen

- Toendertijd was ik op de hoogte van subsidies op het gebruik van zonneenergie

- Ik heb nog geen problemen gehad met het systeem

- De zonnepanelen zijn mooi geïntegreerd in mijn dak

- Ik denk dat zonne-energie de best beschikbare technologie is om zelfvoorzienend te zijn

- Ik heb een rendabel zonne-energie systeem

Dit is het einde van de vragenlijst. Hartelijk dank voor uw medewerking! 



\section{Appendix D: \\ Questionnaire and answer key - Bieslandsolar}

Deze vragenlijst is onderdeel van het Organext project en beoogt uw standpunt op zonne-energie vast te leggen. De vragenlijst bestaat uit verschillende onderdelen: vragen over uw persoonlijke situatie, uw visie op duurzame ontwikkeling en uw visie op zonneenergie. Het invullen van de vragenlijst duurt ongeveer 10 minuten. De antwoorden worden anoniem verwerkt.

\section{Zonne-energie}

1. Kunt $u$ aangeven of $u$ het eens of oneens bent met onderstaande stellingen?

Eens; Oneens; Weet niet / n.v.t.

- $\quad$ Ik heb de aanschaf van zonnepanelen ooit overwogen

- Momenteel overweeg ik om zonnepanelen aan te schaffen

- $\quad$ Ik ben bekend met de kosten van zonnepanelen

- $\quad$ Ik vind de investering in zonne-energie betaalbaar

- $\quad$ Ik ben op de hoogte van subsidies en het gebruik van zonne-energie

- Het invullen van een subsidie aanvraag is een belemmering in de aanschaf

- $\quad$ Ik ben bekend met de werking van een zonnepaneel

- $\quad$ Er wordt voldoende informatie over zonne-energie verstrekt en de mogelijkheden ervan

- $\quad$ Ik heb behoefte aan informatie over de mogelijkheden van zonne-energie

- Bekenden van me hebben al zonnepanelen aangeschaft

- $\quad$ Ik heb al met mijn sociale omgeving (familie, vrienden, buren, etc.) gesproken over zonnepanelen

- Ik ervaar druk van mijn sociale omgeving (familie, vrienden, buren, etc.) om zonnepanelen aan te schaffen

- $\quad$ Ik vind het belangrijk dat zonnepanelen mooi geïntegreerd zijn in mijn dak

- $\quad$ Ik ben op de hoogte van de levensduur van de installatie

- $\quad$ Ik ben op de hoogte van de terugverdientijd van een installatie 
2. Kritiek op zonne-energie heeft vaak te maken met de prijs, de efficiëntie, de visuele representatie (uiterlijk van het systeem), de levensduur en de integreerbaarheid. Welke twee kenmerken zijn voor $u$ het belangrijkste en welke het minste belangrijk?

- Prijs

- $\quad$ Efficiëntie - hoeveelheid energie

- Visuele representatie

- $\quad$ Levensduur van het systeem

- Integreerbaarheid

3. Welk van de volgende informatiebronnen heft u geraadpleegd om meer informatie over zonnepanelen te verkrijgen?

Meerdere antwoorden mogelijk

- Vrienden, familie, kennissen

- Beurzen

- Informatiefolders van installateurs

- Websites van installateurs

- Brochures van de overheid

- Websites van de overheid

- Online fora over zonnepalen of zonne-energie

- Andere websites (ODE, zon zoekt dak. ....)

- Architecten

- Banken

- Consumentenorganisaties

- Artikelen in kranten of tijdschriften

- Informatiebijeenkomsten

- Ik heb nog geen informatie gezocht

- Anders:

4. Welk van onderstaande overwegingen hebben een rol gespeeld om nog geen zonnepalen aan te schaffen?

Maximaal 3 antwoorden mogelijk

- Te weinig informatie / lk wil me eerste verdiepen

- Te hoge investeringskosten

- Te lage energieopbrengst

- Uiterlijk van het systeem - visuele representatie

- Te innovatief systeem (high-tech), te onbekend

- Moeilijk monteerbaar

- Vrees voor het niet behalen van het beloofde rendement 
- Vrees voor aanpassingen aan het subsidiebeleid

- Ik ben geen huiseigenaar

o Ik woon in een appartement / flat

- Ik heb plannen om te verhuizen

- Kennissen zijn ontevreden over hun installatie

○ Geen enkele overweging, ik heb er überhaupt nog niet over nagedacht en weet het ook niet

o Anders:

5. In welke situatie zou u overgaan tot de aanschaf van zonnepanelen?

Maximaal 2 antwoorden mogelijk

- Als de investering van zonnepanelen flink daalt, zo'n $25 \%$

- Als de investering van zonnepanelen flink daalt, zo'n $50 \%$

- Als de terugverdientijd maximaal 2.5 jaar is

- Als de terugverdientijd maximaal 5 jaar is

- Als de terugverdientijd maximaal 7.5 jaar is

- Als het systeem mooi geïntegreerd kan worden in mijn dak

- Als de kwaliteit van het systeem verbetert

- Als het systeem makkelijk zelf monteerbaar is

- Als er een aantrekkelijk subsidie programma komt

- In geen enkele situatie

o Anders:

\section{Biesland Solar}

6. Wanneer heeft u voor het eerst over dit initiatief gehoord?

7. Hoe bent u over dit initiatief geïnformeerd?

8. In welke situatie zou u overgaan tot de aanschaf van zonnepanelen?

Meerdere antwoorden mogelijk

- De coöperatie regelt de installatie en het onderhoud

- Lagere elektriciteitsrekening

- Terugdringen van $\mathrm{CO} 2$ uitstoot 
- Het collectief inkopen van zonnepanelen

- Biesland, de eerst volledig klimaat neutrale wijk in Maastricht

- Zonnepanelen tegen een lagere prijs aanschaffen

- De coöperatie houdt me op de hoogte van subsidiemogelijkheden

- Lokaal energie opwekken

- Onafhankelijkheid van grote monopolistische energiemaatschappijen

- Onafhankelijkheid van fossiele brandstoffen

9. Is uw visie op zonnepanelen veranderd door deze informatiebijeenkomst?

- Ik ben positiever over de installatie en het gebruik van zonnepanelen dan voor de bijeenkomst

- Deze bijeenkomst heeft mijn visie op zonnepanelen bevestigd

- Ik ben negatiever over de installatie en het gebruik van zonnepanelen dan voor de bijeenkomst

10. Is uw bereidheid om zonnepanelen aan te schaffen toegenomen?
○ Ja
○ Nee
○ Weet niet

11. Wat is uw indruk van het initiatief?

$\begin{array}{lllll}1 & 2 & 3 & 4 & 5\end{array}$

Negatief Positief

12. Wat is uw indruk van de informatiebijeenkomst?

$\begin{array}{lllll}1 & 2 & 3 & 4 & 5\end{array}$

Negatief Positief

\section{Algemene vragen}

13. Wat is uw geslacht?
o Man
o Vrouw

14. Wat is uw leeftijd? 
15. Wat is uw hoogste opleidingsniveau?
- Geen onderwijs / basisschool
- Middelbare school (VMBO, HAVO, VWO, enz.)
- Lager beroepsonderwijs (LTS, LEAO, LHNO, enz.)
- Middelbaar beroepsonderwijs (MBO)
- Hoger beroepsonderwijs (HBO)
○ Universitair onderwijs (WO)
o Anders:

16. Bent u op dit moment werkzaam?
○ Ja, ik ben fulltime werkzaam
- Ja, ik ben parttime werkzaam ( $21 \mathrm{t} / \mathrm{m} 32$ uur per week)
- Ja, ik ben parttime werkzaam (12 t/m 20 uur per week)
- Nee, ik ben niet werkzaam of minder dan 12 uur
- Nee, ik ben met pensioen
- Ik verricht momenteel vrijwilligerswerk
- Ik volg momenteel een studie

17. Wat is je netto inkomen per maand?
- Minder dan 900 euro per maand
- Tussen de 900 en 1250 euro per maand
- Tussen de 1250 en 1850 euro per maand
- Tussen de 1850 en 3000 euro per maand
- Tussen de 3000 en 5000 euro per maand
- Meer dan 5000 euro per maand
o Weet niet/ wil ik niet zeggen

18. In welk type huis woont u?
- Vrijstaand huis
- Rijtjeshuis
o Twee-onder-een-kap
- Appartement / flat
o Boerderij
o Anders:

19. Wie is de eigenaar van uw woning?
o Ikzelf
- Woonstichting
- Particuliere huiseigenaar
o Anders: 
20. Hoe oud is de woning waar u nu woont?

Druk uit in jaren a.u.b.

21. Sinds wanneer woont $u$ in deze woning?

Druk uit in jaren a.u.b.

22. Bent u tevreden met uw huidige woonsituatie?

$\begin{array}{ccccc}1 & 2 & 3 & 4 & 5 \\ \text { Oneens } & & & \text { Eens }\end{array}$

23. Kunt $\mathrm{u}$ aangeven welk van onderstaande milieuvriendelijke investeringen reeds gedaan heeft in uw woning en welk van deze investeringen u overweegt om in de toekomst uit te voeren?

Meerdere antwoorden mogelijk. Niet van toepassing komt overeen met de vraag niet beantwoorden.

Reeds gedaan; Van plan in de toekomst

- Dubbel of driedubbele beglazing

- Geïsoleerd dak

- Vloerisolatie

- Hoge rendementsketel

- Zonneboiler

- Warmtepomp

- Waterput

- Muurisolatie

- Anders:

24. Indien u opmerkingen heeft, dan kunt u hiervoor onderstaande ruimte gebruiken.

Dit is het einde van de vragenlijst. Hartelijk dank voor uw medewerking! 


\section{Summary}

\section{A sunny future for photovoltaic systems in the Netherlands?}

An analysis of the role of government and users in the diffusion of an emerging technology

One promising technology to generate useful and sustainable power from renewable resources is solar photovoltaic (PV). This sustainable technology has until recently not been developed as a serious option for energy generation in the Netherlands. Although the first off-grid solar house was opened in Castricum in 1988, after more than 25 years the use of PV is rather limited. The slow growth and even decline in the Netherlands over the years contrasts sharply with the explosive growth in other European countries, Germany for example, where incentive schemes have stimulated the growth of installed PV capacity such that up to $7 \mathrm{GW}$ per year. The Dutch case clearly shows that a large problem in the formation of a domestic market lies with the inconsistent government market support. As example, the upward trend of installed PV stalled in 2003, the PV market decreased from almost $20 \mathrm{MW}$ per year in 2003 to less than $0.5 \mathrm{MW}$ per year in 2006. The 'gold rush' of 2003 has been the result of an announcement of the governments that a subsidy regime would end; no incentive came in place till 2008 and the new incentive did not have significant impact on the market. The Dutch policy focused on research and development with the goal of bringing the cost down and raising the efficiency to make solar power more competitive with fossil fuels.

Since 2011 there is a substantially grown, 195 MW installed PV capacity over 2012. Falling prices and the possibility of net metering make it more interesting for individuals to install panels without a subsidy. A relevant question that arises is whether this will be just a repeat case of the collapsed gold rush towards the installation of PV panels in 2003 or will this herald a sunny future for PV in the Netherlands? To answer this question, a detailed analysis of the actual development, adoption and diffusion of PV is necessary. Such an analysis allows pinpointing how various factors influence the diffusion process. Furthermore, gaining a better understanding of how a number of these factors might interrelate and trigger a positive inducement mechanism can help to speed up the diffusion process of an emerging technology.

Research on the development, adoption and diffusion process of more sustainable renewable energy technologies often draws on transition and innovation studies. However, these approaches pay little attention to the actual adoption decisions people make. On the micro scale, theories of social practices might be useful to shed light on people's adoption decisions. In this thesis, I draw on all three aforementioned bodies of literature 
to study the willingness of consumer-citizens to adopt a PV system and the heterogeneity of those who already took the decision to install such a system. In so doing, interesting reflections on the conceptual frameworks I apply are possible. The following research questions function as the backbone of my enquiry:

1. How is user behaviour conceptualised in socio-technical transition research? How are user choices studied empirically?

2. Which factors account for the slow diffusion of PV in the Netherlands and what does this imply for policy support and socio-technical management?

3. Which factors account for the adoption and non-adoption of PV in the Netherlands?

4. What can be learned from combining the user perspective with the technological innovation system approach and the multilevel perspective on socio-technical transitions in terms of possible inducement mechanisms to accelerate the adoption and the diffusion of $P V$ ?

In answering the research questions, a mixture of theoretical and empirical material was used. The theoretical part of the thesis describes the potential of niche-based approaches to contribute to wider changes in socio-technical regimes. Social theories that can help to accelerate the transition to a more sustainable energy system are discussed from a systemic and a user perspective. The empirical part of the PhD research comprised a study of the history and dynamics of PV. Data were derived from 1) a literature review; 2) an event analysis; 3) interviews; and 4) questionnaires. The thesis consists of six empirical chapters, a theory chapter, a methodology chapter, a synthesis chapter as well as an introductory and a concluding chapter.

Following the introduction, chapter 2 offers a literature review of the socio-technical literature of transitions and technology innovation studies. The first-mentioned describe how new technologies emerge within more or less protected niches, and how they turn into configurations that shape and reshape regimes (e.g. Geels, Kemp, Rotmans). The latter, technological innovation studies, focuses on the structure of the system (actors, institutions and networks) and on the key processes that take place within a system. These processes contribute to the build-up of a TIS and thereby to the successful development, diffusion and utilization of the emerging technology (e.g. Hekkert, Negro, Bergek). It is motivated by the observation that little attention in these studies is being given to actual adoption decisions by people. To this end, I have introduced the sustainable consumption research which studies the specific conditions for consumption in sociotechnical systems and the relations between providers and consumers (e.g. Shove and Spaargaren). However, this body of literature do not examine the adoption decisions of individuals in any detail. In this thesis, I draw on all three aforementioned bodies of literature to study the willingness of consumer-citizens to adopt a PV system and the heterogeneity of those who already took the decision to install such a system. 
Chapter 3 presents a three step approach in which technology and society co-construct each other. The focus is on social-technical transitions in which technology (technological innovation) on the one hand, and society (users with their lifestyles and habits) on the other hand are analysed in interaction. The three-step approach is built upon the idea that technological innovations can be studied as a system in which a number of phases can be differentiated that shape new technologies and technological landscapes. The system includes suppliers, users (consumer-citizens), inventors, on the one hand, as well as content, facts and meanings, on the other hand, but also social, legal and ethical problems emerge as the result of what is called a 'technological innovation'. In this approach, three steps are distinguished: (1) the development and diffusion of innovative technologies; (2) the adoption of innovative technologies; (3) learning processes. Each of these steps addresses a different aspect of the dynamics of technological innovations.

Chapter 4 describes the history of the development of the PV innovation system in terms of seven key processes (system functions) that are essential for the build-up of innovation systems.

After 30 years of policy efforts, the PV technology has not been implemented on a large scale. Throughout the years the many activities carried out by entrepreneurs, researchers and investors seem to neither have major impact, nor to lead to a momentum. Processes related to knowledge development are found to be stable but I observe large fluctuations in the processes related to guidance of the search and market formation. Inconsistent regulations, unpredictable behaviour of the government and the lack of a clear vision for PV are the main barriers. After the government removed the 'Energy Contribution Regulation' (EPR) subsidy in 2003 and simultaneously the global PV market was growing, the Netherlands did not pursue consistent efforts to promote deployment. Surprisingly, entrepreneurial activities are not too much affected by fluctuating market formation activities. I relate this to market formation in neighbouring countries. An interesting example is Shell Solar. Shell Solar, and with it the human capital, moved to Germany to profit from the favourable, stable and long-term institutional conditions implemented there. The government made no effort to keep the Dutch PV industry in the Netherlands. The German market was a good enough substitute for the home market to keep the sector going also in times when Dutch policy was not in favour of creating a market for solar energy. Therefore, the policy implication might be that a government may decide not to strengthen some parts of the innovation system when neighbouring countries fulfil these functions sufficiently.

Chapter 5 examines the role of policy in the evolution of the technological innovation system and the diffusion of PV panels in Germany and the Netherlands. PV development and diffusion have been actively supported in both countries; however, Germany has a well-developed technological innovation system and a successful industry, whereas the 
Netherlands does not. The focus of this study is on the dynamic relationship between policy developments and technology innovation systems developments.

The main conclusions from the analysis about the role of policy are as follows: (1) the creation of a strong technological innovation system for PV requires market pull besides research and technology development support; (2) policy support should be consistent and not erratic; (3) when giving support to a fledging technology the regulator should make sure that the level of support is not too low or too high; (4) policy should be mindful about interaction effects (e.g. between government and industry); (5) innovation policy should go beyond research and development and should be oriented towards the creation of a TIS; (6) the analysis demonstrates the importance of taking into account policy design aspects and the importance of performing a longitudinal analysis for studying the link between innovation and policy.

Chapter 6 focuses on the development and diffusion of PV in Japan and the Netherlands. Both cases are analysed with the TIS framework. I included international factors in the framework such as import, export and international knowledge transfer. Based on the differences in cases I can formulate a number of lessons for the Dutch PV TIS. (1) System functions such as guidance of the search (F4) and advocacy coalitions (F7) need to be strengthened in order to reinforce each other in a positive way; (2) formulate, maintain and translate consistent long-term goals into long-term policies and stimulation measures in order to allow a gradual build-up of networks and skills/expertise; (3) buildup and maintain legitimacy within the institutional setting; and (4) strengthen the TIS in order for SMEs to grow in terms of capital and capabilities.

From the analysis it becomes clear that for the breakthrough of technologies the international dimension is very important. For the Dutch case, export is found to be attractive since the Dutch home market is suffering from inconsistent policies and lack of investment and commitment. In foreign markets, Dutch actors find favourable and consistent institutional settings and consistent demand. International knowledge exchange appears to be important for Dutch R\&D in order to stay in a leading position worldwide with respect to research. International markets appear to be just as attractive for Japanese firms, but are not as vital since there is already a large domestic market. Collaboration and involvement of multiple actors in the home market that exchange knowledge with each other (i.e. entrepreneurs with governments as well as with research institutes) remains important for learning processes within both countries.

Chapter 7 analyses from a user perspective whether users (consumer-citizens) of PV have similar personal values and (environmental) lifestyles. By taking into account different typologies of lifestyles which are used in the building market in the Netherlands, I introduced a segmentation model for analysing the diffusion of technological innovations, in particular PV. The empirical analysis, based on a questionnaire completed by 817 Dutch households, resulted in four relatively homogeneous groups of technological 
users based on their adoption or rejection of a specific technological innovation. The four groups are voluntary adopters, involuntary adopters, potential adopters and rejecters. The introduced model allows us to answer the question whether adopters and nonadopters consider the same or different attributes for their decisions. In order to answer this question, I split the results in non-determining and determining factors to explain how the groups differ from each other.

Regarding the determining factors, the costs of a PV system are included as a benefit of having PV for voluntary adopters which obviously refer to the positive consequences of having a system (e.g. self-sufficiency and environmental benefits). For non-adopters the benefits of PV which also refer to the positive consequences of having a system do not outweigh the negative consequences (e.g. price and financial uncertainty). Regarding the non-determining factors, voluntary adopters are on average middle-aged, high educated, take big decisions independent of others and take care of the environment by for example recycling paper and avoiding the car on a regularly basis. The opposite are the rejecters who have on average a lower income, take big decisions dependent on others and need also considerable time for big decisions.

Chapter 8 studies factors underlying the adoption and non-adoption of PV in the Netherlands. The main purpose of this chapter is to gain insight in and to understand the adoption of PV in the Netherlands from a user perspective. The influence of the following four factors is studied: the perceived relative advantage of the technology, the perceived complexity of the innovation as a negative factor, social influence, and knowledge of subsidies and costs. For each of the factors, different proxies are used in an attempt to study individual components (e.g. the expectation of increasing prices of oil and gas; the expectation that the subsidy procedure is clear). In this research, I use descriptive analyses and logistic regression analyses.

I show that the cost of a PV system is an important element behind the adoption and non-adoption of PV in the Netherlands. For adopters, the costs of PV are considered affordable whereas for non-adopters they are viewed as being too high. However, it is not just a matter of costs only, although they certainly play an important role. Furthermore, I find that one of the reasons why potential adopters have not adopted a system so far is that they lack knowledge about PV. The importance of this was revealed through the statistical analysis, where I found that knowledge about PV is a predictor for adoption. This suggests that better information about solar energy will stimulate adoption. Not only information of the costs and quality aspects is important, also information on social and environmental matters. The latter and the knowledge of available subsidies and associated costs were found to be positive predictors for the willingness to adopt. This suggests that two useful strategies to stimulate the diffusion of PV are: to reduce the investment costs and increase the knowledge about it. The relative effectiveness of both strategies cannot be determined from my analysis. 
Chapter 9 presents a case study on Biesland Solar, a technology-specific local initiative, to discuss how individuals interact with each other about PV and what decisions they reach in terms of adoption and non-adoption. Bielsand Solar is a district initiative in the city of Maastricht that focused on the collective procurement of the technology.

Biesland Solar was initiated by several local citizens and promotes PV via a brochure and website. They organised an information meeting with a direct link to a recommended PV installer, which made the adoption process easier. This empirical research is based on data collection through a questionnaire performed immediately after the information meeting and on interviews one and a half year later. I structure the results according to three relevant factors influencing the purchasing of PV: (1) provision of information; (2) financial concern; and (3) the personal attitude people have.

The empirical results confirm the usefulness of information meetings in people's decision-making process of adopting PV. However, only a few respondents actually purchased a system which shows that even with knowledge of PV technology, high environmental concern, and the assistance of the government grants, additional triggers appear to be still needed for more people to adopt PV. Important reasons mentioned why participants decided not to adopt a PV system are age (a bias towards middle-aged and older individuals), the length of time it takes to recover the costs, the visual impact of the system, concerns about maintenance of the system, and the lack of understandable information. On the other hand, a trigger for the adoption of PV systems could be that a PV system offers a 'fixed price' while the electricity price would inevitable rise the coming years due to the increasing scarcity of fossil fuels. In line with this, another reason mentioned for the adoption is that retired people tend to particularly benefit from the bill reduction compared to other groups. Self-sufficiency and the environmental advantage are other motivations.

Chapter 10 studies the barriers in the PV transition process in the Netherlands and studies what can be done to accelerate the PV transitions. I show that technological and social changes interact and mutually influence each other and that various forms of learning take place. I find that the development of the PV technology depends on the evolution of energy prices, changes in global energy demand, changes in infrastructure, targets and regulations, and changes in the energy sector. Attention is also given to interaction of technological alternatives, specifically competitive and synergetic effects between them.

The research framework of this thesis is further elaborated in this chapter to indicate how various factors influence this process. Instead of the notion of barriers I think in terms of a 'web of constraints' acting as a blocking mechanism. Instead of a single driver I think in terms of multiple drivers creating a positive inducement mechanism when they support each other. Positive stimuli interact with negative ones. Based on the different analyses which are done in this research, I formulated five mechanisms for the case of PV in the Netherlands: (1) policies and targets that included the use of more renewable 
energy technologies as source of reduction of greenhouse gas emissions; (2) better quality of the integrated PV systems and PV system guarantees can be expected to encourage PV technology adoption; (3) social involvement can arouse consumer curiosity and broaden consumer choice; (4) the collaboration between the local, national and international dimension can arouse the breakthrough of PV; and (5) PV can become an attractor in the building market.

The strength of the various mechanisms, or causal chains, differs from one or the other, but also from sector to sector. Some loops are more rapid, such as prices that may fall in the course of a few years, whereas other loops are slow or discontinuously changing, such as the improvement of technological quality. Altogether, these developments suggest that the transition path for PV still has a long way to go.

In chapter 11 the main results and conclusions from this thesis are summarized.

My PhD research shows how supply interacts and co-evolves with demand for innovation. The empirical cases shed an ambivalent light on the build-up of the Dutch PV TIS. Guidance of the search, resource mobilisation, and creation of legitimacy in the Netherlands is weak, and due to the lack of an ambitious view for PV from the government, there are not enough (financial) resources and an insufficient lobbying power to overcome resistance. Furthermore, the market formation strongly fluctuates over the years due to the lack of a Dutch PV market at the moment. With about $195 \mathrm{MW}$ installed PV capacity in 2012 (best year ever), the Dutch contribution to PV-generated electricity in Europe is limited. In other European countries, incentive schemes have stimulated the growth of installed PV capacity such that up to $1 \mathrm{GW}$ per year is installed like for example in Germany. Interestingly, knowledge development and entrepreneurial activities were not very much affected by the periods of poor market formation due to the focus on the international market. They have flourished to a globally recognized status. By studying the influence of users, it was found that the slow diffusion of PV is not driven by single factors such as price or technological change, but typically involves co-evolution between multiple developments. It is related to consumer preferences, product offerings and slow introduction of policies to promote the use of renewables.

The case of PV clearly showed that at the side of the technology innovation system approach and at the side of the user perspective, various forms of learning take place. These forms of learning are interrelated in the sense that at the very beginning suppliers of the technology have to inform consumers about the innovation, but then suppliers themselves gradually learn how to evaluate demand as an innovation diffuses. Learning in this case entails the availability of new skills and knowledge, new social connotations, changing future expectations, new supply-demand relationships and changes in the regulatory framework. Consumers, with their different ways of interpreting, using and talking about PV technologies, further contribute to the social shaping of the technology. However, it is also possible that there are not enough experiences or critical mass of users to trigger any significant development. Depending on the strength of the learning 
at both sides (demand and supply), it is possible to observe dynamics that lie somewhere in between these two extremes. Thus, the case of PV shows that both the technology and the relevant social context change is a complex co-evolution process with evolutionary traits of variation, selection and retention. It also shows how learning processes can be interrelated. 


\section{Samenvatting}

\section{Een zonnige toekomst voor photovoltaische systemen in Nederland?}

Een analyse van de rol van de overheid en de gebruikers in de verspreiding van een opkomende technologie

Een veelbelovende optie om duurzame energie op te wekken zijn fotovoltaïsche systemen (PV). Deze duurzame technologie heeft zich in Nederland tot voor kort niet ontwikkeld als een serieuze optie. Hoewel het eerste off-grid zonnehuis in Castricum werd geopend in 1988, is het gebruik van PV na meer dan 25 jaar vrij beperkt. De trage groei en zelfs daling in Nederland door de jaren heen, staat in scherp contrast met de explosieve groei in andere Europese landen, Duitsland bijvoorbeeld, waar stimuleringsmaatregelen de groei van het geïnstalleerde PV vermogen tot $7 \mathrm{GW}$ per jaar hebben gestimuleerd. De Nederlandse casus laat duidelijk zien dat een groot probleem in het creëren van een binnenlandse markt ligt bij inconsistent overheidsbeleid. Bijvoorbeeld, de stijgende trend geïnstalleerd PV-vermogen stagneerde in 2003; de PV-markt daalde van bijna 20 MW per jaar in 2003 tot minder dan 0,5 MW per jaar in 2006. De 'gold rush' van 2003 is het resultaat van een aankondiging van de overheid dat een subsidieregeling zou eindigen; er is geen incentive voor in de plaats gekomen tot 2008 en de nieuwe incentive had geen significante impact op de markt. Het Nederlandse beleid richtte zich op onderzoek en ontwikkeling met het doel om de kosten te verlagen en het verhogen van de efficiëntie, zodat zonne-energie beter kan concurreren met fossiele brandstoffen.

Sinds 2011 is er een sterke groei, 195 MW PV-vermogen is geïnstalleerd over 2012. Dalende prijzen en de mogelijkheid van salderen maakt het interessanter voor individuen om panelen te installeren zonder subsidie. Een relevante vraag is of dit slechts een herhaling is van de ingestorte 'gold rush' naar de installatie van PV-panelen in 2003 of is dit de aankondiging voor een zonnige toekomst voor PV in Nederland? Om deze vraag te beantwoorden is een gedetailleerde analyse van de ontwikkeling, adoptie en verspreiding van PV noodzakelijk. Een dergelijke analyse geeft inzicht in hoe verschillende factoren het diffusieproces beïnvloeden. Daarnaast kan ook het beter begrijpen van hoe een aantal van deze factoren met elkaar in verband staan en kunnen leiden tot een positieve stimulansmechanisme, helpen het diffusieproces van een opkomende technologie te versnellen.

Onderzoek naar de ontwikkeling, adoptie en verspreiding van meer duurzame technologieën richt zich vaak transitie- en innovatiestudies. Echter, deze benaderingen besteden weinig aandacht aan de werkelijke adoptiebeslissingen die mensen maken. Op microschaal kunnen theorieën over sociale praktijken nuttig zijn om opheldering te verschaf- 
fen over adoptiebeslissingen van mensen. In dit proefschrift ga ik in op alle drie bovengenoemde takken van literatuur om de bereidheid van consumenten-burgers om een PV-systeem aan te schaffen te bestuderen, als ook de heterogeniteit van degenen die reeds de beslissing namen om een dergelijk systeem te installeren. Daarbij zijn er interessante reflecties op de conceptuele raamwerken die ik toepas mogelijk. De volgende onderzoeksvragen fungeren als de ruggengraat van mijn onderzoek:

1. Hoe wordt het gedrag van gebruikers geconceptualiseerd in socio-technisch transitieonderzoek? Hoe worden de keuzes van de gebruiker empirisch onderzocht?

2. Welke factoren zijn verantwoordelijk voor de trage verspreiding van PV in Nederland en wat betekent dit voor beleidsondersteuning en sociaal-technisch management?

3. Welke factoren zijn verantwoordelijk voor de adoptie en niet-adoptie van PV in Nederland?

4. Wat kan er worden geleerd van het combineren van het gebruikersperspectief met de technologische innovatiesysteem benadering (TIS) en het multi-level perspectief op socio-technische transities in termen van mogelijke stimulansmechanismen om de adoptie en de verspreiding van PV te versnellen?

Bij de beantwoording van de onderzoeksvragen wordt een mix van theoretisch en empirisch materiaal gebruikt. Het theoretisch deel van dit proefschrift beschrijft de mogelijkheden van niche-gebaseerde benaderingen en de bijdrage voor grotere veranderingen in de socio-technische regimes, en vergelijkt deze met andere benaderingen, zoals het technologische innovatiesysteem. Het empirisch deel van het promotieonderzoek bestaat uit een studie naar de geschiedenis en de dynamiek van de PV-sector in Nederland. Data is afkomstig van (1) literatuur onderzoek; (2) event-analyse; (3) interviews; en (4) vragenlijsten. Het proefschrift bestaat uit zes empirische hoofdstukken, een theorie hoofdstuk, een methodologie hoofdstuk, een synthesehoofdstuk, evenals een inleidend en een concluderend hoofdstuk.

Hoofdstuk 2 biedt een literatuuroverzicht van de socio-technische literatuur van transities en technologische innovatiestudies. De eerstgenoemde beschrijft hoe nieuwe technologieën ontstaan binnen min of meer beschermde niches, en hoe ze veranderen in configuraties die regimes vormen en hervormen (bv. Geels, Kemp, Rotmans). De laatste genoemde, technologische innovatie studies, richt zich op de structuur van het systeem (actoren, instituties en netwerken) en op de essentiële processen die plaatsvinden binnen een systeem. Deze processen dragen bij tot de opbouw van het technologisch innovatiesysteem (TIS) en daarmee tot de succesvolle ontwikkeling, verspreiding en het gebruik van de opkomende technologie (bv. Hekkert, Negro, Bergek). Gemotiveerd door constatering dat er weinig aandacht in deze studies wordt gegeven aan de werkelijke adoptiebeslissingen van mensen, heb ik het onderzoek naar duurzame consumptiepatronen geïntroduceerd dat de specifieke voorwaarden voor consumptie in socio- 
technische systemen en de relaties tussen aanbieders en consumenten bestudeert (bv. Shove en Spaargaren). Echter, deze tak van literatuur onderzoekt niet in detail de adoptiebeslissingen van individuen. In dit proefschrift ga ik in op alle drie bovengenoemde takken van literatuur om de bereidheid van consumenten-burgers om een PV-systeem aan te schaffen te bestuderen als ook de heterogeniteit van degenen die reeds de beslissing namen om een dergelijk systeem te (laten) installeren.

Hoofdstuk 3 presenteert een drie-stappen aanpak waarin technologie en maatschappij elkaar beïnvloeden (co-constructie). De focus ligt op sociaal-technische transities waarin technologie (technologische innovatie) enerzijds, en de maatschappij (gebruikers met hun levensstijl en gewoonten) anderzijds, in interactie worden geanalyseerd. De driestappen aanpak is gebaseerd op het idee dat technologische innovaties als een systeem bestudeerd kunnen worden waarin een aantal fasen te onderscheiden zijn die vormgeven aan nieuwe technologieën en het technologische landschap. Het systeem bevat leveranciers, gebruikers (consumenten-burgers) en uitvinders enerzijds, en content, feiten en betekenissen anderzijds, maar ook sociale, wettelijke en ethische problemen als gevolg van wat een "technologische innovatie" wordt genoemd. In deze aanpak zijn drie stappen te onderscheiden: (1) de ontwikkeling en verspreiding van innovatieve technologieën; (2) de adoptie van innovatieve technologieën; (3) leerprocessen. Elk van deze stappen behandelt een ander aspect van de dynamiek van technologische innovaties.

Hoofdstuk 4 beschrijft de geschiedenis van de ontwikkeling van het PV-innovatiesysteem in termen van zeven sleutelprocessen (systeem-functies) die essentieel zijn voor de opbouw van het innovatiesysteem.

$\mathrm{Na} 30$ jaar beleidsinspanningen is de PV-technologie niet geïmplementeerd op grote schaal. Door de jaren heen zijn vele activiteiten uitgevoerd door ondernemers, onderzoekers en investeerders maar deze lijken noch grote invloed te hebben, noch tot een momentum te leiden. Processen met betrekking tot kennisontwikkeling blijken stabiel te zijn, maar ik observeer grote fluctuaties in de processen met betrekking tot sturing en marktcreatie. Inconsistent beleid, onvoorspelbaar gedrag van de overheid en het gebrek aan een duidelijke visie voor PV zijn de belangrijkste barrières. Nadat de overheid de 'Energie Premie Regeling' (EPR) stopte in 2003 en tegelijkertijd de mondiale PV-markt groeide, deed Nederland geen consistente inspanningen om de implementatie te bevorderen.

Ondernemersactiviteiten werden niet veel beïnvloed tijdens de perioden van slechte marktcreactie. Ik relateer dit aan de marktcreatie in buurlanden. Een interessant voorbeeld is Shell Solar. Shell Solar verhuisde naar Duitsland om te profiteren van de gunstige, stabiele en langdurige institutionele condities die daar geïmplementeerd zijn. De overheid heeft geen moeite gedaan om de Nederlandse PV-industrie in Nederland te houden. De Duitse markt was een goed alternatief om de sector draaiende te houden 
ook in tijden waarin het Nederlandse beleid onvoldoende was voor het creëren van een markt voor zonne-energie. De beleidsimplicatie zou daarom kunnen zijn dat een regering kan besluiten tot het niet versterken van sommige delen van het innovatiesysteem wanneer naburige landen voldoen aan de vervulling deze functies.

Hoofdstuk 5 gaat in op de rol van het beleid in de evolutie van het technologisch innovatiesysteem en de verspreiding van PV-panelen in Duitsland en Nederland. De ontwikkeling en verspreiding van PV zijn actief ondersteund in beide landen. Duitsland heeft een goed ontwikkelde technologisch innovatiesysteem en een succesvolle industrie, terwijl Nederland dit niet heeft. De focus van deze studie ligt op de dynamische relatie tussen beleidsontwikkelingen en de ontwikkelingen binnen het technologische innovatiesysteem.

De belangrijkste conclusies voortkomend uit de analyse over de rol van het beleid zijn: (1) het creëren van een sterke technologisch innovatiesysteem voor PV vereist market pull naast de ondersteuning van onderzoek en technologie-ontwikkeling; (2) het beleid moet consistent zijn en niet onstabiel; (3) bij het geven van ondersteuning aan een opkomende technologie moet de regelgever ervoor zorgen dat de mate van ondersteuning niet te laag of te hoog is; (4) beleid moet zich van interactie-effecten bewust zijn (bv. tussen overheid en bedrijfsleven); (5) innovatiebeleid moet verder gaan dan onderzoek en ontwikkeling en moet gericht zijn op het creëren van een TIS; (6) de analyse laat het belang zien van het rekeninghouden met aspecten rondom beleidsontwerp en het uitvoeren van een longitudinale analyse voor het bestuderen van het verband tussen innovatie en beleid.

Hoofdstuk 6 richt zich op de ontwikkeling en verspreiding van PV in Japan en Nederland. Beide casussen worden geanalyseerd met het TIS raamwerk. Internationale factoren heb ik toegevoegd aan dit raamwerk zoals import, export en internationale kennisoverdracht. Op basis van de verschillen in casussen heb ik een aantal lessen geformuleerd voor het Nederlandse PV-TIS. (1) Systeem-functies zoals sturing (F4) en advocacy coalities (F7) moeten worden versterkt om elkaar op een positieve manier te versterken; (2) formuleer, onderhoud en vertaal consistente langetermijndoelstellingen naar langetermijnbeleid en stimuleringsmaatregelen om een geleidelijke opbouw van netwerken en vaardigheden/ deskundigheid mogelijk te maken; (3) legitimiteit opbouwen en behouden binnen het institutionele kader; en (4) versterken van de TIS om het MKB te laten groeien in termen van kapitaal en mogelijkheden.

De analyse laat duidelijk zien dat voor de doorbraak van technologieën de internationale dimensie erg belangrijk is. Voor de Nederlandse casus wordt export aantrekkelijk bevonden aangezien de Nederlandse thuismarkt lijdt aan inconsistent beleid en gebrek aan investeringen en inzet. Nederlandse actoren vinden gunstige en consistente institutionele instellingen en consistente vraag op buitenlandse markten. Internationale kennisuitwisseling lijkt belangrijk voor de Nederlandse R\&D te zijn om een leidende onderzoeks- 
positie wereldwijd te behouden. Internationale markten lijken net zo aantrekkelijk voor Japanse bedrijven te zijn, maar zijn niet zo belangrijk omdat er al een grote binnenlandse markt is. Samenwerking en betrokkenheid van meerdere actoren op de thuismarkt die kennis met elkaar uitwisselen (d.w.z. ondernemers met overheden, alsook met onderzoeksinstituten) blijft belangrijk voor leerprocessen binnen beide landen.

Hoofdstuk 7 analyseert vanuit een gebruikersperspectief of gebruikers (consumentenburgers) van PV vergelijkbare persoonlijke waarden en (milieu-) levensstijlen hebben. Door rekening te houden met verschillende typologieën van levensstijlen die worden gebruikt in de bouwmarkt in Nederland heb ik een segmentatie-model geïntroduceerd voor de analyse van de verspreiding van technologische innovaties, in het bijzonder PV. De empirische analyse, gebaseerd op een vragenlijst welke is ingevuld door 817 Nederlandse huishoudens, resulteerde in vier relatief homogene groepen van technologische gebruikers op basis van hun adoptie of afwijzing van een specifieke technologische innovatie. De vier groepen zijn vrijwillige adopters, onvrijwillige adopters, potentiële adopters en non-adopters (rejectors en zij die een keuze nooit overwogen hebben). Het geïntroduceerde model laat ons toe om een antwoord te geven op de vraag of adopters en non-adopters dezelfde of verschillende attributen overwegen voor hun beslissingen. Om deze vraag te beantwoorden heb ik de resultaten onderverdeeld in determinerende en niet-determinerende factoren om uit te leggen hoe de groepen van elkaar verschillen.

Met betrekking tot de determinerende factoren is het zo dat de kosten van een PVsysteem worden meegenomen als een voordeel van het hebben van PV voor vrijwillige adopters, welke duidelijk verwijzen naar de positieve consequenties van het hebben van een systeem (bv. zelfvoorziening en de milieuvoordelen). De voordelen van PV voor nonadopters, welke ook verwijzen naar de positieve gevolgen van het hebben van een systeem, wegen niet op tegen de negatieve gevolgen (zoals prijs en financiële onzekerheid). Met betrekking tot de niet-determinerende (mee-bepalende) factoren is het zo dat vrijwillige adopters gemiddeld genomen van middelbare leeftijd zijn, hoog opgeleid zijn grote beslissingen onafhankelijk van anderen nemen, en vaker papier recyclen en overmatig autogebruik vermijden. Daar tegenover staan de rejectors die gemiddeld een lager inkomen hebben, grote beslissingen afhankelijk van anderen nemen en veel tijd voor grote beslissingen nemen.

Hoofdstuk 8 bestudeert de factoren die ten grondslag liggen aan de adoptie en de nonadoptie van PV in Nederland. Het belangrijkste doel van dit hoofdstuk is om inzicht te krijgen in, en om de adoptie van PV in Nederland te begrijpen vanuit een gebruikersperspectief. De invloed van de volgende vier factoren wordt bestudeerd: het waargenomen relatieve voordeel van de technologie, de wargenomen complexiteit van de innovatie als een negatieve factor, sociale invloed, en de kennis van subsidies en kosten. Voor elk van de genoemde factoren worden verschillende proxies gebruikt in een poging om de individuele onderdelen te bestuderen (bv. de verwachting van stijgende prijzen van olie 
en gas; de verwachting dat de subsidie procedure duidelijk is). In dit onderzoek maak ik gebruik van beschrijvende analyses en logistische regressie analyses.

Ik vind dat de kosten van een PV-systeem een belangrijk element is voor de adoptie en non-adoptie van PV in Nederland. Voor adopters worden de kosten van PV beschouwd als betaalbaar, terwijl voor non-adopters ze worden gezien als te hoog. Het is echter niet alleen een kwestie van de kosten, hoewel het zeker een belangrijke rol speelt. Het gebrek aan kennis over PV is een andere reden waarom potentiële adopters tot nu toe nog geen systeem hebben aangeschaft. Dit kwam naar voren met behulp van de statistische analyse waar duidelijk werd dat kennis over PV een voorspeller voor adoptie is. Dit suggereert dat betere informatie over zonne-energie adoptie zal stimuleren. Niet alleen informatie over de kosten en kwaliteitsaspecten zijn van belang, ook informatie op sociaal en milieugebied. Deze laatste en de kennis van beschikbare subsidies en bijkomende kosten bleken positieve voorspellers te zijn voor de bereidheid om PV aan te schaffen. Twee nuttige strategieën om de verspreiding van PV te stimuleren zijn het reduceren van de investeringskosten en het vergroten van de kennis over PV. De relatieve effectiviteit van beide strategieën kan niet worden bepaald uit mijn analyse.

Hoofdstuk 9 presenteert een case studie over Biesland Solar, een technologie-specifiek lokaal initiatief, om te laten zien hoe mensen interacteren met elkaar aangaande PV en welke beslissingen zij nemen in termen van adoptie en non-adoptie. Biesland Solar is een wijkinitiatief in Maastricht, dat gericht is op de collectieve aanschaf van de technologie. Biesland Solar is geïnitieerd door verschillende lokale burgers en promoot PV via een brochure en website. Zij hebben een informatiebijeenkomst georganiseerd met een directe link naar een PV-installateur, die het adoptieproces makkelijker maakt. Dit empirische onderzoek is gebaseerd op datacollectie door middel van een enquête uitgevoerd direct na de informatiebijeenkomst en interviews anderhalf jaar later. De resultaten zijn gestructureerd op basis van drie relevante factoren die invloed hebben op de aanschaf van PV: (1) het verstrekken van informatie; (2) financiële belang; en (3) de persoonlijke houding die mensen hebben.

De empirische resultaten bevestigen het nut van informatiebijeenkomsten tijdens het besluitvormingsproces van de adoptie van PV. Slechts een paar respondenten hebben daadwerkelijk een PV-systeem gekocht waaruit blijkt dat zelfs met kennis van de PVtechnologie, hoge milieubewustheid, en de hulp van overheidssubsidies, extra triggers nodig lijken te zijn voor mensen om PV aan te schaffen.

Belangrijke redenen warom mensen besloten geen PV-systeem aan te schaffen zijn leeftijd (een voorkeur voor middelbare leeftijd en oudere mensen), de tijd die het kost om de kosten terug te krijgen, de visuele impact van het systeem, zorgen over het onderhoud van het systeem en het gebrek aan begrijpelijke informatie. Aan de andere kant, een trigger voor de aanschaf van een PV-systeem kan zijn dat een PV-systeem een 'vaste prijs' biedt, terwijl de elektriciteitsprijzen onvermijdelijk gaan stijgen de komende jaren als gevolg van de toenemende schaarste van fossiele brandstoffen. Een andere 
reden voor adoptie, in lijn met het voorgaande, is dat gepensioneerde mensen extra kunnen profiteren van een lagere energierekening ten opzichte van andere groepen. Zelfvoorziening en de milieuvoordelen zijn andere motivaties.

Hoofdstuk 10 bestudeert de barrières in het PV-transitieproces in Nederland en bestudeert wat er gedaan kan worden om de PV-transitie te versnellen. Ik laat zien dat technologische en maatschappelijke veranderingen op elkaar inwerken en elkaar beïnvloeden en dat er verschillende vormen van leren plaatsvinden. Ik vind dat de ontwikkeling van de PV-technologie afhankelijk is van de evolutie van de energieprijzen, veranderingen in de wereldwijde vraag naar energie, wijzigingen in infrastructuur, doelstellingen en regelgeving, en veranderingen in de energiesector. Ook wordt er aandacht besteed aan de interactie van technologische alternatieven, in het bijzonder competitieve en synergetische effecten tussen hen.

Het onderzoeksraamwerk van dit proefschrift wordt verder uitgewerkt in dit hoofdstuk om aan te geven hoe de verschillende factoren dit transitieproces beïnvloeden. In plaats van het begrip 'barrières' denk ik in termen van een 'web van tegenwerkende factoren' welke fungeert als een blokkeermechanisme. Positieve stimuli interacteren met negatieve. Op basis van de verschillende analyses die zijn gedaan in dit onderzoek formuleerde ik vijf mechanismen voor de casus PV in Nederland: (1) beleid en doelen waarin het gebruik van hernieuwbare energie als bron van vermindering van de uitstoot van broeikasgassen wordt opgenomen; (2) betere kwaliteit van de geïntegreerde systemen en PV systeem garantie kan de adoptie van de PV-technologie bevorderen; (3) maatschappelijke betrokkenheid kan de consument nieuwsgierig maken en de keuze van de consument verbreden; (4) de samenwerking tussen de lokale, nationale en internationale dimensie kan zorgen voor de doorbraak van PV; en (5) PV kan een attractor worden in de bouwmarkt.

De sterkte van de verschillende mechanismen of causale verbanden verschilt per verband, maar ook per sector. Sommige loops zijn sneller, zoals de prijzen die in de loop van een paar jaar kan dalen, terwijl andere loops traag of met tussenpozen veranderen, zoals de verbetering van de technologische kwaliteit. Alles samengenomen suggereren deze ontwikkelingen dat het transitiepad voor PV nog een lange weg te gaan heeft.

In hoofdstuk 11 worden de belangrijkste resultaten en conclusies van dit proefschrift samengevat.

Mijn promotieonderzoek laat de interactie en co-evolutie tussen het aanbod en de vraag naar innovatie zien. De empirische casussen geven duidelijk het dualistische beeld weer betreffende de opbouw van een TIS. Sturing, mobilisatie van middelen, en het creëren van legitimiteit in Nederland is zwak, en door het ontbreken van een ambitieuze visie voor PV van de overheid zijn er niet genoeg (financiële) middelen en is er onvoldoende lobbykracht om dit te overwinnen. Bovendien fluctueert de marktcreatie sterk over de jaren heen vanwege het ontbreken van een Nederlandse PV-markt op dit moment. Met 
ongeveer 195 MW geïnstalleerde PV-vermogen in 2012 (beste jaar ooit), is de Nederlandse bijdrage aan PV-opgewekte elektriciteit in Europa beperkt. In andere Europese landen zoals Duitsland hebben stimuleringsmaatregelen de groei van het geïnstalleerde PV-vermogen zodanig gestimuleerd dat tot $1 \mathrm{GW}$ per jaar wordt geïnstalleerd. Opmerkelijk is dat de kennisontwikkeling en ondernemersactiviteiten niet veel werden beïnvloed tijdens de perioden van slechte marktcreatie als gevolg van de focus op de internationale markt. Deze (kennisontwikkeling en ondernemersactiviteiten) hebben er een wereldwijd erkende status op na gehouden. Door het bestuderen van de invloed van de gebruikers, bleek dat de langzame diffusie van PV niet wordt aangestuurd door een enkele factoren zoals prijs of technologische verandering, maar het omvat co-evolutie tussen meerdere ontwikkelingen. Het is gerelateerd aan de voorkeuren van consumenten, productaanbod en langzame introductie van het beleid om het gebruik van hernieuwbare energiebronnen te bevorderen.

De PV-casus laat duidelijk zien dat binnen het technologisch innovatiesysteem aan de aanbodzijde en aan de zijde van (potentiele) gebruikers verschillende vormen van leren plaatsvindt. Deze vormen van leren worden met elkaar verbonden in de zin dat bij het begin leveranciers van de technologie de consumenten moeten informeren over de innovatie, de leveranciers leren dan geleidelijk hoe de vraag te evalueren als een innovatie verspreidt. Leren in dit geval leidt tot de beschikbaarheid van nieuwe vaardigheden en kennis, nieuwe sociale connotaties, veranderende verwachtingen voor de toekomst, nieuwe vraag en aanbod verhoudingen en veranderingen in de regelgeving. Consumenten, met hun verschillende manieren van interpretatie, het gebruik en het praten over PV-technologieën kunnen verder bijdragen aan de sociale vorming van de technologie. Het is echter ook mogelijk dat er onvoldoende ervaringen of kritische massa van gebruikers is om de ontwikkeling op gang te zetten. Voor de casus PV blijkt dat zowel de technologie als de verandering aangaande de relevante sociale context een complex coevolutie proces met evolutionaire kenmerken van variatie, selectie en retentie is. Het laat ook zien hoe leerprocessen met elkaar verbonden zijn en kunnen worden verbeterd. 


\section{Valorisation}

\section{Social and economic relevance}

This thesis offers an analysis of the technology innovation system for solar photovoltaic systems (PV) in the Netherlands with special attention to the role of users. The thesis consists of six empirical chapters, a theory chapter, a methodology chapter, a synthesis chapter plus the introduction and conclusions chapter.

It is motivated by the observation that little attention in transition and innovation studies is being given to actual adoption decisions by people. The same oddly enough applies to social practice studies, which do not examine the adoption decisions of individual in any detail. In this thesis I study the reasons for adoption and non-adoption of PV technologies in the Netherlands. This is being done through the use of a specially designed questionnaire and through interviews with people involved in a local energy initiative for the adoption of PV in the city of Maastricht in the Netherlands. I also describe and analyse the evolution of the technological innovation system (TIS) for PV in the Netherlands, where I compare the evolution with that of Japan and Germany. In those chapters, which make up the first empirical part of the thesis, and which were being done in the first period of the PhD. user decisions are not studied. They predate the adoption and non-adoption analysis of which the results are given in Part 3. The purpose of the thesis was not to build a new theory of societal transitions but to study the adoption and nonadoption decisions of people and thereby obtain a deeper understanding of the many concerns and determinants behind adoption and non-adoption of PV systems. In this thesis, users are viewed an important source of information but the thesis does not make an attempt to study the feedback from users that producers obtained over time. This is left for future research. The focus of the study is on the evolution of the TIS for PV in the Netherlands and the heterogeneity of people with regard to their willingness to adopt PV and their heterogeneity with respect to possessing a PV system on their roof (as a consequence of a decision to adopt it or as a consequence of the decision to buy a home with PV panels).

This explorative research into user involvement in the diffusion of more sustainable energy technologies has scientific relevance in studying an understudied topic in the social practice literature and the transition and technological innovation system literature. It has societal relevance in offering information which is relevant for government officials interested in the promotion of PV as a sustainable energy technology. helping 
them to achieve the 16\% renewable energy goal in 2020 (a goal from which the Netherlands is more than 10 percentage points away in 2012). Moreover, the energy industry might learn how to react and act on user needs in energy innovation processes. The case of solar energy is relevant given its huge potential worldwide as well as in the Netherlands and the need to reduce greenhouse gas emissions worldwide.

\section{Target group}

The transition to renewable energy is already underway. It has become a major political issue on the agenda of international, national and local governments. Over the years, many successes are identified and different thresholds are experienced, however, there is still a long way to go. Therefore, this type of research is not only relevant for the academic community but also for government officials, businesses and active citizens. Below I give an overview to whom my research results are of interest and why.

\section{Governmental officials}

The research results are interesting for policymakers. A better understanding of the Dutch PV innovation system (Part 2) identifies leverage points for enhancing innovative performance and overall competitiveness. It assist in pinpointing mismatches within the system, both among institutions and in relation to government policies, which can thwart technology development and diffusion. The comparison of the Dutch PV case with Germany (chapter 5) and Japan (chapter 6) have shown that countries differ in the way in which knowledge flows are structured and in the relative importance of different types of institutions and actors. The development of PV takes place within a specific structure and national context (system), therefore a better understanding of this system will lead to better policies.

The research results of consumer behaviour (part 2) are interesting for policymakers in the area of energy provision for households, at national and local level. At national level, the gained insights into the reasons for non-adoption of PV applications by potential adopters provides handholds to formulate an appropriate policy or service view that can help the government to transform the current energy system into a more sustainable one. In order to motivate these potential adopters to adopt a system, 'education and communication' is an important issue (indicated in the questionnaire). Education on the interrelated issues of energy, climate change, and sustainability, and communication of strategies for reducing consumption and emissions (ranging from energy efficiency and conservation to more sustainable energy technologies). At local level, households (and communities) start participating more in bottom-up energy initiatives, thereby increasing the share of more sustainable energy technologies in the energy market. My research results provide a better understanding on the motivations and considerations of people that decide to invest in PV via a community. These results are helpful for local 
governments and their planners as they have an important role to play in promoting more sustainable energy technologies. The results provide insights in how to facilitate initiatives (chapter 9). But it includes also efforts for demonstration projects, education, and national and international alliances.

\section{Business/industry}

Second, from this study the energy industry gained insights in how to react and act on user needs in energy innovation processes. For providers in the field of more sustainable energy technologies, insights and lessons are highly relevant to further tighten their own strategy. The typology I introduced (voluntary adopters; involuntary adopter; potential adopters; rejecters) can be expanded to a market instrument typology, which is also interesting for marketing.

\section{Active citizens/citizens}

The research results are also of interest for (active) citizens. The introduced segmentation model can be expanded to an awareness tool (which type of consumer I am ...). But also for citizens who are interested in starting up their own community or are looking for support for one already running. Lessons from the Biesland study contribute to the ongoing discussion about bottom-up initiatives and demonstrate the relevance of local and strategic partnerships for the emergence of such citizen participation models in the field of PV.

\section{Research and science community}

And finally, the research results are valuable for the research and science community. Researchers dealing with energy issues, behaviour studies and governance aspect may benefit from this study. The introduced model can also be used for other technologies, but also in other countries.

In fact, the research results are interesting for anyone wanting to get started with renewable energy. It is valuable as a guide to broaden the mind-set and to grasp the new accelerating factors / new levers for sustainability.

\section{Activities and products}

This thesis contributes to three concrete products: a three step approach, a segmentation model and peer-reviewed papers.

First, a three step approach in which technology and society co-construct each other. The focus is on social-technical transitions in which technology (technological innovation) on the one hand, and society (users with their lifestyles and habits) on the other hand are analysed in interaction. The three-step approach is built upon the idea that technological innovations can be studied as a system in which a number of phases can 
be differentiated that shape new technologies and technological landscapes. In this approach, three steps are distinguished: (1) the development and diffusion of innovative technologies; (2) the adoption of innovative technologies; (3) learning processes. Each of these steps addresses a different aspect of the dynamics of technological innovations.

Second, a segmentation model for analysing the diffusion of technological innovations, in particular PV. Based on an empirical analysis four groups of technological users are identified. The four groups are voluntary adopters, involuntary adopters, potential adopters and rejecters. The introduced model allows us to answer the question whether adopters and non-adopters consider the same or different attributes for their decisions. So, it gives more specific insight in the adoption of PV but can also be used to insight in the adoption of other technologies and/or in other countries. Moreover, the research method is accessible and workable for other researchers interested in gaining insights in adoption processes.

Third, four accepted papers in peer-reviewed journals. The first paper highlights the barriers that hamper the build-up of the Dutch PV innovation system. In paper two and paper three I compared the Dutch PV case with respectively Germany and Japan. The focus of paper two was on the dynamic relationship between policy developments and technology innovation systems developments, and in paper three I was able to identify international factors in the TIS framework (such as import, export and international knowledge transfer). In this paper it becomes clear that for the breakthrough of technologies the international dimension is very important. The fourth paper is innovative in many respects. It uses logistic regression analysis in order to identify relevant factor underlying the adoption and non-adoption of PV. This study is based on a large-scale survey in the Netherlands. This paper is accepted for publication in Renewable and Sustainable Energy Reviews which has an impact factor of 5.5 in 2013.

\section{Innovation}

Innovative elements of the PhD thesis are divided into theoretical elements and empirical elements.

\section{Theoretical}

(1) consumer behaviour and the introduced segmentation model provide new insights to the sustainability transition literature;

(2) including international factors in the TIS framework;

(3) a typology of users, which also can be used for other technologies;

(4) a guide how the transition to a more sustainable energy system can be strengthened, from the role of government and the (potential) user. 


\section{Empirical}

(1) a historical analysis of PV;

(2) several comparative studies (the Netherlands, Germany and Japan) with regard to the introduction of PV systems;

(3) by studying different groups of characteristics of more than 800 Dutch households, my research provides new empirical data about adoption of PV;

(4) the information meeting with inhabitants provides first hand data on their willingness, consideration and potential of energy provision;

(5) the combination of four research methods in order to unravel the contribution of users in the evolution of socio-technical systems of more sustainable technologies.

\section{Implementation}

As mentioned before, this thesis offers an analysis of the technology innovation system for PV in the Netherlands with special attention to the role of users. The thesis contributes to three concrete products: a three step approach, a segmentation model and peer-reviewed papers. As I have not introduced a commercial product, question regarding the market opportunities and the costs involved are not answerable. 



\section{Acknowledgements}

Vele personen hebben bijgedragen aan de tot standkoming van dit proefschirft. Allereerst wil ik mijn dank en waardering uitspreken aan mijn promotor, prof. dr. R. P. M. Kemp. Beste René, bedankt voor de mogelijkheid om bij jou te promoveren. Als dagelijks begeleider en ook als promotor heb je met je scherpe en vaak ook kritische bijdrage een grote rol gespeeld in mijn ontwikkeling als onderzoeker en waarschijnlijk ook als mens. Als ik worstelde met vraagstukken in mijn onderzoek, was jij degene die dan zei: "Zo moeilijk is het ook weer niet". Ik heb veel van je geleerd en hoop in de toekomst nog veel van je te mogen leren. Dank daarvoor.

Simona, jij bent degene die mij destijds op deze promotieplek wees. Ik kan dan ook met $100 \%$ zekerheid zeggen dat zonder jou dit proefschrift er niet geweest zou zijn. Je hebt me altijd gemotiveerd en me het gevoel gegeven dat ik trots mag zijn met waar ik mee bezig ben. De hoofdstukken 4 en 6 zijn mede door jouw hulp stukken beter geworden. Bedankt!

De leden van de promotiecommissie, prof. dr. Pim Martens, prof. dr. ir. Harro van Lente, dr. Floortje Alkemade en dr. Jacques Kimman, dank ik voor het lezen en beoordelen van het manuscript. Pim, ik heb het zeer gewaardeerd dat je het voorzitterschap van mijn commissie met enthousiasme op je hebt genomen en voor het flitsende optreden om de antwoorden van alle commissieleden op tijd te verkrijgen. We hebben de afgelopen jaren niet veel samengewerkt, desalniettemin hebben we vele aangename gesprekken gevoerd. Ik hoop in de toekomst nog veel triatlons/hardloopwedstrijden samen met je te starten, zodat we 'the battle' in stand houden. Harro, bedankt voor de prettige samenwerking de afgelopen jaren. Floortje, dank voor je enthousiasme en voor je tijd bij het lezen en beoordelen van mijn proefschrift. Ik zie ernaar uit met je van gedachten te wisselen. Jacques, bedankt voor je kritische blik en commentaar.

Ik ben dank verontschuldigd aan degene die mijn promotietraject financieel mogelijk hebben gemaakt: het College van Bestuur van de Universiteit Maastricht (zaaigeld voor innovatie en duurzame ontwikkeling) en het ORANEXT project. Ook wil ik mede-autheurs (Linda Kamp, Marco Hekkert en Wilfried van Sark) en de reviewers van mijn artikelen bedanken als ook alle andere personen die mij door de jaren heen van nuttig commentaar hebben voorzien.

Ik wil al mijn collega's en ex-collega's bij ICIS bedanken voor de gezellige werksfeer wat het schrijven van een proefschrift een stuk leuker maakt. Ik kan deze niet allemaal per- 
soonlijk opnemen in dit dankwoord maar voor een paar maak ik een uitzondering. Ron en Anja wil ik als eerste met naam benoemen. Als PhD student is het bijzonder prettig om te kunnen werken in een omgeving die tegelijkertijd stimulerend en veilig is, jullie (tot vorige jaar ook met de inzet van Pim) hebben de groep zo vorm gegeven dat jonge onderzoekers niet alleen de kans krijgen zichzelf te ontwikkelingen maar bovendien ook serieus genomen worden als volwaardige leden van de groep. Ik wil jullie hartelijk danken voor jullie vertrouwen en de mogelijkheden die jullie me hebben aangereikt. Jullie interesse voor het onderzoek, voor mij en mijn sportprestaties heb ik altijd erg gewaardeerd. Annet, bedankt voor je hulp bij diverse regelklusjes, voor de gezellige praatjes op de gang en voor al het lekkers wat zo nu en dan in de keuken verschijnt. Mijn lieve, leuke, behulpzame en soms-ietwat-té-gezellige collega Astrid. We hebben zware discussies gevoerd over het doen van onderzoek (jullie lezen het goed), maar ook enorm veel gelachen. Jouw kamer was daarom een favoriete plek voor een kop koffie op ieder moment van de dag. Su-Mia en Carijn, het was een groot plezier om jullie kamergenoot te zijn de afgelopen vier jaar. Het is heerlijk om kamergenoten te hebben die mij door en door kennen. Ik heb genoten van de talloze gesprekken over onze onderzoeken en ons leven buiten ICIS. Het woord 'tegenvallers' werd in onze kamer ingeruild voor 'meevallers'. Ik hoop dat we samen nog vele meevallers mogen vieren en dat jullie ook snel op de promotie-sneltrein kunnen stappen, want die meevaller hebben jullie wel verdiend! Ook hier een woord van dank voor Annemarie, mijn nieuwe kamergenoot. Nicole, ongeacht of onze gesprekken gaan over ons onderzoek, de academische wereld, of sociale activiteiten, je bent altijd zeer enthouiast en daarmee erg motiverend. Ook Maud wil ik hier bij naam noemen. Maud, wat fijn om een collega te hebben die ook sleutels kwijt is, portemonnees vergeet, pinpassen zoekt raakt, ... Marc en Julia, ook jullie verdienen het om bij naam in dit proefschrift te worden vermeld. Ik heb leuke en leerzame inhoudelijke discussies met jullie gehad en hoop dat in de toekomst nog vaak te hebben.

Daarnaast wil ik al mijn vrienden en familie bedanken voor die de nodige afleiding en gezelligheid de afgelopen jaren. In het bijzonder bedank ik mijn Ferro Mosae vriendinnen: Kim, Carçia, Evelien, Heleen en Marloes. De heerlijke avonden die wij samen in het Limburgse heuvelland hebben doorgebracht op de racefiets, mountainbike of met de loopschoentjes aan, hebben voor de nodige ontspanning gezorgd hetgeen absoluut noodzakelijk is geweest om mij tijdens werktijd te blijven concentreren op mijn proefschrift. Ik heb ook veel van jullie geleerd: 'tracheacanule', 'gastrointestinaal stelsel', 'pneumonie', enz... Als ik ooit een carrièreswitch wil maken ben ik in de geneeskunde al een heel eind op weg. 
Esther, Sophie, Marla, Monique, Hannah, Ellen, Maaike en Milou, ook jullie hebben gezorgd voor de nodige afleiding tijdens de vele etentjes, trainingen, wedstrijden, feestjes, filmavonden en weekendjes weg. Jornie, bedankt voor het prachtige ontwerp van de omslag.

Dit dankwoord zou niet compleet zijn zonder een oprecht dankwoord aan mijn ouders. Pap en mam bedankt voor het warme nest waarin ik ben opgegroeid en waarop ik nog altijd kan terugvallen. Ik weet dat jullie trots op me zijn en dat heeft me enorm geholpen bij het schrijven van dit proefschrift. Ook wil ik mijn zussen Sabine en Dorien bedanken, jullie weten denk ik maar half hoe blij ik met jullie ben! Ik weet dat ik te vaak terug heb moeten komen op gemaakte beloftes en jullie weer een teleurstellend telefoontje of berichtje moest sturen dat het me weer eens niet lukte om naar de Zeeuwse kust te komen. Het wordt dus de hoogste tijd om hier verandering in te brengen...

Daarnaast wil ik ook graag mijn schoonfamilie, de Familie Kuijpers, bedanken. Johan en Grietje, Henk en Etta, Gijs-Peter en Coby, Alexander en Marliese, Jon-Anders en Jojenneke, Gideon en alle neefjes en nichtjes, bedankt dat jullie altijd zo geïnteresseerd waren en meegeleefd hebben in het proefschrift-traject.

En dan de twee mannen uit mijn leven. Ik zou heel dramatisch kunnen zeggen dat jullie mij door allerlei moeilijke momenten heen hebben gesleept en dat zonder jullie dit proefschrift er niet geweest zou zijn. Maar om eerlijk te zijn zou dit proefschrift er zelfs eerder geweest zijn, al was ik vast en zeker niet zo vrolijk gebleven... Roelof, van jou heb ik geleerd dat ik niet alles tegelijk moet willen en me toe te leggen op dat waarvoor ik gekozen heb. Ook heb ik geleerd dat een dag echt maar 24 uur heeft en dat er in die tijd ook nog geslapen moet worden. Zonder jouw vertrouwen in de goede afloop was ik dit avontuur niet begonnen. We hebben het goed samen, ik ben super blij met je! Abel, jij bent het liefste, ondeugendste, grappigste mannetje van de hele wereld! De zorg en aandacht die je afgelopen jaar van me vroeg en de vele lachjes, knuffels en kusjes die ik van je kreeg, zorgden voor de nodige relativering tijdens de afronding van dit proefschrift.

En iedereen die ik per ongeluk vergeten ben, waar ik natuurlijk pas achter kom zodra het boekje gedrukt is.

Véronique Vasseur

Maastricht, 2014 



\section{About the author}

Véronique Vasseur was born in Oostburg, the Netherlands on the 8th of July 1983. She studied Chemistry, with a specialisation in Process Technology, at University College Ghent and Science and Innovation Management, with a specialisation in Energy and Materials, at Utrecht University. In 2008, she graduted and started her professional career at Sustainalitics, an international sustainability research firm to the financial sector. She conducted research on the Environment, Social and Gov-ernance (ESG) performance of companies. In 2009, she moved from Utrecht to Maastricht to work as a PhD researcher at the International Centre for Integrative assessment and Sustainable development (ICIS), Maastricht University, a research institute that focuses on interdisciplinairy and applied research related to sustain-blity issues. Besides, Véronique was involved in the ORGANEXT project, which aims at strengthening the international position of Euregio Maas-Rhein as a top technology region in the field of next generation organic opto-electronic applications and thin film solar cells.

As from September 2014 she will be working as a post-doc researcher on the TRANSIT (TRANsformative Social Innovation Theory) project, a EC-funded (FP7) research initiative, responding to the call for research on "Social Innovation - em-powering people, changing societies?". 


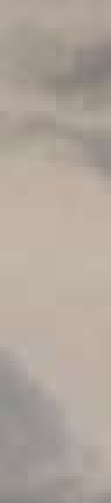

\section{$x^{\circ}$}

Fit

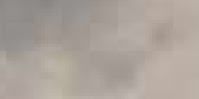
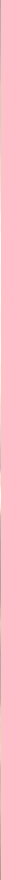